UNIVERSITY OF SZEGED, FACULTY OF MEDICINE AND

BIOLOGICAL RESEARCH CENTRE

HUNGARIAN ACADEMY OF SCIENCES, SZEGED

\title{
PROTECTION \\ OF THE BLOOD-BRAIN BARRIER \\ UNDER PATHOLOGICAL CONDITIONS
}

Ph.D. thesis

\section{Andrea Tóth}

Supervisor:

Mária Deli, M.D., Ph.D., D.Sc.

SZEGED

2014 


\section{CONTENTS}

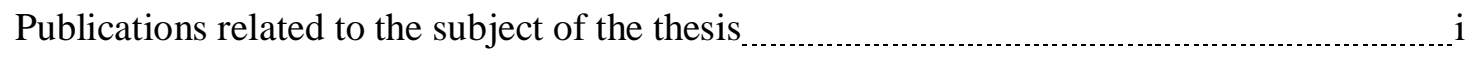

Other publications _ i i

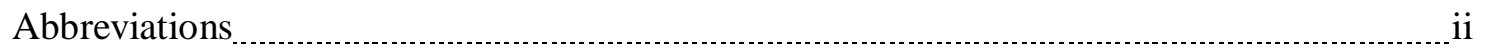

1. Introduction 1

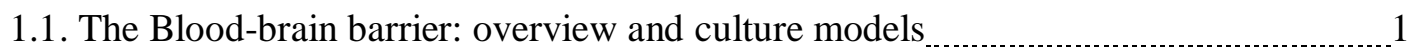

1.2. The blood-brain barrier under pathological conditions 3

1.2.1. The blood-brain barrier in Alzheimer's disease $\ldots \ldots \ldots$

1.2.2. The blood-brain barrier and methylglyoxal $\ldots \ldots$

1.3. The blood-brain barrier as a therapeutical target 7

1.3.1. Pentosan polysulfate

1.3.2. Docosahexaenoic acid

1.3.3. Edaravone

1.4. Aims

2. Materials and methods 12

2.1. Materials 12

2.2. Cell culture

2.2.1. Primary rat brain endothelial cell cultures and BBB models _......................... 13

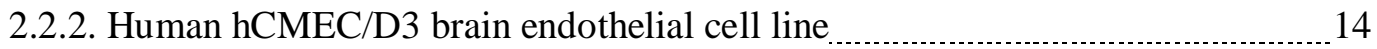

2.3. Treatments 14

2.4. Viability and cytotoxicity assays

2.4.1. Dye reduction cell viability assay 15

2.4.2. Real-time monitoring of impedance

2.5. Investigation of cell morphology

2.5.1. Electron microscopy 16

2.5.2. Phase contrast microscopy

2.5.3. Holographic phase contrast microscopy 16

2.6. Evaluation of the barrier integrity 17

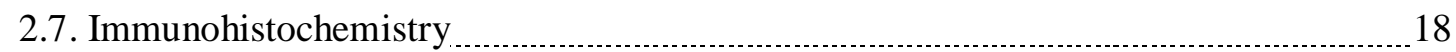

2.8. Detection of reactive oxygen species 19

2.9. Functional assay for P-glycoprotein $\ldots$

2.10. Protein modification experiment

2.11. Statistical analysis $\ldots \ldots$ 
3.1. Effect of pathological factors on brain endothelial cells _............................................... 20

3.1.1. Effect of $A \beta$ peptides on viability of brain endothelial cells _........................... 20

3.1.2. Effect of $A \beta_{42}$ on the morphology of brain endothelial cells _ $\quad 21$

3.1.3. Effect of methylglyoxal on viability of human brain endothelial cells _.............. 23

3.1.4. Effect of methylglyoxal on morphology of human brain endothelial cells ......... 23

3. 2. Protection of brain endothelial cells by pentosan polysulfate _ 24

3.2.1. Pentosan protects against $A \beta_{42}$-induced toxicity ....................................... 24

3.2.2. Pentosan protects against $A \beta_{42}$-induced permeability increase $\quad 25$

3.2.3. Pentosan protects against $A \beta_{42}$-induced changes in TJ morphology _................ 26

3.3. Protection of brain endothelial cells by docosahexaenoic acid _............................... 27

3.3.1. DHA protects against iso $A \beta_{42}$-induced toxicity $\quad 27$

3.3.2. DHA protects against iso $A \beta_{42}$-induced morphological changes __............................ 28

3.3.3. DHA protects against iso $A \beta_{42}$-induced permeability increase _......................... 28

3.3.4. DHA acid protects against iso $A \beta_{42}$-induced brain endothelial dysfunction _....... 29

3.4. Protection of brain endothelial cells by edaravone _............................................... 29

3.4.1. Edaravone protects against methylglyoxal-induced toxicity $\quad 29$

3.4.2. Edaravone protects against methylglyoxal-induced morphological changes $\quad 30$

3.4.3. Edaravone protects against methylglyoxal-induced permeability increase .......... 31

3.4.4. Edaravone protects against methylglyoxal-induced changes in junctional

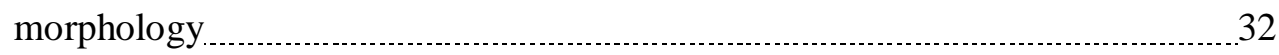

3.4.5. Edaravone protects against methylglyoxal-induced changes: ROS production and protein modification

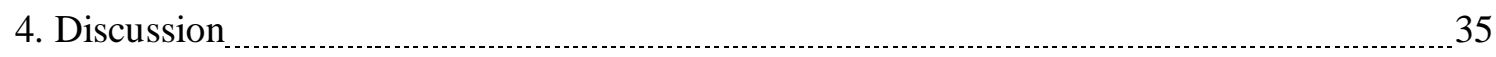

4.1. Effect of pathological factors on brain endothelial cells _ 35

4.1.1. Amyloid- $\beta$ induced changes in brain endothelial cells ............................... 35

4.1.2. Methylglyoxal induced changes in brain endothelial cells 36

4.2. Protection against brain endothelial dysfunction _ 38

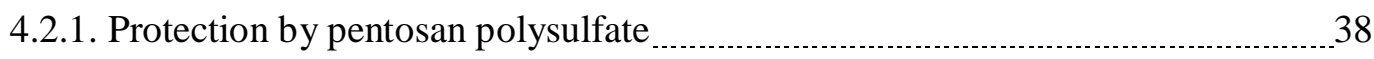

4.2.2. Protection by docosahexaenoic acid $\quad 40$

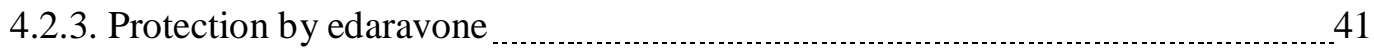

4.3. Conclusion and perspectives 43

5. Summary

6. Acknowledgement 46

7. References 47

8. Annex 


\section{PUBLICATIONS RELATED TO THE SUBJECT OF THE THESIS}

I. Deli MA, Veszelka S, Csiszár B, Tóth A, Kittel A, Csete M, Sipos A, Szalai A, Fülöp L, Penke B, Ábrahám CS, Niwa M

Protection of the blood-brain barrier by pentosan against amyloid-beta-induced toxicity

Journal of Alzheimer's Disease 22: 777-794 (2010)

IF: 4.261, Citation: $9(6 / 3)$

II. Tóth A, Veszelka S, Nakagawa S, Niwa M, Deli MA

Patented in vitro blood-brain barrier models in CNS drug discovery

Recent Patents on CNS Drug Discovery 6: 107-118 (2011)

IF:-, Citation: 21 (18/3)

III. Veszelka S, Tóth AE, Walter FR, Datki Z, Mózes E, Fülöp L, Bozsó Z, Hellinger É, Vastag M, Orsolits B, Környei Z, Penke B, Deli MA

Docosahexaenoic acid reduces amyloid $\beta$-induced toxicity in cells of the neurovascular unit

Journal of Alzheimer's Disease 36: 487-501 (2013)

IF: 4.174 (2012), Citation: 7 (5/2)

IV. Tóth AE, Walter FR, Bocsik A, Sántha P, Veszelka S, Nagy L, Puskás LG, Couraud PO, Takata F, Dohgu S, Kataoka Y, Deli MA

Edaravone protects against methylglyoxal-induced barrier damage in human brain endothelial cells

PLoS ONE (Online publication date; July 17, 2014)

IF: 3.730 (2012), Citation:-

\section{OTHER PUBLICATIONS}

I. Horvát S, Fehér A, Wolburg H, Sipos P, Veszelka S, Tóth A, Kis L, Kurunczi A, Balogh G, Kürti L, Erős I, Szabó-Révész P, Deli MA

Sodium hyaluronate as a mucoadhesive component in nasal formulation enhances delivery of molecules to brain tissue

European Journal of Pharmaceutics and Biopharmaceutics 72: 252-259 (2009)

IF: 3.151, Citation: 29 (20/9)

II. Hellinger E, Veszelka S, Tóth AE, Walter F, Kittel A, Bakk ML, Tihanyi K, Hada V, Nakagawa S, Thuy DHD, Niwa M, Deli MA, Vastag M

Comparison of brain capillary endothelial cell-based and epithelial (MDCK-MDR1, Caco-2, and VB-Caco-2) cell-based surrogate blood-brain barrier penetration models

European Journal of Pharmaceutics and Biopharmaceutics 82: 340-351, (2012)

IF: 3.826, Citation: $10(10 / 0)$

III. Cardoso FL, Kittel A, Veszelka S, Palmela I, Tóth A, Brites D, Deli MA, Brito MA.

Exposure to lipopolysaccharide and/or unconjugated bilirubin impair the integrity and function of brain microvascular endothelial cells.

PLoS ONE 7: 1-14 (2012)

IF: 4.092, Citation: $19(17 / 2)$ 


\section{ABBREVIATIONS}

$\begin{array}{ll}\text { A } \beta & \text { amyloid- } \beta \text { peptide } \\ \text { A } \beta_{42} & \text { amyloid- } \beta \text { 1-42 peptide } \\ \text { AD } & \text { Alzheimer's disease } \\ \text { AJ } & \text { adherent junctions } \\ \text { AGE } & \text { advanced glycated endproducts } \\ \text { ANOVA } & \text { analysis of variance } \\ \text { BBB } & \text { blood-brain barrier } \\ \text { BSA } & \text { bovine serum albumin } \\ \text { CNS } & \text { central nervous system } \\ \text { DCFDA } & \text { chloromethyl-dichloro-dihydro-fluorescein diacetate } \\ \text { DHA } & \text { docosahexaenoic acid } \\ \text { DMEM } & \text { Dulbecco's-modified Eagle's medium } \\ \text { EBA } & \text { Evans blue-labelled albumin } \\ \text { EBM-2 } & \text { endothelial Growth Basal Medium-2 } \\ \text { EDTA } & \text { ethylenediaminetetraacetic acid } \\ \text { FBS } & \text { fetal bovine serum } \\ \text { FITC } & \text { fluorescein isothiocyanate } \\ \text { hCMEC/D3 } & \text { human cerebral microvascular endothelial cell line D3 } \\ \text { Hepes } & \text { 4-(2-hydroxyethyl)piperazine-1-ethanesulfonic acid solution } \\ \text { isoA } \beta_{42} & \text { iso-amyloid- } \beta \text { 1-42 peptide } \\ \text { LDH } & \text { lactate dehydrogenase } \\ \text { MTT } & \text { 3-(4,5-dimethylthiazol-2-yl)-2,5-diphenyltetrazolium bromide } \\ \text { mw } & \text { molecular weight } \\ \text { Papp } & \text { apparent permeability coefficient } \\ \text { Pe } & \text { tight junction } \\ \text { PBS } & \text { zonula occludens protein } \\ \text { P-gp } & \text { endothelial permeability coefficient } \\ \text { PPS } & \text { phosphate buffer solution } \\ \text { PUFA } & \text { P-glycoprotein } \\ \text { RAGE } & \text { pentosan polysulfate } \\ \text { ROS } & \text { long-chain polyunsaturated } \omega-3 \text { fatty acids } \\ \text { RTCA-SP } & \text { receptor for advanced glycation end products } \\ \text { SD } & \text { reactive oxygen species } \\ \text { SEM } & \text { Roche xCelligence Real Time Cell Analyser Single Plate } \\ \text { SF } & \text { standard deviation } \\ \text { SLC } & \text { standard error of mean } \\ \text { TEER } & \text { solute carrier transporter } \\ \text { TJ } & \text { transendothelial electrical resistance } \\ \text { ZO } & \end{array}$




\section{INTRODUCTION}

\subsection{The blood-brain barrier: overview and culture models}

The microvessels of the brain differ fundamentally from peripheral vasculature. In humans, the estimated total length of cerebral capillaries is about $650 \mathrm{~km}$ and the total surface area is between 12 and $18 \mathrm{~m}^{2}$ (Nag and Begley, 2005). The microvessels together with neurons and glial cells form the neurovascular unit, which is involved in cerebral activity dependent regulation of the cerebral blood flow, cerebral angiogenesis, neurogenesis, development and maintenance of brain homeostasis (Neuwelt et al., 2011). Brain capillaries constitute the bloodbrain barrier (BBB) as a functional unit. (Pardridge, 2002; Cecchelli et al., 2007).

Cerebral endothelial cells were identified as the anatomical basis of the BBB (Abbott et $a l ., 2006)$. They have a dynamic interaction with the other neighboring cells, such as astroglia, pericytes, perivascular microglia, and neurons (Fig. 1). The cross-talk between these cells induces a unique phenotype in endothelial cells including (i) a morphological barrier based on interendothelial junctions that markedly limit paracellular permeability, (ii) a unique pattern of receptors, transporters and drug efflux pumps, and (iii) enzymatic and metabolic barriers (Abbott et al., 2010).

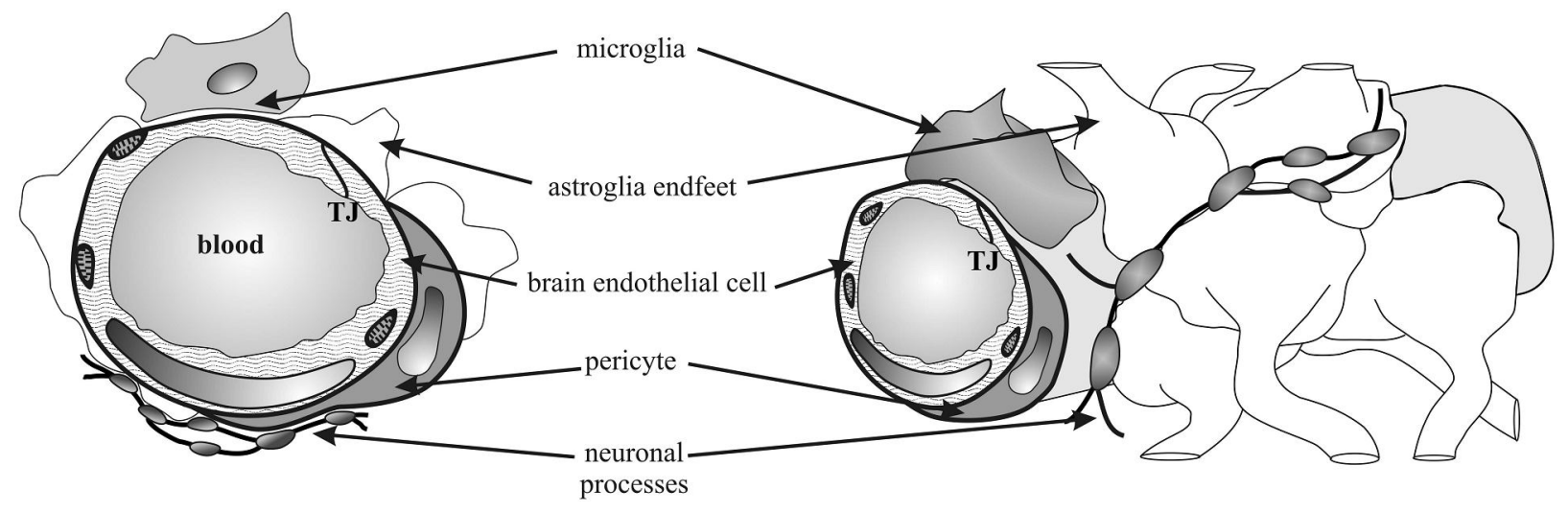

Figure 1. Drawing on the structure of the neurovascular unit. Brain endothelial cells and the tight junctions (TJ) between them constitute the anatomical basis of the blood-brain barrier (Tóth et al., 2011, Annex II.)

The three major functions of the $\mathrm{BBB}$ are the creation and maintenance of ionic homeostasis for neuronal functions, supply of the central nervous system (CNS) with nutrients, and protection from toxic insults (Abbott et al., 2006). The tightness of the paracellular barrier, regulated by tight junctions (TJs) and adherens junctions (AJs), is a fundamental property of BBB (Zlokovic, 2008). TJs prevents hydrophilic molecules and even ions and water to enter freely the CNS. They are multiprotein complexes situated in lipid rafts and composed of integral proteins that associate with cytoplasmic linker proteins. Integral membrane proteins, such as occludin and claudins mediate cell-cell adhesion. Among the claudins, the endothelial cell-specific claudin-5 is expressed at the highest level at the BBB (Abbott et al., 2010). Linkers, like zonula occludens 
proteins $(\mathrm{ZO}-1,-2,-3)$ and $\beta$-catenin, connect integral membrane junctional proteins to the cytoskeleton. ZOs interact with occludins, claudins and junctional adhesion molecules and also participate in cell signaling (Krizbai and Deli, 2003). In AJs the cytoplasmic tail of vascular endothelial cadherin (VE-cadherin) is attached to the actin cytoskeleton by $\beta$-catenin. Besides its role as a cytoskeletal linker, $\beta$-catenin is an important signaling and transcriptional factor at the $\mathrm{BBB}$ regulating its tightness (Liebner and Plate, 2010). Absence of fenestration and low number of pinocytotic vesicles are also important elements of the physiological barrier (Abbott et al., 2010). The resistance of brain parenchymal microvessels reflecting paracellular tightness in vivo exceeds $1000 \Omega \times \mathrm{cm}^{2}$ (Butt et al., 1990). The polarized expression of transporters, receptors and enzymes at either the luminal or abluminal cell surface is a crucial aspect of the BBB. Saturable, bidirectional transport systems exist for nutrients, vitamins and minerals at the BBB (Abbott et al., 2010; Deli, 2011). About 40 members of the solute carrier (SLC) transporter family were identified in brain microvessels (Enerson et al., 2006). The most important SLC carriers supply the CNS with glucose, ketons or amino acids, like glucose transporter 1, monocarboxylic acid transporter 1, large neutral amino acid transporter 1. Efflux pumps protect the brain from xenobiotics, but they are also responsible for restricting the penetration of many therapeutic molecules to brain. The primary efflux pumps at the BBB, P-glycoprotein (P-gp) and breast cancer resistance protein belong to the ATP-binding cassette transporter family (Terasaki and Ohtsuki, 2005). The elements of the metabolic barrier include alkaline phosphatase, $\gamma$-glutamyl transpeptidase, monoamine oxidases or cytochrome P450 enzymes (Deli, 2011).

Cell culture-based models proved to be one of the most versatile tools in basic BBB research and also in testing CNS drug penetration (Annex II.). All models should show some elements of general endothelial and specific BBB properties (Veszelka et al., 2011). Adjacent cells should possess endothelial morphology, like growing in monolayer and having TJs between overlapping plasma membranes. One of the most direct methods to determine the tightness of a model is the measurement of transendothelial electrical resistance (TEER) (Deli et al., 2005) An in vitro $\mathrm{BBB}$ models should reach a tightness of at least $150-200 \Omega \times \mathrm{cm}^{2}$ to study the permeability or transport of molecules (Table 1). Another way to assess the integrity of the paracellular barrier is the measurement of passive flux of small hydrophilic tracers across monolayers. The endothelial or apparent permeability coefficients $\left(\mathrm{P}_{\mathrm{e}}\right.$ or $\left.\mathrm{P}_{\mathrm{app}}\right)$ are important parameters of the quality of BBB models (Gaillard and Boer, 2000). Furthermore, an ideal in vitro model should not only show $\mathrm{BBB}$ characteristics, it also needs to be simple to use, reproducible, cost-effective and applicable for medium or high throughput screening. Unfortunately, none of the available model fulfills all the above mentioned criteria, but models expressing the most critical features of the $\mathrm{BBB}$ can provide valuable information on $\mathrm{BBB}$ permeability and be useful tools in CNS drug discovery (Annex II.). 


\begin{tabular}{|c|c|c|c|}
\hline BBB model name & Cell types & BBB quality parameters & Pat. \\
\hline \multicolumn{4}{|l|}{ Monolayers } \\
\hline $\begin{array}{l}\text { Immortalized brain } \\
\text { endothelial line }\end{array}$ & $\begin{array}{l}\text { Immortalized bovine brain endothelial cell } \\
\text { line (TBMEC) }\end{array}$ & $P_{e}$ sucrose: $26 \times 10^{-6} \mathrm{~cm} / \mathrm{s}$ & 1 \\
\hline $\begin{array}{l}\text { BBB model tightened by } \\
\text { Wnt/ } \beta \text {-catenin signaling }\end{array}$ & $\begin{array}{l}\text { Mouse primary or immortalized endothelial } \\
\text { cells }(\mathrm{H} 5 \mathrm{~V})\end{array}$ & ND & 2 \\
\hline Human BBB model & $\begin{array}{l}\text { Immortalized human brain endothelial cell } \\
\text { line (hCMEC/D3) }\end{array}$ & $\begin{array}{l}\text { TEER: } 40 \Omega \times \mathrm{cm}^{2} \\
\mathrm{P}_{\mathrm{e}} \text { sucrose: } 27.6 \times 10^{-6} \mathrm{~cm} / \mathrm{s} \\
\mathrm{P}_{\mathrm{e}} \text { fluorescein: } 6 \times 10^{-6} \mathrm{~cm} / \mathrm{s}\end{array}$ & 3 \\
\hline \multicolumn{4}{|l|}{ Co-culture: 2 cell types } \\
\hline $\begin{array}{l}\text { BBB model tightened by } \\
\text { cAMP signaling }\end{array}$ & $\begin{array}{l}\text { Primary endothelial cells } \\
\text { Primary brain astrocytes }\end{array}$ & TEER $>200 \Omega \times \mathrm{cm}^{2}$ & 4 \\
\hline $\begin{array}{l}\text { Co-culture of } \\
\text { conditionally immortalized } \\
\text { cell lines (TR-BBB) }\end{array}$ & $\begin{array}{l}\text { Temperature sensitive immortalized rat } \\
\text { brain endothelial cell line } \\
\text { Temperature sensitive immortalized rat } \\
\text { astrocyte cell line }\end{array}$ & TEER: $106 \Omega \times \mathrm{xm}^{2}$ & 5 \\
\hline Dynamic BBB model & $\begin{array}{l}\text { Endothelial cells } \\
\text { Astrocytes }\end{array}$ & ND & 6 \\
\hline Multicellular BBB model & $\begin{array}{l}\text { Primary brain or embryonic stem cell } \\
\text { derived endothelial cells } \\
\text { Neuronal progenitor cells }\end{array}$ & TEER: $100-250 \Omega \times \mathrm{cm}^{2}$ & 7 \\
\hline \multicolumn{4}{|l|}{ Co-culture: 3 cell types } \\
\hline $\begin{array}{l}\text { Triple co-culture, } \\
\text { mimicking the anatomical } \\
\text { structure of the BBB }\end{array}$ & $\begin{array}{l}\text { Primary brain endothelial cells } \\
\text { Primary brain astrocytes } \\
\text { Primary brain pericytes }\end{array}$ & $\begin{array}{l}\text { TEER: } 350-600 \Omega \times \mathrm{cm}^{2} \\
P_{\mathrm{e}} \text { sucrose: } 1.1 \times 10^{-6} \mathrm{~cm} / \mathrm{s} \\
P_{\mathrm{e}} \text { fluorescein: } 2.5 \times 10^{-6} \mathrm{~cm} / \mathrm{s}\end{array}$ & 8 \\
\hline
\end{tabular}

Table 1. Patented in vitro BBB models and their parameters. Abbreviations: ND, no data; TEER, transendothelial electrical resistance; $\mathrm{P}_{\mathrm{e}}$, endothelial permeability coefficient; Pat., patent number (see at the end of Reference section). Table is modified from Tóth et al., 2011 (Annex II.)

\subsection{The blood-brain barrier under pathological conditions}

The morphology and functions of BBB are changed under pathological conditions, like neurodegenerative diseases, stroke, epilepsy, brain tumors, traumatic injuries of the central nervous system, brain infection, sepsis and metabolic disease (Deli, 2005; Zlokovic, 2008; Neuwelt et al., 2011). Alterations at the BBB in diseases include downregulation of TJ proteins, upregulation of vesicular transport in brain endothelium and decrease in nutrient transport. Pharmacoresistance due to upregulation of efflux pumps at the neurovascular unit in epilepsy and brain tumors makes clinical treatment very difficult (Neuwelt et al., 2011). Disturbances of CNS homeostasis as a result of barrier deficiencies could contribute to secondary neuronal loss and exacerbate the neuropathology (Deli, 2005; Zlokovic, 2008; Neuwelt et al., 2011). 


\subsubsection{The blood-brain barrier in Alzheimer's disease}

Alzheimer's disease (AD) is the most common type of dementia which affects 36 million individuals worldwide (http://www.alz.co.uk/research/world-report). AD presents with symptoms of memory loss and cognitive impairment late in life. Because of the growing aged population future $\mathrm{AD}$ prevalence is expected to increase to an extent that it may threaten the sustainability of healthcare systems worldwide (Erickson and Banks, 2013). This necessitates to better understand $\mathrm{AD}$, with the goal of identifying biomarkers for early diagnostic tests and developing treatments that can prevent or slow $\mathrm{AD}$ progression (Olah et al., 2012). As AD is a multifactorial disease there are several mechnisms to explain the cause and the development of the disease (Carreiras $e t$ al., 2013), like amyloid cascade and cholinergic (Pákáski and Kálmán, 2008), tau (Medina and Avila, 2014) oxidative stress (Padurariu et al., 2013), and neurovascular (Zlokovic, 2005) hypotheses.

Recent clinical data indicate that vascular changes play an important role early in AD pathogenesis. Cerebral blood flow and cerebral glucose uptake reductions were demonstrated in the early stages of $\mathrm{AD}$ and both low cerebral blood flow and reduced brain glucose uptake may precede neurodegeneration and contribute to the progression of dementia prior to cerebral atrophy (Bell and Zlokovic, 2009). Positive links and overlap exist between cerebrovascular disorders and AD. Severe atherosclerosis increases threefold the risk of developing $\mathrm{AD}$ or vascular dementia (van Oijen et al., 2007).

Pathological amyloid- $\beta(\mathrm{A} \beta)$ fibrils are deposited both in brain parenchyma and around brain vessels in AD (Grammas et al., 2002; Bell and Zlokovic, 2009). The major component of deposits are $\mathrm{A} \beta$ peptides, cleaved from amyloid precursor protein by secretases (Forman et al., 2004). A $\beta$ peptides can form soluble monomers, dimers, oligomers, protofibrils and insoluble fibrils (DeMager et al., 2002). The cerebrovascular amyloidosis or cerebral amyloid angiopathy is a hallmark of the disease, it is present in more than $80 \%$ of $\mathrm{AD}$ patients and causally involved in the development of neurodegeneration in Alzheimer's disease (Grammas et al., 2002; Bell and Zlokovic, 2009). Accumulation of $A \beta$ in the wall of cerebral blood vessels and in the brain parenchyma in $A D$ is due to imbalance between its production and clearance from the brain (Bell and Zlokovic, 2009). Several transporters were identified to participate in the transport of $A \beta$ across the $B B B$, including receptor for advanced glycation end products (RAGE) (Deane et al., 2003; Giri et al., 200), low-density lipoprotein receptor related protein 1 (Shibata et al., 2000; Deane et al., 2004) and 2 (Calero et al., 1999), P-glycoprotein (P-gp) (Cirrito et al., 2005), breast cancer resistance protein (Zlokovic, 2008) and multidrug resistance protein-1 (Pahnke et al., 2014) 

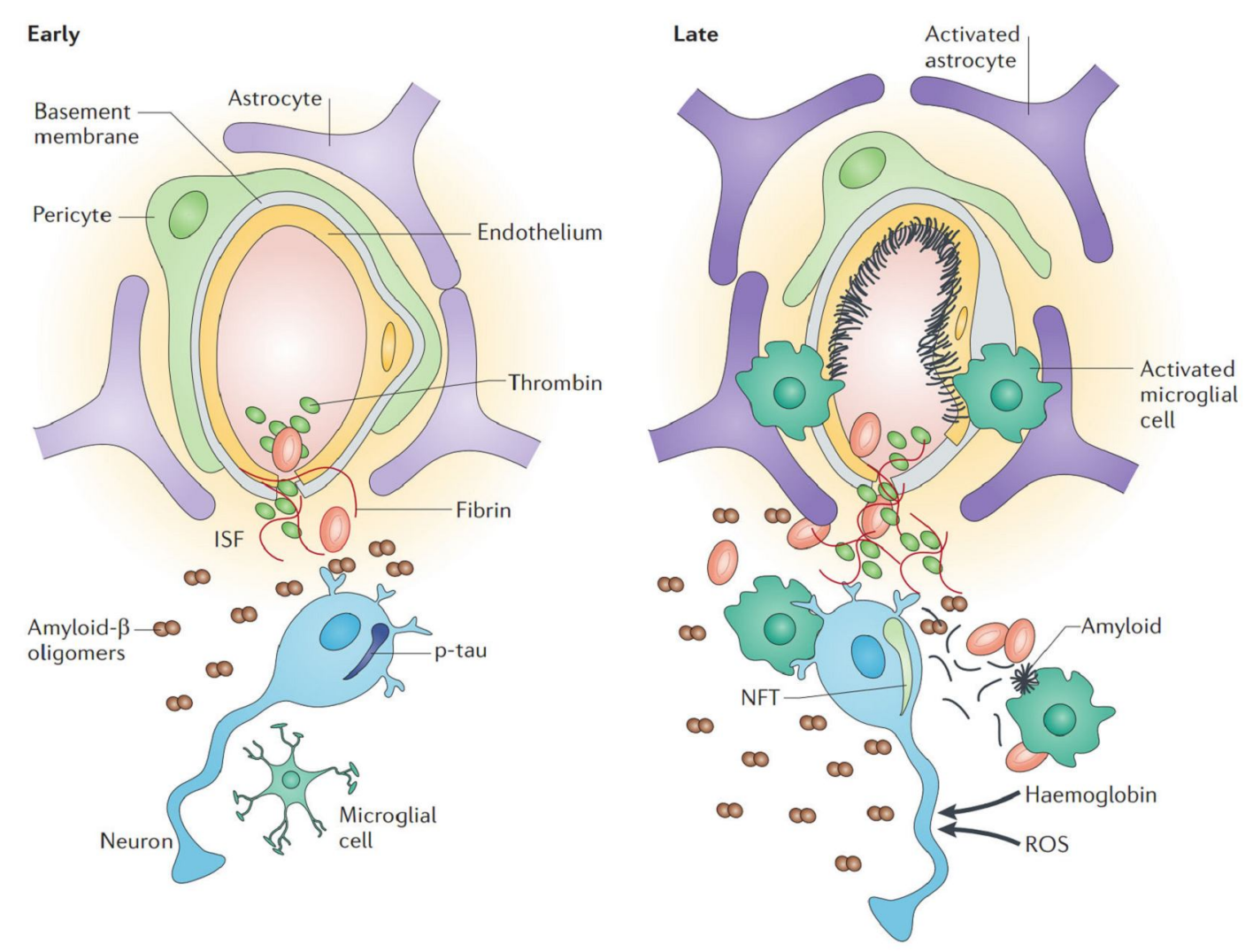

Figure 2. A model of microvascular damage in Alzheimer's disease. Abbreviations: ROS, reactive oxygen species; NFT, neurofibrillary tangles; ISF, interstitial fluid; p-tau, hyperphosphorylated tau (Zlokovic, 2011)

Morphological abnormalities in the cerebral microvasculature in AD were also demonstrated during the disease progression in AD (Kalaria and Hedera, 1995). Small pial and intracerebral arteries with amyloid deposits develop a hypercontractile phenotype and cause dysregulated cerebral blood flow. With time pathological alterations in the vessel wall lead to muscle layer atrophy and rupture of the vessels resulting in microbleeds. Amyloid angiopathy can be observed parallelly with the appearance of cognitive decline (Zlokovic, 2011). At the level of capillaries due to faulty $A \beta$ clearance $A \beta$ oligomers accumulate in the interstitial fluid (Fig. 2). Microhaemorrhages occur and blood-derived molecules like thrombin, fibrin, albumin exert toxic effects on neurons. In a later phase microvascular degeneration leads to increased deposition of basement membrane proteins and perivascular amyloid formation, which obstruct capillary blood flow (Zlokovic, 2011). Hypoperfusion increases the dysfunction of efflux pumps and the accumulation of metabolic waste products, alters $\mathrm{pH}$ and electrolyte composition and all these changes aggravate neuronal dysfunction. Ischaemic injury, rising $A \beta$ levels, neuroinflammation induced by activated microglia and astrocytes contribute to neuronal damage and accumulation of neurofibrillary tangles. The morphological changes are accompanied by functional alterations (Zlokovic, 2011). Enhancing A $\beta$ clearance across the $\mathrm{BBB}$, as well as protection of the BBB from injury are among the proposed new strategies for the therapy of AD (Zlokovic et al., 2000). 


\subsubsection{The blood-brain barrier and methylglyoxal}

Methylglyoxal (2-oxopropanal) is a highly reactive $\alpha$-oxoaldehyde (Fig. 3A) with strong oxidant and glycation properties (Turk, 2010). Methylglyoxal is an endogenous metabolite, which is formed by elimination of phosphate from glyceraldehyde 3-phosphate and dihydroxyacetone phosphate, or by the oxidation of hydroxyacetone and aminoacetone (Sousa Silva et al., 2013). As it is a highly reactive molecule, its immediate elimination by detoxification systems is crucial. Methylglyoxal is oxidized by the glyoxalase pathway to D-lactate, and metabolized reductively to acetol (Német et al., 2006). Accumulated methylglyoxal triggers carbonyl stress by reacting with proteins, DNA and other biomolecules (Stitt et al., 2002), and the end products of these reactions are insoluble protease-resistant polymers, advanced glycated end products (AGE) (Lo et al., 1994). The cellular effects of methylglyoxal include inhibition of enzyme activity (Murata-Kamiya et al. 2001), transcriptional activation of genes (Yao et al., 2006) and apoptosis (Thornalley et al., 1996). Methylglyoxal causes complications in several conditions and diseases, like diabetes mellitus (Lapolla et al., 2003; Vander Jagt et al. 2003), cardiovascular diseases (Uchida 2000; Rabbani et al., 2011), metabolic syndrome (Liu et al. 2011), obesity (Matafome et al. 2013), aging (Beeri et al., 2011; Srikanth et al., 2013) dementias (Dukic-Stefanovic et al., 2001) and other neurodegenerative diseases, like AD (Münch et al., 2012).
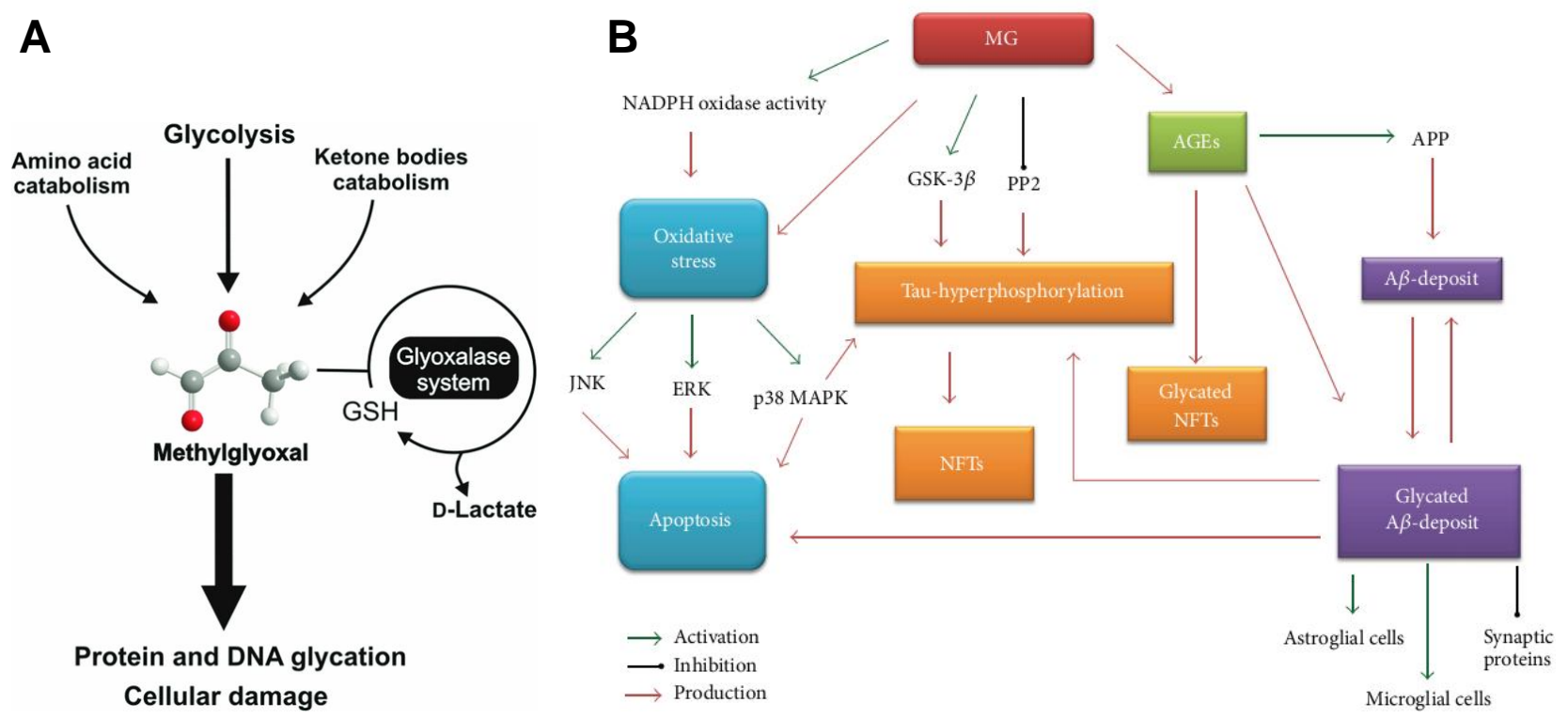

Figure 3. Formation and detoxification of methylglyoxal (MG) (A; Sousa Silva et al., 2013). Role of MG and MGderived advanced glycated endptoducts (AGEs) in Alzheimers disease (B; Angeloni et al., 2014). Abbreviations: APP, amyloid- $\beta$ protein precursor; ERK, extracellular-signal-regulated kinases; GSH, glutathione; GSK, glycogen synthase kinase; JNK, c-Jun N-terminal kinase; MAPK, mitogen activated protein kinase; NADPH, nicotinamide adenine dinucleotide phosphate; NFTs, neurofibrillary tangles; PP, protein phosphatase. 
For the pathological alterations in $\mathrm{AD}$ not just $\mathrm{A} \beta$ but other factors are also responsible, including methylglyoxal. The polymerization of $\mathrm{A} \beta$ is enhanced by this reactive ketoaldehyde which level is doubled in the liquor of AD patients (Kuhla et al., 2005). Methylglyoxal reacts with the amino groups of $A \beta$ peptide. Glycation destroys irreversibly the structure of the protein and induces $\mathrm{A} \beta$ aggregation (Fig. 3B). The byproducts of this reaction are AGE and their accumulation leads to enhanced production of amyloid precursor protein (Ko et al., 2010), further protein deposits and amyloidosis (Münch et al., 1999). Methylglyoxal have serious impact on neurons, too. It triggers the formation neurofibrillary tangles (Ledesma et al., 1994) and contribute to the production of harmful agents like reactive oxygen species (ROS) and nitrogen monoxide (Loske et al., 1998). In cerebral endothelial cells A $\beta$ and AGE has a common influx receptor, RAGE. This receptor is responsible for the regulation of $A \beta$ and AGE level among brain, blood and liquor (Srikanth et al., 2011). The expression level of RAGE is low in healthy brain, but is increased in AD (Miller et al., 2008).

Carbonyl stress induced by high level of methylglyoxal is responsible for the diabetes related vascular complications (Mukohda et al., 2012), which can partly explain the higher incidence of stroke, dementia and Alzheimer's disease in diabetes mellitus (Whitmer, 2007; Bruno et al., 2010). Therefore, considerable attention has been paid to the effects of MG on cerebral blood vessels recently. Methylglyoxal activates a series of inflammatory responses leading to accelerated vascular endothelial damage (Yamawaki et al., 2008; Okouchi et al., 2009; Sena et al., 2012). In human brain endothelial cells, methylglyoxal induced mitochondrial apoptotic signaling: decreased mitochondrial membrane potential, activated caspases and perturbed the cellular glutathione redox status (Okouchi et al., 2009), In another study, methylglyoxal caused barrier dysfunction. It glycated the TJ protein, occludin and disturbed the architectural organization of ZO-1 in cultured endothelial cells, and in brain microvessels of diabetic rats (Li et al., 2013b). These findings indicate that methylglyoxal-induced carbonyl and oxidative stress may play an important role in neurovascular pathology, and brain endothelium can be an early and significant target site of methylglyoxal.

\subsection{The blood-brain barrier as a therapeutical target}

The BBB is indispensable for creating and maintaining the homeostasis of the CNS, and even minor functional changes at the $\mathrm{BBB}$ without morphological alterations can lead to severe and lasting neurological dysfunction (Deli, 2005; Zlokovic, 2008). Therefore, the BBB is increasingly considered as a target of new therapeutical approaches in neurodegenerative disorders (Vangilder et al., 2011). There are several groups of potentially protective molecules acting on brain endothelial cells, including anti-inflammatory drugs, lipids, natural compounds, and neuropeptides (Heneka et al., 2011; Ishrat et al., 2012; Pintér et al., 2014). For brain 
endothelial protection experiments only a limited number of anti-inflammatory molecules were selected with proved efficacy on other cell types and in clinical studies. From the three different compounds tested, pentosan polysulfate and edaravone are already used in clinical therapy for other indications, while docosahexaenoic acid is widely used as a dietary supplement.

\subsubsection{Pentosan polysulfate}

Pentosan polysulfate (PPS) is a semisynthetic polysaccharide obtained from beech tree (Fagus silvatica) shavings. It is a highly sulphated polyanion (average mw: 3-6 kDa) structurally related to the mammalian glycosaminoglycans (Fig. 4A). The high sulfation rate and charge density enables PPS to compete more effectively than other polyanions, i.e. heparin, with endogenous glycosaminoglycans (Ghosh, 1999). Glycosaminoglycans are important regulators in many biologically diverse processes, therefore PPS has also diverse molecular activities (Maffrand et al., 1991; Ghosh, 1999). PPS can inhibit protein kinase A and C, tyrosine protein kinases, serine proteases, matrix metalloproteinases, lysosomal enzymes, coagulation factors, complement factors, cytokines. It stimulates the release of tissue-type plasminogen activator, superoxide dismutase, and lipase in different cells and tissues (Ghosh, 1999). In clinical practice pentosan was used as an anti-coagulant (Maffrand et al., 1991) and as a treatment for inflamed varicose veins and for interstitial cystitis (Nordling, 2004). The FDA approved the drug under the brand name Elmiron (http://www.rxlist.com). In Hungary it is sold in form of tablets, injection and gel named SP 54 (Fig. 4B; http://www.pharmindex-online.hu). PPS is also used in the prevention and therapy of human prion diseases, which belong to the family of protein conformational diseases, similarly to AD (Panegyres and Armari, 2013).

\section{A}

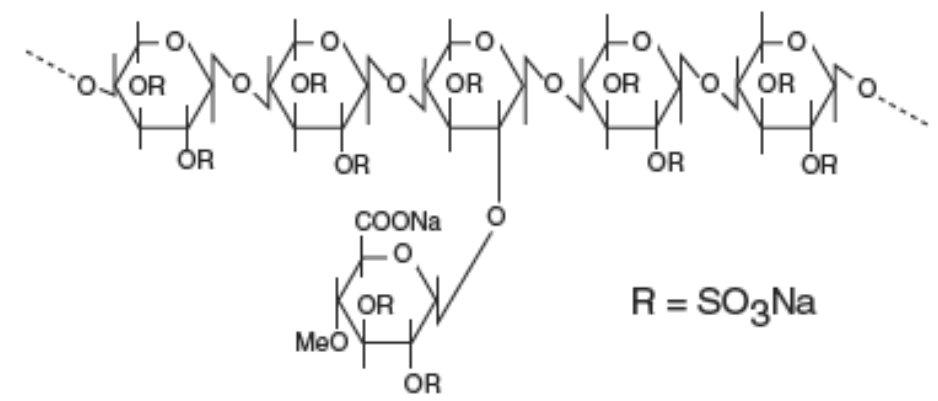

B

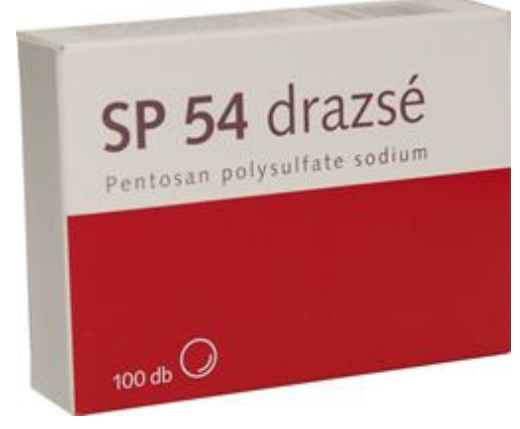

Figure 4. The structure of pentosan polysulfate (A). Form of the drug SP 54 (B).

PPS can favorably regulate BBB phenotype (Deli et al., 2000), and protect against lipopolysaccharide-induced toxicity in brain endothelial cells (Veszelka et al., 2007). Damage induced by prion peptide treatment in brain endothelial cells was also attenuated by PPS (Deli et 
al., 2000b). Importantly, prion peptide forms insoluble aggregates and plays a central role in prion diseases, similarly to $A \beta$ in AD. PPS can inhibit the binding of endogenous glycosaminoglycans to $A \beta$ and this effect was suggested as a potentially effective therapeutical approach to prevent or slow amyloidogenesis in AD (Leveugle et al., 1994). However, pentosan was not tested on brain endothelial cells treated with $\mathrm{A} \beta$ peptides.

\subsubsection{Docosahexaenoic acid}

Docosahexaenoic acid (DHA) is the end product of long-chain polyunsaturated $\omega-3$ fatty acids (n-3 PUFAs) synthesis (Fig. 5A). It is an essential fatty acid, because the human body synthesizes it only in a small amount (Voss et al., 2011). The majority of DHA comes from nutrition. The richest sources of DHA are marine fishes and algae. Commercially available DHA nutritional supplements (Fig. 5B) are produced by microalgae such as Crypthecodinium cohnii and Schizochytrium species (Rapoport et al., 2007; Innis, 2007).

DHA is vital for brain maturation and plays a primary role in neurotransmission as an important membrane component of neurons. It protects developing cholinergic neurons against glutamate cytotoxicity (Högyes et al., 2003). DHA has a hypotriglyceridemic and antiinflammatory effects. Classically, n-3 PUFAs antagonize n-6 PUFA arachidonic acid-induced proinflammatory prostaglandin E formation (De Caterina et al., 2000). Another well-known mechanism by which n-3 PUFAs exert their anti-inflammatory effects is via reduction of nuclear factor- $\mathrm{kB}$ activation. This transcription factor is a potent inducer of pro-inflammatory cytokine, e.g. interleukin-6 and tumor necrosis factor- $\alpha$, production (Siriwardhana et al., 2012a). DHA can also inhibit the attachment of monocytes to endothelium (De Caterina et al., 2000). The antiapoptotic effect of DHA is mediated through the upregulation of Bcl-2 genes or inhibition of their phosphorylation (Marszalek et al., 2005).

A

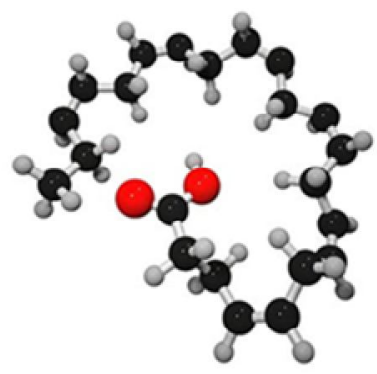

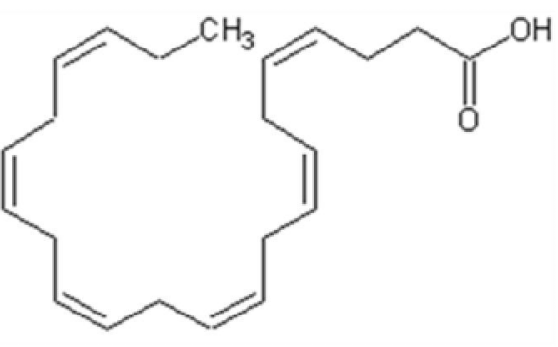

B

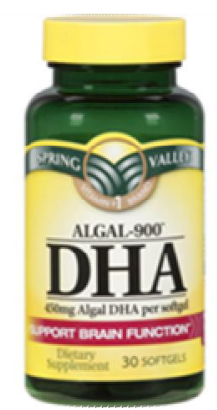

Figure 5. The structure of docosahexaenoic acid (A) and a nutritional supplement containing this fatty acid (B). 
The dietary intake of DHA is beneficial in cardiovascular diseases, metabolic disorders, cancer, depression, arthritis, pregnancy and aging (Siriwardhana et al., 2012b). Epidemiological observations suggest that high unsaturated fatty acid intake is associated with decreased risk of dementia (Lopez et al., 2011). The absence of DHA could lead to reduced neuronal survival (McNamara et al., 2007), and cell death accompanied with declining cognitive functions (Serhan et al., 2004). The level of DHA is reduced in AD patients (Tully et al., 2003) and in AD postmortem brains (Söderberg et al., 1991) compared with age-matched healthy controls. DHA reduces amyloid- $\beta$ 1-42 (A $\left.\beta_{42}\right)$ peptide production in animal models of AD (Lim et al., 2005; Oksman et al., 2006) and chronic DHA treatment improves cognition in a transgenic mouse model of AD (Arsenault et al., 2011). DHA inhibits aggregation of amyloid and tau proteins (Lim et al., 2005; Hashimoto et al., 2005). Although, clinical studies found only minor effect of DHA on the improvement of cognitive functions in the very early stage of AD (Freund-Levi et al., 2006; Quinn et al., 2010).

Based on these data DHA can be potentially important in the prevention of $\mathrm{AD}$, however there are no data on its effect on the cells of the neurovascular unit, except neurons (Grimm et al., 2011). Therefore our aim was to test the effect of DHA not only on neurons, but also on other important elements of the neurovascular unit, such as brain endothelial cells.

\subsubsection{Edaravone}

Edaravone (3-methyl-1-phenyl-2-pyrazolin-5-one, MCI-186) is a neuroprotective free radical scavenger (Fig. 6A). It is the active substance of the Japanese medicine Radicut (Fig. 6B), which helps neurological recovery following acute cerebral ischemia and subsequent cerebral infarct (Watanabe et al., 1994).
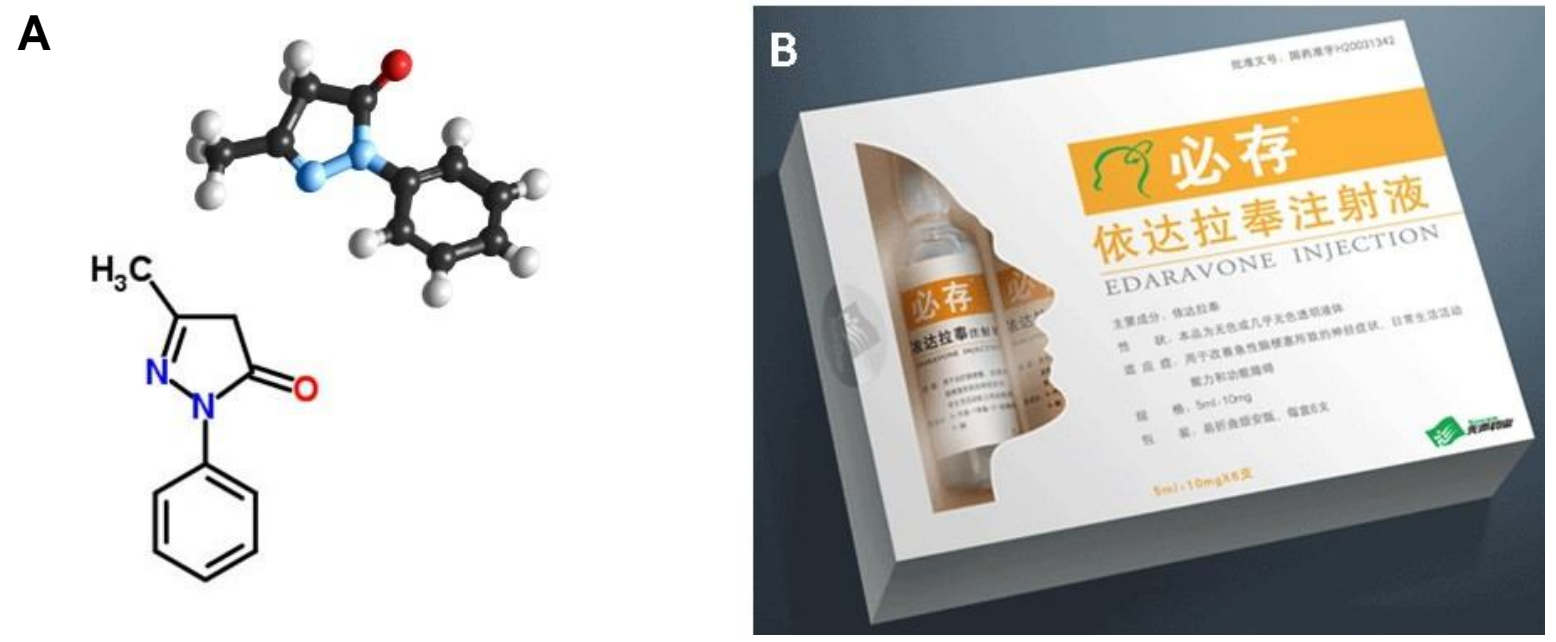

Figure 6. The structure of edaravone (A) and an edaravone containing drug to treat ischemic stroke (B). 
The free radical scavenger edaravone exerts anti-oxidant effects by inhibiting hydroxyl radical-dependent and independent lipid peroxidation (Watanabe et al., 2004). Edaravone also suppresses increased hydroxyl and superoxide anion radical levels in models of ischemiareperfusion (Okatani et al., 2003). In addition to its free radical scavenging property, edaravone showed anti-apoptotic, anti-necrotic and anti-cytokine effects in animal models of various diseases (Kikuchi et al., 2012). To further reveal the mechanism of protection, brain microvessels (Yamashita et al., 2009) and the blood-brain barrier (Lukic-Panin et al., 2010) were investigated as potential pharmaceutical targets of edaravone in animal models of stroke. The effect of edaravone alone has been described on barrier function; it promoted tight junction formation via activation of sphingosin-1-phospate signaling pathway (Omori et al., 2007) and down-regulation of interleukin-1 $\beta$ induced monocyte chemoattractant protein-1 secretion (Onodera et al., 2013).

In a recent study, edaravone pre-treatment protected human microvascular endothelial cells from methylglyoxal-induced injury by inhibiting AGEs/RAGE/oxidative stress (Li et al., 2013b). However, it remained unanswered whether edaravone can also protect against methylglyoxal-induced barrier dysfunction of brain endothelial monolayers.

\subsection{Aims}

The role of the BBB to protect the brain in physiological and pathological conditions is increasingly emphasized. Protective strategies at the level of BBB are in the focus of new studies. We have selected $A \beta_{42}$ and methylglyoxal, two major pathological factors in $\mathrm{AD}$ causing $\mathrm{BBB}$ dysfunction, to study potential protective molecules using in vitro BBB models. Three compounds were used in our studies based on previous results from our group and literature data.

Therefore the main aims of our studies were the following:

1. to examine the effects of $A \beta_{42}$ on morphology and barrier properties using rat coculture based in vitro BBB models and to reveal the underlying mechanisms

2. to test the protective action of PPS on $A \beta_{42}$-induced changes on a BBB model

3. to reveal the protective action of DHA on $\mathrm{A} \beta_{42}$-induced changes in brain endothelial cells

4. to study the effects of methylglyoxal on barrier properties of human brain endothelial monolayers

5. to evaluate the barrier protective effects of edaravone on methylglyoxal-induced changes 


\section{MATERIALS AND METHODS}

\subsection{Materials}

All reagents were purchased from Sigma-Aldrich Ltd., Hungary, unless otherwise indicated.

$\mathrm{A} \beta$ and scrambled peptides were synthesized at the Department of Medical Chemistry, University of Szeged. The synthesis of $A \beta_{42}$ (mw: $4514 \mathrm{Da}$ ) and scrambled peptides and their dissolution in buffers were previously described (Zarándi et al., 2007; Annex I). Oligomerization of the peptides was checked by transmission electron microscope according to a standard protocol (Hetényi et al., 2008). Samples contained globulomers with a diameter of 5-7 nm either alone or in chain-like or annular assemblies, but not classical protofibrillar aggregates, which are 50-200 nm long (Fig. 7).

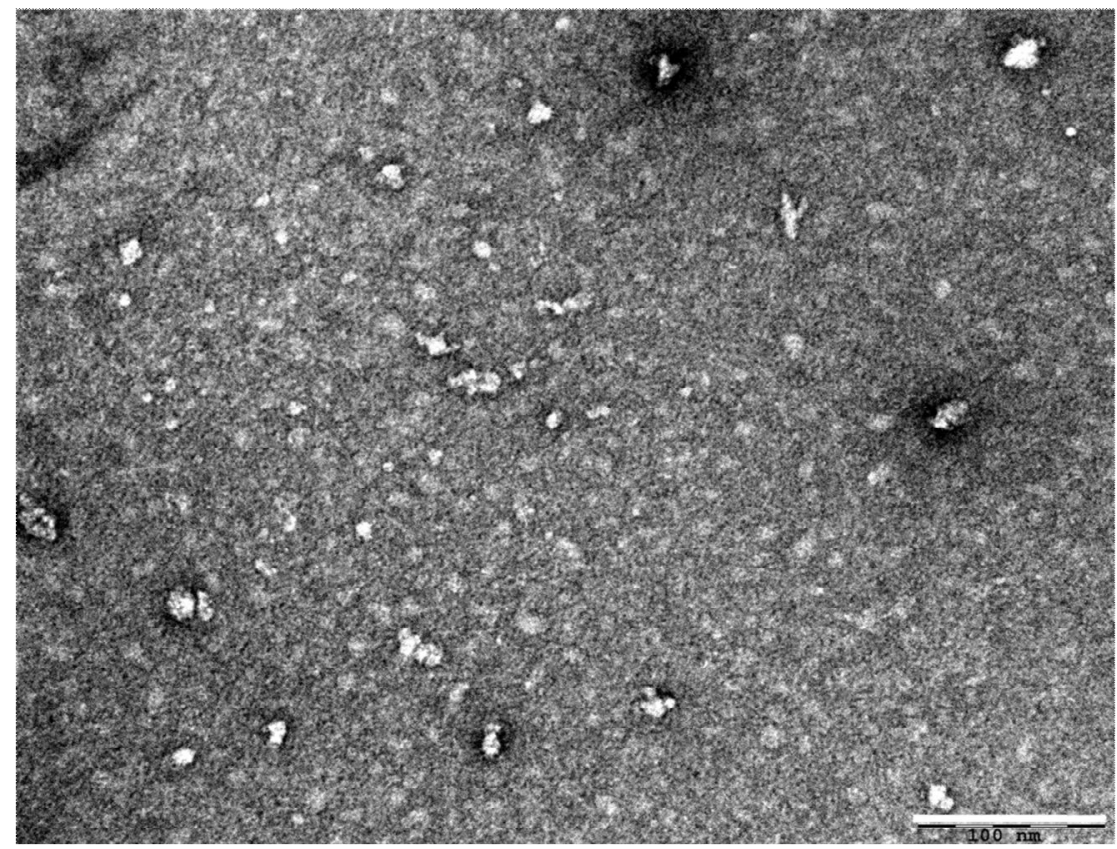

Figure 7. Transmission electron microscope image of $A \beta_{42}$ peptide dissolved in PBS to a concentration of $75 \mu \mathrm{M}$, containing a mixture of oligomers and small protofibrillar structures. Scale: $100 \mathrm{~nm}$.

The iso-amyloid- $\beta$ 1-42 (iso $A \beta_{42}$; mw: $4515 \mathrm{Da}$ ) was prepared according to the protocol of Bozsó et al. (for details see: Bozsó et al., 2009; Annex III) At physiological conditions $\left(37^{\circ} \mathrm{C}\right.$ and $\left.\mathrm{pH} 7.4\right)$ iso $\mathrm{A} \beta_{42}$ in situ forms oligomeric $\mathrm{A} \beta_{42}$ via an $\mathrm{O}-\mathrm{N}$ acyl-transfer reaction. The aggregates were visualized by transmission electron microscopy. Iso $A \beta_{42}$ forms round shaped oligomers, which can be characterized with a bimodal size-distribution: the small aggregates have an average diameter of $5.3 \pm 1.0 \mathrm{~nm}$, the large spherical aggregates have $7.9 \pm 3.3 \mathrm{~nm}$. The oligomers applied in $15 \mu \mathrm{M}$ concentration aggregate slowly in vitro after $24 \mathrm{~h}$ of incubation. At this time point protofibrillar assemblies having a length of 30 $100 \mathrm{~nm}$ with an average diameter of $8.4 \pm 2.1 \mathrm{~nm}$ are present together with spherical oligomers. 


\subsection{Cell cultures}

Monoculture, double or triple co-culture of primary rat brain endothelial cells (Fig. 8) and human hCMEC/D3 brain endothelial cell line (Weksler et al., 2013) under passage number 35 were used in the experiments.

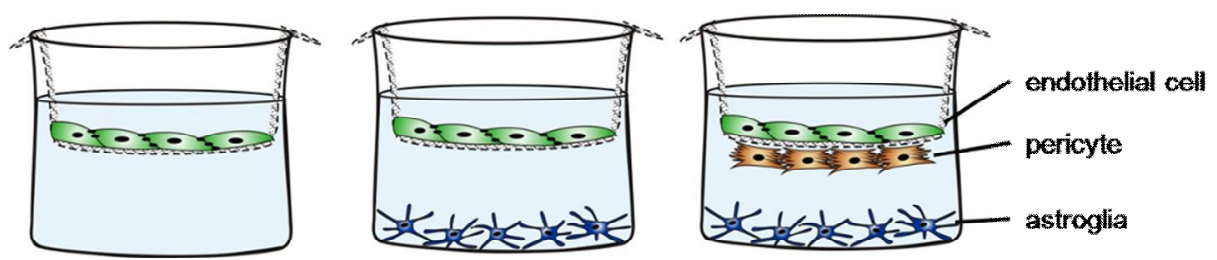

Figure 8. In vitro BBB models: monoculture, double and triple co-culture of brain endothelial cells.

\subsubsection{Primary rat brain endothelial cell cultures and BBB models}

Primary cultures of cerebral endothelial cells were prepared from 2-week-old rats. Forebrains were collected in ice-cold sterile PBS; meninges were removed, gray matter was minced by scalpels to $1 \mathrm{~mm}^{3}$ pieces and digested with collagenase CLS2 $(1 \mathrm{mg} / \mathrm{ml}$; Worthington, USA) in Dulbecco's modified Eagle medium (DMEM) for $1.5 \mathrm{~h}$ at $37{ }^{\circ} \mathrm{C}$. Microvessels were separated by centrifugation in $20 \%$ bovine serum albumin (BSA)-DMEM $(1000 \times \mathrm{g}, 20 \mathrm{~min})$ from myelin containing elements, and further digested with collagenasedispase ( $1 \mathrm{mg} / \mathrm{ml}$; Roche) in DMEM for $1 \mathrm{~h}$. Microvascular endothelial cell clusters were separated on a $33 \%$ continuous Percoll gradient $(1000 \times \mathrm{g}, 10 \mathrm{~min})$, collected, and washed twice in DMEM before plating on collagen type IV and fibronectin coated dishes (Falcon, Becton Dickinson). Cultures were maintained in DMEM/F12 supplemented with $15 \%$ plasma-derived bovine serum (First Link, UK), gentamicin $(50 \mu \mathrm{g} / \mathrm{ml})$, basic fibroblast growth factor $(1 \mathrm{ng} / \mathrm{ml}$; Roche), insulin $(5 \mu \mathrm{g} / \mathrm{ml})$, transferrin $(5 \mu \mathrm{g} / \mathrm{ml})$, sodium selenite $(5 \mathrm{ng} / \mathrm{ml})$, and heparin $(100 \mu \mathrm{g} / \mathrm{ml})$. In the first 3 days, culture medium contained puromycin $(4 \mu \mathrm{g} / \mathrm{ml})$ to selectively remove P-glycoprotein negative contaminating cells (Perrière et al., 2005). The endothelial cell cultures were immunopositive for von Willebrand factor and negative for the astroglia cell marker glial fibrillary acidic protein and $\alpha$-smooth muscle actin in accordance with earlier published results (Perrière et al., 2005; Nakagawa et al., 2007). When the cultures reached $80 \%$ confluency (fourth day in vitro), the purified endothelial cells were passaged to multiwell plates or Transwell filter inserts by a brief treatment with trypsinEDTA (w/v \%: 0.05 and 0.02) solution, and used for experiments. To induce BBB characteristics, brain endothelial cells were treated with glia- and pericyte-conditioned medium or co-cultured with rat primary glial cells and with rat primary pericytes (Nakagawa et al., 2009). Preparation of primary rat glial and cerebral pericyte cultures were prepared as described in Annex I and III.

For co-culture, brain endothelial cells were placed on cell culture inserts into multiwells containing astroglia at the bottom of the wells with endothelial culture medium in 
both compartments. When brain endothelial cells became almost confluent hydrocortisone (550 nM) was added to the culture medium (Deli et al., 2005). To construct the three cell type BBB model, first pericytes were seeded on the bottom side of the inserts and finally endothelial cells were passaged to the upper side of the inserts coated with fibronectin and collagen type IV with endothelial culture medium in both compartments (Nakagawa et al., 2009).

\subsubsection{Human hCMEC/D3 brain endothelial cell line}

Human brain endothelial cells were plated on rat tail collagen-coated culture dishes (Orange Scientific, Braine-l'Alleud, Belgium) and cultured at $37{ }^{\circ} \mathrm{C}, 5 \% \mathrm{CO}_{2}$ in EBM-2 medium (Lonza, Basel, Switzerland) containing $5 \%$ fetal bovine serum (FBS), hydrocortisone $(1.4 \mu \mathrm{M})$, Hepes $(10 \mathrm{mM})$, gentamicin $(50 \mu \mathrm{g} / \mathrm{ml})$, ascorbic acid $(5 \mu \mathrm{g} / \mathrm{ml})$, chemically defined lipid concentrate (v/w: $1 \%)$ and basic fibroblast growth factor $(1 \mathrm{ng} / \mathrm{ml}$; Roche, Basel, Switzerland). Cells were seeded in culture dishes at a density of $2.5 \times 10^{4}$ cells $/ \mathrm{cm}^{2}$ and the medium was changed every 3 days. At the first change of medium, $10 \mathrm{mM}$ lithium chloride supplement was added to the cells (Paolinelli et al., 2013). When cells reached approximately $80-90 \%$ of confluence in the dish, they were subcultured with $0.05 \%$ trypsin-EDTA solution and used for experiments.

\subsection{Treatments}

All stock solutions were prepared freshly and separately, and added to the cells consecutively. The cell viability and ROS-detection experiments were done in 96-well format, where the abluminal surface was not available, therefore the cultures were treated only luminally. In all other experiments where endothelial cells were cultured on the membrane of the inserts treatment solutions were added both luminally and abluminally. Incubations of brain endothelial cells with the agents were performed in endothelial culture medium. Treatment of cells varied between $0-48 \mathrm{~h}$, as described in the text and figure legends.

$\mathrm{A} \beta_{42}$ peptides were tested at $0-200 \mu \mathrm{g} / \mathrm{ml}(0-45 \mu \mathrm{M})$ concentrations. IsoA $\beta_{42}$ was investigated at $0-30 \mu \mathrm{M}(0-135 \mu \mathrm{g} / \mathrm{ml})$ concentrations. The $75 \mu \mathrm{M}$ stock solution of iso $\mathrm{A} \beta_{42}$ was freshly prepared in PBS and further diluted in cell culture medium for cell treatment. Methylglyoxal treatment solutions were made in the $100-1000 \mu \mathrm{M}$ concentration range in EBM-2 medium containing $10 \%$ FBS, Hepes $(10 \mathrm{mM})$ and gentamicin $(50 \mu \mathrm{g} / \mathrm{ml})$.

The stock solutions of protective agents were prepared in sterile distilled water and further diluted in culture medium, unless otherwise indicated. The concentration of PPS (Cartrophen, Biopharm Australia Pty Ltd.) varied between 1.6 and $166.6 \mu \mathrm{M}$ ( 1-100 $\mu \mathrm{g} / \mathrm{ml})$, as described in previous studies (Deli et al., 2000a; Veszelka et al., 2007). DHA stock solution $(300 \mathrm{mM})$ was prepared in ethanol and further diluted in culture medium $(1-300 \mu \mathrm{M})$ to treat the cells. Edaravone was used in the 600-3000 $\mu \mathrm{M}$. Aminoguanidine, a well-known antiglycation agent, was tested at $600-2000 \mu \mathrm{M}$ concentration and applied as a positive 
control against the effect of methylglyoxal (Edelstein et al., 1992). Triton X-100 detergent was used at $10 \mathrm{mg} / \mathrm{ml}$ concentration in viability assays as a reference compound to cause cell death. Control conditions were similar to other treatment conditions except they did not contain any of the investigated agents. The medium for the controls was also diluted with the vehicle (PBS) in the appropriate proportion.

\subsection{Viability and cytotoxicity assays}

For colorimetric dye reduction assays cells were cultured in 96-well culture plates (Orange Scientific, Braine-l'Alleud, Belgium). For real-time cell electronic sensing 96-well plates with gold electrodes (E-plate 96, ACEA Biosciences, San Diego, USA) were used.

\subsubsection{Dye reduction cell viability assay}

Living cells convert the yellow dye 3-(4,5-dimethyltiazol-2-yl)-2,5diphenyltetrazolium bromide (MTT) to purple, insoluble formazan crystals. Decrease in dye conversion reflects cellular damage. Endothelial cells grown to confluency were treated, then the medium was removed and the cells were incubated with MTT solution $(0.5 \mathrm{mg} / \mathrm{ml})$ in DMEM for $3 \mathrm{~h}$ in $\mathrm{CO}_{2}$ incubator. The amount of formazan crystals was dissolved in dimethylsulfoxide and determined by measuring absorbance at $570 \mathrm{~nm}$ wavelength with a microplate reader (Fluostar Optima, BMG Labtechnologies, Germany). The control group was considered as $100 \%$ viable.

Lactate dehydrogenase (LDH) release is the indicator of cell membrane damage, which was determined from culture supernatants by a commercially available kit (Cytotoxicity detection kit LDH, Roche, Basel, Switzerland). After the treatment $50 \mu 1$ samples from culture supernatants were removed and incubated with equal amounts of reaction mixture for 15 minutes. The enzyme reaction was stopped by $0.1 \mathrm{M} \mathrm{HCl}$. Absorbance was measured at a wavelength of $492 \mathrm{~nm}$ with a microplate reader (Fluostar Optima, BMG Labtechnologies, Ortenberg, Germany). Cell death was calculated as percentage of the total LDH release from cells treated by $10 \mathrm{mg} / \mathrm{ml}$ Triton X-100 detergent.

\subsubsection{Real-time monitoring of impedance}

Impedance-based cell electronic sensing is a label-free technique for dynamic monitoring of living cells. The Real Time Cell Analyser Single Plate instrument (RTCA-SP; ACEA Biosciences Inc., USA) utilizes an automatic and continuous impedance measurement to non-invasively quantify adherent cell proliferation and viability in real-time. This method has been successfully used to measure number, adherence, growth and health of cells in control and treatment conditions (Ózsvári et al., 2010; Kiss et al., 2013). E-plates were coated with rat tail collagen at room temperature and dried for 40 minutes under UV and air-flow. Culture medium $(50 \mu \mathrm{l})$ was added to each well for background readings, then $50 \mu \mathrm{L}$ of cell 
suspension was dispensed at the density of $1.6 \times 10^{4}$ cells/well. The cells were kept in incubator at $37{ }^{\circ} \mathrm{C}$ for 5 days until reaching confluence. Impedance was monitored every 2 minutes. The cell index at each time point was defined as $\left(R_{n}-R_{b}\right) / 15$, where $R_{n}$ is the cellelectrode impedance of the well when it contains cells and $\mathrm{R}_{\mathrm{b}}$ is the background impedance of the well with the medium alone.

\subsection{Investigation of cell morphology}

\subsubsection{Electron microscopy}

Cells grown on the membrane of culture inserts were fixed with $3 \%$ paraformaldehyde in cacodylate buffer ( $\mathrm{pH} 7.5$ ) for 30 minutes at $4{ }^{\circ} \mathrm{C}$. After washing with cacodylate buffer several times, the membranes of the culture inserts with the cells were removed from their support and placed into 24-well chamber slide and were postfixed in $1 \% \mathrm{OsO}_{4}$ for 30 minutes. Following washing with distilled water, the cells on the membrane were dehydrated in graded ethanol, block-stained with $2 \%$ uranyl acetate in $70 \%$ ethanol for $1 \mathrm{~h}$ and embedded in Taab 812 (Taab; Aldermaston, Berks, UK). Ultrathin sections were cut perpendicularly for the membrane using a Leica UCT ultramicrotome (Leica Microsystems, Milton Keynes, UK) and examined using a Hitachi 7100 transmission electron microscope (Hitachi Ltd., Tokyo, Japan). Electron micrographs were made by Megaview II (lower resolution, Soft Imaging System, Münster, Germany). Brightness and contrast were adjusted if necessary using Adobe Photoshop CS3 (San Jose, CA, USA).

\subsubsection{Phase contrast microscopy}

Cultures grown in plastic dishes with or without treatment were examined by a Nikon Eclipse TE 2000 U phase contrast microscope (Nikon, Japan) and photographed by a Spot RT digital camera (Diagnostic Instruments, USA).

\subsubsection{Holographic phase contrast microscopy}

Digital holographic images were taken with a Holo-Monitor M3 instrument (Phase Holographic Imaging AB, Phiab, Sweden). Endothelial cells were cultured on collagen coated culture dishes with borosilicate glass bottom (MatTek, Ashland, MA, USA). Holographic images of the same culture area were captured before and during treatments. Cell morphological changes were analysed by the Holostudio 2.4 software provided with the microscope (Phase Holographic Imaging AB, Phiab, Sweden). Each point in the box plot reflects the data obtained on a single cell (Alm et al., 2013; Madácsi et al., 2013).

\subsection{Evaluation of the barrier integrity}

Transendothelial electrical resistance (TEER) reflects the permeability of intercellular tight junctions for ions. TEER was measured by an EVOM resistance meter using STX-2 
electrodes (World Precision Instruments Inc., Sarasota, FL, USA) and expressed relative to the surface area $\left(\Omega \times \mathrm{cm}^{2}\right)$. TEER values of cell-free inserts were subtracted from the measured data. Resistance measurements were carried out before and after treatments to check the barrier integrity. The TEER values are presented as percent of non treated control groups.

To measure the flux of permeability marker molecules sodium fluorescein (mw: $376 \mathrm{Da}$ ) or fluorescein isothiocyanate labeled dextran (FITC-dextran, mw: $4.4 \mathrm{kDa}$ ) and Evans blue-labeled albumin (EBA; mw: $67 \mathrm{kDa}$ ) across endothelial cell layers, cells were seeded onto Transwell inserts. Inserts with confluent layers were transferred to 12-well plates containing $1.5 \mathrm{ml}$ Ringer-Hepes solution $(118 \mathrm{mM} \mathrm{NaCl}, 4.8 \mathrm{mM} \mathrm{KCl}, 2.5 \mathrm{mM} \mathrm{CaCl}$, $1.2 \mathrm{mM} \mathrm{MgSO}_{4}, 5.5 \mathrm{mM}$ D-glucose, $20 \mathrm{mM}$ Hepes, $\mathrm{pH}$ 7.4), which was the abluminal (lower) compartment in the permeability experiments. In the upper chambers (luminal compartment) culture medium was replaced by $500 \mu \mathrm{l}$ of Ringer-Hepes buffer containing sodium fluorescein or FITC-dextran solution (both $10 \mu \mathrm{g} / \mathrm{ml}$ ) and Evans blue bound to $0.1 \%$ BSA (165 $\mu \mathrm{g} / \mathrm{ml}$ ). The plates were kept in incubator at $37{ }^{\circ} \mathrm{C}$ with $5 \% \mathrm{CO}_{2}$ on a horizontal shaker $(100 \mathrm{rpm})$. The inserts were transferred at 20,40 and 60 minutes to a new well containing Ringer-Hepes solution. After incubation the concentrations of the marker molecules in samples from the luminal (upper) and abluminal (lower) compartments were determined by a fluorescent microplate reader (Fluostar Optima; emission wavelength: $485 \mathrm{~nm}$, excitation wavelength: $520 \mathrm{~nm}$ ). Flux across cell-free inserts was also measured. The endothelial permability coefficient $\left(\mathrm{P}_{\mathrm{e}}\right.$; in $\left.10^{-6} \mathrm{~cm} / \mathrm{s}\right)$ or the apparent coefficient $\left(\mathrm{P}_{\mathrm{app}}\right.$, in $\left.10^{-6} \mathrm{~cm} / \mathrm{s}\right)$ was calculated, as described in the literature (Youdim et al., 2003).

$\mathrm{P}_{\mathrm{e}}$ is calculated from the concentration $(\mathrm{C})$ of the tracer in the abluminal and luminal compartments and the volume $(\mathrm{V})$ of the abluminal compartment $(0.5 \mathrm{ml})$ by the following equation:

$$
\text { Cleared volume }(\mu \mathrm{l})=\frac{C_{\text {abluminal }} \times V_{\text {abluminal }}}{C_{\text {luminal }}}
$$

The average cleared volume was plotted vs. time, and permeability $\times$ surface area product value for endothelial monolayer $\left(\mathrm{PS}_{\mathrm{e}}\right)$ was calculated by the following formula:

$$
\frac{1}{P S_{\text {endothelial }}}=\frac{1}{P S_{\text {total }}}-\frac{1}{P S_{\text {insert }}}
$$

$\mathrm{PS}_{\mathrm{e}}$ divided by the surface area $\left(1 \mathrm{~cm}^{2}\right.$ for Transwell-12) generated the endothelial permability coefficient $\left(\mathrm{P}_{\mathrm{e}}\right.$; in $\left.10^{-6} \mathrm{~cm} / \mathrm{s}\right)$.

The apparent permeability coefficient $\left(\mathrm{P}_{\mathrm{app}}\right)$ was calculated from the concentration difference of the tracer in the abluminal compartments $\left(\Delta[\mathrm{C}]_{\mathrm{A}}\right)$ after 1 hour and luminal 
compartments at 0 hour $\left([\mathrm{C}]_{\mathrm{L}}\right)$, the volume of the abluminal compartment $\left(\mathrm{V}_{\mathrm{A}} ; 1.5 \mathrm{ml}\right)$ and the surface area available for permeability $\left(\mathrm{A} ; 1.1 \mathrm{~cm}^{2}\right)$ by the following equation. The $\mathrm{P}_{\text {app }}$ values were presented as percent of non treated control groups.

$$
P_{\text {app }}(\mathrm{cm} / \mathrm{s})=\frac{\Delta[C]_{A} \times V_{A}}{A \times[C]_{L} \times \Delta t}
$$

\subsection{Immunohistochemistry}

Cell-cell connections and morphology of primary rat brain endothelial cells were confirmed by immunostaining for tight junctional proteins ZO-1, occludin and claudin-5. Cells were cultured on fibronectin- and collagen-coated glass coverslips and treated with $\mathrm{A} \beta_{42}$ peptides in the absence or presence of PPS. The cultures were washed in PBS and fixed with ethanol-acetic acid $(95: 5 \mathrm{v} \%)$ for 10 minutes at $-20{ }^{\circ} \mathrm{C}(\mathrm{ZO}-1)$, with ethanol for 30 minutes at $4{ }^{\circ} \mathrm{C}$ (claudin-5) with paraformaldehyde $\left(4 \%\right.$ ) for $30 \mathrm{~min}$ at $4{ }^{\circ} \mathrm{C}$ (occludin). Cells were blocked with $3 \%$ BSA and incubated with primary antibodies anti-ZO-1, anti-claudin-5 and anti-occludin (all from Zymed, USA), for $1 \mathrm{~h}$ and 30 minutes. Incubation with secondary antibody Cy3-labelled anti-rabbit IgG lasted for $1 \mathrm{~h}$. Between incubations cells were washed three times with PBS.

The human hCMEC/D3 cells were investigated for junctional proteins $\beta$-catenin and claudin-5. D3 cells were cultured on rat tail collagen coated Transwell inserts. After treatments, cells were washed in PBS and fixed with acetone-methanol (1:1) for $\beta$-catenin and with ethanol-acetic acid $(95: 5 \mathrm{v} \%)$ for claudin- 5 at $-20{ }^{\circ} \mathrm{C}$ for 10 minutes. After rehydrating with PBS containing 1\% FBS and washing with PBS cells were blocked with $3 \%$ BSA in PBS at room temperature for $30 \mathrm{~min}$. Samples were incubated overnight at $4{ }^{\circ} \mathrm{C}$ with anti- $\beta$ catenin primary antibody (Invitrogen, Life Technologies Corp., Carlsbad, USA; 1:200) and with anti-claudin-5 primary antibody. Incubation with Cy3-labeled or Alexa Fluoro 488labeled anti-rabbit IgG secondary antibodies and bis-benzimide (Hoechst dye 33342) to stain cell nuclei was performed for $1 \mathrm{~h}$.

Between and after incubations cells were washed three times with PBS. Coverslips and inserts were mounted in Gel Mount (Biomeda, USA) and staining was examined by NikonEclipse TE2000 fluorescent microscope (Nikon, Japan), Olympus Fluoview FV1000 (Olympus, Japan) or Leica SP5 confocal laser scanning microscopes (Leica Microsystems $\mathrm{GmbH}$, Wetzlar, Germany).

\subsection{Detection of reactive oxygen species}

To measure ROS, we used a fluorometric detection probe, chloromethyl-dichlorodihydro-fluorescein diacetate (DCFDA; Molecular Probes, Life Technologies Corp., Carlsbad, USA). This indicator penetrates the cells by diffusion and becomes deacetylated by 
intracellular esterases. Oxidation of DCFDA by reactive oxygen species yields a fluorescent molecule. Confluent brain endothelial cell layers cultured in 96-well plates were pretreated, then washed, and incubated with Ringer-Hepes buffer containing $2 \mu \mathrm{M}$ DCFDA and 1,5 $\mu \mathrm{M}$ pluronic acid (Life Technologies, USA) for $1 \mathrm{~h}$ at $37^{\circ} \mathrm{C}$. Hydrogen peroxide pretreatment (100 $\mu \mathrm{M}, 30 \mathrm{~min}$ ) served as a positive control in the ROS assay. The plates were measured by Fluostar Optima fluorescent plate reader (BMG Labtechnologies, Germany) at $485 \mathrm{~nm}$ excitation and $520 \mathrm{~nm}$ emission wavelengths. The fluorescent values were presented as percent of the control group after $1 \mathrm{~h}$ incubation with DCFDA indicator.

\subsection{Functional assay for P-glycoprotein}

P-gp efflux pump activity was determined by the measurement of cellular accumulation of rhodamine 123 (Fontaine et al., 1996). Endothelial monolayers pretreated with isoA $\beta_{42}(15 \mu \mathrm{M})$ and/or DHA $(30 \mu \mathrm{M})$ for $24 \mathrm{~h}$ in 24 -well plates were washed, and incubated with Ringer-Hepes buffer containing $10 \mu \mathrm{M}$ rhodamine 123 for $1 \mathrm{~h}$ at $37{ }^{\circ} \mathrm{C}$. The solution was quickly removed; endothelial cells were washed three times with ice-cold PBS, and solubilized in $0.2 \mathrm{M} \mathrm{NaOH}$. Rhodamine 123 content was determined by Fluostra Optima (BMG Labtechnologies, Germany) at excitation at $485 \mathrm{~nm}$, emission at $520 \mathrm{~nm}$ wavelengths. Verapamil ( $2 \mathrm{mM}, 30$ min preincubation) was used as a reference P-gp inhibitor.

\subsection{Protein modification experiment}

Bovine serum albumin $(50 \mathrm{mg} / \mathrm{ml})$ was incubated with methylglyoxal $(2 \mathrm{mM})$ in the presence or absence of protective agents in PBS (pH 7.4) in $1 \mathrm{ml}$ total volume, at $37{ }^{\circ} \mathrm{C}$ for 7 days. Each solution was kept in a capped tube in the dark, and incubation was carried out in triplicate tubes. The formation of modified albumin was assessed by the characteristic fluorescence excitation wavelength at $360 \mathrm{~nm}$ and emission wavelength at $460 \mathrm{~nm}$ with a fluorescent microplate reader (Fluostar Optima, BMG Labtechnologies, Germany).

\subsection{Statistical Analysis}

All data presented are means \pm SD or SEM as indicated in the text. The values were compared using the analysis of variance followed by Dunnett or Bonferroni posthoc tests using GraphPad Prism 5.0 software (GraphPad Software Inc., San Diego, CA, USA). Changes were considered statistically significant at $p<0.05$. All experiments were repeated at least three times, the number of parallel wells or inserts for each treatment and time point varied between 3 and 16 . 


\section{RESULTS}

\subsection{Effect of pathological factors on brain endothelial cells}

\subsubsection{Effect of $A \beta$ peptides on viability of brain endothelial cells}

The direct effect of $A \beta_{42}$ peptide on primary rat brain endothelial cell viability was examined by two colorimetric assays. Cell viability in control group measured by MTT assay, was reflected in the high absorbance values $(0.98 \pm 0.04$ OD, mean \pm SEM; Fig. 9A), and was considered as $100 \%$. Treatment with $A \beta_{42}$ for $48 \mathrm{~h}$ significantly decreased the viability of endothelial cells, whereas that with scrambled peptide did not.
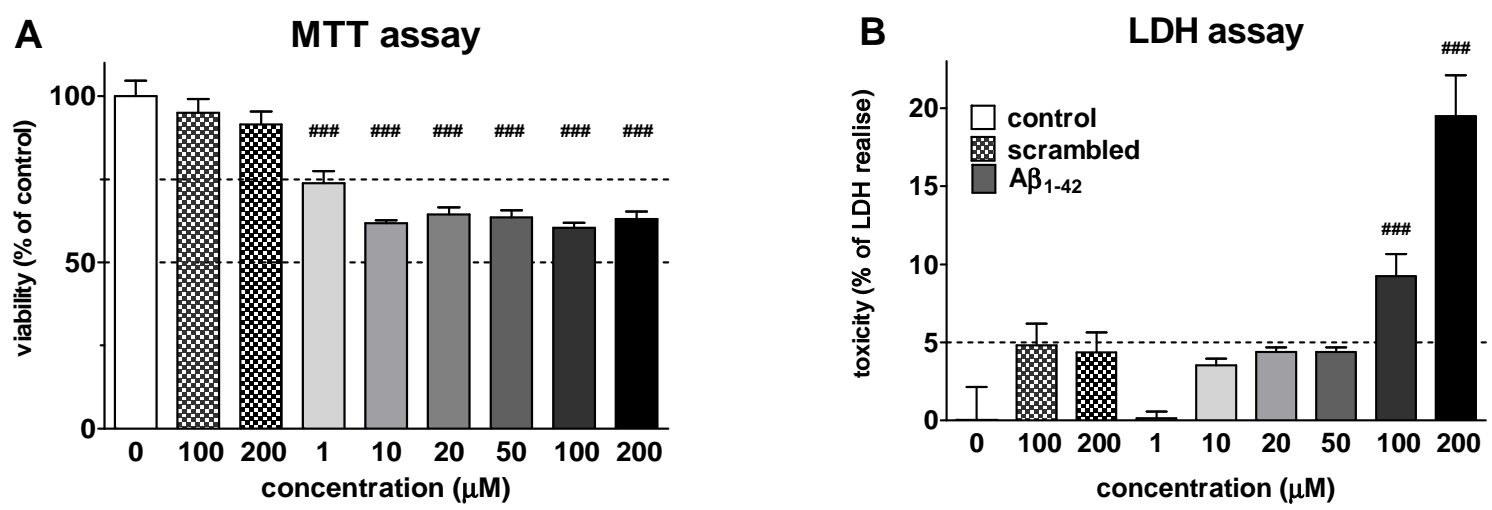

Figure 9. The effect of $A \beta_{42}$ peptide fragments on rat brain endothelial cells after $48 \mathrm{~h}$ treatment measured by MTT reduction assay (A) and LDH release assay (B). All values presented are means \pm SEM, $n=8$. Statistical analysis: one-way ANOVA followed by Dunnett test. Statistically significant differences $(p<0.05)$ from the control group are (\#) indicated.

In LDH toxicity assay no enzyme leakage was seen in the control group. Significant release of $\mathrm{LDH}$ from brain endothelial cells, indicating membrane damage, was induced by $\mathrm{A} \beta_{42}$ at $100 \mu \mathrm{M}(9.2 \pm 1.4 \%)$ and $200 \mu \mathrm{M}(19.5 \pm 2.6 \%)$ concentrations (Fig. 9B). Lower concentrations of $\mathrm{A} \beta_{42}$ did not exert toxic effect on brain endothelial cells in this test. Likewise, a peptide with scrambled amino acid sequence had no effect on endothelial cells in these viability tests, proving the specificity of the $A \beta_{42}$ peptide treatment.
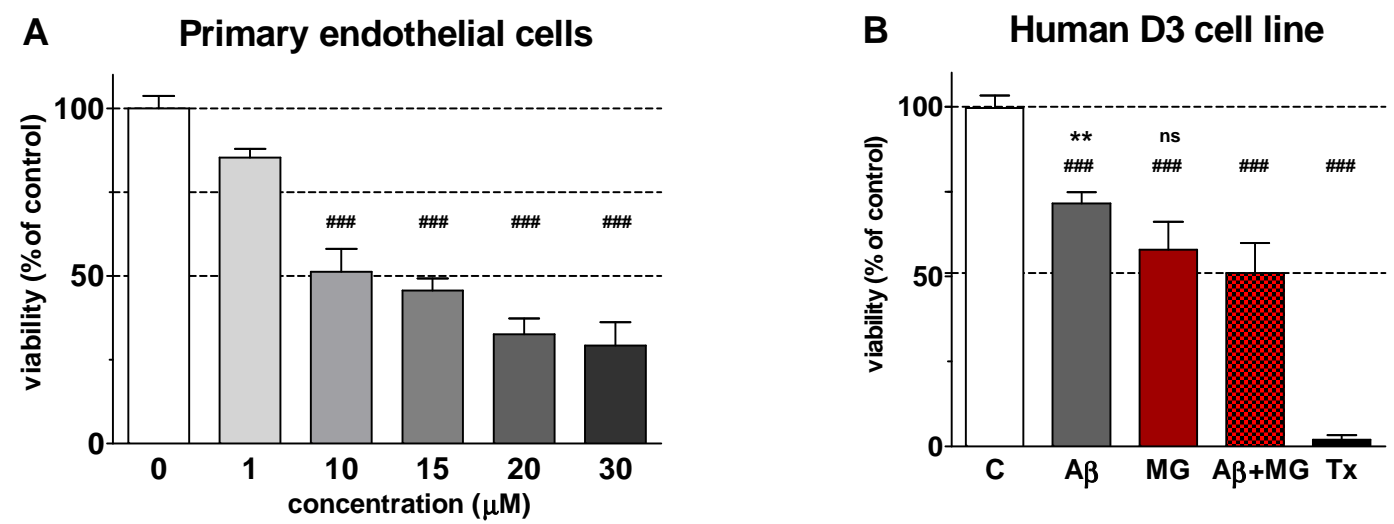

Figure 10. Concentration dependent toxic effect of iso $A \beta_{42}(\mathrm{~A} \beta)$ on primary rat brain endothelial cell cultures (A); and modulating effect of methylglyoxal $(\mathrm{MG} ; 600 \mu \mathrm{M})$ on iso $\mathrm{A} \beta_{42}$-induced $(10 \mu \mathrm{M})$ changes in human D3 brain endothelial cell line (B) measured by MTT assay. Values presented are means \pm SEM, $n=8$. Statistical analysis: one-way ANOVA followed by Dunnett or Bonferroni test. Statistically significant differences $(p<0.05)$ compared to the control $(\mathrm{C})$ groups $(\#)$ and to $\mathrm{A} \beta+\mathrm{MG}$ treated group $(*)$ are indicated. 
The effect of isoA $\beta_{42}$ on the viability of primary rat brain endothelial cells was also examined by MTT viability assay. The isoA $\beta_{42}$ treatment caused a concentration-dependent decrease in viability (Fig. 10A). At concentrations of 10-30 $\mu \mathrm{M}$ it significantly decreased the viability of endothelial cells at $24 \mathrm{~h}$ timepoint $(10 \mu \mathrm{M}, 51.3 \pm 7.6 \% ; 15 \mu \mathrm{M}, 45.7 \pm 3.6 \%$ of the control). When isoA $\beta_{42}(10 \mu \mathrm{M})$ was co-administered with methylglyoxal $(600 \mu \mathrm{M})$ significantly reduced viability was measured as compared to control or iso $A \beta_{42}$ treatment (Fig. 10B). This indicates that methylglyoxal aggravated the toxicity of the amyloid peptide.

\subsubsection{Effect of $A \beta_{42}$ on the morphology of brain endothelial cells}

To visualize the $A \beta_{42}$ caused changes cerebral endothelial cells were investigated by phase contrast and electron microscopy (Fig. 11). Large assemblies of peptide oligomers adhered to the surface of treated endothelial cells, making it difficult to assess the shape of cells by phase contrast microscopy. The most prominent change in $\mathrm{A} \beta_{42}$-treated cells was vacuolization, which could be observed around the nucleus in the cell cytoplasm, indicated by asterisks (Fig. 11B), not present in control cells.

By electron microscopy endothelial cells show smooth oval nuclei with uneven distribution of chromatin substance and several caveolae and caveolae-like invaginations on the luminal side (Fig. 11C). In the cytoplasm of control cells every organelle is bordered by clearly visibly membrane. In $A \beta_{42}$-treated cells the shape of nuclei is less regular; the chromatin substance is more uniform. No caveolae-like invaginations but vacuoles can be observed. The cytoplasm is dense and ribosomes are indistinguishable (Fig. 11D).

Elaborate intercellular junctions could be seen in brain endothelial cells. A long overlapping part of two cell processes is shown on Fig. 3E. Points of attachment, "kissing points" are indicated by arrows. The dense material at the kissing points demonstrates tight intercellular junctions. In contrast, the connection between two $A \beta_{42}$-treated endothelial cells is not tight, the processes do not lie on each other but one process is circled by the other one (Fig. 11F). Pale kissing points (arrows) can be observed. The process on the left hand side is full with vacuoles.

Although some regular TJs can be found in the $A \beta_{42}$-treated cells too, the irregular contacts, junctions with less kissing points were more typical. Vacuolisation of processes and cell bodies (shown by asterisks) and decreased number of caveolae were common.

In control cells well-developed Golgi, mitochondria, and small dots of ribosomes are visible (Fig. 11G). Cytoplasm of the $A \beta_{42}$-treated endothelial cell is more dense than the control one and several mitochondria can be seen (Fig. 11H). The structure of mitochondria in $\mathrm{A} \beta_{42}$-treated cells shows less space between the outer and inner membranes but there is some separation from the cytoplasm. In $A \beta_{42}$-treated cells less, if any, well preserved Golgi, more vacuoles and organelles unidentifiable by morphology were found compared with the control ones. 


\section{Control}
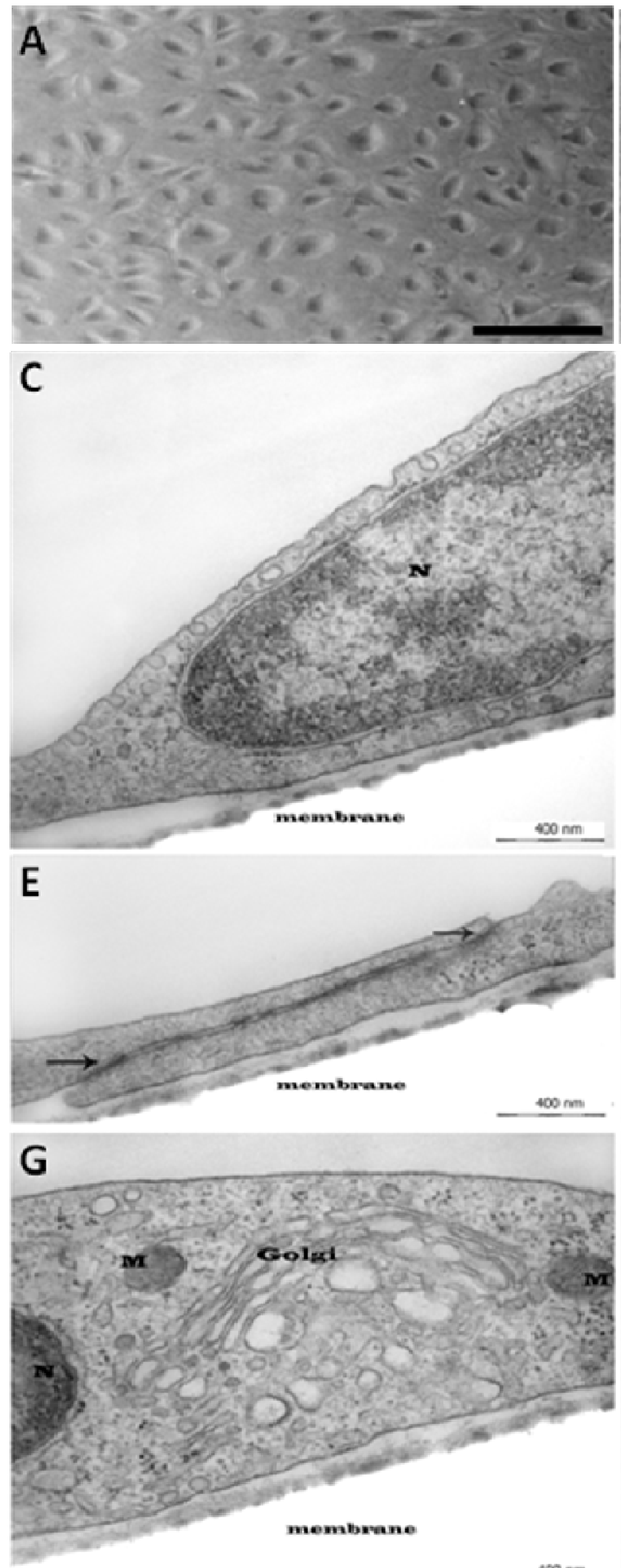

$\mathbf{A} \boldsymbol{\beta}_{42}$

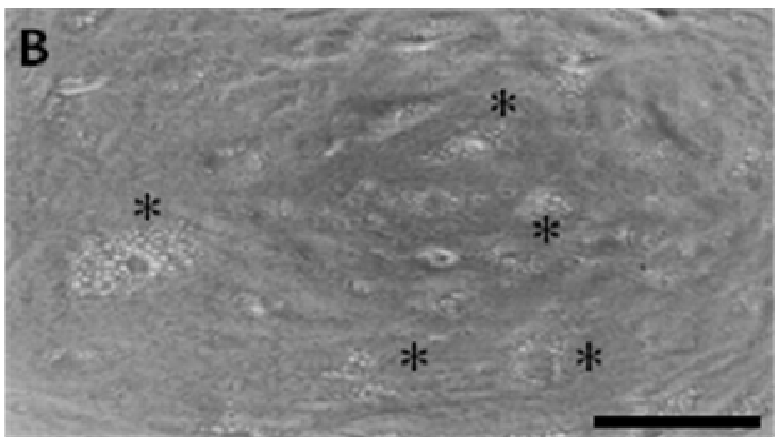

D

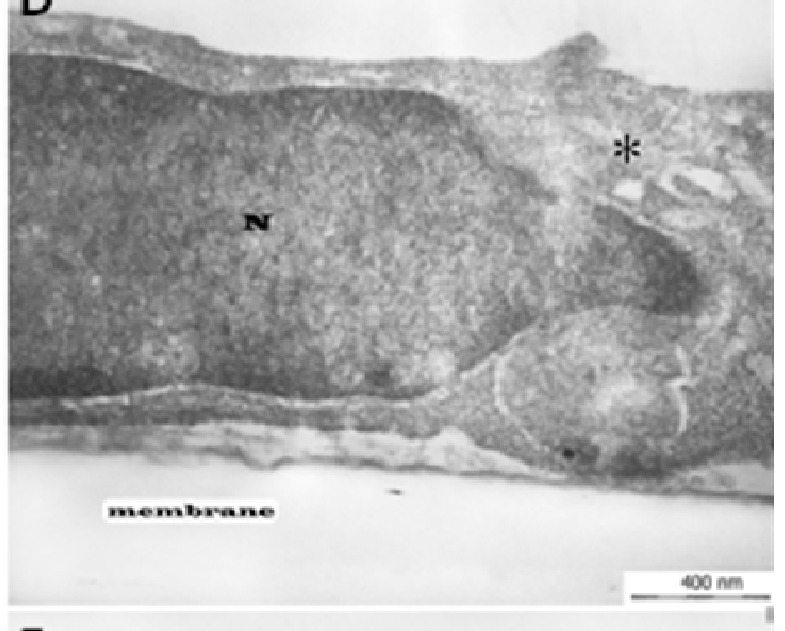

F
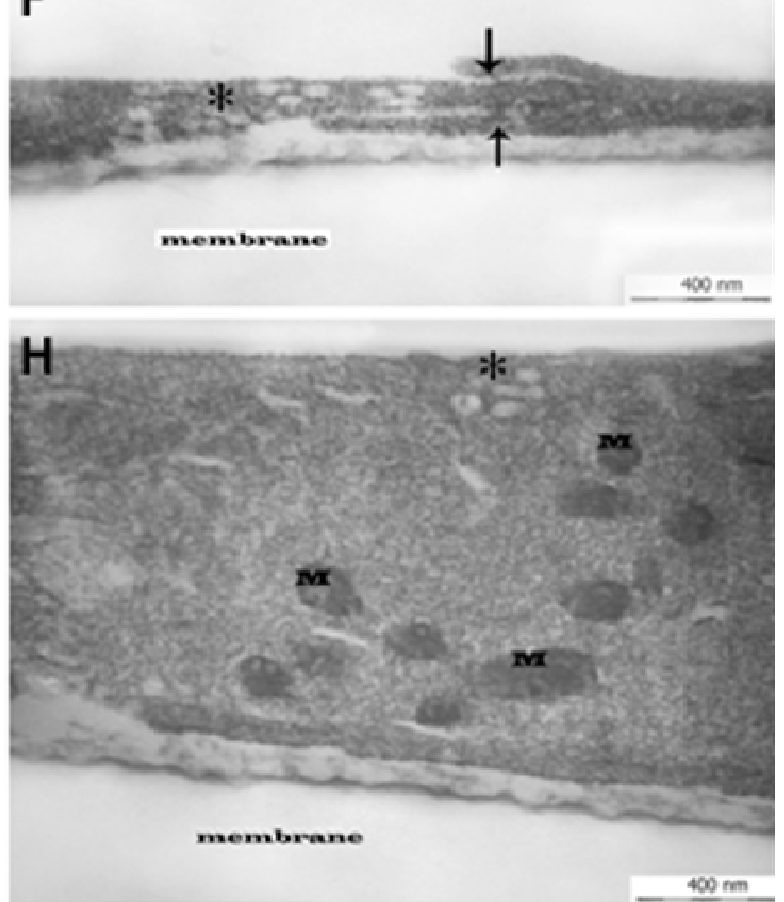

Figure 11. The effect of $A \beta_{42}$ peptide on the morphology of cultured rat brain endothelial cells. Phase contrast (A-B) and transmission electron microscopy $(\mathrm{C}-\mathrm{H})$ images of brain endothelial cells grown on the filter membrane of Transwell inserts. Typical details of control (A,C,E,G) and $A \beta_{42}$ treated $(\mathrm{B}, \mathrm{D}, \mathrm{F}, \mathrm{H})$ endothelial cells. Bar for phase contrast microscopy (A-B): $100 \mu \mathrm{m}$; Bar for electron microscopy (C-H): $400 \mathrm{~nm}$. Asterisks show cytoplasmic vacuoles and arrows indicate the kissing points of the interendothelial junctions. N: nucleus, M: mitochondria. 


\subsubsection{Effect of methylglyoxal on viability of human brain endothelial cells}

Methylglyoxal showed concentration- and time-dependent toxicity in hCMEC/D3 endothelial cells measured by RTCA-SP instrument (Fig. 12). The highest concentrations of methylglyoxal (300-1000 $\mu \mathrm{M})$ caused a very quick and significant decrease of cell index values compared to control. However, this initial impedance drop was compensated with time depending on the amount of methylglyoxal. In case of cells treated with 100-400 $\mu \mathrm{M}$ methylglyoxal no effect on cell index was measured from 3 to $24 \mathrm{~h}$. A significant toxicity of methylglyoxal was seen in concentrations of 500-1000 $\mu \mathrm{M}$. Irreversible cell damage was observed at 800 and $1000 \mu \mathrm{M}$. To validate our data, $600 \mu \mathrm{M}$ methylglyoxal concentration was tested using MTT assay at $8 \mathrm{~h}$ time point. The cell viability values after methylglyoxal treatment, measured by MTT test, decreased to $56.7 \pm 4.6 \%$ (mean $\pm \mathrm{SD}, \mathrm{n}=50$ ) in good agreement with the decrease of cell index at the same concentration of methylglyoxal at the same time point $(58.2 \pm 5.8 \%$, mean $\pm \mathrm{SD}, \mathrm{n}=10)$. The $600 \mu \mathrm{M}$ concentration of methylglyoxal causing approximately $50 \%$ toxicity was selected for further tests.

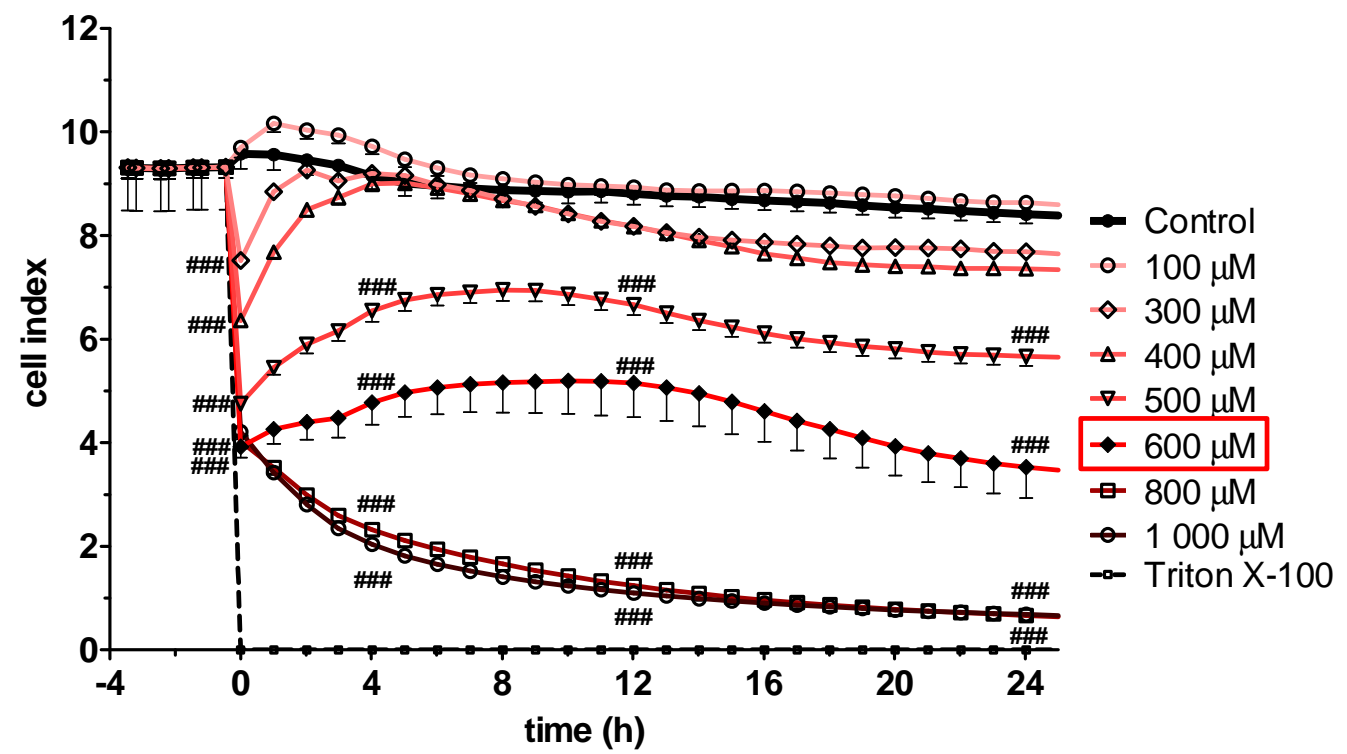

Figure 12. Effect of methylglyoxal (100-1000 $\mu \mathrm{M})$ on human hCMEC/D3 endothelial cells measured by realtime cell electronic sensing method. Cell index is expressed as an arbitrary unit and calculated from impedance measurements between cells and sensors. Data are presented as mean $\pm S D, n=10$. Triton X-100 was used at $10 \mathrm{mg} / \mathrm{ml}$ concentration. Statistical analysis: two-way ANOVA followed by Bonferroni test. Statistically significant differences $(p<0.05)$ from the control group (\#) are indicated.

\subsubsection{Effect of methylglyoxal on morphology of human brain endothelial cells}

Holographic phase contrast microscopic analysis was performed to visualize the morphological changes caused by methylglyoxal (Fig. 13). This novel technology enabled us to follow living cells in a label-free and non-invasive way. Endothelial cells show a flat, elongated shape and grow next to each other. Treatment with methylglyoxal caused drastic changes in cell morphology; growth of cell height was especially prominent as indicated by the color-scale. 
oh

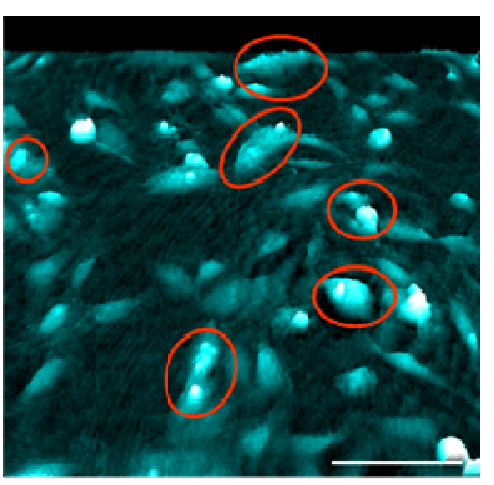

$1 \mathrm{~h}$

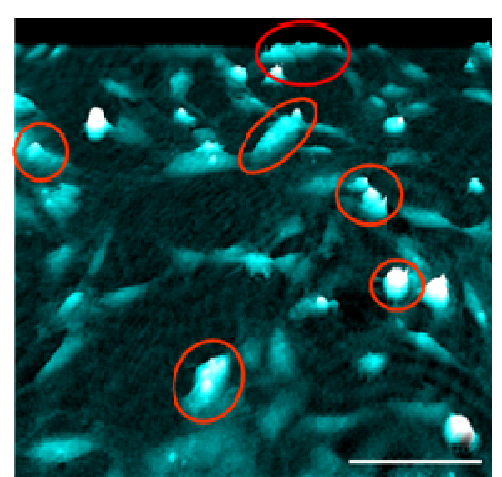

$4 \mathrm{~h}$

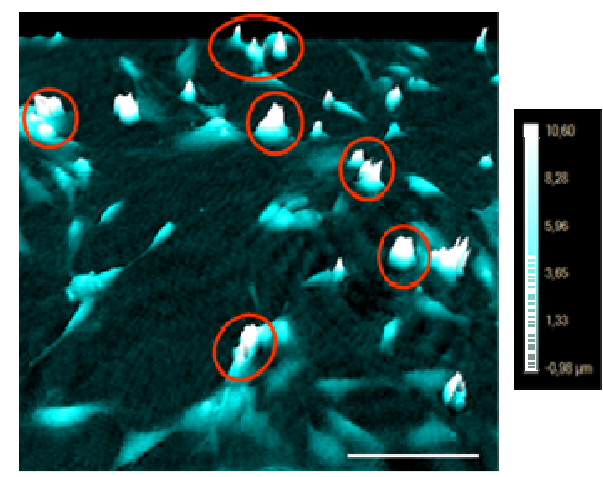

Figure 13. Holographic phase contrast images of morphological alterations induced in hCMEC/D3 human brain endothelial cells by treatment with methylglyoxal $(\mathrm{MG} ; 600 \mu \mathrm{M})$ for $4 \mathrm{~h}$. Color scale bar correspond to the height of single cells. Data were analysed by HoloStudio 2.4 software. Red circles indicate cells with drastical changes in cell morphology. Bar $=100 \mu \mathrm{m}$

The analysis of morphological data is shown on Fig. 14. During treatment with methylglyoxal the area of the cells significantly decreased $(63.1 \pm 33.7 \%)$ and their optical thickness increased by 1.8 fold $(176.2 \pm 36.1 \%)$ compared to the values at the beginning of treatment. These data indicate that endothelial cells treated with methylglyoxal contracted and rounded up which is also shown on Fig. 14. The volume of the cells was unchanged (data not shown).
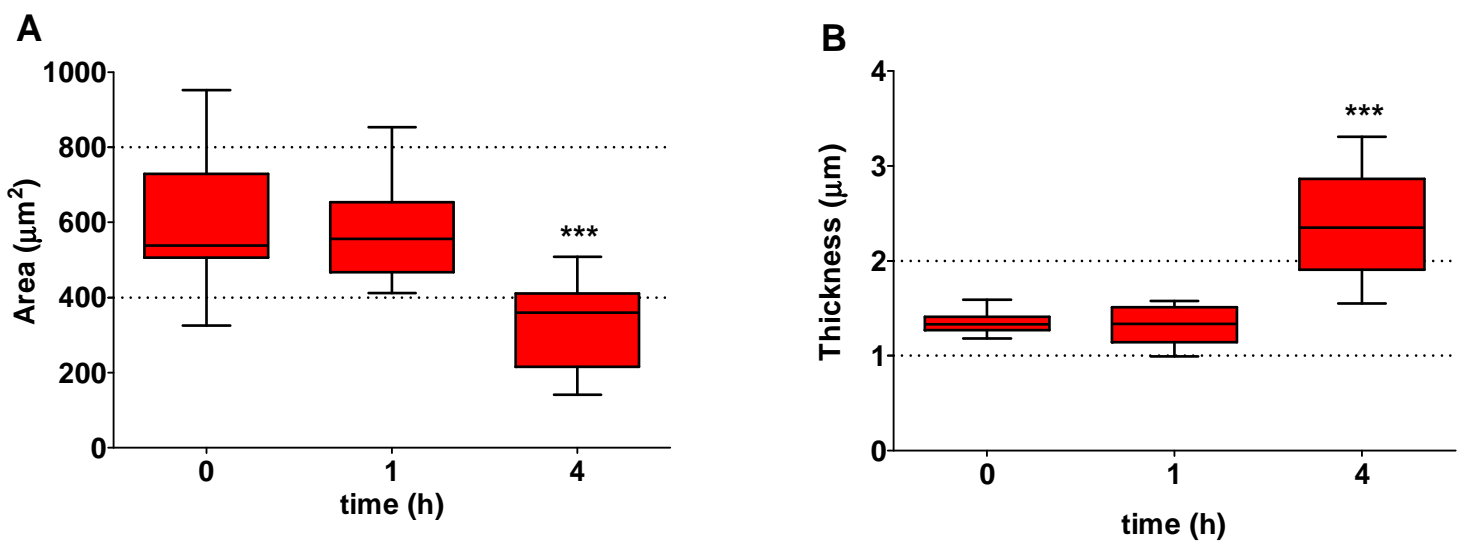

Figure 14. Morphological alterations induced in human brain endothelial cells (hCMEC/D3) by treatment with methylglyoxal at $600 \mu \mathrm{M}$ (A-B) for $4 \mathrm{~h}$. Surface area (A) and average optical thickness (B) were calculated before and during treatments. Box represents 25 and 75 percentiles. Horizontal line represent the median. Whiskers show minimum and maximum values. $\mathrm{n}=12$. Statistical analysis: ANOVA followed by Dunnett test. Statistically significant differences $(p<0.05)$ from $0 \mathrm{~h}$ time point $(\#)$ are indicated.

\section{2. Protection of brain endothelial cells by pentosan polysulfate}

\subsubsection{Pentosan protects against $A \beta_{42}$-induced toxicity}

In the MTT viability assay PPS could significantly inhibit the $A \beta_{42}(25 \mu \mathrm{M} ; 48 \mathrm{~h})$ induced decrease in cell metabolism at the highest, $100 \mu \mathrm{g} / \mathrm{ml}$ concentration (Fig. 15A). Lower concentrations of PPS $(0.1-10 \mu \mathrm{g} / \mathrm{ml})$ had no protecting effect against $\mathrm{A} \beta_{42}$ toxicity. Pentosan alone, even at high concentration, did not change MTT reduction. Similarly to MTT 
assay, PPS at $100 \mu \mathrm{g} / \mathrm{ml}$ concentration could effectively block the LDH release after amyloid exposure (Fig. 15B).
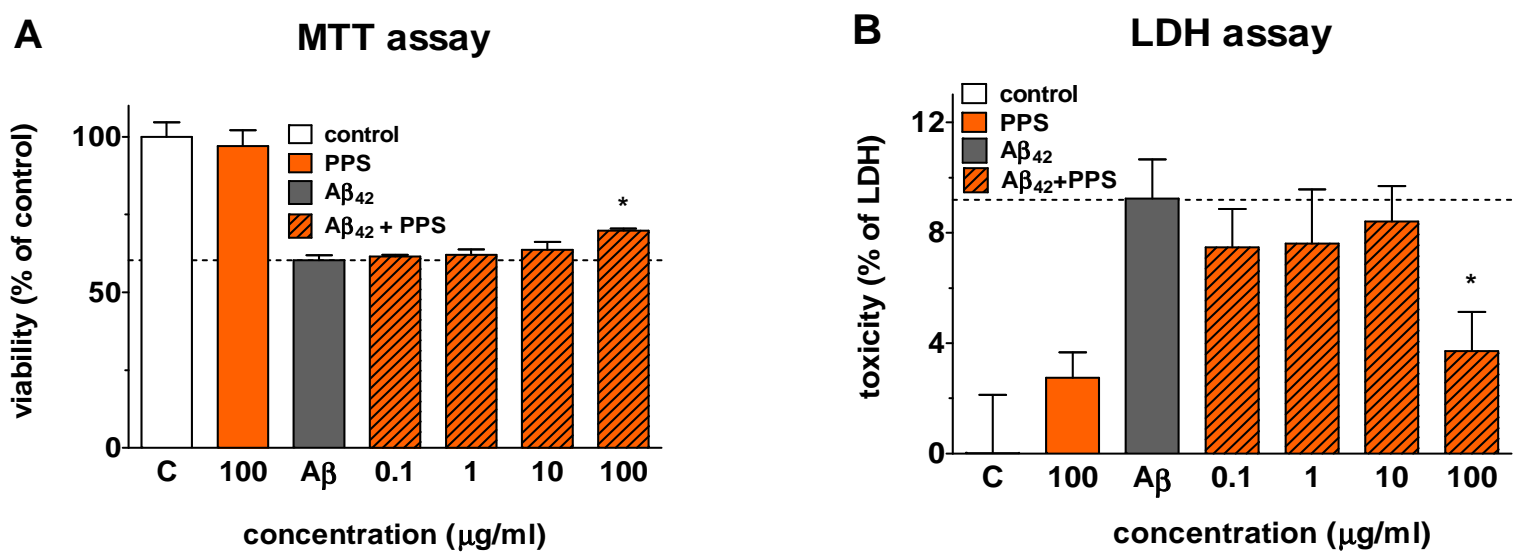

Figure 15. The effect of pentosan (PPS) on $\mathrm{A} \beta_{42}$-induced $(25 \mu \mathrm{M})$ toxicity in rat brain endothelial cells measured by MTT viability (A) and LDH toxicity (B) assays after $48 \mathrm{~h}$ treatment. All values presented are means \pm SEM, $\mathrm{n}=8$. Statistical analysis: one-way ANOVA followed by Dunnett test. Statistically significant differences $(p<0.05)$ from the $\mathrm{A} \beta_{42}$-treated group are $(*)$ indicated.

\subsubsection{Pentosan protects against $A \beta_{42}$-induced permeability increase}

The $A \beta_{42}$ peptide induced TEER decrease in brain endothelial cells at both $24 \mathrm{~h}$ and $48 \mathrm{~h}$ timepoints. Co-administration of PPS $(100 \mu \mathrm{g} / \mathrm{ml})$ could attenuate this effect of $\mathrm{A} \beta_{42}$ (Annex I). In accordance with TEER data, $A \beta_{42}$ treatment $(48 \mathrm{~h})$ induced increases in the BBB permeability for markers (Fig. 16). The $\mathrm{P}_{\mathrm{e}}$ values for albumin were lower with one order of magnitude than the values for fluorescein, in agreement with the literature (Deli et al., 2005) Co-administration of PPS significantly tightened the barrier and decreased permeability for both markers (Fig. 16). However, PPS treatment alone had no effect on the resistance or permeability of the barrier (Annex I, Fig. 16).
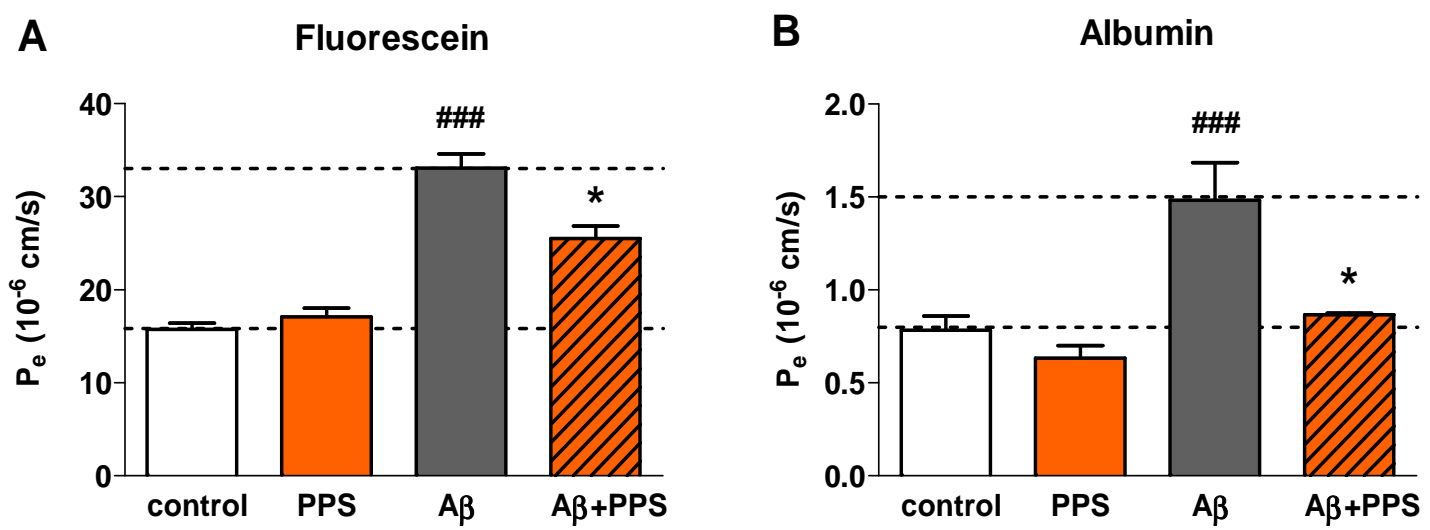

Figure 16. Changes in transendothelial permeability $\left(\mathrm{P}_{\mathrm{e}}\right)$ for permeability markers fluorescein $(\mathrm{A})$ and Evans blue labeled albumin (B) in rat brain endothelial cell monolayers treated with $\mathrm{A} \beta_{42}$ peptide $(25 \mu \mathrm{M})$ and pentosan polysulfate (PPS, $100 \mu \mathrm{g} / \mathrm{ml}$ ) for $48 \mathrm{~h}$. All values presented are means $\pm \mathrm{SEM}, \mathrm{n}=4$. Statistical analysis: oneway ANOVA followed by Bonferroni test. Statistically significant differences $(p<0.05)$ from control (\#) and from the $A \beta_{42}$-treated group are (*) indicated. 


\subsubsection{Pentosan protects against $A \beta_{42}$-induced changes in $\mathrm{TJ}$ morphology}

To further investigate the effect of $A \beta_{42}$ on the morphology of interendothelial junctions of brain endothelial cells immunostaining for junctional proteins was also performed. In control monolayers ZO-1, occludin and claudin-5 staining localized to the cell border and the tightly apposed, elongated endothelial cells were well delineated (Fig. 17). The pattern of immunostaining dramatically changed in $\mathrm{A} \beta_{42}$-treated $(25 \mu \mathrm{M}, 48 \mathrm{~h})$ cells, fluorescent staining intensity decreased, fragmentation or loss of the continuous cortical staining pattern, and appearance of intercellular gaps were visible in rat brain endothelial cells. Co-administration of PPS inhibited these changes, the monolayer integrity was better preserved and the immunostaining pattern resembled to the control ones. The visualization of $\mathrm{A} \beta_{42}$ aggregates attached to the cells as cloudy patches by the anti-claudin-5 antibody (Fig. 17) is most probably due to non-specific binding of the antibody to the aggregates.

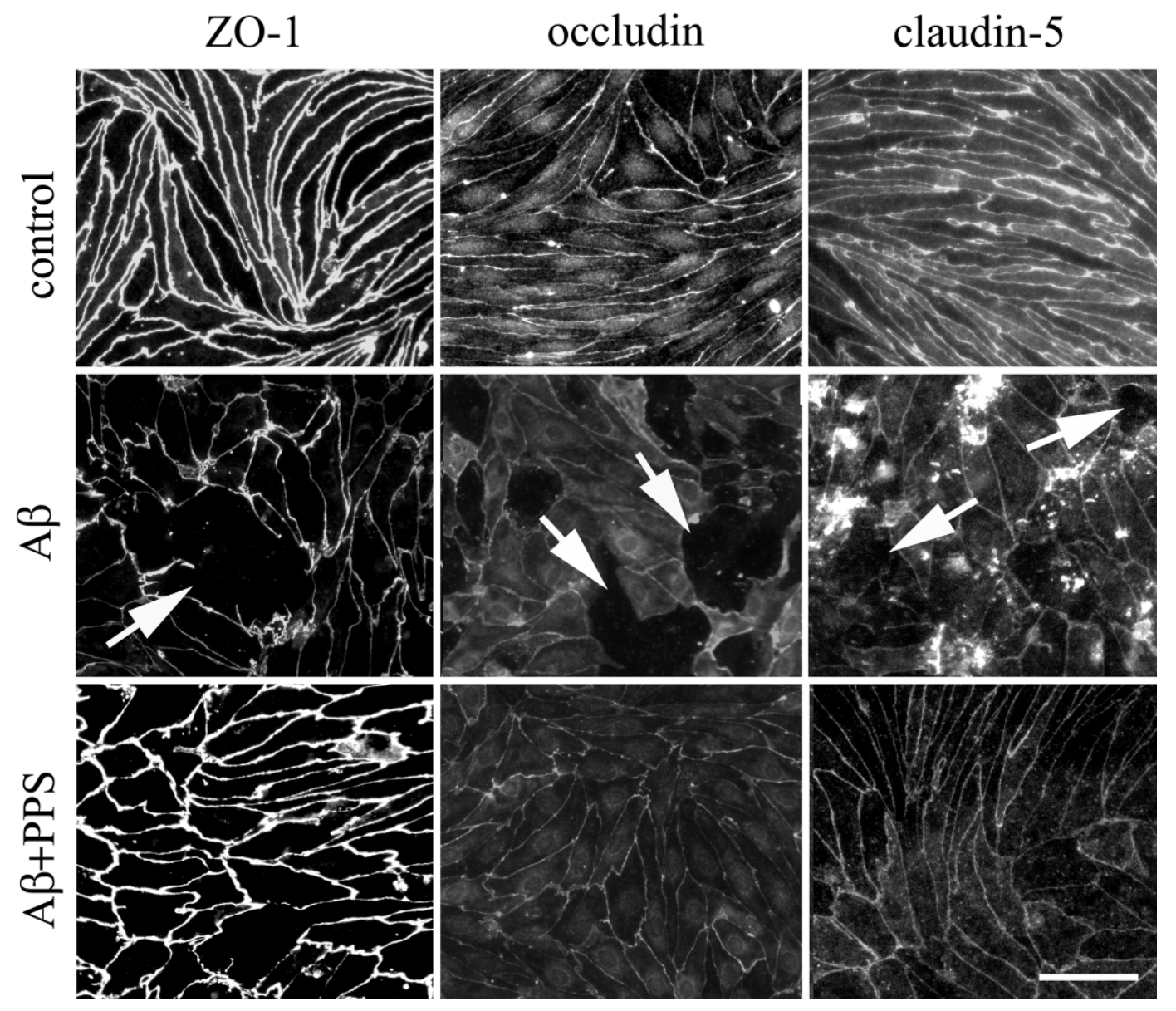

Figure 17. Effect of $\mathrm{A} \beta_{42}$ peptide $(25 \mu \mathrm{M})$ and pentosan polysulfate (PPS, $100 \mu \mathrm{g} / \mathrm{ml}$ ) for $48 \mathrm{~h}$ on immunostaining for junctional proteins $\mathrm{ZO}-1$, occludin, and claudin-5 in rat brain endothelial cells. Arrows show holes formed between endothelial cells, fragmentation or loss of junctional immunostaining. Bar: $25 \mu \mathrm{m}$.

The effect of $A \beta_{42}$ on brain endothelial tight junctions was also evident on the electron microscopy pictures, the connection between cells became looser, processes did not lie on each other (Fig. 18C). PPS treatment ameliorated the ultrastructural changes induced by $\mathrm{A} \beta_{42}$ (Fig. 18D), long overlapping processes of endothelial cell with dense material at the kissing 
points demonstrating tight intercellular junctions were visible. PPS treatment did not change the morphology of brain endothelial cells (Fig. 18B) as compared to control (Fig. 18A).
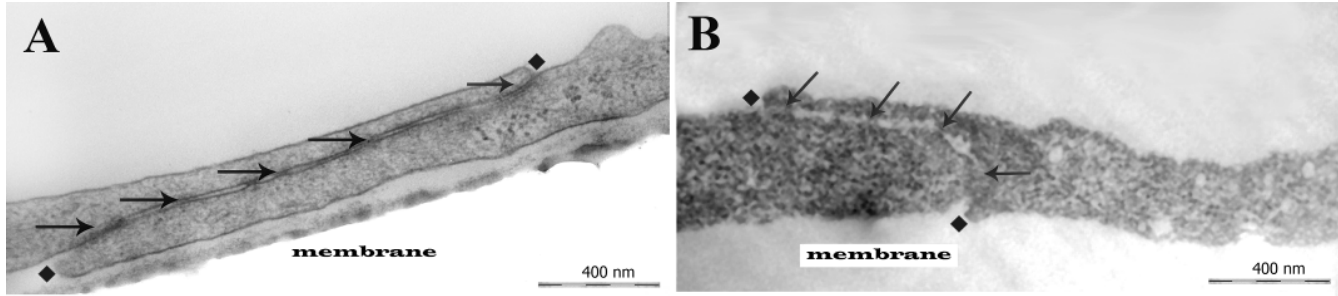

C

D
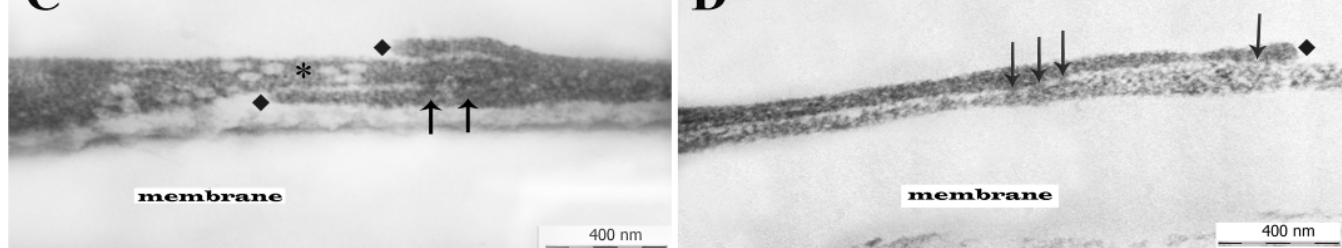

Figure 18. The effect of amyloid $\beta$ peptide fragments on the morphology of intercellular junctions of rat brain endothelial cells by transmission electron microscopy. Typical details of control (A), pentosan (B), A $\beta_{42}$ peptide (C), $\mathrm{A} \beta_{42}$ and pentosan (D) treated endothelial cells. Bar: $400 \mathrm{~nm}$. The squares indicate the starting and the ending point, arrows the kissing points of the interendothelial junctions. Asterisks show cytoplasmic vacuoles.

\subsection{Protection of brain endothelial cells by docosahexaenoic acid}

\subsubsection{DHA protects against iso $A \beta_{42}$-induced toxicity}

Based on the results of the toxicity assay (Fig. 10) the $15 \mu \mathrm{M}$ concentration of iso $A \beta_{42}$ was selected to be optimal to reproducibly induce damages in brain endothelial cell cultures. The $30 \mu \mathrm{M}$ concentration of DHA, causing no harm, was chosen to be tested as a protective agent against isoA $\beta_{42}$ toxicity. This concentration of DHA significantly attenuated the toxic effect of isoA $\beta_{42}$ measured by MTT viability assay in both rat primary endothelial cells (Fig. 19A) and human D3 cell line (Fig. 19B). D3 endothelial cells treated with both isoA $\beta_{42}$ and methylglyoxal, but not with methylglyoxal alone, were also protected (Fig. 19B).
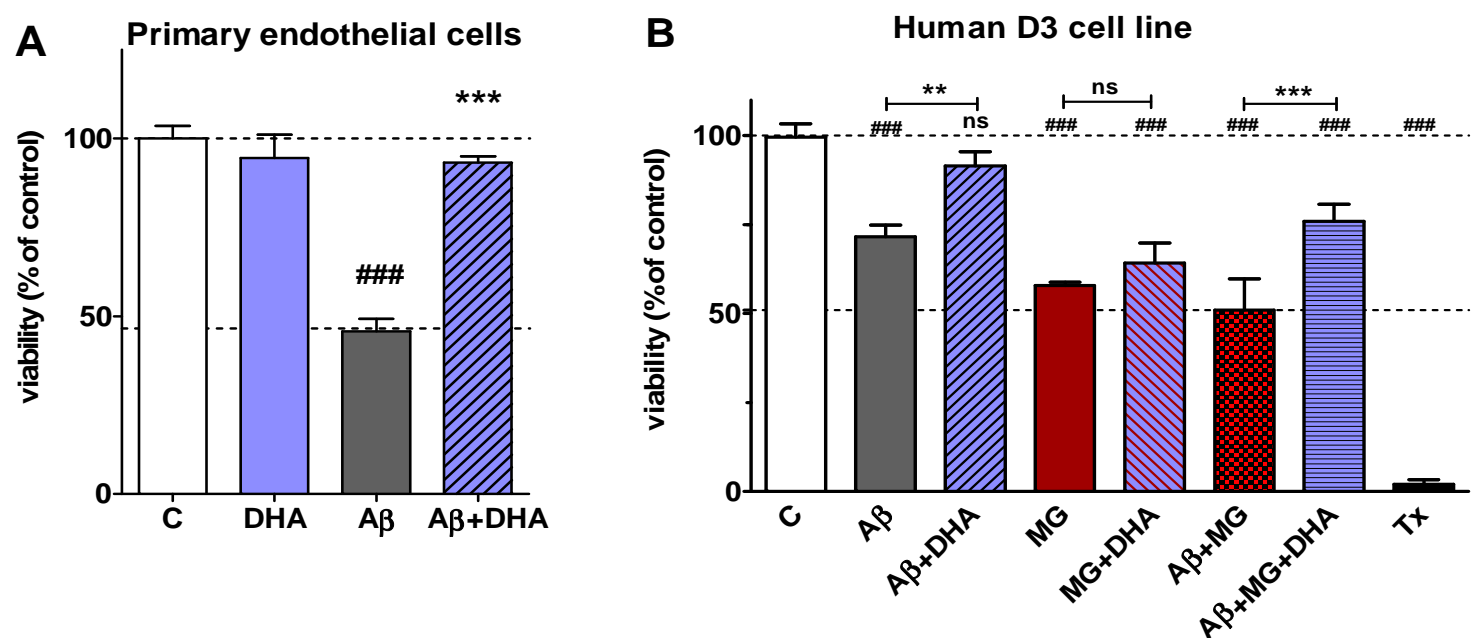

Figure 19. The effect of docosahexaenoic acid (DHA; $30 \mu \mathrm{M})$ on isoA $\beta_{42}(\mathrm{~A} \beta ; 15 \mu \mathrm{M})$ and methylglyoxal (MG; $600 \mu \mathrm{M}$ ) induced toxicity in rat primary (A) and human D3 brain endothelial cells (B). Values presented are means \pm SEM, $\mathrm{n}=8$. Statistical analysis: one-way ANOVA followed by Bonferroni test. Statistically significant differences $(p<0.05)$ compared to the control $(\mathrm{C})$ groups $(\#)$, and to iso $\mathrm{A} \beta_{42}$ treated groups $(*)$ are indicated. 


\subsubsection{DHA protects against isoA $\beta_{42}$-induced morphological changes}

Treatment with isoA $\beta_{42}$ resulted in big intercellular gaps in the confluent monolayers of brain endothelial cells and floating apoptotic cells in the culture medium (Fig. 20B). Such gaps and damage of the monolayers were also visible after $A \beta_{42}$ treatment (Fig. 17). At higher magnification cytoplasmic vacuolization could be observed, similarly to $A \beta_{42}$-treated cells (Fig. 11). DHA inhibited the changes caused by isoA $\beta_{42}$; the monolayer integrity was better preserved and resembled to the control ones (Fig. 20C).
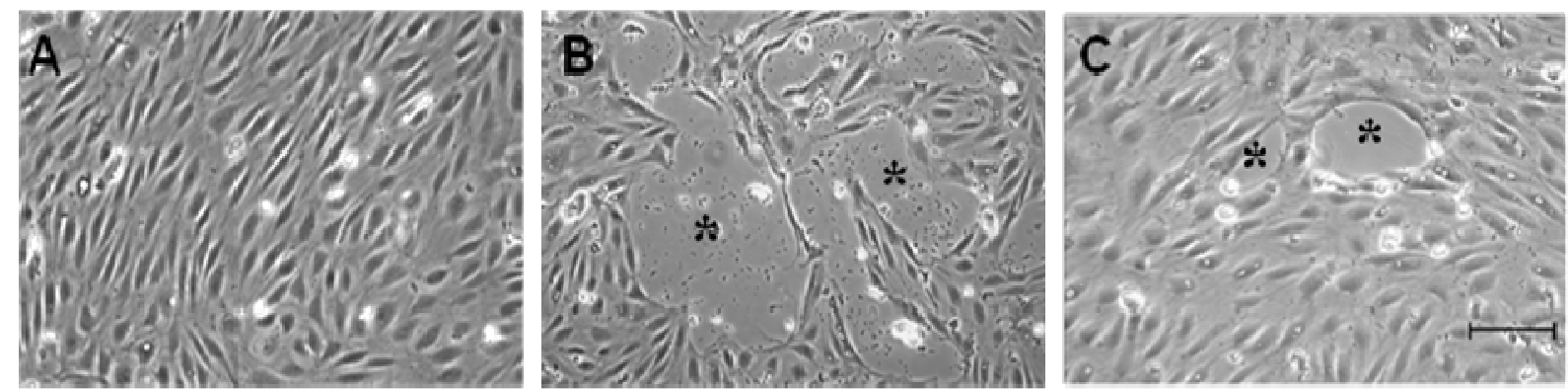

Figure 20. The effect of docosahexaenoic acid $(30 \mu \mathrm{M})$ on iso $\beta_{42}(15 \mu \mathrm{M})$ induced toxicity on the morphology of rat brain endothelial cell cultures examined by phase contrast microscopy. Asterisks show holes in endothelial monolayers. Control (A), $A \beta_{42}(B), A \beta_{42}$ and docosahexaenoic acid (C). Bar: $50 \mu \mathrm{m}$.

\subsubsection{DHA protects against iso $A \beta_{42}$-induced permeability increase}

Treatment of endothelial cell monolayers with iso $A \beta_{42}(15 \mu \mathrm{M})$ reduced the TEER by $70 \%$ of the control after $24 \mathrm{~h}$ (Annex III). The flux of the paracellular marker fluorescein was 4.6 fold higher in iso $\beta_{42}$ treated monolayers as compared to the control group (Fig. 21A). The $P_{e}$ values for albumin were lower with one order of magnitude than the values for fluorescein, in agreement with data presented on Fig. 16. The permeability for albumin was elevated by 5.9 fold in monolayers treated with iso $A \beta_{42}$ (Fig. 21B). The flux of permeability markers through endothelial monolayers was significantly decreased by co-administration of DHA, while DHA alone had no effect on permeability.
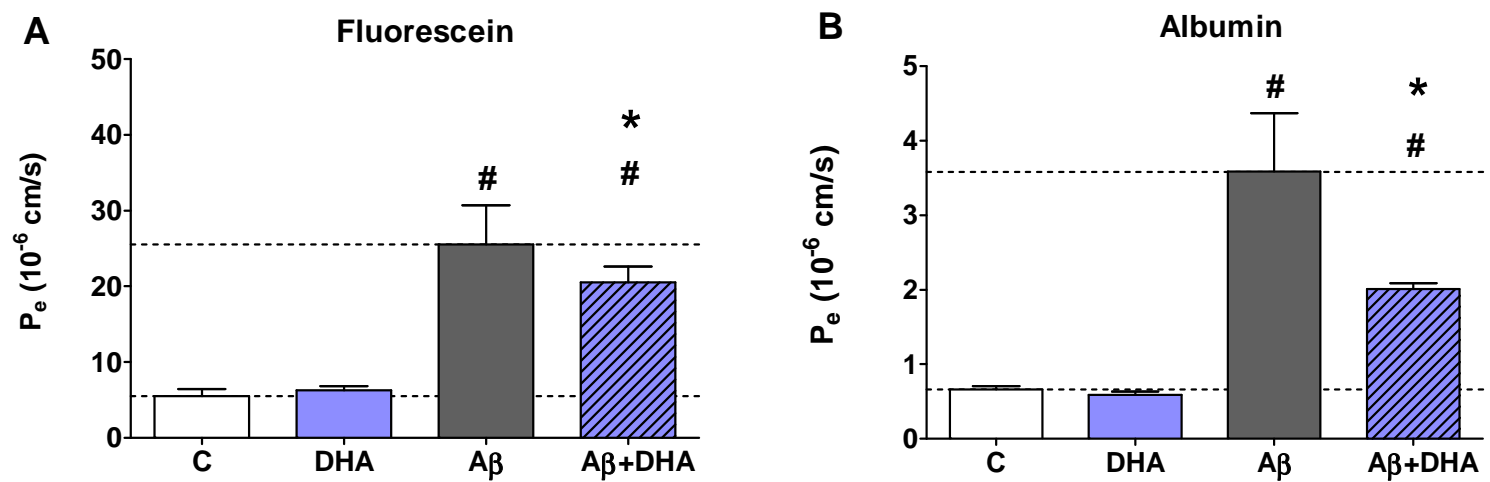

Figure 21. Effect of docosahexaenoic acid (DHA, $30 \mu \mathrm{M})$ on isoA $\beta_{42}(\mathrm{~A} \beta, 15 \mu \mathrm{M})$ induced changes in the permeability of primary brain endothelial cells for fluorescein (A) and Evans blue labeled albumin (B). Values presented are means \pm SEM, $n=6$. Statistical analysis: one-way ANOVA followed by Bonferroni test. Statistically significant differences $(p<0.05)$ compared to control $(C)$ groups $(\#)$, and to isoA $\beta_{42}$ treated groups (*) are indicated. 


\subsubsection{DHA protects against isoA $\beta_{42}$-induced brain endothelial dysfunction}

Iso $A \beta_{42}$ treatment $(15 \mu \mathrm{M}, 24 \mathrm{~h})$ significantly enhanced (1.4 fold) the production of ROS in brain endothelial cells measured by DCFDA assay (Fig. 22A). DHA (30 $\mu \mathrm{M})$ caused no change alone, but effectively inhibited the isoA $\beta_{42}$-induced elevation in ROS production. Hydrogen peroxide treatment $(100 \mu \mathrm{M}, 15 \mathrm{~min})$, a positive control in the ROS assay, elevated the amount of ROS measured by 3.4 fold in brain endothelial cells.

A

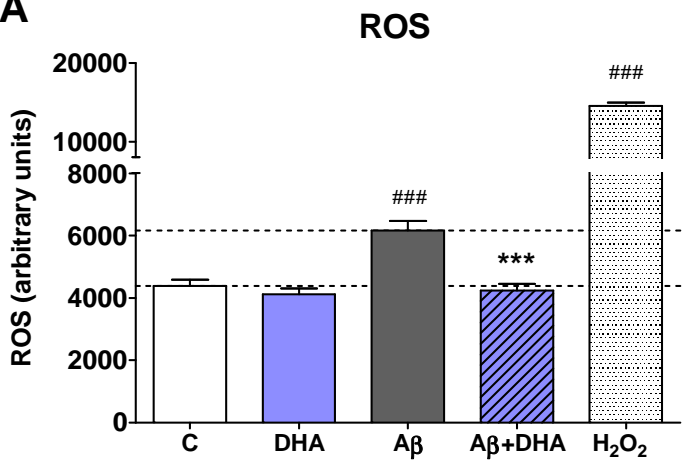

B

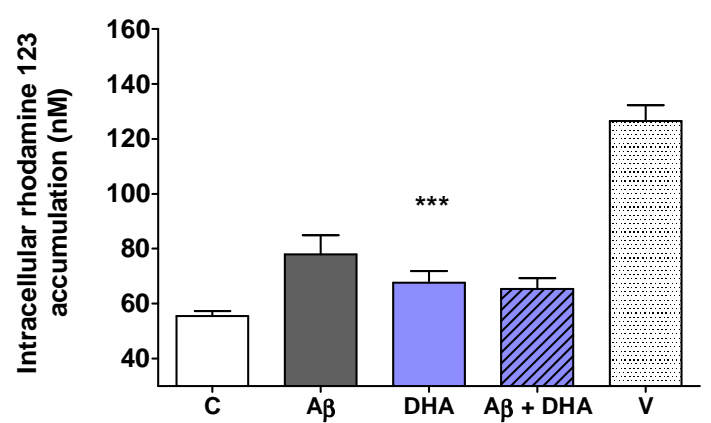

Figure 22. Effect of docosahexaenoic acid (DHA, $30 \mu \mathrm{M})$ on isoA $\beta_{42}(15 \mu \mathrm{M})$ induced changes in ROS production (A) and P-glycoprotein (P-gp) efflux pump activity (B) of primary rat brain endothelial cells. Values presented are means \pm SEM., $n=5$. Statistical analysis: one-way ANOVA followed by Bonferroni test. Statistically significant differences $(p<0.05)$ compared to control groups $(\#)$, and to iso $A \beta_{42}$ treated groups $(*)$ are indicated.

To examine the function of P-glycoprotein efflux pump rhodamine 123 uptake assay was used (Fig. 22B). Pre-treatment with isoA $\beta_{42}(15 \mu \mathrm{M}, 24 \mathrm{~h})$ significantly decreased efflux pump activity in rat brain endothelial cells as indicated by the increased level of rhodamine 123 accumulation. Co-administration of DHA prevented the inhibition of P-gp. DHAtreatment alone did not change the function of the efflux pump. Verapamil, an inhibitor of P-gp, was used as a reference blocker (Fig. 22B).

\section{4. Protection of brain endothelial cells by edaravone}

\subsubsection{Edaravone protects against methylglyoxal-induced toxicity}

To investigate the protective effects of edaravone on methylglyoxal-induced cell injury human brain endothelial cells were co-treated with different concentrations of edaravone and with a fixed concentration of methylglyoxal $(600 \mu \mathrm{M})$. Edaravone protected cells at 1-3 mM concentrations and reversed or attenuated the drop in cell index caused by methylglyoxal in a concentration- and time-dependent way (Fig. 23). Edaravone at $1 \mathrm{mM}$ had a short term (0.5-2 h) but significant effect. The 1.5 and $2 \mathrm{mM}$ concentrations of edaravone could protect the endothelial cells for 6 and $8 \mathrm{~h}$, respectively. Long lasting protection of hCMEC/D3 cells could be observed at 2.5 and $3 \mathrm{mM}$ concentrations of edaravone. The reference drug aminoguanidine $(2 \mathrm{mM})$ showed a complete protection against methylglyoxalinduced cellular toxicity. 
To determine the effect of protective agents alone, cells were incubated with different concentrations of edaravone $(600-3000 \mu \mathrm{M})$ and aminoguanidine $(600-2000 \mu \mathrm{M})$. There was no decrease in cell viability measured by MTT assay and impedance monitoring in cells treated with edaravone or aminoguanidine alone (Annex IV S1). Edaravone at $3 \mathrm{mM}$ concentration slightly but statistically significantly increased both the impedance of the endothelial layers and the metabolic activity measured by MTT assay $(121.8 \pm 5.9 \%)$. Based on these results, the $3 \mathrm{mM}$ concentration of edaravone, which protected brain endothelial cells the most efficiently, was selected for other investigations.

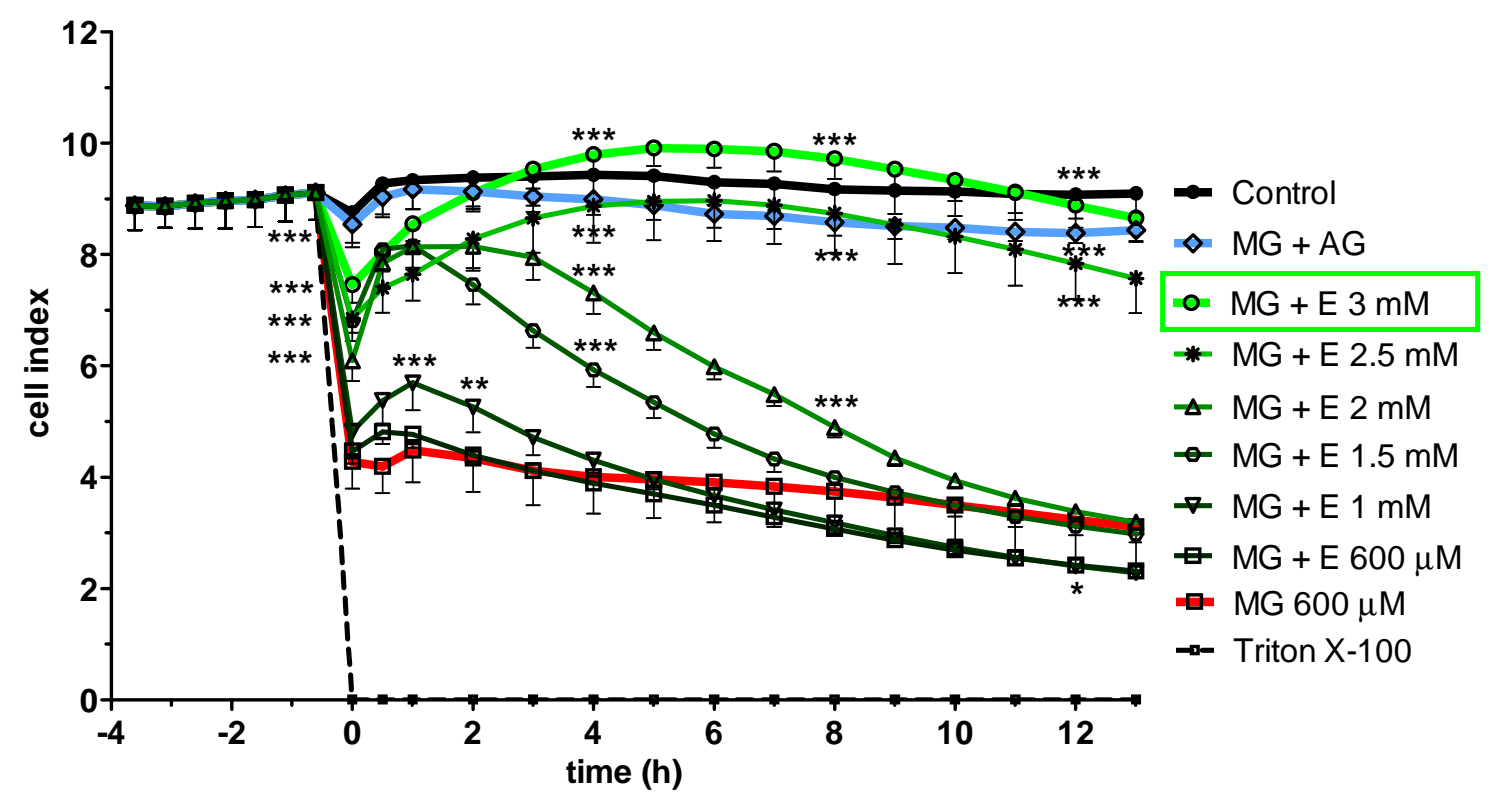

Figure 23. Effect of co-treatment with methylglyoxal $(600 \mu \mathrm{M})$ and different concentrations of edaravone (MG+E; $600-3000 \mu \mathrm{M})$ or aminoguanidine $(\mathrm{MG}+\mathrm{AG} ; 2 \mathrm{mM})$. Cell index is expressed as an arbitrary unit and calculated from impedance measurements between cells and sensors. Data are presented as mean $\pm \mathrm{SD}, \mathrm{n}=10$. Triton X-100 was used at $10 \mathrm{mg} / \mathrm{mL}$ concentration. Statistical analysis: two-way ANOVA followed by Bonferroni test. Statistically significant differences $(p<0.05)$ from the methylglyoxal treated group $(*)$ are indicated.

\subsubsection{Edaravone protects against methylglyoxal-induced morphological changes}

Morphological changes caused by methylglyoxal and the protective effect of edaravone were visualized by holographic phase contrast microscopy (Fig. 24). Methylglyoxal weakened cell-cell and cell-basal membrane connections and cells were rounded up (Fig. 13,14). In endothelial cells co-treated with edaravone $(3 \mathrm{mM})$ and methylglyoxal $(600 \mu \mathrm{M})$ there was no change in cell morphology during the treatment period $(4 \mathrm{~h})$. Accordingly, cell area and optical thickness did not change significantly in endothelial cells co-treated with edaravone (Annex IV.). 

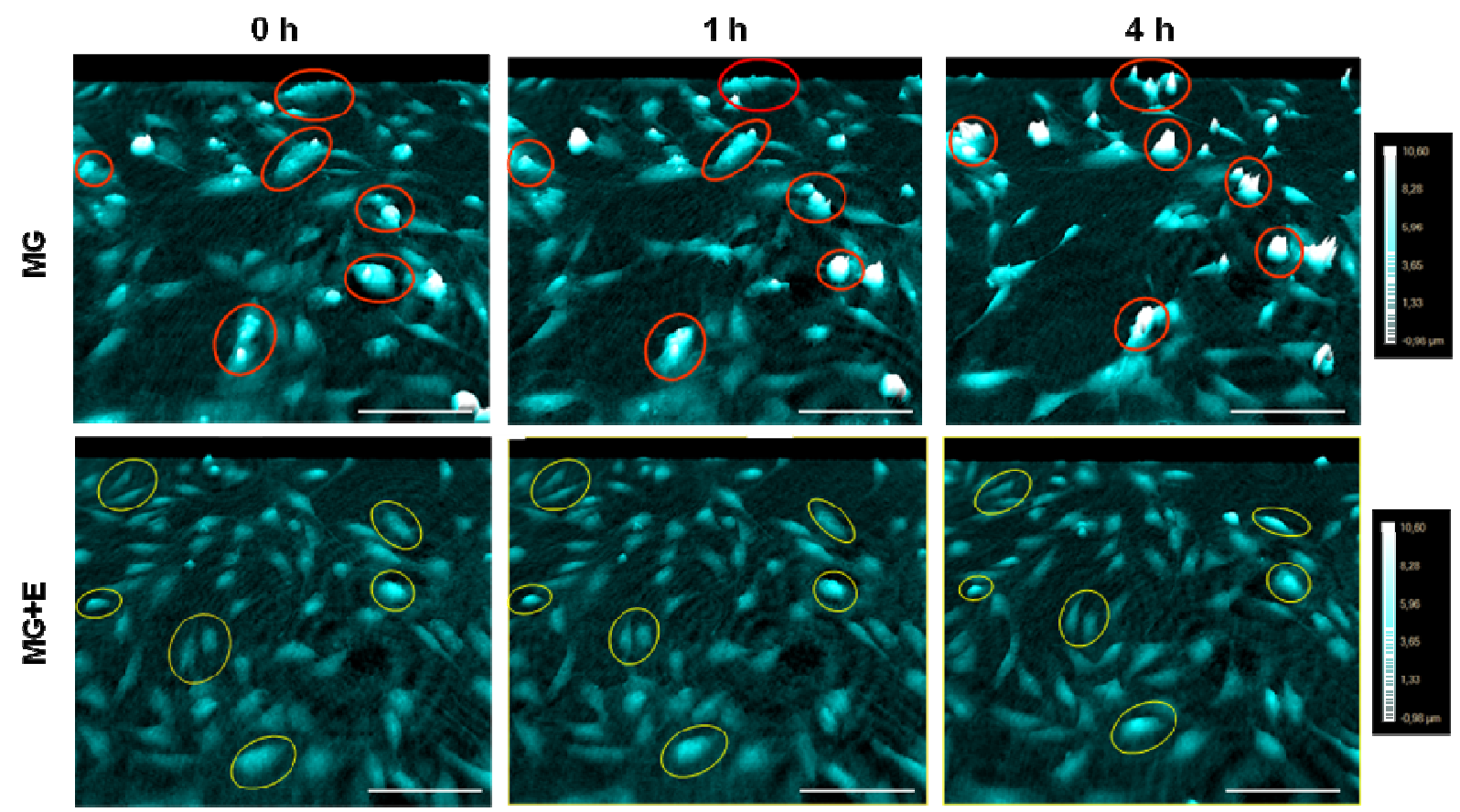

Figure 24. Holographic phase contrast images of morphological alterations induced in hCMEC/D3 human brain endothelial cells by treatment with methylglyoxal $(\mathrm{MG} ; 600 \mu \mathrm{M})$ and co-treatment with $3 \mathrm{mM}$ edaravone $(\mathrm{MG}+\mathrm{E})$ for $4 \mathrm{~h}$. Color scale bar correspond to the height of single cells. Data were analyzed by means of HoloStudio 2.4 software. Red circles indicate cells with drastical changes in cell morphology. Yellow circles indicate cells without any morphological changes. Bar $=100 \mu \mathrm{m}$

\subsubsection{Edaravone protects against methylglyoxal-induced permeability increase}

The direct effect of methylglyoxal on the permeability of brain endothelial monolayers was determined by TEER and permeability measurement. Treatment of endothelial cell monolayers with methylglyoxal at $600 \mu \mathrm{M}$ concentrations significantly decreased TEER to $90.6 \pm 2.5 \%$ compared to control (Annex IV) and increased the permeability for both markers in hCMEC/D3 endothelial cells (Fig. 25). The flux of FITC-dextran (4.4 kDa) was elevated by 1.5 fold as compared to the control group (Fig. 25A). The permeability coefficient values for albumin $(65 \mathrm{kDa})$ were one sixth of the values for FITC-dextran $(0.6 \pm 0.03 \times 106 \mathrm{~cm} / \mathrm{s}$ vs. $3.6 \pm 0.8 \times 106 \mathrm{~cm} / \mathrm{s}$ ), as published previously (Deli et al., 2005). The permeability for albumin was doubled after incubation with methylglyoxal (Fig. 25B). Edaravone (3 mM) completely protected brain endothelial monolayers from the damaging effects of methylglyoxal and kept TEER and the permeability at the level of the control group for both markers (Annex IV, Fig. 25). The same effect was seen by the co-administration of aminoguanidine (Fig. 25B). 

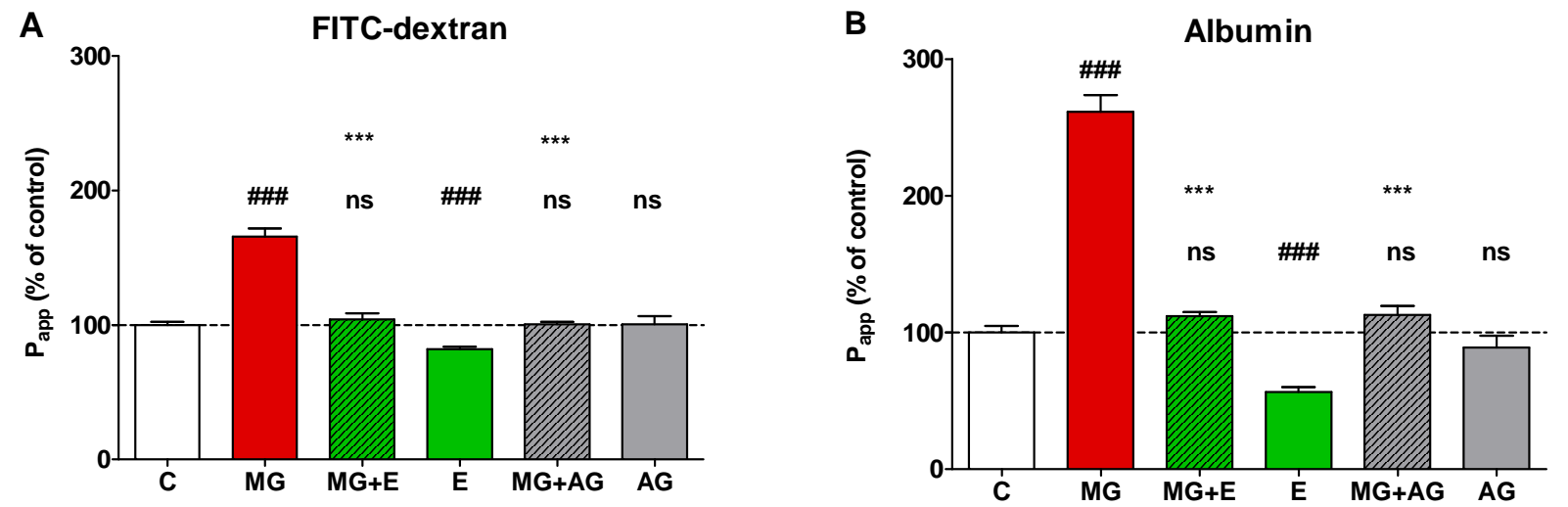

Figure 25. Changes in transendothelial permeability $\left(\mathrm{P}_{\text {app }}\right)$ for permeability markers FITC-dextran (A) and Evans blue labeled albumin (B) in human brain endothelial cell monolayers treated with methylglyoxal (MG; $600 \mu \mathrm{M})$ and edaravone $(\mathrm{E}, 3 \mathrm{mM})$ or aminoguanidine $(\mathrm{AG})$ for $4 \mathrm{~h}$. All values presented are means $\pm \mathrm{SD}, \mathrm{n}=4$. Statistical analysis: one-way ANOVA followed by Bonferroni test. Statistically significant differences $(p<0.05)$ from the control group (*) and from methylglyoxal-treated group are (*) indicated.

\subsubsection{Edaravone protects against methylglyoxal-induced changes in junctional morphology}

The effect of methylglyoxal on cell-cell adhesion was investigated by staining of cell nuclei and immunostaining for $\beta$-catenin, a cytoplasmic adherens junction protein, and claudin-5, a transmembrane tight junction protein (Fig. 26).
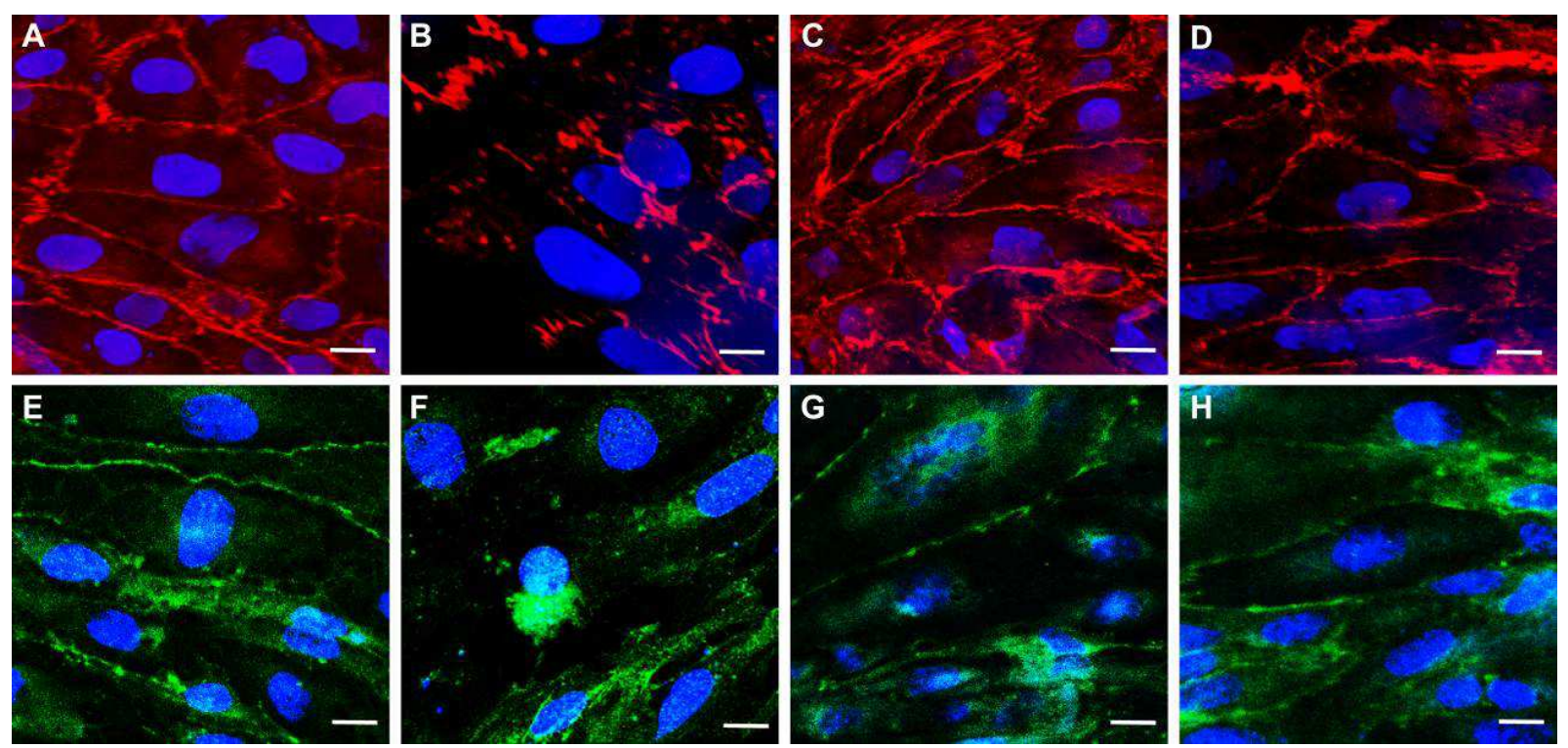

Figure 26. Immunostaining for adherens junction protein $\beta$-catenin (A-D) and integral tight junction membrane protein claudin-5 (E-H) in human hCMEC/D3 brain endothelial cells. Control (A and E), $4 \mathrm{~h}$ treatment with methylglyoxal $(600 \mu \mathrm{M}$; B and F), co-treatment with edaravone $(3 \mathrm{mM}$; C and $\mathrm{G})$ or aminoguanidine $(2 \mathrm{mM}$; D and $\mathrm{H})$. Blue color: bis-benzimide staining of cell nuclei; red color: immunostaining for $\beta$-cathenin; green color: immunostaining for claudin-5. Bar=20 $\mu \mathrm{m}$. 
In control monolayers $\beta$-catenin staining was localized to the cell border and the tightly apposed, elongated endothelial cells were well delineated (Fig. 26A). Claudin-5 localization at the interendothelial junctions was less stringent than for $\beta$-catenin but clearly visible in part of the cell borders (Fig. 26E) and resembled the immunostaining shown in the paper describing this cell line (Weksler et. al., 2005). The pattern of the staining was dramatically changed in methylglyoxal $(600 \mu \mathrm{M}, 4 \mathrm{~h})$ treated cells. Treatment with methylglyoxal resulted in decreased immunostaining intensity, fragmentation or loss of the continuous cortical staining pattern, the appearance of intercellular gaps (Fig. 26B and 26F) and apoptotic cells (Fig. 26F). Coadministration of protective agents, edaravone (Fig. 26C and 26G) and aminoguanidine (Fig. 26D and $26 \mathrm{H})$ attenuated these changes; The monolayer integrity was better preserved and the immunostaining pattern resembled to the control ones.

\subsubsection{Edaravone protects against methylglyoxal-induced changes: ROS production and protein modification}

As methylglyoxal generates carbonyl and oxidative stress (Kalapos, 2008), ROS production and protein modification were measured (Fig. 27).
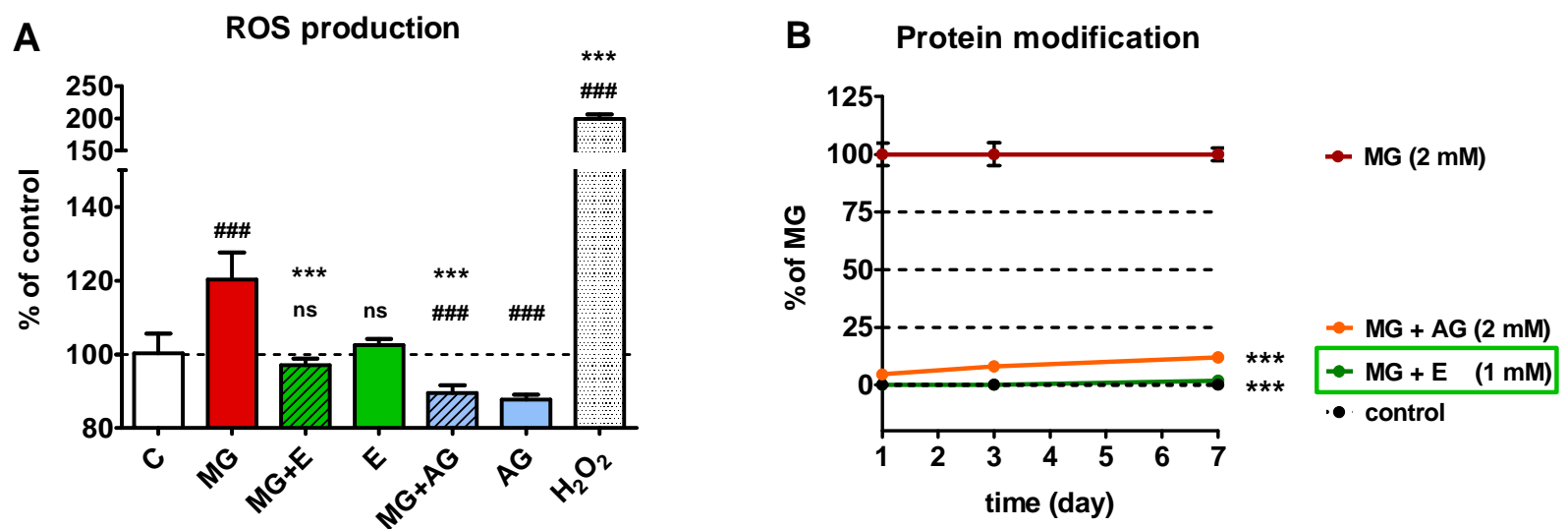

Figure 27. Effect of co-treatment with $600 \mu \mathrm{M}$ methylglyoxal and $3 \mathrm{mM}$ edaravone (MG+E) or $2 \mathrm{mM}$ aminoguanidine $(\mathrm{MG}+\mathrm{AG})$. ROS production of human brain endothelial cells after $4 \mathrm{~h}$ treatment (A). Fluorescent intensity of ROS expressed as a percentage of control (C). Modification of BSA by methylglyoxal and its inhibition by protective agents (B). Fluorescent intensity was expressed as a percentage of methylglyoxal (MG). Values presented are means $\pm \mathrm{SD}, \mathrm{n}=9$. Statistical analysis: ANOVA followed by Bonferroni test. Statistically significant differences $(p<0.05)$ from the control group (\#) and from the methylglyoxal-treated group (*) are indicated.

In cells treated with methylglyoxal $(600 \mu \mathrm{M} ; 4 \mathrm{~h})$, ROS production was significantly enhanced $(120.9 \pm 7.3 \%)$. Edaravone $(3 \mathrm{mM})$ completely inhibited the methylglyoxal-induced increase in ROS production bringing back to the level of control $(97.2 \pm 1.7 \%)$. Coadministration of aminoguanidine $(2 \mathrm{mM})$ also decreased ROS production $(89.1 \pm 2.1 \%)$. In 
contrast to edaravone, which had no effect alone $(102.5 \pm 1.7 \%)$, treatment with aminoguanidine alone decreased the amount of ROS in endothelial cells below the level of the control group $(87.4 \pm 1.3 \%)$. Hydrogen peroxide treatment $(100 \mu \mathrm{M}, 15 \mathrm{~min})$, a positive control in the ROS assay, doubled the amount of ROS. (Fig. 27A).

Incubation of BSA with methylglyoxal (2 mM; 0-7 days) resulted in significant elevation of modified BSA's fluorescence at the wavelength pair of 360 and $460 \mathrm{~nm}$ (Fig 19B). The fluorescence of BSA by methylglyoxal treated samples was considered as $100 \%$. Edaravone $(1 \mathrm{mM})$ and aminoguanidine $(2 \mathrm{mM})$ reduced the BSA's fluorescence indicating almost complete inhibition of protein modification for 7 days (Fig. 27B). 


\section{DISCUSSION}

\subsection{Effect of pathological factors on brain endothelial cells}

\subsubsection{Amyloid- $\beta$ induced changes in brain endothelial cells}

In our study, $A \beta_{42}$ peptide induced remarkable ultrastructural alterations in primary rat brain endothelial cells, which have not been described in the literature earlier. In agreement with A $\beta$-induced changes in brain microvessel morphology in pathological samples and animal studies (Erickson and Banks, 2013; Kalaria and Hedera, 1995) degeneration of the cells, namely dark cytoplasm, pronounced vacuolization, decreased number of caveolae and Golgi, and shrunken mitochondria could be observed after peptide treatment. Irregular interendothelial contacts and junctions with less kissing points were especially notable, indicating an increased paracellular pathway. Cytoplasmic vacuolization could be seen by both electron and phase contrast microscopy. These toxic effects were also confirmed by reduced MTT dye reduction, and increased LDH release indicating plasma membrane damage. Our results are in agreement with experimental data from other laboratories showing the damaging effects of $A \beta$ on cultured endothelial cells. A $\beta$ peptides inhibited the proliferation of brain endothelial cells (Grammas et al., 2002). In addition, $\mathrm{A} \beta$ peptides exerted toxic effects on both peripheral and cerebral microvessel endothelial cells (Blanc et al., 1997; Preston et al., 1998). Furthermore aggregates of various $\mathrm{A} \beta$ peptides decreased viability on cultured human cerebrovascular endothelial cells obtained from the brain of a victim of AD (Eisenhauer et al., 2000). The Akt (Yin et al., 2005), and protein kinase C (Pákáski et al., 2002) signalling pathways, RAGE (Baiguera et al., 2009) and the activation of caspase- 8 (Folin et al., 2006) can participate in the decrease of cell viability and apoptotic cascade induced by $\mathrm{A} \beta$ in endothelial cells.

The effect of $A \beta_{42}$ was also studied on several aspects of the barrier function of rat primary brain endothelial cells, in which barrier properties were induced by glial cells and/or pericytes. $A \beta_{42}$ decreased the resistance and increased the permeability for markers fluorescein and albumin. Since the paracellular barrier at the BBB is regulated by TJ proteins, immunostaining for these proteins was investigated after $A \beta$ treatment in brain endothelial cells. $\mathrm{A} \beta_{42}$ led to fragmentation and loss of junctional immunostaining for occludin, claudin-5 and ZO1 in our model. These data are in accordance with previous observations, where $A \beta_{42}$ altered occludin, claudin-5 and ZO-2 TJ protein distribution and expression (Marco and Skaper et al., 2006). Interestingly, a specific decrease of occludin but not of claudin-5 and ZO- 1 was described in an immortalized human brain endothelial cell line (Tai et al., 2010).

In $\mathrm{AD}$, the accumulation of $A \beta_{42}$ increases the production of reactive oxygen species. In the present study ROS production was elevated by iso $A \beta_{42}$ in primary brain endothelial cells, in agreement with data obtained on an endothelial cell line (Carrano et al., 2011). P-gp in brain 
endothelial cells participates in A $\beta$ peptide efflux transport (Candela et al., 2010). In our experiments iso $\beta_{42}$ pretreatment inhibited the activity of P-gp on brain endothelial cells, in concordance with other observations (Kuhnke et al., 2007; Kania et al., 2011). The relevance of these results is emphasized by a recent clinical observation providing the first direct evidence that P-glycoprotein transporter at the BBB is compromised in AD (van Assema et al., 2012).

Cell-free aggregation experiments and a culture study on neurons indicated, that methylglyoxal can conribute to the harmful effect of $\mathrm{A} \beta$ peptides (Angeloni et al., 2014). This recent study, which investigated the difference between authentic and glycated $A \beta$ (A $\beta$-AGE) treatment in embryonic hippocampal neurons found that $A \beta$-AGE was more toxic, than $A \beta$ alone. In neurons $\mathrm{A} \beta-\mathrm{AGE}$ decreased viability, increased apoptosis, induced tau hyperphosphorylation, and reduced synaptic proteins significantly compaired with authentic A $\beta$-treatment ( $\mathrm{Li} \mathrm{XH} \mathrm{et} \mathrm{al.,}$ 2013). Co-treatment with methylglyoxal and $A \beta$ has not been investigated on endothelial cells previously. We found, that brain endothelial damage induced by isoA $\beta_{42}$ was more pronounced in the presence of methylglyoxal. Our data support the link between methylglyoxal and AD (Angeloni et al., 2014).

\subsubsection{Methylglyoxal induced changes in brain endothelial cells}

A direct toxic effect of methylglyoxal on brain microvessels was proposed in a recent paper (Li et al. 2013b). In the present study we further supported the fact that methylglyoxal alone could induce damage to brain endothelial cells. Methylglyoxal exerted a time- and concentration-dependent toxicity on cultured human brain endothelial cells; it significantly reduced the integrity of the barrier measured by both functional and morphological experiments. This is the first observation on the kinetics of methylglyoxal toxicity by impedance-based cell electronic sensing. The two different cell viability assays we used were in complete agreement on the direct cellular damaging effect of methylglyoxal. Impedance data reflecting changes in cell adhesion, shape and number were confirmed by MTT tests measuring the metabolic activity of cells. Our data lend support to and expand previous findings on the effect of methylglyoxal on human brain endothelial cells (Okouchi et al., 2009; Li et al., 2013a; Li et al., 2013b; Li et al., 2013c). We selected the human hCMEC/D3 cell line as a simplified model of the BBB. This cell line is widely used in different experiments, including pharmacological and drug studies (Weksler et al., 2013). To support the relevance of our data on hCMEC/D3 endothelial cell line, the effect of methylglyoxal was also tested on primary cultures of rat brain endothelial cells (Annex IV. Fig. S2 and S3). The results were in agreement with our observations on the human cell line, indicating a similar sensitivity of primary endothelial cells and hCMEC/D3 endothelial cell line for the toxic effects of methylglyoxal. We found no data on primary brain endothelial cells related to methylglyoxal in the literature, therefore the present study is the first to include 
primary brain endothelial cells in this setting. The relevance of our findings on endothelial cells is limited by the use of high concentrations of methylglyoxal to induce barrier damage, a common concern in cell culture studies. However, in four recent and independent papers both the time needed to measure methylglyoxal-induced injury in cultured endothelial cells and the concentrations used were in similar range as in our study (Okouchi et al., 2009; Li et al., 2013a; Li et al., 2013b; Li et al., 2013c).

Damage by methylglyoxal is mediated not only via carbonyl, but also by oxidative stress (Yim et al., 1995; Kalapos 2008). ROS are generated as by-products of protein glycation (Lee et al., 1998). Furthermore, methylglyoxal increases glycation of selected mitochondrial proteins resulting in increased formation of superoxide (Rabbani et al., 2008). Elevated level of ROS weakens the barrier integrity (Pun et al., 2009), however the contribution of methylglyoxaltriggered ROS production in the increased endothelial permeability is controversial (Li et al., 2013b). In the present study we confirmed that methylglyoxal treatment promotes oxidative stress in brain endothelial cells, similarly to previous results on endothelial cells (Li et al., 2013b; Li et $a l ., 2013 \mathrm{c}$ ) and other cellular systems (Desai and $\mathrm{Wu}, 2008$ ). The kinetics of ROS production helped to determine the optimal time point for protection assays and other experiments: the $4 \mathrm{~h}$ time point, where ROS formation was still elevated, was purposefully selected.

In good agreement with data from toxicity measurements methylglyoxal increased the permeability of human and rat brain endothelial monolayers. The effect was concentrationdependent, with only high concentrations of methylglyoxal causing significant damage to barrier integrity. These data are in accordance with previous findings showing that methylglyoxal induced an increase in the permeability of brain endothelial cells (Li et al., 2013b). In that study decreased TEER and increased dextran flux were coupled with glycation of occludin and disturbed localization of ZO-1 TJ proteins. We found the redistribution of two other junctional proteins important for the regulation of brain endothelial permeability, namely the TJ protein claudin-5 and AJ protein $\beta$-catenin in methylglyoxal treated brain endothelial cells. Decreased expression, delocalization or redistribution of claudin-5 and $\beta$-catenin in brain endothelial cells are linked to permeability increase in many pathologies (Liebner and Plate, 2010). We demonstrated for the first time, that treatment with methylglyoxal resulted in fragmentation and loss of the continuous cortical pattern of $\beta$-catenin in brain endothelial cells, confirming the importance of $\beta$-catenin in the regulation of barrier tightness.

For the maintenance of the integrity of the BBB permeability the attachment of endothelial cells to the basement membrane is crucial (Del Zoppo et al., 2006). Damage to the basal lamina weakens microvascular wall structures and results in increase of brain vessel permeability in vivo (Wang et al., 2007). Our data confirmed these observations and visualized for the first time the kinetics of morphological changes caused by methylglyoxal using a novel technique, holographic phase contrast microscopy in living cells (Alm et al., 2013; Madácsi et 
al., 2013). Methylglyoxal changed drastically the shape of brain endothelial cells by time: the area of cells decreased, their optical height significantly increased indicating cell-cell and cellbasal lamina detachment. Similar observation was made in case of peripheral endothelial cells, where modification of basement membrane by methylglyoxal caused cell detachment, anoikis and inhibition of angiogenesis (Dobler et al., 2006).

\subsection{Protection against brain endothelial dysfunction}

Brain endothelial dysfunction initiates and contributes to the disease process in AD (Deli, 2005; Zlokovic, 2011), therefore in addition to neurons, brain endothelial cells and other elements of the neurovascular unit are increasingly recognized as therapeutical targets in $\mathrm{AD}$ (Neuwelt et al., 2011). Since previous therapeutic attempts of AD were focused on the prevention of neuronal death, there are a great number of experimental data on the protection of neurons against the toxic effects of $A \beta$. In contrast, only few studies examined protective molecules in brain endothelial cells (Zlokovic, 2011).

The prevention of methylglyoxal-induced injury is in the focus of current research (Desai and $\mathrm{Wu}, 2007)$. Aminoguanidine was the first drug extensively studied, and attenuated the development of a range of diabetic vascular complications both in vitro and in vivo. However, due to toxic side effects at high doses, it failed in clinical trials. This compound is considered as a prototype for antiglycation agents and used as a reference molecule in experiments (Thornalley, 2003).

\subsubsection{Protection by pentosan polysulfate}

PPS, a drug of plant origin used clinically for a long time, protected primary mouse cerebral endothelial cells against prion peptide toxicity (Deli et al., 2000b) and attenuated both the permeability barrier impairment and inhibition of P-gp in lipopolysaccharide-exposed primary rat brain endothelial cells (Veszelka et al., 2007) in our previous experiments. We have demonstrated that PPS successfully attenuates the toxic effects of A $\beta$ peptides and protects the barrier integrity of endothelial monolayers treated with $A \beta$, however it does not change $\mathrm{BBB}$ parameters of TEER, permeability, or morphology in cultured brain endothelial cells. Because PPS does not cross the BBB, endothelial cells of the blood-nerve and blood-brain barriers may be among the cellular targets of PPS (Leveugle et al., 1998).

The exact mode of action of PPS at the BBB has not been elucidated yet. In other cell types PPS inhibits a wide range of enzymes and biological modulators, like protein kinases in smooth muscle cells (Maffrand et al., 1991), serine proteases, matrix metalloproteinases, lysosomal enzymes, coagulation factors, complement factors and pro-inflammatory cytokines in chondrocytes. In peripheral endothelial cells PPS stimulates the release of anti-coagulant tissue- 
type plasminogen activator and anti-oxidant superoxide dismutase contributing to its efficacy in arthritis (Ghosh, 1999). The inhibition of serine proteases, matrix metalloproteinases and cytokines or increased levels of superoxide dismutase (Ghosh, 1999) could also contribute to the protection of the BBB; however other actions of PPS could be also important.

Surface plasmon resonance and atomic force microscopy data indicate for the first time that PPS can directly interact with $A \beta_{42}$, and may have a physicochemical effect resulting in fewer adherences to the examined surfaces (Annex I). This is in agreement with the only study that examined the effect of PPS on the binding of heparan sulfate glycosaminoglycans to A $\beta$. PPS was the most effective to displace heparan sulfate glycosaminoglycans bound to A $\beta$. Since heparan sulfate glycosaminoglycans are involved in $\mathrm{A} \beta$ aggregation in vivo, sulfated polyanions, like PPS, can be useful against amyloid deposition in AD brain (Leveugle et al., 1994). Pentosan may exert multiple effects (Fig. 28); some of these could be cellular while others could be related to its direct interaction with $A \beta$. The present results support pentosan's dual mode of action and the endothelial protective properties.
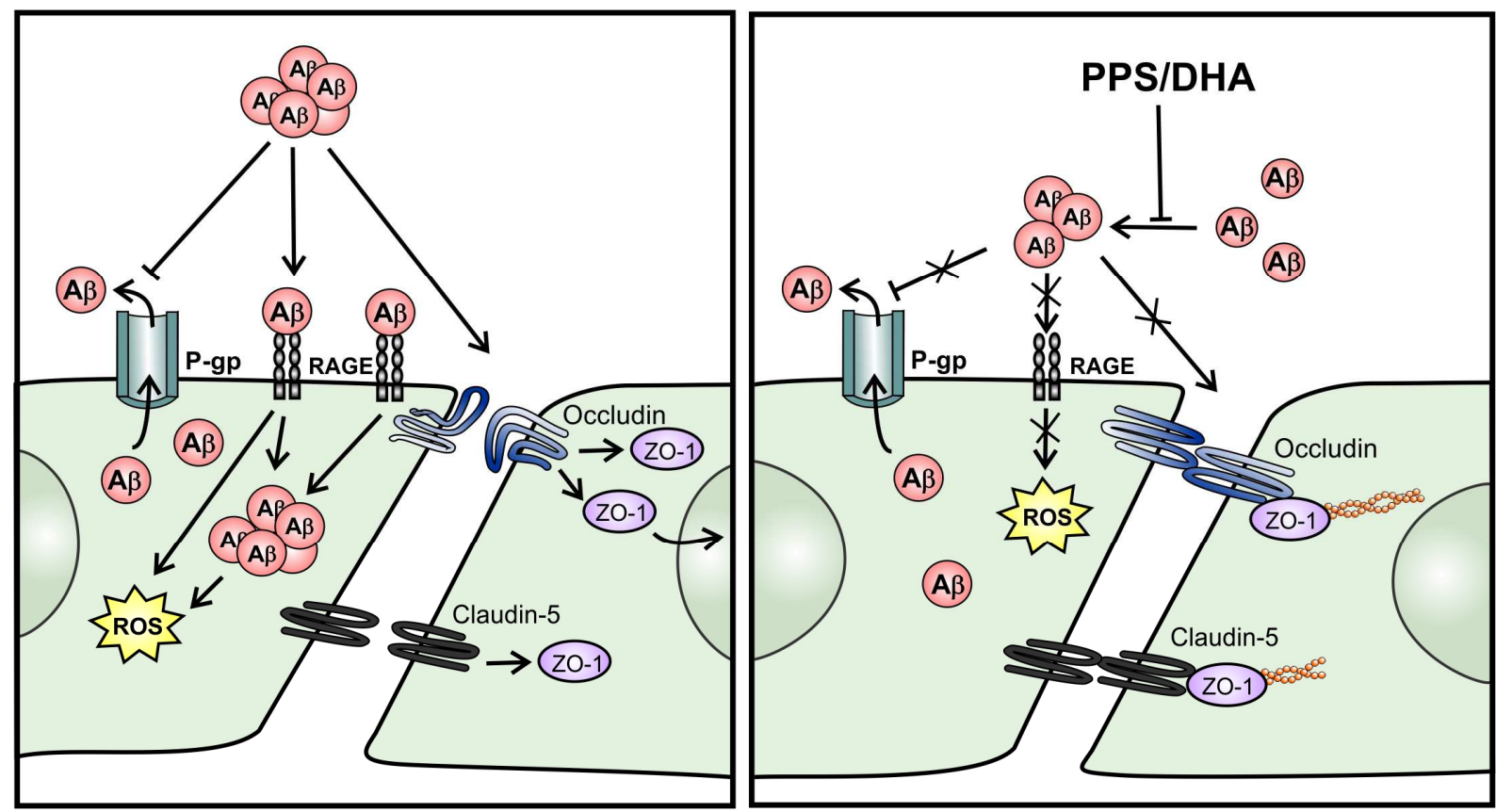

Figure 28. Effect of amyloid- $\beta$ 1-42 peptide and pentosan or docosahexaenoic acid on brain endothelial cells. Abbreviations: A $\beta$ : amyloid- $\beta$ 1-42 peptide; DHA: docosahexaenoic acid; P-gp: P-glycoprotein; PPS: pentosan polysulfate; RAGE: receptor for advanced glycated endproducts; ROS: reactive oxygen species; ZO-1: zonula occludens protein-1. 


\subsubsection{Protection by docosahexaenoic acid}

The beneficial effect of DHA was investigated in several models of $\mathrm{AD}$, but these were focused on neurons (Oksman et al., 2006; Grimm et al., 2011). In our study DHA was not only protective against oligomeric $A \beta_{42}$ toxicity in primary neurons, but also on acute hippocampal slices, a more complex ex vivo model (Annex III.) Importantly, DHA readily crosses the BBB by diffusion (Ouellet et al., 2009) and can easily reach glial cells and neurons. Our main results indicate for the first time that DHA can protect not only neurons, but also the other elements of the neurovascular unit, like brain endothelial cells, from the toxic effects of isoA $\beta_{42}$ (Fig. 28). DHA was effective in toxicity tests and improved the morphological changes after $A \beta_{42}$ treatment, indicating a more extensive and diverse protective effect than previously supposed. The permeability of cerebral endothelial monolayers was increased by isoA $\beta_{42}$ similarly to our another study (Annex I), and was attenuated by DHA.

The decrease in P-gp activity induced by isoA $\beta_{42}$ treatment was also prevented by DHA in our experiments. Since decreased P-gp function is involved in the pathogenesis of AD (Candela et al., 2010), our novel finding strengthens the therapeutical potential of DHA. The effect of A $\beta_{42}$ on P-gp is mediated via Wnt/ $\beta$-catenin signaling (Kania et al., 2011), which activation increases BBB functions (Liebner et al., 2008). It is tempting to speculate that DHA may also act through this pathway.

The mechanism of the DHA action is not fully understood. RAGE is both a gate for A $\beta$ peptides toward the brain (Candela et al., 2010), and a receptor for the methylglyoxal derived AGE (Srikanth et al., 2011). The expression level of RAGE in brain endothelial cells is low in healthy brain, however it is increased in $\mathrm{AD}$, because this receptor is up-regulated by its ligands (Zlokovic, 2004). A $\beta$ is not able to enter from the blood toward the brain in RAGE knock-out mice which highlights the importance of RAGE in AD (Deane et al., 2003). While there are no data on how DHA may affect RAGE, it was recently demonstrated in cultured brain endothelial cells that $\mathrm{A} \beta$ accumulation is lipid raft and caveolae dependent and involves RAGE (András et $a l ., 2012)$. Disruption of lipid rafts by pretreatment with $\beta$-methyl-cyclodextrin protected against A $\beta$ accumulation in this model. DHA is a well known inducer of membrane fluidity (Yang et al., 2011) and by reducing cholesterol (Grimm et al., 2011). It destabilizes rafts and decreases the docking of A $\beta$ (Hashimoto et al., 2011) that may influence RAGE activity and contribute to the protective effect of DHA.

In $\mathrm{AD}$ the accumulation of $\mathrm{A} \beta_{42}$ increases the production of ROS, resulting in increased lipid peroxidation in the brain (Floyd and Hensley, 2002). Oxidative damage and formation of oxidized lipids and proteins have been observed in the brains of patients with AD during postmortem analysis (Choi et al., 2004). Lipid peroxide levels are significantly lower in DHAadministered rats indicating that dietary DHA contributes to the antioxidant defense, decreases 
oxidative stress, and protects against memory loss (Morley and Banks, 2010). The levels of ROS in the cerebral cortex and hippocampus increase significantly after the infusion of $A \beta_{42}$ into the cerebral ventricle of rats, but then decrease significantly after the dietary administration of DHA (Hashimoto et al., 2005). In our experiments, similarly to cytotoxicity and BBB dysfunction, ROS production elevated by oligomeric $A \beta_{42}$ could be also inhibited by DHA in primary brain endothelial cells. A $\beta$-induced oxidative stress-mediated BBB changes were observed on a brain endothelial cell line in concordance with our results (Carrano et al., 2011). These observations suggest that DHA increases the antioxidant defense in the brain, including the BBB, and its mode of action may be related to direct scavenging of ROS or to the induction of antioxidant enzymes.

Methylglyoxal is also a strong inducer of oxidative stress and this phenomenon is thought to be one of the links between AD and carbonyl stress (Angeloni et al., 2014). The beneficial effects of DHA on brain endothelial cells were also visible during iso $\mathrm{A} \beta_{42}$ and methylglyoxal cotreatment. DHA attenuated the combined toxic effect of the two agents in human brain endothelial cell; however no complete protection was achieved. There may be several reasons to explain this observation. Methylglyoxal enhances $A \beta$-toxicity via several ways. It induces oxidative stress, partly through RAGE signaling pathway, and modifies proteins such as A $\beta$ and tau. DHA has antioxidant effect and supposedly may influence RAGE activity, but has no antiglycation effect and cannot protect against protein modification as proved in our experiments (data of BSA modification experiments are not shown). Based on these data, DHA could be a promising molecule for the prevention of BBB dysfunction. However, to fully prevent the damages caused by carbonyl stress in AD in addition to DHA other agents, like edaravone, may be needed.

\subsubsection{Protection by edaravone}

Edaravone was reported to protect the neurovascular unit and the BBB after ischemic stroke (Yamashita et al., 2009; Lukic-Panin et al., 2010). In a recent study, edaravone reduced cell injury in oxygen-glucose deprivation in vitro model. Edaravone pretreatment attenuated methylglyoxal-induced decrease in cell viability of brain endothelial cells (Li et al. 2013c). In our study co-treatment with edaravone provided a complete protection against the toxic effect of methylglyoxal (Fig. 29). We could see a concentration- and time-dependent effect based on kinetic data from impedance measurements. Our data are in agreement with viability studies on the effect of edaravone pretreatment against methylglyoxal-induced toxicity (Li et al., 2013c). Edaravone treatment alone increased the metabolic activity and impedance of the endothelial layers. A beneficial effect of edaravone on human endothelial cells was also found previously by resistance measurement and proteomic assay (Omori et al., 2007; Onodera et al., 2013). The used edaravone concentrations were in the millimolar range similarly to another independent work on 
cultured human brain endothelial cells (Onodera et al., 2013). For long-lasting protection suprapharmacological concentration of edaravone (Kaste et al., 2013) was needed in our culture study. However, the applied methylglyoxal levels were also comparably high, as in other in vitro methylglyoxal studies (Okouchi et al., 2009; Li et al. 2013a; Li et al., 2013b; Li et al., 2013c). Although we used higher concentrations in cultured cells, importantly, the ratio of the methylglyoxal to edaravone used in our study was the same as the ratio of the pathological plasma methylglyoxal concentrations (Kalapos, 2013) to clinical concentrations of edaravone (Kaste et al., 2013).
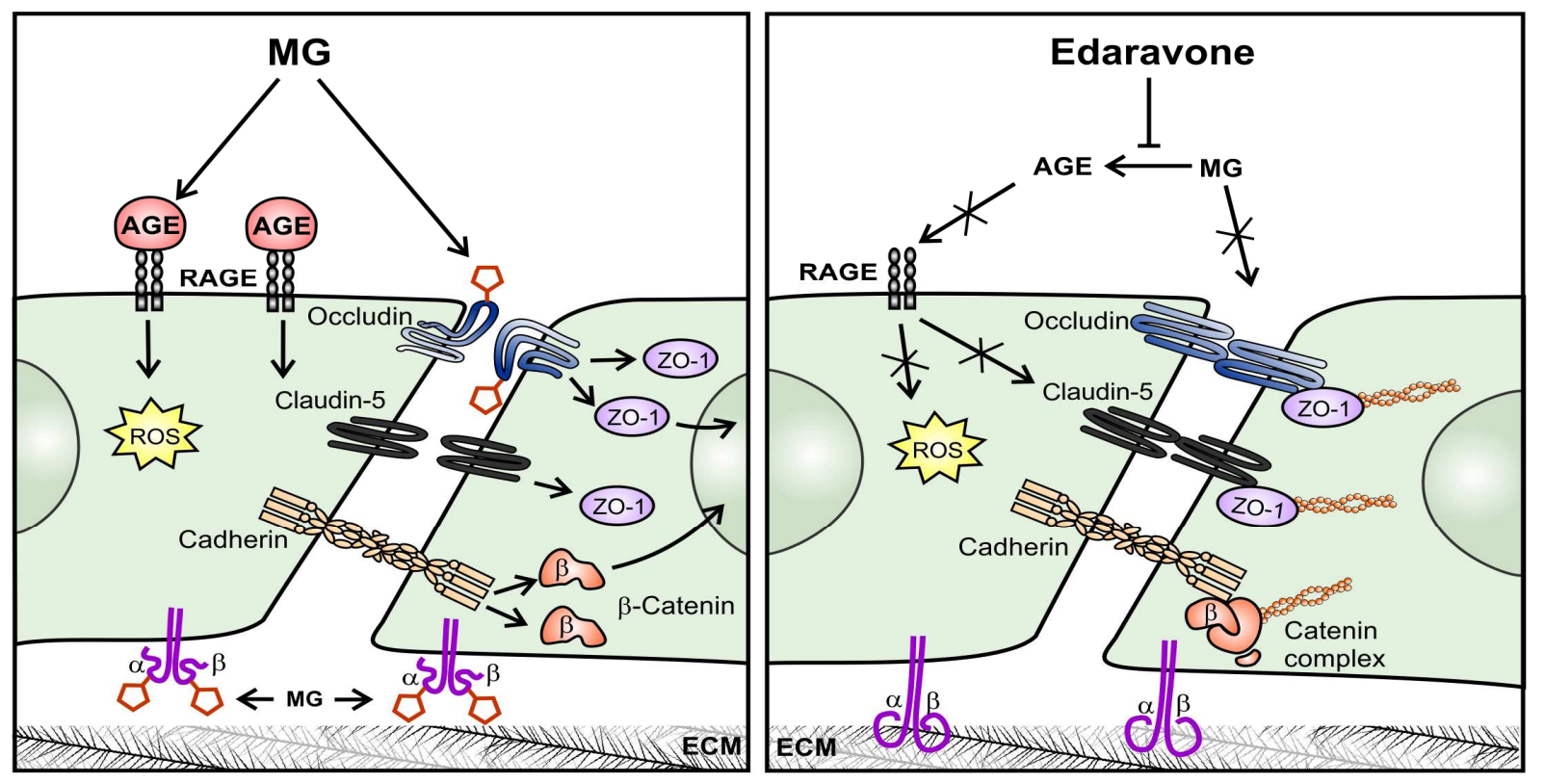

Figure 29. Effect of methylglyoxal and edaravone on brain endothelial cells. Abbreviations: AGE: advanced glycated end-products; ECM: extracellular matrix; MG: methylglyoxal; RAGE: receptor for AGE; ROS: reactive oxygen species; ZO-1: zonula occludens protein-1.

Originally, edaravone was a drug to promote neuronal rehabilitation after ischemic stroke by protecting against oxidative stress (Watanabe et al., 1994). Its antioxidant effect was observed in our experiment, too. In a recent independent study edaravone suppressed methyglyoxalinduced ROS production in human brain endothelial cells by two possible mechanisms (Li et al., 2013c). Pre-treatment with edaravone decreased methylglyoxal-induced AGE accumulation and activation of its receptor RAGE (Li XH et al., 2013), and the subsequent production of ROS (Mangalmurti et al., 2010; Rouhiainen et al., 2013). Furthermore, as in our experiments, edaravone inhibited protein-modification of BSA by methylglyoxal, therefore it decreased ROS generated as by-products during protein glycation (Lee et al., 1998). All these results together indicate that the antioxidant mechanisms induced by edaravone contribute to its protective effect against methylglyoxal-induced oxidative stress. 
Prior work described, that edaravone protects from methylglyoxal-induced injury by inhibiting AGEs/RAGE/oxidative stress in human brain microvascular endothelial cells (Li et al., 2013c). However, it remained unanswered whether edaravone can also protect against methylglyoxal-induced barrier dysfunction in brain endothelial monolayers. Therefore, this study focused on the protective effect of edaravone against methylglyoxal-induced barrier damage. We found that co-treatment with edaravone restored barrier properties of endothelial cells and protected against methylglyoxal-induced decrease of resistance and increase in permeability for paracellular and transcellular markers. Moreover, we also demonstrated that edaravone treatment alone tightened the brain endothelial barrier. Our data expand and further support previous observations on barrier enhancing effect of edaravone (Omori et al., 2007; Onodera et al., 2013).

Increased endothelial permeability was coupled with disturbed localization of junctional proteins claudin-5 and $\beta$-catenin after incubation with methylglyoxal, while co-treatment with edaravone restored distribution of both proteins along the cell borders. Similar observation was made in a previous study, where edaravone treatment enhanced $\beta$-catenin at cell-cell contact area and the cortical arrangement for its linked protein, actin on half confluent peripheral endothelial monolayer (Omori et al., 2007). Our holographic phase contrast microscopic data are in accordance with these observations; edaravone completely prevented methylglyoxal-induced changes in cell morphology, no sign of detachment and cellular morphological alteration was observed, indicating no cytoskeletal rearrangement.

\subsection{Conclusion and perspectives}

Because of the increasing prevalence of CNS disorders there is a large number of new centrally active drug candidates, especially biomolecules, under development. Reliable BBB models that present physiologically realistic cell architecture and other attributes of in vivo BBB phenotype are needed as testing and screening tools. The primary brain endothelial cell-based coculture models used in our studies involve also other elements of the neurovascular unit, especially glial cells and pericytes, and can be considered as one of the most complex and pertinent BBB models to date. Since species differences exist in the expression and pharmacokinetic parameters of transporters at the BBB, human models are valuable and important research tools. For this reason we also used the human brain endothelial cell line hCMEC/D3 in our experiments. Importantly, the reliability of this model was tested against primary cultures and similar data were obtained on both models. Further progress is expected in several areas of BBB modelling to reach the goal of better modelling BBB functions. Human models and human data are very important for further development. A simple, cost-effective, validated human BBB culture model is not yet available. We can predict that in long term the cell culture based models will be replaced by human models for drug testing, but rodent models will 
continue to be valuable tools in primary BBB research. The BBB culture models enabled us to test the effect of two major pathological factors, $A \beta_{42}$ and methylglyoxal involved in AD. Our observations further support the toxic effects of amyloid peptides and methylglyoxal on brain endothelial cells and strengthen the link between AD and carbonyl stress. Oxidative stress was found as a common pathway induced by both toxic agents in brain endothelial cells, similarly to previous observations on other cellular systems. As a consequence, the BBB is considered as therapeutic target in $\mathrm{AD}$, and anti-inflammatory molecules are among the possible protective pharmacons.

The prospect of reducing the risk of $\mathrm{AD}$ by preventive strategies such as diet or lifestyle modification is highly favorable. Several epidemiological studies and growing experimental data has shown that dietary DHA may improve neuronal development, restore and enhance cognitive functions and increase neuronal resistance to amyloid-induced oxidative stress. DHA may be a potent agent to prevent $A \beta$-induced damages on the cells of the neurovascular unit acting via multiple ways. Based on our new observations DHA might exert a protective effect not only on neurons but also on the BBB and its functions, and this effect may be beneficial in the prevention of AD. Pentosan and edaravone can represent a new type of drugs to protect brain endothelial cells in pathological conditions, including $A \beta$ toxicity, and carbonyl stress. As a new application these drugs may contribute to the maintenance of BBB functions, brain homeostasis and prevention of neuronal loss in AD. The presented results provide compelling evidence for barrier protective effect of DHA, pentosan and edaravone in cultured brain endothelium. Data from our studies could have therapeutical implication for disorders and diseases that are associated with carbonyl stress and AD. 


\section{SUMMARY}

The role of cerebral endothelial cells forming the blood-brain barrier to protect the brain in pathological conditions is increasingly emphasized in the literature. We have tested amyloid- $\beta$ 1$42\left(\mathrm{~A} \beta_{42}\right)$ and methylglyoxal, two major pathological factors, involved in Alzheimer's disease and carbonyl stress. The hallmarks of Alzheimer's disease are perivascular deposits and senile plaques of $A \beta$ peptides in the brain. The formation of these aggregates is enhanced by dicarbonyl compounds such as methylglyoxal. To study potential protective molecules, primary rat and human (hCMEC/D3 cell line) blood-brain barrier models were used. The effect of treatments was tested on cell viability and barrier functions. $A \beta_{42}$ and methylglyoxal induced concentration- and time dependent toxicity and dramatically changed cell morphology. In $A \beta_{42}$-treated brain endothelial cells cytoplasmic vacuolization, disruption of the structure of cytoplasmic organelles and tight junctions were visible. Additionally, methylglyoxal treatment caused detachment of endothelial cells. Further damage of barrier function was demonstrated by decreased resistance and increased para- and transcellular permeability of the endothelial monolayers. The production of reactive oxygen species in brain endothelial cells was also elevated. Pentosan polysulfate, a drug of plant origin, and the polyunsaturated fatty acid docosahexaenoic acid could attenuate the toxic effects of $A \beta_{42}$ peptides. Co-treatment of the cells with $A \beta_{42}$ and the protective agents prevented the morphological changes and cell cultures integrity resembled to the control ones. Furthermore, pentosan and docosahexaenoic acid could significantly protect the barrier from damaging actions of peptides. The barrier function of endothelial monolayers, mirrored by low permeability and high resistance, was restored. At molecular level, pentosan modified the size and decreased the number of amyloid aggregates demonstrated by atomic force microscopy. Docosahexaenoic acid had a different molecular mechanism, it decreased the elevated reactive oxygen species level and restored P-glycoprotein efflux pump activity. These results indicate for the first time that pentosan and docosahexaenoic acid can protect the blood-brain barrier from the toxic effects of $A \beta_{42}$ and these protective molecules may be beneficial in Alzheimer's disease. Edaravone, the active substance of a Japanese medicine, was effective against methylglyoxal induced damages. Co-administration of edaravone restored cell viability, barrier integrity and functions of brain endothelial cells. Edaravone prevented the methylglyoxal-induced cell detachment. The production of reactive oxygen species in human endothelial cells and proteinmodification were also blocked. We demonstrated that edaravone is protective in oxidative and carbonyl stress induced barrier damages. Our observations further support the toxic effects of amyloid peptides and methylglyoxal, and show for the first time the protective effect of pentosan, docosahexaenoic acid and edaravone on brain endothelial cells. The present data may contribute to the development of compounds protecting the blood-brain barrier in carbonyl stress related diseases, especially in Alzheimer's disease. 


\section{ACKNOWLEDGEMENT}

I am grateful to my supervisor, Dr. Mária Deli for her scientific guidance and support throughout my PhD studies.

I thank Prof. Pál Ormos, director of the Institute of Biophysics at the Biological Research Centre, and Dr. László Siklós, head of the Molecular Neurobiology Research Unit for their support.

I am indebted to our cooperating partners, Prof. Masami Niwa, Prof. Yasufumi Kataoka, Dr. Shinya Dohgu, Dr. Fuyuko Takata, Dr. Csongor Ábrahám and Dr. Gábor Rákhely for their help; Dr. Monika Vastag and Dr. Éva Hellinger for western blot experiments; Dr. László Puskás and Lajos Nagy for holographic phase contrast microscopy experiments; Dr. Ágnes Kittel for electronmicroscopical studies; Dr. Mária Csete, Dr. Áron Sipos, Anikó Szalai for performing the atomic force microscopy analysis; Prof. Botond Penke, Dr. Lívia Fülöp, Dr. Zsolt Datki, Dr. Zsolt Bozsó for preparation of amyloid peptides and experiments on hippocampal slices; and Dr. Pierre-Olivier Couraud for providing the human brain endothelial cell line.

I am grateful to my colleagues, Dr. Szilvia Veszelka, Fruzsina Walter, Alexandra Bocsik, Petra Sántha, András Harazin, Lóránd Kiss, Ngo Thi Khue Dung, Boglárka Csiszár, Ilona Gróf for their kind help during the experiments.

Finally, I am especially thankful to my family and friends for their love, untiring support and encouragement during my studies.

The research was supported by grants from the Hungarian Research Fund (OTKA T37834, M36252), from other agencies (RET 08/2004, GVOP-KMA-52) and from the European Union and the State of Hungary, co-financed by the European Social Fund in the framework of TÁMOP 4.2.4. A/2-11-1-2012-0001 'National Excellence Program', TÁMOP-4.2.2-08/1/20080002; TÁMOP-4.2.2.A-11/1/KONV-2012-0052. The student grant and training course of the Hungarian Intellectual Property Office, the financial support of Richter Gedeon Centenarium Foundation and Jedlik Ányos Fellowship program (TÁMOP 4.2.4. A/2-11-1-2012-0001) are gratefully acknowledged. 


\section{REFERENCES}

Abbott NJ, Patabendige AA, Dolman DE, Yusof SR, Begley DJ (2010). Structure and function of the blood-brain barrier. Neurobiol Dis. 37: 13-25.

Abbott NJ, Rönnbäck L, Hansson E (2006). Astrocyte-endothelial interactions at the blood-brain barrier. Nature Rev Neurosci. 7: 41-53.

Alm K, El-Schich Z, Miniotis FM, Wingren AG, Janicke B and Oredsson S (2013). Cells and Holograms - Holograms and Digital Holographic Microscopy as a Tool to Study the Morphology of Living Cells. In: Mihaylova, (ed.) Holography - Basic Principles and Contemporary Applications: ISSB: 978-953-5151117-7, InTech.

András IE, Eum SY, Toborek M. (2012). Lipid rafts and functional caveolae regulate HIVinduced amyloid beta accumulation in brain endothelial cells. Biochem Biophys Res Commun. 421: 177-183

Angeloni C, Zambonin L, Hrelia S (2014). Role of methylglyoxal in Alzheimer's disease. Biomed Res Int. 2014: Article ID 238485.

Arsenault D, Julien C, Tremblay C, Calon F (2011). DHA improves cognition and prevents dysfunction of entorhinal cortex neurons in 3 x TG-AD mice. PLoS ONE. 23: e17397.

van Assema DM, Lubberink M, Bauer M, van der Flier WM, Schuit RC, Windhorst AD, Comans EF, Hoetjes NJ, Tolboom N, Langer O, Müller M, Scheltens P, Lammertsma AA, van Berckel BN (2012). Blood-brain barrier P-glycoprotein function in Alzheimer's disease. Brain. 135: 181-189.

Baiguera S, Fioravanzo L, Grandi C, Di Liddo R, Parnigotto PP, Folin M (2009). Involvement of the receptor for advanced glycation-end products (RAGE) in $\beta$-amyloid-induced toxic effects in rat cerebromicrovascular endothelial cells cultured in vitro. Int J Mol Med 24: 9-15.

Beeri MS, Moshier E, Schmeidler J, Godbold J, Uribarri J, Reddy S, Sano M, Grossman HT, Cai W, Vlassara H, Silverman JM. (2011). Serum concentration of an inflammatory glycotoxin, methylglyoxal, is associated with increased cognitive decline in elderly individuals. Mech Ageing Dev. 132: 583-587.

Bell RD, Zlokovic BV (2009). Neurovascular mechanisms and blood-brain barrier disorder in Alzheimer's disease. Acta Neuropathol. 118: 103-113.

Blanc EM, Toborek M, Mark RJ, Hennig B, Mattson MP (1997). Amyloid $\beta$-peptide induces cell monolayer albumin permeability, impairs glucose transport, and induces apoptosis in vascular endothelial cells. J Neurochem 68: 1870-1881.

Bozsó Z, Penke B, Simon D, Laczkó I, Juhász G, Szegedi V, Kasza A, Soós K, Hetényi A, Wéber E, Tóháti H, Csete M, Zarándi M, Fülöp L (2010). Controlled in situ preparation of $\mathrm{A} \beta(1-42)$ oligomers from the isopeptide "iso-A $\beta(1-42) "$, physicochemical and biological characterization. Peptides. 31: 248-256.

Bruno A, Liebeskind D, Hao Q, Raychev R, Investigators US (2010). Diabetes mellitus, acute hyperglycemia, and ischemic stroke. Curr Treat Options Neurol. 12: 492-503.

Butt AM, Jones HC, Abbott NJ (1990). Electrical resistance across the blood-brain barrier in anaesthetized rats: a developmental study. J Physiol. 429: 47-62.

Calero M, Tokuda T, Rostagno A, Kumar A, Zlokovic B, Frangione B, Ghiso J (1999). Functional and structural properties of lipid-associated apolipoprotein $\mathbf{J}$ (clusterin). Biochem J. 344: 375-383.

Candela P, Gosselet F, Saint-Pol J, Sevin E, Boucau MC, Boulanger E, Cecchelli R, Fenart L. (2010). Apical-to-basolateral transport of amyloid- $\beta$ peptides through blood-brain barrier 
cells is mediated by the receptor for advanced glycation end-products and is restricted by $\mathrm{P}$ glycoprotein. J Alzheimers Dis. 22: 849-859.

Carrano A, Hoozemans JJ, van der Vies SM, Rozemuller AJ, van Horssen J, de Vries HE. (2011). Amyloid Beta induces oxidative stress-mediated blood-brain barrier changes in capillary amyloid angiopathy. Antioxid Redox Signal. 15: 1167-1178.

Carreiras MC, Mendes E, Perry MJ, Francisco AP, Marco-Contelles J (2013). The multifactorial nature of Alzheimer's disease for developing potential therapeutics. Curr Top Med Chem. 13: 1745-1770.

Cecchelli R, Berezowski V, Lundquist S, Culot M, Renftel M, Dehouck MP, Fenart L (2007). Modelling of the blood-brain barrier in drug discovery and development. Nat Rev Drug Discov. 6: 650-661.

Choi J, Levey AI, Weintraub ST, Rees HD, Gearing M, Chin LS, Li L (2004). Oxidative modifications and down-regulation of ubiquitin carboxyl-terminal hydrolase L1 associated with idiopathic Parkinson's and Alzheimer's diseases. J Biol Chem 279: 13256-13264.

Cirrito JR, Deane R, Fagan AM, Spinner ML, Parsadanian M, Finn MB, Jiang H, Prior JL, Sagare A, Bales KR, Paul SM, Zlokovic BV, Piwnica-Worms D, Holtzman DM (2005). P-glycoprotein deficiency at the blood-brain barrier increases amyloid- $\beta$ deposition in an Alzheimer disease mouse model. J Clin Invest. 115: 3285-3290.

Deane R, Du Yan S, Submamaryan RK, LaRue B, Jovanovic S, Hogg E, Welch D, Manness L, Lin C, Yu J, Zhu H, Ghiso J, Frangione B, Stern A, Schmidt AM, Armstrong DL, Arnold B, Liliensiek B, Nawroth P, Hofman F, Kindy M, Stern D, Zlokovic B (2003). RAGE mediates amyloid- $\beta$ peptide transport across the blood-brain barrier and accumulation in brain. Nat Med. 9: 907-913.

Deane R, Wu Z, Sagare A, Davis J, Du Yan S, Hamm K, Xu F, Parisi M, LaRue B, Hu HW, Spijkers P, Guo H, Song X, Lenting PJ, Van Nostrand WE, Zlokovic BV (2004). LRP/amyloid $\beta$-peptide interaction mediates differential brain efflux of $A \beta$ isoforms. Neuron. 43: 333-344.

De Caterina R, Liao JK, Libby P (2000). Fatty acid modulation of endothelial activation. Am J Clin Nutr. 71: 213S-223S.

Del Zoppo GJ, Milner R, Mabuchi T, Hung S, Wang X, Koziol JA (2006). Vascular matrix adhesion and the blood-brain barrier. Biochem Soc Trans 34: 1261-1266.

Deli MA (2005). The role of blood-brain barrier in neurodegenerative diseases. In: Molecular Bases of Neurodegeneration. Di Liegro I, Savettieri G, (eds.) Research Signpost, Kerala, India, 2005. pp. 137-161.

Deli MA (2011). Drug Transport and the Blood-Brain Barrier: Chapter 8. In: Tihanyi K, Vastag M (eds.) In: Solubility, delivery, and ADME problems of drugs and drug-candidates. Washington: Bentham Science Publ. Ltd. pp. 144-165.

Deli MA, Ábrahám CS, Kataoka Y, Niwa M (2005). Permeability studies on in vitro blood-brain barrier models: physiology, pathology and pharmacology. Cell Mol Neurobiol. 25: 59-127.

Deli MA, Ábrahám CS, Takahata H, Katamine S, Niwa M (2000a). Pentosan polysulfate regulates scavenger receptor-mediated, but not fluid phase endocytosis in immortalized cerebral endothelial cell. Cell Mol Neurobiol. 20: 731-745.

Deli MA, Sakaguchi S, Nakaoke R, Ábrahám CS, Takahata H, Kopácek J, Shigematsu K, Katamine S, Niwa M (2000b). PrP fragment 106-126 is toxic to cerebral endothelial cells expressing $\operatorname{PrP}^{\mathrm{C}}$. Neuroreport. 11: 3931-3936.

DeMager PP, Penke B, Walter R, Harkany T, H“artignny W (2002). Pathological peptide folding in Alzheimer's disease and other conformational disorders. Curr Med Chem. 9: 1763-1780. 
Desai KM, Wu L (2008). Free radical generation by methylglyoxal in tissues. Drug Metabol Drug Interact 23: 151-173.

Desai K, Wu L (2007). Methylglyoxal and advanced glycation endproducts: new therapeutic horizons? Recent Pat Cardiovasc Drug Discov 2: 89-99.

Dobler D, Ahmed N, Song L, Eboigbodin KE, Thornalley PJ (2006). Increased dicarbonyl metabolism in endothelial cells in hyperglycemia induces anoikis and impairs angiogenesis by RGD and GFOGER motif modification. Diabetes 55: 1961-1969.

Dukic-Stefanovic S, Schinzel R, Riederer P, Munch G (2001). AGES in brain ageing: AGEinhibitors as neuroprotective and anti-dementia drugs? Biogerontology. 2: 19-34.

Edelstein D, Brownlee M (1992). Mechanistic studies of advanced glycosylation end product inhibition by aminoguanidine. Diabetes. 41: 26-29.

Eisenhauer PB, Johnson RJ, Wells JM, Davies TA, Fine RE (2000). Toxicity of various amyloid $\beta$ peptide species in cultured human blood-brain barrier endothelial cells: increased toxicity of dutch-type mutant. J Neurosci Res 60: 804-810.

Enerson BE, Drewes LR (2006). The rat blood-brain barrier transcriptome. J Cereb Blood Flow Metab. 26: 959-973.

Erickson MA, Banks WA (2013). Blood-brain barrier dysfunction as a cause and consequence of Alzheimer's disease. J Cereb Blood Flow Metab. 33: 1500-1513.

Floyd RA, Hensley K (2002). Oxidative stress in brain aging. Implications for therapeutics of neurodegenerative diseases. Neurobiol Aging 23: 795-807.

Folin M, Baiguera S, Fioravanzo L, Conconi MT, Grandi C, Nussdorfer GG, Parnigotto PP (2006). Caspase- 8 activation and oxidative stress are involved in the cytotoxic effect of $\beta$ amyloid on rat brain microvascular endothelial cells. Int J Mol Med 17: 431-435.

Fontaine M, Elmquist WF, Miller DW (1996). Use of rhodamine 123 to examine the functional activity of P-glycoprotein in primary cultured brain microvessels endothelial cell monolayers. Life Sci 59, 1521-1531.

Forman MS, Trojanowski JQ, Lee VM (2004). Neurodegenerative diseases: a decade of discoveries paves the way for therapeutic breakthroughs. Nat Med. 10: 1055-1063.

Freund-Levi Y, Eriksdotter-Jönhagen M, Cederholm T, Basun H, Faxén-Irving G, Garlind A, Vedin I, Vessby B, Wahlund LO, Palmblad J (2006). Omega-3 fatty acid treatment in 174 patients with mild to moderate Alzheimer disease: OmegAD study: a randomized doubleblind trial. Arch Neurol. 63: 1402-1408.

Gaillard PJ, de Boer AG (2000). Relationship between permeability status of the blood-brain barrier and in vitro permeability coefficient of a drug. Eur J Pharm Sci; 12: 95-102.

Ghosh P (1999). The pathobiology of osteoarthritis and the rationale for the use of pentosan polysulfate for its treatment. Semin Arthritis Rheum. 28: 211-267.

Giri R, Shen Y, Stins M, Du Yan S, Schmidt AM, Stern D, Kim KS, Zlokovic B, Kalra VK (2000). $\beta$-Amyloid-induced migration of monocytes across human brain endothelial cells involves RAGE and PECAM-1. Am J Physiol Cell Physiol. 279: C1772-C1781.

Grammas P, Yamada M, Zlokovic BV (2002). The cerebro-microvasculature: a key player in the pathogenesis of Alzheimer's disease. J Alzheimers Dis. 4: 217-223.

Grimm MO, Kuchenbecker J, Grösgen S, Burg VK, Hundsdörfer B, Rothhaar TL, Friess P, de Wilde MC, Broersen LM, Penke B, Péter M, Vígh L, Grimm HS, Hartmann T (2011). Docosahexaenoic acid reduces amyloid beta production via multiple pleiotropic mechanisms. J Biol Chem. 22: 14028-14039. 
Hashimoto M, Katakura M, Hossain S, Rahman A, Shimada T, Shido O (2011). Docosahexaenoic acid withstands the A $\beta(25-35)$-induced neurotoxicity in SH-SY5Y cells. J Nutr Biochem 22: 22-29.

Hashimoto M, Tanabe Y, Fujii Y, Kikuta T, Shibata H, Shido O (2005). Chronic administration of docosahexaenoic acid ameliorates the impairment of spatial cognition learning ability in amyloid beta-infused rats. J Nutr. 135: 549-555.

Heneka MT, Kummer MP, Weggen S, Bulic B, Multhaup G, Münter L, Hüll M, Pflanzner T, Pietrzik CU (2011). Molecular mechanisms and therapeutic application of NSAIDs and derived compounds in Alzheimer's disease. Curr Alzheimer Res. 8: 115-131.

Hetényi A, Fülöp L, Martinek TA, Wéber E, Soós K, Penke B (2008). Ligand-induced flocculation of neurotoxic fibrillar $A \beta(1-42)$ by noncovalent crosslinking. ChemBioChem. 9: 748-757.

Hőgyes E, Nyakas C, Kiliaan A, Farkas T, Penke B, Luiten PG (2003). Neuroprotective effect of developmental docosahexaenoic acid supplement against excitotoxic brain damage in infant rats. Neuroscience. 119: 999-1012.

Innis SM (2007). Dietary (n-3) fatty acids and brain development. J Nut. 137: 855-859.

Ishrat T, Soliman S, Guan W, Saler M, Fagan SC (2012). Vascular protection to increase the safety of tissue plasminogen activator for stroke. Curr Pharm Des. 18: 3677-3684.

Kalapos MP (2008). The tandem of free radicals and methylglyoxal. Chem Biol Interact. 171: 251-271.

Kalapos MP (2013). Where does plasma methylglyoxal originate from? Diabetes Res Clin Pract 99: 260-271.

Kalaria RN, Hedera P (1995). Differential degeneration of the cerebral microvasculature in Alzheimer's disease. Neuroreport. 6: 477-480.

Kania KD, Wijesuriya HC, Hladky SB, Barrand MA. (2011). Beta amyloid effects on expression of multidrug efflux transporters in brain endothelial cells. Brain Res. 1418: 1-11.

Kaste M, Murayama S, Ford GA, Dippel DW, Walters MR, Tatlisumak T (2013). Safety, tolerability and pharmacokinetics of MCI-186 in patients with acute ischemic stroke: new formulation and dosing regimen. Cerebrovasc Dis 36: 196-204.

Kikuchi K, Takeshige N, Miura N, Morimoto Y, Ito T, Tancharoen S, Miyata K, Kikuchi C, Iida N, Uchikado H, Miyagi N, Shiomi N, Kuramoto T, Maruyama I, Morioka M, Kawahara KI (2012). Beyond free radical scavenging: Beneficial effects of edaravone (Radicut) in various diseases. Exp Ther Med. 3: 3-8.

Kiss L, Walter FR, Bocsik A, Veszelka S, Ózsvári B, Puskás LG, Szabó-Révész P, Deli MA (2013). Kinetic analysis of the toxicity of pharmaceutical excipients Cremophor EL and RH40 on endothelial and epithelial cells. J Pharm Sci. 102: 1173-1181.

Ko SY, Lin YP, Lin YS, Chang SS (2010). Advanced glycation end products enhance amyloid precursor protein expression by inducing reactive oxygen species. Free Radic Biol Med. 49: 474-480.

Krizbai IA, Deli MA (2003). Signalling pathways regulating the tight junction permeability in the blood-brain barrier. Cell Mol Biol. 49(1): 23-31.

Kuhla B, Lüth HJ, Haferburg D, Boeck K, Arendt T, Münch G (2005). Methylglyoxal, glyoxal, and their detoxification in Alzheimer's disease. Ann N Y Acad Sci. 1043: 211-216.

Kuhnke D, Jedlitschky G, Grube M, Krohn M, Jucker M, Mosyagin I, Cascorbi I, Walker LC, Kroemer HK, Warzok RW, Vogelgesang S. (2007). MDR1-P-Glycoprotein (ABCB1) Mediates Transport of Alzheimer's amyloid-beta peptides--implications for the mechanisms of Abeta clearance at the blood-brain barrier. Brain Pathol. 17: 347-353. 
Lapolla A, Flamini R, Dalla Vedova A, Senesi A, Reitano R, Fedele D, Basso E, Seraglia R, Traldi P (2003). Glyoxal and methylglyoxal levels in diabetic patients: quantitative determination by a new GC/MS method. Clin Chem Lab Med. 41: 1166-1173.

Ledesma MD, Bonay P, Colaço C, Avila J (1994). Analysis of microtubule-associated protein tau glycation in paired helical filaments. J Biol Chem. 269: 21614-21619.

Leveugle B, Ding W, Laurence F, Dehouck M-P, Scanameo A, Cecchelli R, Fillit H (1998). Heparin oligosaccharides that pass the blood-brain barrier inhibit $\beta$-amyloid precursor protein secretion and heparin binding to $\beta$-amyloid peptide. J Neurochem 70: 736-744.

Leveugle B, Scanameo A, Ding W, Fillit H (1994). Binding of heparan sulfate glycosaminoglycan to beta-amyloid peptide: inhibition by potentially therapeutic polysulfated compounds. Neuroreport. 5: 1389-1392.

Lee C, Yim MB, Chock PB, Yim HS, Kang S (1998). Oxidation-reduction properties of methylglyoxal-modified protein in relation to free radical generation. J Biol Chem 273: 25272-25278.

Li W, Liu J, He P, Ni Z, Hu Y, Xu H, Dai H (2013a). Hydroxysafflor yellow A protects methylglyoxal-induced injury in the cultured human brain microvascular endothelial cells. Neurosci Lett 549: 146-150.

Li W, Maloney RE, Circu ML, Alexander JS, Aw TY (2013b). Acute carbonyl stress induces occludin glycation and brain microvascular endothelial barrier dysfunction: role for glutathione-dependent metabolism of methylglyoxal. Free Radic Biol Med. 54: 51-61.

Li W, Xu H, Hu Y, He P, Ni Z, Xu H, Zhang Z, Dai H (2013c). Edaravone Protected Human Brain Microvascular Endothelial Cells from Methylglyoxal-Induced Injury by Inhibiting AGEs/RAGE/Oxidative Stress. PLoS One 8: e76025.

Li XH, Du LL, Cheng XS, Jiang X, Zhang Y, Lv BL, Liu R, Wang JZ, Zhou XW (2013). Glycation exacerbates the neuronal toxicity of $\beta$-amyloid. Cell Death Dis. 13: e673.

Liebner S, Corada M, Bangsow T, Babbage J, Taddei A, Czupalla CJ, Reis M, Felici A, Wolburg H, Fruttiger M, Taketo MM, von Melchner H, Plate KH, Gerhardt H, Dejana E (2008). Wnt/beta-catenin signaling controls development of the blood-brain barrier. J Cell Biol. 183: 409-417.

Liebner S, Plate KH (2010) Differentiation of the brain vasculature: the answer came blowing by the Wnt. J Angiogenesis Res. 2: 1.

Lim GP, Calon F, Morihara T, Yang F, Teter B, Ubeda O, Salem NJr, Frautschy SA, Cole GM (2005). A diet enriched with the omega-3 fatty acid docosahexaenoic acid reduces amyloid burden in an aged Alzheimer mouse model. J Neurosci. 25: 3032-3040.

Liu J, Wang R, Desai K, Wu L (2011). Upregulation of aldolase B and overproduction of methylglyoxal in vascular tissues from rats with metabolic syndrome. Cardiovasc Res. 92: 494-503.

Lo TW, Westwood ME, McLellan AC, Selwood T, Thornalley PJ (1994). Binding and modification of proteins by methylglyoxal under physiological conditions. A kinetic and mechanistic study with $\mathrm{N}$ alpha-acetylarginine, $\mathrm{N}$ alpha-acetylcysteine, and $\mathrm{N}$ alphaacetyllysine, and bovine serum albumin. J Biol Chem. 269: 32299-32305.

Lopez LB, Kritz-Silverstein D, Barrett Connor E (2011). High dietary and plasma levels of the omega-3 fatty acid docosahexaenoic acid are associated with decreased dementia risk: the Rancho Bernardo study. J Nutr Health Aging. 15: 25-31.

Loske C, Neumann A, Cunningham AM, Nichol K, Schinzel R, Riederer P, Münch G (1998). Cytotoxicity of advanced glycation endproducts is mediated by oxidative stress. J Neural Transm. 105: 1005-1015. 
Lukic-Panin V, Deguchi K, Yamashita T, Shang J, Zhang X, Tian F, Liu N, Kawai H, Matsuura T, Abe K (2010). Free radical scavenger edaravone administration protects against tissue plasminogen activator induced oxidative stress and blood brain barrier damage. Curr Neurovasc Res 7: 319-329.

Madácsi R, Kanizsai I, Fehér LZ, Gyuris M, Ózsvári B, Erdélyi A, Wölfling J, Puskás LG (2013). Aromatic sulfonamides containing a condensed piperidine moiety as potential oxidative stress-inducing anticancer agents. Med Chem. 9: 911-919.

Maffrand JP, Herbert JM, Bernat A, Defreyn G, Delebasse D, Savi P, Pinot JJ, Sampol J (1991). Experimental and clinical pharmacology of pentosan polysulfate. Semin Thrombosis Hemostasis. 17: 186-198.

Mangalmurti NS, Chatterjee S, Cheng G, Andersen E, Mohammed A, Siegel DL, Schmidt AM, Albelda SM, Lee JS (2010). Advanced glycation end products on stored red blood cells increase endothelial reactive oxygen species generation through interaction with receptor for advanced glycation end products. Transfusion 50: 2353-2361.

Marco S, Skaper SD (2006). Amyloid $\beta$-peptide 1-42 alters tight junction protein distribution and expression in brain microvessel endothelial cells. Neurosci Lett 401: 219-224.

Marszalek JR, Lodish HF (2005). Docosahexaenoic acid, fatty acid-interacting proteins, and neuronal function. Annu Rev Cell Dev Biol. 21: 633-657.

Matafome P, Sena C, Seica R (2013). Methylglyoxal, obesity, and diabetes. Endocrine 43: 472484.

McNamara RK, Hahn CG, Jandacek R, Rider T, Tso P, Stanford KE, Richtand NM (2007). Selective deficits in the omega-3 fatty acid docosahexaenoic acid in the postmortem orbitofrontal cortex of patients with major depressive disorder. Biol Psychiatry. 62: 17-24.

Medina M, Avila J (2014). New perspectives on the role of tau in Alzheimer's disease. Implications for therapy. Biochem Pharmacol. 15;88: 540-547.

Miller MC, Tavares R, Johanson CE, Hovanesian V, Donahue JE, Gonzalez L, Silverberg GD, Stopa EG (2008). Hippocampal RAGE immunoreactivity in early and advanced Alzheimer's disease. Brain Res. 16: 273-280.

Morley JE, Banks WA (2010). Lipids and cognition. J Alzheimers Dis 20: 737-747.

Mukohda M, Okada M, Hara Y, Yamawaki H (2012). Exploring mechanisms of diabetes-related macrovascular complications: role of methylglyoxal, a metabolite of glucose on regulation of vascular contractility. J Pharmacol Sci. 118: 303-310.

Münch G, Schicktanz D, Behme A, Gerlach M, Riederer P, Palm D, Schinzel R (1999). Amino acid specificity of glycation and protein-AGE crosslinking reactivities determined with a dipeptide SPOT library. Nat Biotechnol. 17: 1006-1010.

Münch G, Westcott B, Menini T, Gugliucci A (2012). Advanced glycation endproducts and their pathogenic roles in neurological disorders. Amino Acids 42: 1221-1236.

Murata-Kamiya N, Kamiya H (2001). Methylglyoxal, an endogenous aldehyde, crosslinks DNA polymerase and the substrate DNA. Nucleic Acids Res. 29: 3433-3438.

Nag S, Begley DJ, (2005). Blood-brain barrier, exchange of metabolites and gases. In: Kalimo, H. (Ed.), Pathology and Genetics. Cerebrovascular Diseases. ISN Neuropath. Press, Basel, pp. 22-29.

Nakagawa S, Deli MA, Nakao S, Honda M, Hayashi K, Nakaoke R, Kataoka Y, Niwa M (2007). Pericytes from brain microvessels strengthen the barrier integrity in primary cultures of rat brain endothelial cells. Cell Mol Neurobiol. 27: 687-694. 
Nakagawa S, Deli MA, Kawaguchi H, Shimizudani T, Shimono T, Kittel Á, Tanaka M, Niwa M (2009). A new blood-brain barrier model using brain endothelial cells, pericytes and astrocytes. Neurochem Int. 54: 253-263.

Német I, Varga-Defterdarović L, Turk Z (2006). Methylglyoxal in food and living organisms. Mol Nutr Food Res. 50: 1105-1117.

Neuwelt EA, Bauer B, Fahlke C, Fricker G, Iadecola C, Janigro D, Leybaert L, Molnár Z, O'Donnell ME, Povlishock JT, Saunders NR, Sharp F, Stanimirovic D, Watts RJ, Drewes LR (2011). Engaging neuroscience to advance translational research in brain barrier biology. Nat Rev Neurosci. 12: 169-182.

Nordling J (2004). Interstitial cystitis: how should we diagnose it and treat it in 2004? Curr Opin Urol. 14: 323-327.

van Oijen M, de Jong FJ, Witteman JC, Hofman A, Koudstaal PJ, Breteler MM (2007) Atherosclerosis and risk for dementia. Ann Neurol. 61: 403-410.

Okatani Y, Wakatsuki A, Enzan H, Miyahara Y (2003). Edaravone protects against ischemia/reperfusion-induced oxidative damage to mitochondria in rat liver. Eur J Pharmacol. 28: $163-170$.

Okouchi M, Okayama N, Aw TY (2009). Preservation of cellular glutathione status and mitochondrial membrane potential by $\mathrm{N}$-acetylcysteine and insulin sensitizers prevent carbonyl stress-induced human brain endothelial cell apoptosis. Curr Neurovasc Res. 6: 267278.

Oksman M, Iivonen H, Hőgyes E, Amtul Z, Penke B, Leenders I, Broersen L, Lütjohann D, Hartmann T, Tanila H (2006). Impact of different saturated fatty acid, polyunsaturated fatty acid and cholesterol containing diets on beta-amyloid accumulation in APP/PS1 transgenic mice. Neurobiol Dis. 23: 563-572.

Olah Z, Pakaski M, Janka Z, Kalman J (2012). Marking the markers of Alzheimer's: too good to diagnose, too bad to use? Neuropsychopharmacol Hung. 14: 165-176.

Omori K, Shikata Y, Sarai K, Watanabe N, Wada J, Goda N, Kataoka N, Shikata K, Makino H. (2007). Edaravone mimics sphingosine-1-phosphate-induced endothelial barrier enhancement in human microvascular endothelial cells. Am J Physiol Cell Physiol 293: C1523-C1531.

Onodera H, Arito M, Sato T, Ito H, Hashimoto T, Tanaka Y, Kurokawa MS, Okamoto K, Suematsu N, Kato T (2013). Novel effects of edaravone on human brain microvascular endothelial cells revealed by a proteomic approach. Brain Res 1534: 87-94.

Ouellet M, Emond V, Chen CT, Julien C, Bourasset F, Oddo S, LaFerla F, Bazinet RP, Calon F. (2009). Diffusion of docosahexaenoic and eicosapentaenoic acids through the blood-brain barrier: An in situ cerebral perfusion study. Neurochem Int 55: 476-482.

Ózsvári B, Puskás LG, Nagy LI, Kanizsai I, Gyuris M, Madácsi R, Fehér LZ, Gerö D, Szabó C (2010). A cell-microelectronic sensing technique for the screening of cytoprotective compounds. Int J Mol Med. 25: 525-530.

Padurariu M, Ciobica A, Lefter R, Serban IL, Stefanescu C, Chirita R (2013). The oxidative stress hypothesis in Alzheimer's disease. Psychiatr Danub. 25: 401-409.

Pahnke J, Langer O, Krohn M (2014). Alzheimer's and ABC transporters - new opportunities for diagnostics and treatment. Neurobiol Dis. 16: Epub ahead of print (DOI: 10.1016/j.nbd.2014.04.001; S0969-9961(14)00083-7).

Pákáski M, Kálmán J (2008). Interactions between the amyloid and cholinergic mechanisms in Alzheimer's disease. Neurochem Int. 53: 103-111.

Pákáski M, Baláspiri L, Checler F, Kása P (2002). Human amyloid- $\beta$ causes changes in the levels of endothelial protein kinase $C$ and its alpha isoform in vitro. Neurochem Int 41: 409-414. 
Panegyres PK, Armari E (2013). Therapies for human prion diseases. Am J Neurodegener Dis. 18: $176-186$.

Paolinelli R CM, Ferrarini L, Devraj K, Artus C, Czupalla CJ, Rudini N,, Maddaluno L PE, Engelhardt B, Couraud PO, Liebner S, Dejana E (2013). Wnt activation of immortalized brain endothelial cells as a tool for generating a standardized model of the blood brain barrier in vitro. PLoS One. 8: e70233.

Pardridge WM (2002). Drug and gene targeting to brain with molecular Trojan horses. Nat Rev Drug Discov. 1: 131-139.

Perrière N, Demeuse P, Garcia E, Regina A, Debray M, Andreux JP, Couvreur P, Scherrmann JM, Temsamani J, Couraud P-O, Deli MA, Roux F (2005). Puromycin-based purification of rat brain capillary endothelial cell cultures. Effect on the expression of blood-brain barrierspecific properties. J Neurochem. 93: 279-289.

Pintér E, Pozsgai G, Hajna Z, Helyes Z, Szolcsányi J (2014). Neuropeptide receptors as potential drug targets in the treatment of inflammatory conditions. Br J Clin Pharmacol. 77: 5-20.

Preston JE, Hipkiss AR, Himsworth DT, Romero IA, Abbott NJ (1998). Toxic effects of $\beta$ amyloid (25-35) on immortalised rat brain endothelial cell: protection by carnosine, homocarnosine and $\beta$-alanine. Neurosci Lett 242: 105-108.

Pun PB, Lu J, Moochhala S (2009). Involvement of ROS in BBB dysfunction. Free Radic Res 43: 348-364.

Quinn JF, Raman R, Thomas RG, Yurko-Mauro K, Nelson EB, Van Dyck C, Galvin JE, Emond J, Jack CRJr, Weiner M, Shinto L, Aisen PS (2010). Docosahexaenoic acid supplementation and cognitive decline in Alzheimer disease: a randomized trial. JAMA. 304: 1903-1911.

Rabbani N, Godfrey L, Xue M, Shaheen F, Geoffrion M, Milne R, Thornalley PJ (2011). Glycation of LDL by methylglyoxal increases arterial atherogenicity: a possible contributor to increased risk of cardiovascular disease in diabetes. Diabetes 60: 1973-1980.

Rabbani N, Thornalley PJ (2008). Dicarbonyls linked to damage in the powerhouse: glycation of mitochondrial proteins and oxidative stress. Biochem Soc Trans 36: 1045-1050.

Rapoport SI, Rao JS, Igarashi M (2007). Brain metabolism of nutritionally essential polyunsaturated fatty acids depends on both the diet and the liver. Prostaglandins Leukot Essent Fatty Acids. 77: 251-261.

Rouhiainen A, Kuja-Panula J, Tumova S, Rauvala H (2013). RAGE-mediated cell signaling. Methods Mol Biol 963: 239-263.

Sena CM, Matafome P, Crisóstomo J, Rodrigues L, Fernandes R, Pereira P, Seiça RM. (2012). Methylglyoxal promotes oxidative stress and endothelial dysfunction. Pharmacol Res. 65: 497-506.

Serhan CN, Gotlinger K, Hong S, Arita M (2004). Resolvins, docosatrienes, and neuroprotectins, novel omega-3-derived mediators, and their aspirin-triggered endogenous epimers: an overview of their protective roles in catabasis. Prostaglandins Other Lipid Mediat. 73: 155172.

Shibata M, Yamada S, Kumar SR, Calero M, Bading J, Frangione B, Holtzman DM, Miller CA, Strickland DK, Ghiso J, Zlokovic BV (2000). Clearance of Alzheimer's amyloid- $\beta$ 1-40 peptide from brain by LDL receptor-related protein-1 at the blood-brain barrier. J Clin Invest. 106: 1489-1499.

Siriwardhana N, Kalupahana NS, Fletcher S, Xin W, Claycombe KJ, Quignard-Boulange A, Zhao L, Saxton AM, Moustaid-Moussa N (2012a). n-3 and n-6 polyunsaturated fatty acids differentially regulate adipose angiotensinogen and other inflammatory adipokines in part via NF-kB-dependent mechanisms. J Nutr Biochem. 23: 1661-1667. 
Siriwardhana N, Kalupahana NS, Moustaid-Moussa N. (2012b) Health benefits of n-3 polyunsaturated fatty acids: eicosapentaenoic acid and docosahexaenoic acid. Adv Food Nutr Res. 65: 211-222.

Sousa Silva M, Gomes RA, Ferreira AE, Ponces Freire A, Cordeiro C (2013). The glyoxalase pathway: the first hundred years... and beyond. Biochem J. 453: 1-15.

Söderberg M, Edlund C, Kristensson K, Dallner G (1991). Fatty acid composition of brain phospholipids in aging and in Alzheimer's disease. Lipids. 26: 421-425.

Srikanth V, Maczurek A, Phan T, Steele M, Westcott B, Juskiw D, Münch G (2011). Advanced glycation endproducts and their receptor RAGE in Alzheimer's disease. Neurobiol Aging. 32: 763-777.

Srikanth V, Westcott B, Forbes J, Phan TG, Beare R, Venn A, Pearson S, Greenaway T, Parameswaran V, Münch G (2013). Methylglyoxal, cognitive function and cerebral atrophy in older people. J Gerontol A Biol Sci Med Sci. 68: 68-73.

Stitt AW, Jenkins AJ, Cooper ME (2002). Advanced glycation end products and diabetic complications. Expert Opin Investig Drugs. 11: 1205-1223.

Tai LM, Holloway KA, Male DK, Loughlin AJ, Romero IA (2010). Amyloid- $\beta$-induced occludin down-regulation and increased permeability in human brain endothelial cells is mediated by MAPK activation. J Cell Mol Med 14: 1101-1112.

Terasaki T, Ohtsuki S (2005). Brain-to-blood transporters for endogenous substrates and xenobiotics at the blood-brain barrier: an overview of biology and methodology. NeuroRx. 2: 63-72.

Thornalley PJ (2003). Use of aminoguanidine (Pimagedine) to prevent the formation of advanced glycation endproducts. Arch Biochem Biophys 419: 31-40.

Thornalley PJ, Edwards LG, Kang Y, Wyatt C, Davies N, Ladan MJ, Double J (1996). Antitumour activity of S-p-bromobenzylglutathione cyclopentyl diester in vitro and in vivo. Inhibition of glyoxalase I and induction of apoptosis. Biochem Pharmacol. 51: 1365-1372.

Tully AM, Roche HM, Doyle R, Fallon C, Bruce I, Lawlor B, Coakley D, Gibney MJ (2003). Low serum cholesteryl ester-docosahexaenoic acid levels in Alzheimer's disease: a casecontrol study. Br J Nutr. 89: 483-489.

Turk Z (2010). Glycotoxines, carbonyl stress and relevance to diabetes and its complications. Physiol Res 59: 147-156.

Uchida K (2000). Role of reactive aldehyde in cardiovascular diseases. Free Radic Biol Med. 28: 1685-1696.

Vander Jagt DL, Hunsaker LA (2003). Methylglyoxal metabolism and diabetic complications: roles of aldose reductase, glyoxalase-I, betaine aldehyde dehydrogenase and 2-oxoaldehyde dehydrogenase. Chem Biol Interact. 143-144: 341-351.

Vangilder RL, Rosen CL, Barr TL, Huber JD (2011). Targeting the neurovascular unit for treatment of neurological disorders. Pharmacol Ther. 130: 239-247.

Veszelka S, Kittel Á, Deli MA (2011). Tools of Modelling Blood-Brain Barrier Penetrability (Chapter 11). In: Tihanyi K, Vastag M (eds.) In: Solubility, Delivery, and ADME Problems of Drugs and Drug Candidates. Washington: Bentham Science Publ. Ltd. pp. 243-261.

Veszelka S, Pásztói M, Farkas AE, Krizbai I, Ngo TK, Niwa M, Abrahám CS, Deli MA (2007). Pentosan polysulfate protects brain endothelial cells against bacterial lipopolysaccharideinduced damages. Neurochem Int. 50: 219-228.

Voss A, Reinhart M, Sankarappa S, Sprecher H (1991). The metabolism of 7,10,13,16,19docosapentaenoic acid to 4,7,10,13,16,19-docosahexaenoic acid in rat liver is independent of a 4-desaturase. J Biol Chem. 25: 19995-20000. 
Wang, CX, Shuaib A (2007). Critical role of microvasculature basal lamina in ischemic brain injury. Prog Neurobiol 83: 140-148.

Watanabe T, Tanaka M, Watanabe K, Takamatsu Y, Tobe A (2004). Research and development of the free radical scavenger edaravone as a neuroprotectant. Yakugaku Zasshi. 124: 99-111.

Watanabe T, Yuki S, Egawa M, Nishi H (1994). Protective effects of MCI-186 on cerebral ischemia: possible involvement of free radical scavenging and antioxidant actions. J Pharmacol Exp Ther. 268: 1597-1604.

Weksler B, Romero IA, Couraud PO (2013). The hCMEC/D3 cell line as a model of the human blood brain barrier. Fluids Barriers CNS. 10: 16.

Weksler BB, Subileau EA, Perriere N, Charneau P, Holloway K, Leveque M, Tricoire-Leignel H, Nicotra A, Bourdoulous S, Turowski P, Male DK, Roux F, Greenwood J, Romero IA, Couraud PO (2005). Blood-brain barrier-specific properties of a human adult brain endothelial cell line. FASEB J. 19: 1872-1874.

Whitmer RA (2007). Type 2 diabetes and risk of cognitive impairment and dementia. Curr Neurol Neurosci Rep. 7: 373-438

Yamashita T, Kamiya T, Deguchi K, Inaba T, Zhang H, Shang J, Miyazaki K, Ohtsuka A, Katayama Y, Abe K (2009). Dissociation and protection of the neurovascular unit after thrombolysis and reperfusion in ischemic rat brain. J Cereb Blood Flow Metab. 29: 715-725.

Yamawaki H, Saito K, Okada M, Hara Y (2008). Methylglyoxal mediates vascular inflammation via JNK and p38 in human endothelial cells. Am J Physiol Cell Physiol. 295: C1510-C1517.

Yang X, Sheng W, Sun GY, Lee JC. (2011). Effects of fatty acid unsaturation numbers on membrane fluidity and $\alpha$-secretase-dependent amyloid precursor protein processing. Neurochem Int. 58: 321-329.

Yao D, Taguchi T, Matsumura T, Pestell R, Edelstein D, Giardino I, Suske G, Ahmed N, Thornalley PJ, Sarthy VP, Hammes HP, Brownlee M. (2006). Methylglyoxal modification of mSin3A links glycolysis to angiopoietin-2 transcription. Cell. 124: 275-286.

Yim HS, Kang SO, Hah YC, Chock PB, Yim MB (1995). Free radicals generated during the glycation reaction of amino acids by methylglyoxal. A model study of protein-cross-linked free radicals.J Biol Chem 270: 28228-28233.

Yin KJ, Lee JM, Chen H, Xu J, Hsu CY (2005). A $\beta 25-35$ alters Akt activity, resulting in Bad translocation and mitochondrial dysfunction in cerebrovascular endothelial cells. J Cereb Blood Flow Metab 25: 1445-1455.

Youdim KA, Avdeef A, Abbott NJ (2003). In vitro trans-monolayer permeability calculations: often forgotten assumptions. Drug Discov Today. 8: 997-1003.

Zarándi M, Soós K, Fülöp L, Bozsó Z, Datki Z, Tóth GK, Penke B (2007). Synthesis of A [1-42] and its derivatives with improved efficiency. J Peptide Sci. 13: 94-99.

Zlokovic BV (2004). Clearing amyloid through the blood-brain barrier. J Neurochem. 89: 807811.

Zlokovic BV (2005). Neurovascular mechanisms of Alzheimer's neurodegeneration. Trends Neurosci. 28: 202-208.

Zlokovic BV (2011). Neurovascular pathways to neurodegeneration in Alzheimer's disease and other disorders. Nat Rev Neurosci. 12: 723-738.

Zlokovic BV (2008). The blood-brain barrier in health and chronic neurodegenerative disorders. Neuron. 57: 178-201.

Zlokovic BV, Yamada S, Holtzman D, Ghiso J, Frangione B (2000). Clearance of amyloid peptide from brain: transport or metabolism? Nat Med. 6: 718-719. 


\section{Patents}

1. Yazdanian, M., Bormann, B.J. Immortalized brain endothelial cells. WO00031240 (2000).

2. Dejana, E., Liebner, S. In vitro model for modulating the blood brain barrier and methods of screening. WO2010014622 (2010).

3. Couraud, P.-O., Romero, I., Weksler, B. Human blood brain barrier model. WO2006056879 (2006).

4. Rubin, L.L., Porter, S., Horner, H.C., Yednock, T.A. Blood-brain barrier model. WO91005038 (1991).

5. Terasaki, T., Nakashima, E., Iizasa, H., Hosoya, K., Hattori, K. Blood-brain barrier reconstruction model prepared by cocultivation. WO01064849 (2001).

6. Janigro, D., McAllister, M.S. Cell and tissue culture modeling device and apparatus and method of using same. WO2003025206 (2003).

7. Shusta, E.V., Weidenfeller, C., Svendsen, C.N. Blood-brain barrier model. US20080044847 (2008).

8. Niwa, M., Nakagawa, S., Deli, M.A. Blood-brain barrier in vitro model, pathologic bloodbrain barrier in vitro model, drug screening method using the same, pathologic blood-brain barrier function analysis method and pathogenesis analysis method. WO2007072953 (2007).

\section{Online links}

Alzheimer's Disease International: http://www.alz.co.uk/research/world-report. Accessed: 2014. 05. 01.

RxList.The Internet Drug Index: http://www.rxlist.com/elmiron-drug.htm. Accessed: 2014. 05. 01.

Pharmindex Online: http://www.pharmindex-online.hu/gyogyszerkeresolista/atc/pentosan-polysulfate-natriumC05BA04. Accessed: 2014. 05. 01. 
ANNEX 
PUBLICATION I. 


\title{
Protection of the Blood-Brain Barrier by Pentosan Against Amyloid- $\beta$-Induced Toxicity
}

\author{
Mária A. Deli ${ }^{\mathrm{a}, *}$, Szilvia Veszelka ${ }^{\mathrm{a}}$, Boglárka Csiszár $^{\mathrm{a}}$, Andrea Tóth $^{\mathrm{a}}$, Ágnes Kittel $^{\mathrm{b}}$, Mária Csete $^{\mathrm{c}}$, \\ Áron Sipos ${ }^{\mathrm{c}}$, Anikó Szalai ${ }^{\mathrm{c}}$, Lívia Fülöp ${ }^{\mathrm{d}}$, Botond Penke ${ }^{\mathrm{d}}$, Csongor S. Ábrahám ${ }^{\mathrm{a}}$ and Masami Niwa ${ }^{\mathrm{e}}$ \\ ${ }^{a}$ Laboratory of Molecular Neurobiology, Institute of Biophysics, Biological Research Center of the Hungarian \\ Academy of Sciences, Szeged, Hungary \\ ${ }^{\mathrm{b}}$ Institute of Experimental Medicine, Hungarian Academy of Sciences, Budapest, Hungary \\ ${ }^{\mathrm{c}}$ Department of Optics and Quantum Electronics, University of Szeged, Szeged, Hungary \\ ${ }^{\mathrm{d}}$ Department of Medical Chemistry, University of Szeged, Szeged, Hungary \\ ${ }^{\mathrm{e}}$ Department of Pharmacology 1, Nagasaki University Graduate School of Biomedical Sciences, Nagasaki, Japan
}

Handling Associate Editor: William Banks

Accepted 20 July 2010

\begin{abstract}
Endothelial cells of brain capillaries forming the blood-brain barrier play an important role in the pathogenesis and therapy of Alzheimer's disease. Amyloid- $\beta(\mathrm{A} \beta)$ peptides are key pathological elements in the development of the disease. A blood-brain barrier model, based on primary rat brain endothelial cells was used in which the barrier properties were induced by glial cells. The effects of amyloid peptides have been tested on cell viability and barrier functions. A $\beta$ showed toxic effects on primary rat brain endothelial cells measured by MTT dye conversion and the lactate dehydrogenase release. Morphologically cytoplasmic vacuolization, disruption of the structure of cytoplasmic organelles and tight junctions could be observed in brain endothelial cells. Treatment with $\mathrm{A} \beta_{1-42}$ decreased the electrical resistance, and increased the permeability of brain endothelial cell monolayers for both fluorescein and albumin. Serum amyloid $\mathrm{P}$ component which stabilizes $\mathrm{A} \beta$ fibrils in cortical amyloid plaques and cerebrovascular amyloid deposits significantly potentiated the barrier-weakening effect of $\mathrm{A} \beta_{1-42}$. Sulfated polysaccharide pentosan could decrease the toxic effects of $\mathrm{A} \beta$ peptides in brain endothelial cells. It could also significantly protect the barrier integrity of monolayers from damaging actions of peptides. Pentosan modified the size, and significantly decreased the number of amyloid aggregates demonstrated by atomic force microscopy. The present data further support the toxic effects of amyloid peptides on brain endothelial cells, and can contribute to the development of molecules protecting the blood-brain barrier in Alzheimer's disease.
\end{abstract}

Keywords: Amyloid- $\beta$, blood-brain barrier, brain endothelial cells, glia, pentosan polysulfate, permeability, rat, serum amyloid P component

\footnotetext{
${ }^{*}$ Correspondence to: Mária A. Deli, M.D., Ph.D., Laboratory of Molecular Neurobiology, Institute of Biophysics, Biological Research Center of the Hungarian Academy of Sciences, Temesvári krt. 62., H-6726 Szeged, Hungary. Tel.: +36 62 599602; Fax: +36 62 433133; E-mail: deli@brc.hu.
}

\section{INTRODUCTION}

Alzheimer's disease (AD) is the most widespread form of dementias. In the European Union, 50-70\% of dementias are diagnosed as AD and the number of patients is over 7 million [1]. Despite intense research efforts there is still no effective therapy for AD. 
Recent findings indicate that neurovascular mechanisms contribute to cognitive decline and neurodegeneration in AD [2-6]. Decreased clearance of amyloid$\beta(\mathrm{A} \beta)$ across the blood-brain barrier (BBB), damaged angiogenesis, dysfunction of the cerebrovascular system all contribute to neurovascular uncoupling, brain hypoperfusion, and neurovascular inflammation $[4,5$, 7]. The BBB is indispensable for creating and maintaining the homeostasis of the central nervous system (CNS), therefore BBB dysfunction leads to disturbed homeostasis, neuronal dysfunction, and secondary neuronal loss $[4,5,8]$. It has also become clear that even subtle functional changes at the BBB without morphological alterations can lead to severe and lasting neurological dysfunction $[3,5]$.

The BBB is increasingly considered as a target of new therapeutical approaches in neurodegenerative disorders, especially in $\mathrm{AD}[5,8]$. In addition to production of the peptide, transport of $\mathrm{A} \beta$ across the $\mathrm{BBB}$ is essential in controlling $A \beta$ levels in the brain [9]. Enhancing $\mathrm{A} \beta$ clearance across the $\mathrm{BBB}$, as well as protection of the $\mathrm{BBB}$ from injury are among the proposed new strategies for the therapy of $\mathrm{AD}$.

$\mathrm{A} \beta_{1-40}$ and $\mathrm{A} \beta_{1-42}$ peptides, cleaved from amyloid$\beta$ protein precursor by secretases, are the main protein components of neuritic plaques and cerebral amyloid deposits and are considered as important factors in the pathogenesis of Alzheimer's disease [10]. A $\beta$ peptides can form soluble monomers, dimers, oligomers, protofibrils and insoluble fibrils [11]. Amyloid peptides have high affinity for serum amyloid $\mathrm{P}$ component (SAP) that stabilizes the aggregates [12]. Direct infusion of $\mathrm{A} \beta_{1-42}$ into the carotid artery increased the permeability of the BBB to albumin in rats [13]. In Tg2576 mice, an AD model, a higher BBB permeability for albumin was measured in cerebral cortex, which preceded senile plaque formation [14].

Experimental data support the direct toxicity of $\mathrm{A} \beta$ peptides on cultured endothelial cells. Treatments with $\mathrm{A} \beta_{1-40}, \mathrm{~A} \beta_{1-42}$, and $\mathrm{A} \beta_{25-35}$ peptides resulted in decreased viability in cultured peripheral [15], as well as brain endothelial cells $[16,17]$. Monolayer integrity of cerebral endothelial cells is also affected by $\mathrm{A} \beta$ peptides. Increased permeability for paracellular markers induced by $\mathrm{A} \beta_{25-35}$ and $\mathrm{A} \beta_{1-40}$ was detected in rat [18], bovine [19], and human brain microvascular endothelial cells [20].

Few protective molecules against the toxic effect of $\mathrm{A} \beta$ peptides in cerebral endothelial cells were identified so far. In our previous studies we found that pentosan polysulfate (PPS), a semisynthetic highly sul- fated polysaccharide can favorably regulate BBB phenotype [21], and protect against prion peptide [22,23] and lipopolysaccharide-induced toxicity [24] in brain endothelial cells. Although pentosan can inhibit the binding of endogenous glycosaminoglycans to $\mathrm{A} \beta$ and this effect was suggested as a potentially effective therapeutical approach to prevent or slow the amyloidogenesis in $\mathrm{AD}$ [25], pentosan was not tested on brain endothelial cells treated with $\mathrm{A} \beta$ peptides.

The aim of the study was to investigate the effect of pentosan on $\mathrm{A} \beta$ peptide-induced changes in cell viability and $\mathrm{BBB}$ functions in a relevant in vitro $\mathrm{BBB}$ model. Primary rat brain endothelial cells were cocultured with rat glial cells to induce barrier properties. The modulatory effects of serum amyloid $\mathrm{P}$ component (SAP) in BBB dysfunction induced by $\mathrm{A} \beta$ were also studied.

\section{MATERIALS AND METHODS}

All reagents were purchased from Sigma, Hungary, unless otherwise indicated.

\section{Peptides}

Peptides $\mathrm{A} \beta_{1-40}$ and $\mathrm{A} \beta_{1-42}$ were synthesized at the Department of Medical Chemistry, University of Szeged, as it was previously described [26,27]. Prior to measurements the purified peptide was dissolved in 1,1,1,3,3,3-hexafluoro-2-propanol (HFIP; Sigma) and incubated overnight at room temparature in order to destroy the pre-formed aggregates. Aliquots were transferred into Eppendorf tubes and HFIP was evaporated in vacuo. Dried peptide films were stored at $-80^{\circ} \mathrm{C}$ until use. Oligomers were prepared by resuspending the film in phosphate buffered saline (PBS). Oligomerization of the peptide was checked by TEM. Sampling for TEM and image preparation was done by following a standard protocol [28,29]. According to the TEM investigations, samples contained globulomers with a diameter of 5-7 nm either alone or in chain-like or annular assemblies, but not classical protofibrillar aggregates, which are 50-200 nm long (Fig. 1).

\section{Cell culture}

Primary cultures of cerebral endothelial cells were prepared from 2-week-old rats as described earlier in detail [24]. Forebrains were collected in ice cold sterile PBS; meninges were removed, gray matter was minced 


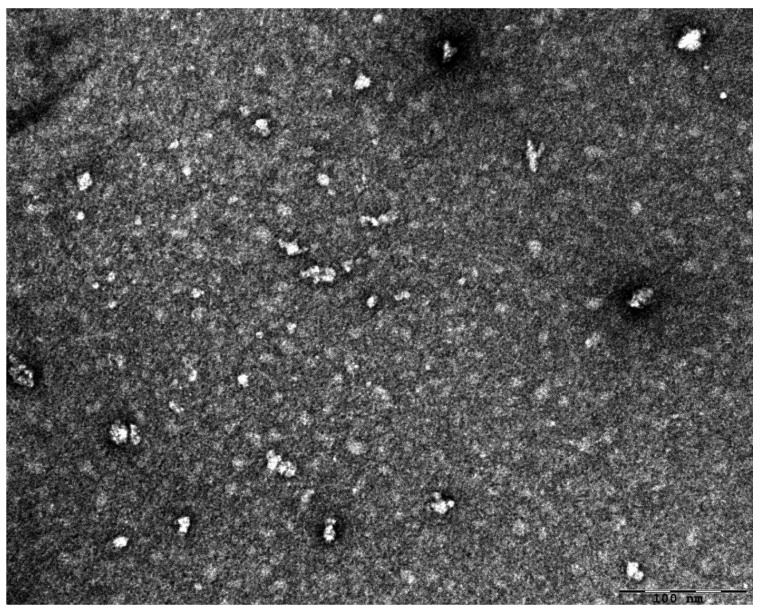

Fig. 1. TEM image of $\mathrm{A} \beta_{1-42}$ peptide dissolved in physiological salt solution to a concentration of $75 \mu \mathrm{M}$, containing a mixture of oligomers and small protofibrillar structures.

by scalpels to $1 \mathrm{~mm}^{3}$ pieces and digested with $1 \mathrm{mg} / \mathrm{ml}$ collagenase CLS2 (Worthington, USA) in Dulbecco's modified Eagle medium (DME) for $1.5 \mathrm{~h}$ at $37^{\circ} \mathrm{C}$. Microvessels were separated by centrifugation in $20 \%$ bovine serum albumin (BSA)-DME $(1000 \times g, 20 \mathrm{~min})$ from myelin containing elements, and further digested with $1 \mathrm{mg} / \mathrm{ml}$ collagenase-dispase (Roche) in DME for $1 \mathrm{~h}$. Microvascular endothelial cell clusters were separated on a $33 \%$ continuous Percoll gradient (1000 $\times g, 10 \mathrm{~min}$ ), collected, and washed twice in DME before plating on collagen type IV and fibronectin coated dishes, multiwell plates (Falcon, Becton Dickinson) or cell culture inserts (Transwell clear, $1 \mathrm{~cm}^{2}$; pore size, $0.4 \mu \mathrm{m}$, Costar). Cultures were maintained in DME supplemented with $5 \mu \mathrm{g} / \mathrm{ml}$ gentamicin, $20 \%$ plasmaderived bovine serum (First Link, UK), $1 \mathrm{ng} / \mathrm{ml}$ basic fibroblast growth factor (Roche) and $100 \mu \mathrm{g} / \mathrm{ml}$ heparin. In the first 2 days, culture medium contained puromycin (4 $\mu \mathrm{g} / \mathrm{ml}$ ) to selectively remove P-glycoprotein negative contaminating cells [30].

Cultures reached confluency within a week and were used for experiments. To induce BBB characteristics, brain endothelial cells were treated with gliaconditioned medium or co-cultured with rat cerebral glial cells $[18,24]$. Primary cultures of glial cells were prepared from newborn Wistar rats. Meninges were removed, and cortical pieces were mechanically dissociated in DME containing $5 \mu \mathrm{g} / \mathrm{ml}$ gentamicin and $10 \%$ fetal bovine serum and plated in poly-L-lysin coated 12-well dishes and kept for minimum 3 weeks before use. In confluent glia cultures $90 \%$ of cells were immunopositive for the astroglia cell marker glial fibril- lary acidic protein, while the remaining $10 \%$ was immunopositive for CD11b, a marker of microglia. For co-culture brain endothelial cells in cell culture inserts were placed into multiwells containing astroglia at the bottom of the wells with endothelial culture medium in both compartments. When brain endothelial cells became almost confluent $550 \mathrm{nM}$ hydrocortisone was added to the culture medium [18]. Before experiments the cells were treated with CPT-cAMP $(250 \mu \mathrm{M})$ and RO 201724 (17.5 $\mu \mathrm{M}$; Roche) for $24 \mathrm{~h}$ to tighten junctions and elevate resistance $[18,30]$.

\section{Treatments}

In case of viability assays the cells were treated with glia-conditioned medium, whereas for all other studies where the culture insert system made it possible coculture was done before treatments. Glia-conditioned medium or glial cells were not present during peptide treatments and experiments.

Peptides were tested at $0-200 \mu \mathrm{g} / \mathrm{ml}$ concentration for $0-48 \mathrm{~h}$ treatment period in brain endothelial cells. The doses of PPS (Cartrophen, Biopharm Australia Pty Ltd.) varied between 1 and $100 \mu \mathrm{g} / \mathrm{ml}$, as described in previous studies $[21,23,24]$. The concentration of human SAP (Merck, Germany) was $40 \mu \mathrm{g} / \mathrm{ml}$. In cell viability experiments done in 96-well format, where the abluminal surface was not available the cultures were treated only luminally. In all other experiments where endothelial cells were cultured on the membrane of the inserts $\mathrm{A} \beta_{1-42}$ was added both luminally and abluminally. Incubations of brain endothelial cells with the peptides were performed in endothelial culture medium.

\section{Electron microscopy}

Cells grown on the membrane were fixed with $3 \%$ paraformaldehyde in cacodylate buffer $(\mathrm{pH}$ 7.5) for $30 \mathrm{~min}$ at $4^{\circ} \mathrm{C}$. After washing with cacodylate buffer several times, the membranes of the culture inserts with the cells on the two sides were removed from their support and placed into 24-well chamber slide and were postfixed in $1 \% \mathrm{OsO}_{4}$ for $30 \mathrm{~min}$. Following washing with distilled water, the cells on the membrane were dehydrated in graded ethanol, block-stained with $2 \%$ uranyl acetate in $70 \%$ ethanol for $1 \mathrm{~h}$ and embedded in Taab 812 (Taab; Aldermaston, Berks, UK). Ultrathin sections were cut perpendicularly for the membrane using a Leica UCT ultramicrotome (Leica Microsystems, Milton Keynes, UK) and examined using a Hi- 
tachi 7100 transmission electron microscope (Hitachi Ltd., Tokyo, Japan). Electron micrographs were made by Megaview II (lower resolution, Soft Imaging System, Munster, Germany). Brightness and contrast were adjusted if necessary using Adobe Photoshop CS3 (San Jose, CA, USA).

\section{Cell cytotoxicity assays}

Living cells convert the yellow dye 3-(4,5-dimethyltiazol-2-yl)-2,5-diphenyltetrazolium bromide (MTT, Sigma M5655) to purple, insoluble formazan crystals. For MTT reduction assay the rat brain endothelial cells were cultured in 96 well plates. After treatments the cells were incubated with $0.5 \mathrm{mg} / \mathrm{ml}$ MTT solution for $3 \mathrm{~h}$ in $\mathrm{CO}_{2}$ incubator. The amount of formazan crystals was dissolved in dimethyl-sulfoxide and determined by measuring absorbance at $570 \mathrm{~nm}$ with microplate reader (Multiskan Ascent, Thermo Electron Corp., MA, USA).

To determine lactate dehydrogenase (LDH) from culture supernatant a commercially available kit (Cytotoxicity detection kit LDH, Roche) was used. For LDH release assay rat brain endothelial cells were cultured in 96 well plates. After treatments $50 \mu \mathrm{l}$ samples from culture supernatants were incubated with equal amounts of reaction mixture for $15 \mathrm{~min}$. The enzymic reaction was stopped by $0.1 \mathrm{M} \mathrm{HCl}$. Absorbance was measured at a wavelength of $492 \mathrm{~nm}$ with a microplate reader (Multiskan Ascent, Thermo Electron Corp., MA, USA). Cytotoxicity is calculated as percentage of the total $\mathrm{LDH}$ release from cells treated by $1 \%$ Triton X-100 detergent.

\section{Evaluation of the barrier integrity}

Transendothelial electrical resistance (TEER), representing the permeability of tight junctions for sodium ions, was measured by an EVOM resistance meter (World Precision Instruments Inc., USA) using STX-2 electrodes, and it was expressed relative to the surface area of endothelial monolayer $\left(\Omega \times \mathrm{cm}^{2}\right)$. TEER values of cell-free inserts $\left(90-100 \Omega \times \mathrm{cm}^{2}\right)$ were subtracted from the measured data. The TEER of rat primary brain endothelial monolayers in co-culture varied between 250 and $700 \Omega \times \mathrm{cm}^{2}$, with an average of $358 \pm$ $41 \Omega \times \mathrm{cm}^{2}$, (mean \pm S.D., $n=84$, experiments from 6 separate isolations).

The flux of sodium fluorescein and Evans bluelabeled albumin across endothelial monolayers was determined as previously described [24,31]. Cell cul- ture inserts, following treatment and measurement of TEER, were transferred to 12 -well plates containing $1.5 \mathrm{ml}$ Ringer-Hepes solution (118 mM NaCl, $4.8 \mathrm{mM}$ $\mathrm{KCl}, 2.5 \mathrm{mM} \mathrm{CaCl}_{2}, 1.2 \mathrm{mM} \mathrm{MgSO} 4,5.5 \mathrm{mM}$ Dglucose, $20 \mathrm{mM}$ Hepes, $\mathrm{pH}$ 7.4) in the basolateral compartments. In apical chambers culture medium was replaced by $500 \mu$ l Ringer-Hepes containing $10 \mu \mathrm{g} / \mathrm{ml}$ sodium fluorescein (mw: $376 \mathrm{Da}$ ) and $165 \mu \mathrm{g} / \mathrm{ml}$ Evans blue bound to $0.1 \%$ BSA (mw: $67 \mathrm{kDa}$ ). The inserts were transferred at 20,40, and $60 \mathrm{~min}$ to a new well containing Ringer-Hepes solution. The concentrations of the marker molecules in samples from the upper and lower compartments were determined. Evans blue concentration was measured by a Labsystems Multiskan plate reader (absorbency: $620 \mathrm{~nm}$ ), and fluorescein levels by a Polarstar Galaxy fluorescent plate reader (BMG Labtechnologies; emission: $525 \mathrm{~nm}$, excitation: $440 \mathrm{~nm}$ ). Flux across cell-free inserts was also measured.

Transport was expressed as $\mu \mathrm{l}$ of donor (luminal) compartment volume from which the tracer is completely cleared. Transendothelial permeability coefficient $\left(\mathrm{P}_{e}\right)$ was calculated as previously described [18, 24]. Cleared volume was calculated from the concentration $(\mathrm{C})$ of the tracer in the abluminal and luminal compartments and the volume (V) of the abluminal compartment $(0.5 \mathrm{ml})$ by the following equation:

$$
\text { Cleared volume }(\mu l)=\frac{C_{\text {abluminal }} \times V_{\text {abluminal }}}{C_{\text {luminal }}}
$$

The average cleared volume was plotted $v s$. time, and permeability $\times$ surface area product value for endothelial monolayer $\left(\mathrm{PS}_{e}\right)$ was calculated by the following formula:

$$
\frac{1}{P S_{\text {endothelial }}}=\frac{1}{P S_{\text {total }}}-\frac{1}{P S_{\text {insert }}}
$$

$\mathrm{PS}_{e}$ divided by the surface area $\left(1 \mathrm{~cm}^{2}\right.$ for Transwell12) generated the endothelial permability coefficient $\left(\mathrm{P}_{e} ;\right.$ in $\left.10^{-3} \mathrm{~cm} / \mathrm{min}\right)$.

\section{Immunohistochemistry}

Brain endothelial cell monolayers cultured on fibronectin- and collagen-coated glass coverslips and treated with $\mathrm{A} \beta$ peptides and/or PPS were stained for ZO-1, occludin and claudin-5 junctional proteins. The cultures were washed in PBS and fixed with ethanol (95 vol.\%)-acetic acid (5 vol.\%) for $10 \mathrm{~min}$ at $-20^{\circ} \mathrm{C}$ (ZO-1), with ethanol for $30 \mathrm{~min}$ at $4^{\circ} \mathrm{C}$ (claudin-5) with $4 \%$ paraformaldehyde for $30 \mathrm{~min}$ at $4^{\circ} \mathrm{C}$ (occludin). Cells were blocked with $3 \%$ BSA and incubat- 
ed with primary antibodies anti-ZO-1 (Zymed, USA), anti-claudin-5 (Zymed, USA), anti-occludin (Zymed, USA), for $1 \mathrm{~h} 30 \mathrm{~min}$. Incubation with secondary antibody Cy3-labelled anti-rabbit IgG (Sigma, Hungary) lasted for $1 \mathrm{~h}$. Between incubations cells were washed three times with PBS. Coverslips were mounted in Gel Mount (Biomeda, USA) and staining was examined by a NikonEclipse TE2000 fluorescent microscope (Nikon, Japan) and photographed by a Spot RT digital camera (Diagnostic Instruments, USA).

\section{Preparation of laser-grated surfaces and atomic force microscopy}

Master grating based two-beam interference (TBI) arrangement was applied to generate sub-micrometer periodic intensity modulation in the beam irradiating the samples [32]. The fourth harmonic of a Nd:YAG laser $(\mathrm{lFH}=266 \mathrm{~nm}, t=10 \mathrm{~ns}, f=10 \mathrm{~Hz})$ impinged on a diffraction grating (PUV 1200, Spectrogon), and the first order diffracted beams were recombined at the sample plane, after propagation trough a fused silica block. The samples were NBK7 substrates evaporated by gold - silver bimetallic layers, and spin-coated by polycarbonate. Samples were treated by s-polarized beams, to produce linear gratings as described earlier [32]. The laser treated surfaces were investigated by atomic force microscopy (AFM) operating in digital pulsed force mode (DPFM, Witec GmbH, Germany). The advantage of this scanning mode is the possibility to map the micromechanical properties of the surface with high resolution. We applied standard PFM tips (NSC 18/NoA1, $2.5 \mathrm{~N} / \mathrm{m}$ ) and collected pictures about the topography and adhesion. The purpose of these measurements was to compare the adhesion distribution on structures produced by different laser-treatment methods.

To examine biomolecules the samples with lasergrated surfaces were completely immersed in fresh PBS solutions containing $\mathrm{A} \beta_{1-42}$ peptide at a concentration of $10 \mu \mathrm{g} / \mathrm{ml}(2.2 \mu \mathrm{M})$, with or without PPS at a concentration of $100 \mu \mathrm{g} / \mathrm{ml}$. This dose of $\mathrm{A} \beta_{1-42}$ was determined in a preliminary experiment to optimize the peptide amount for AFM measurement and particle counting. Incubation of the samples in the solutions lasted for $1 \mathrm{~h}$ at $37^{\circ} \mathrm{C}$, then all samples were washed three times in sterile distilled water on a horizontal shaker and finally allowed to dry overnight at room temperature. A PSIA AFM operating in tapping-mode was applied to detect the attached biomolecules using NTMDT tips (NSG11, 5.5 N/m, $150 \mathrm{kHz}$ ). The AFM pic- tures were analyzed by Spot Advance software (Diagnostic Instruments Inc., Sterling Heights, MI, USA) to obtain the number and size of the attached biomolecule particles on the laser-grated surface of the samples. Particles were counted on 25 fields of $1 \mu \mathrm{m}^{2}$ size from 3 different samples from each treatment groups from 2 separate experiments.

\section{Statistical analysis}

All data presented in Results section are means \pm S.E.M. The values were compared using the analysis of variance followed by Dunnett, Bonferroni or NewmanKeuls posthoc tests using GraphPad Prism 5.0 software. Changes were considered statistically significant at $p<0.05$. All experiments were repeated at least three times, the number of parallel wells or inserts for each treatment and time point varied between 3 and 8 .

\section{RESULTS}

The effect of A $\beta$ peptide fragments on the morphology of rat brain endothelial cells

In physiological solutions the $\mathrm{A} \beta_{1-42}$ peptide can easily aggregate into oligomers, protofibrils and fibrils. The size distribution of the aggregates is highly dependent on the experimental conditions. In our experiments the amyloid peptides were applied in oligomeric form, as it is represented in Fig. 1. Under the circumstances we applied, A $\beta_{1-42}$ formed globular specii (5$7 \mathrm{~nm}$ ), which were arranged occassionally into annular or beaded chain-like assemblies with a maximum size of 15-20 nm. In the course of $\mathrm{A} \beta_{1-42}$ treatment, the oligomers were diluted directly to the cell culture medium to the required concentration. In the solution phase, these oligomers are assumed to remain stable for an elongated time, as their molecular environment is very similar to that of the so-called 'Amyloid Derived Diffusible Ligands' (ADDLs), which possessed the same structural characteristics, i.e., globular oligomers in cell culture medium and kept their stability in the course of the biological experiments [33]. In-depth examination of the ADDL population revealed, that it contains fairly stable subpopulations of amyloid oligomers of different size [34]. Therefore, upon application of such preparations, one has to consider that the observed effect was exerted by a heterogeneous oligomeric population.

Furthermore, the amyloid aggregates can be accumulated on the membrane surfaces, as it was observed 

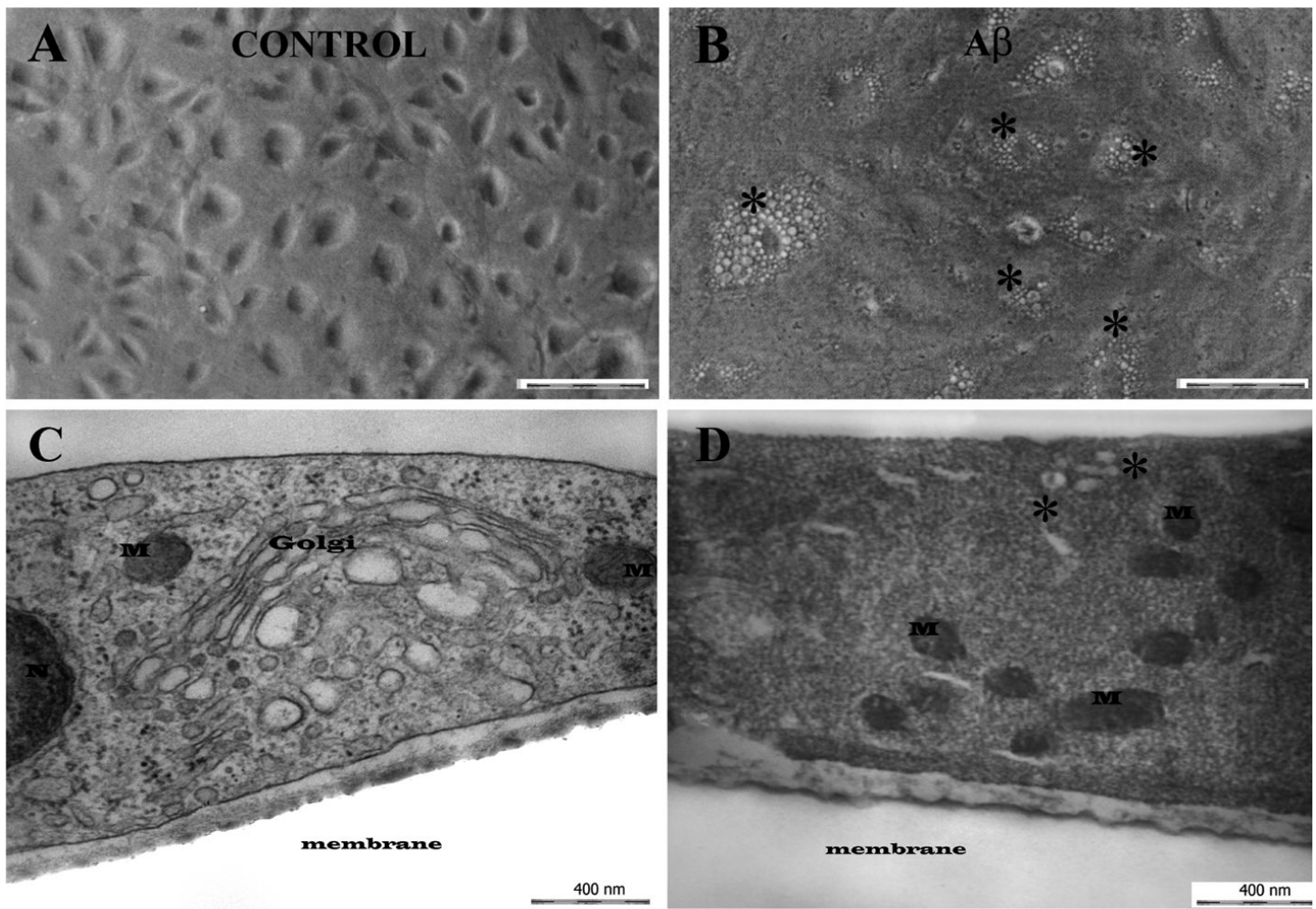

Fig. 2. The effect of $\mathrm{A} \beta$ peptide fragments on the morphology of rat brain endothelial cells. Phase contrast (A-B) and transmission electron microscopy (C-D) images of brain endothelial cells grown on the filter membrane of Transwell inserts. Typical details of control (A,C) and A $\beta$ 1-42 peptide treated (B,D) endothelial cells. Bar for phase contrast microscopy (A-B): $100 \mu \mathrm{m}$; Bar for electron microscopy (C-D): $400 \mathrm{~nm}$. Asterisks show cytoplasmic vacuoles. N: nucleus, M: mitochondria.

in our experiments as well. Large assemblies of the oligomers were found to adhere to the surface of the endothelial cells from the culture medium therefore the shape of cells could hardly be seen in light microscopy (Fig. 2B). A remarkable vacualisation could be observed around the nucleus in the cell cytoplasm induced by the peptide treatment (Fig. 2B). In the cytoplasm of control cells every cell organelle is bordered by clearly visibly membrane (Fig. 2C). In control cells well-developed Golgi, mitochondria, a small part of the nucleus, and small dots of ribosomes are visible (Fig. 2C), while the cytoplasm of the $\mathrm{A} \beta$-treated endothelial cell is more dense than the control one and several mitochondria can be seen (Fig. 2D). The structure of mitochondria in $\mathrm{A} \beta$ peptide-treated cells shows less space between the outer and inner membranes but there is some separation from the cytoplasm. In $\mathrm{A} \beta_{1-42^{-}}$ treated cells less, if any, well preserved Golgi, more vacuoles and organelles unidentifiable by morphology were found compared with the control ones.

In control conditions endothelial cells show smooth oval nuclei with uneven distribution of chromatin sub- stance and several caveolae and caveolae-like invaginations on the luminal side (Fig. 3A). Ribosomes are clearly visible. The shape of nuclei of the $\mathrm{A} \beta_{1-42}$ peptide-treated endothelial cells are less regular, the chromatin substance is more uniform. No caveolaelike invaginations but vacuoles can be observed. The cytoplasm is dense and ribosomes are indistinguishable (Fig. 3C). In untreated cells elaborate intercellular junctions could be seen. A long overlapping part of two endothelial cell processes is shown on Fig. 4A, "kissing points" are indicated by arrows. The dense material at the kissing points demonstrates tight intercellular junctions. In contrast, the connection between two $\mathrm{A} \beta_{1-42}$-treated endothelial cells (Fig. 4C) is not tight, the processes do not lie on each other but one process is circled by the other one. Pale kissing points (arrows) can be observed. The process on the left hand side is full with vacuoles. Although some regular tight junctions (TJs) can be found in the $\mathrm{A} \beta_{1-42}$-treated cells too, the irregular contacts, junctions with less kissing points were more typical. Vacuolisation of processes and cell bodies and decreased number of caveolae were 

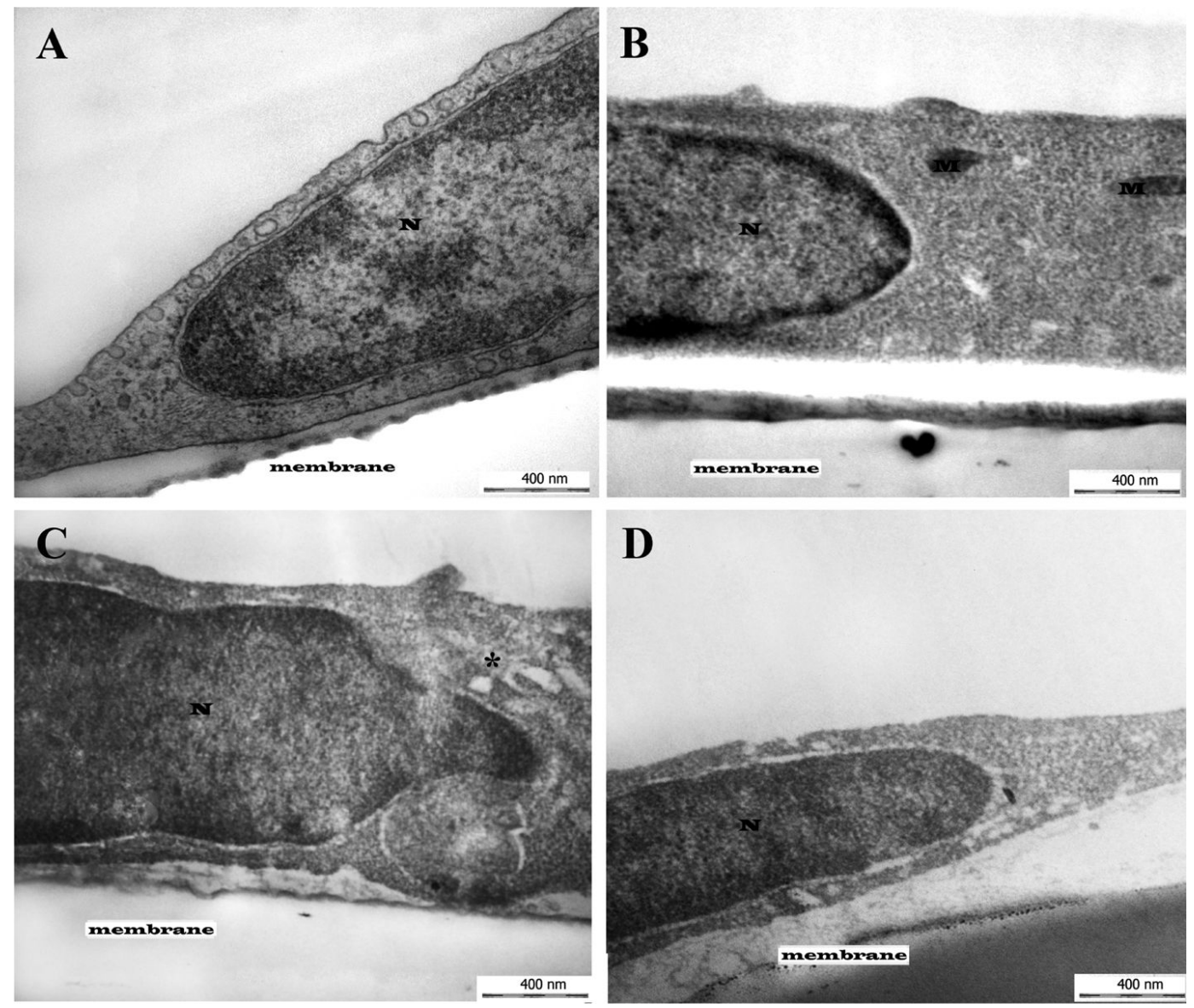

Fig. 3. The effect of $\mathrm{A} \beta$ peptide fragments on the morphology of rat brain endothelial cells by transmission electron microscopy. Brain endothelial cells were grown on filter membranes of Transwell inserts. Typical details of control (A), pentosan (B), A $\beta_{1-42}$ peptide (C), A $\beta_{1-42}$ and pentosan (D) treated endothelial cells. Bar for electron microscopy: $400 \mathrm{~nm}$. Asterisks show cytoplasmic vacuoles. N: nucleus, M: mitochondria.

common (shown by asterisks on Figs 2-4). PPS treatment did not change the morphology of brain endothelial cells as compared to control (Figs 3B and 4B) and could ameliorate the ultrastructural changes induced by $\mathrm{A} \beta_{1-42}$ (Figs 3D and 4D).

\section{The effect of $A \beta$ peptide fragments on rat brain endothelial cells: toxicity assays}

The direct effect of $\mathrm{A} \beta$ peptid fragments on brain endothelial cell viability was examined in two toxicity assays. The yellow MTT dye was efficiently converted to purple formazan crystals by non-treated and scrambled peptide treated endothelial cells as demonstrated by the high absorbance values (Fig. 5A). A $\beta_{1-42}$ peptide-treatment in concentrations higher than $10 \mu \mathrm{M}$ for $48 \mathrm{~h}$ significantly decreased the MTT reduction. A similar effect was seen for $\mathrm{A} \beta_{1-40}$ peptide at $50 \mu \mathrm{M}$ dose. In the LDH release assay the $100 \mu \mathrm{M}$ and 200 $\mu \mathrm{M}$ concentrations of $\mathrm{A} \beta_{1-42}$ peptide produced significant enzyme leakage from the brain endothelial cells indicating membrane damage (Fig. 5B). The calculated cytotoxicity based on $\mathrm{LDH}$ release was $9.2 \%$ at $100 \mu \mathrm{M}$ and $19.5 \%$ at $200 \mu \mathrm{M} \mathrm{A} \beta_{1-42}$ peptide concentrations. Lower doses of $\mathrm{A} \beta_{1-40}$ and $\mathrm{A} \beta_{1-42}$ peptides did not exert toxic effect on brain endothelial cells in this test.

Modulating effect of SAP on A $\beta_{1-42}$ peptide-induced changes in endothelial barrier integrity

In preliminary functional studies $25 \mu \mathrm{M} \mathrm{A} \beta_{1-42}$ was found to be optimal to reproducibly induce damage to BBB integrity and to examine protective effects. The selected $25 \mu \mathrm{M}$ dose of $\mathrm{A} \beta$ for the permeability experiments is in good agreement with the treatment doses of $\mathrm{A} \beta$ for brain endothelial cells in the literature [15, $16,35,36]$. 

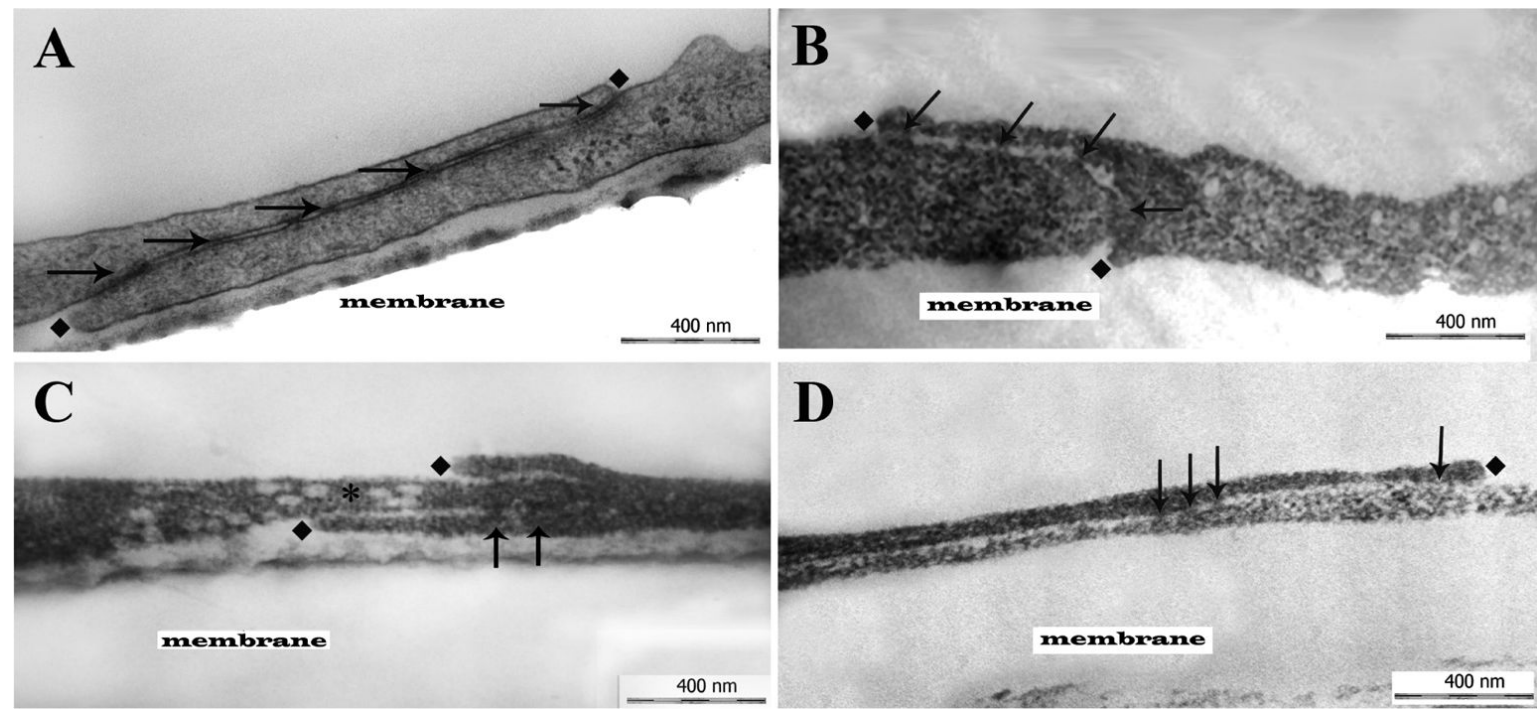

Fig. 4. The effect of $\mathrm{A} \beta$ peptide fragments on the morphology of intercellular junctions of rat brain endothelial cells by transmission electron microscopy. Brain endothelial cells were grown on filter membranes of Transwell inserts. Typical details of control (A), pentosan (B), A $\beta_{1-42}$ peptide (C), $\mathrm{A} \beta_{1-42}$ and pentosan (D) treated endothelial cells. Bar for electron microscopy: $400 \mathrm{~nm}$. The squares indicate the starting and the ending point, arrows the kissing points of the interendothelial junctions. Asterisks show cytoplasmic vacuoles.
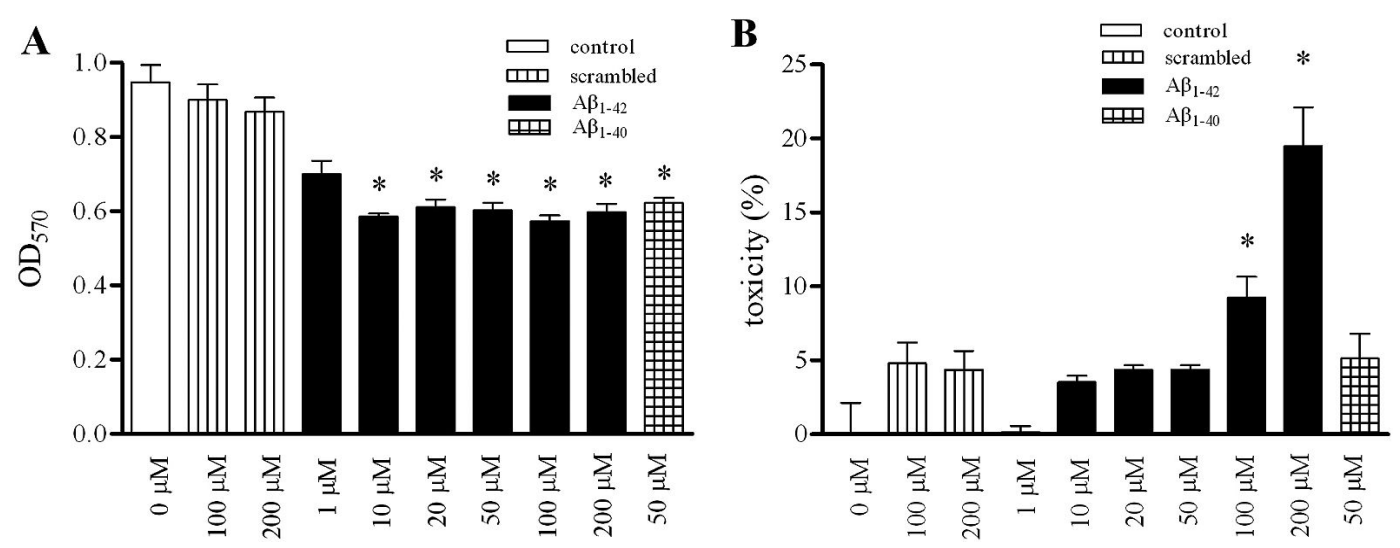

Fig. 5. The effect of $\mathrm{A} \beta$ peptide fragments on rat brain endothelial cells after $48 \mathrm{~h}$ treatment in MTT reduction assay (A) and LDH release assay (B). All values presented are means \pm S.E.M., $n=8, p<0.05$.

Treatment of monolayers with $\mathrm{A} \beta_{1-42}$ reduced the TEER significantly after $24 \mathrm{~h}$ and the values further decreased at the $48 \mathrm{~h}$ timepoint (Fig. 6A). In A $\beta_{1-42}$ peptide treated monolayers the flux of fluorescein increased as compared to the control (Fig. 6B). The $\mathrm{P}_{e}$ values for permeability marker albumin were lower with one order of magnitude than the values for fluorescein, a paracellular marker, in agreement with literature data $[18,37]$ and our previous results [24,31]. The permeability for albumin was also significantly elevated in monolayers treated with $\mathrm{A} \beta_{1-42}$ (Fig. 6C).

When $\mathrm{A} \beta_{1-42}$ was co-administered with physiological concentration of SAP ( $40 \mu \mathrm{g} / \mathrm{ml})$ significantly re- duced TEER values were measured at $24 \mathrm{~h}$ and $48 \mathrm{~h}$ timepoints as compared to control or $\mathrm{A} \beta_{1-42}$ peptidetreated monolayers (Fig. 6A). The $\mathrm{A} \beta_{1-42}$ peptideinduced elevations in both fluorescein (Fig. 6B) and albumin (Fig. 6C) permeability were siginificantly further increased by the presence of SAP. SAP treatment alone had no effect on the resistance or permeability of the endothelial monolayers (Fig. 6).

The effect of PPS on $A \beta_{1-42}$ peptide-induced changes in rat brain endothelial cell morphology and function

In the viability assays pentosan could only slightly inhibit the $\mathrm{A} \beta_{1-42}$ peptide-induced decrease in MTT 

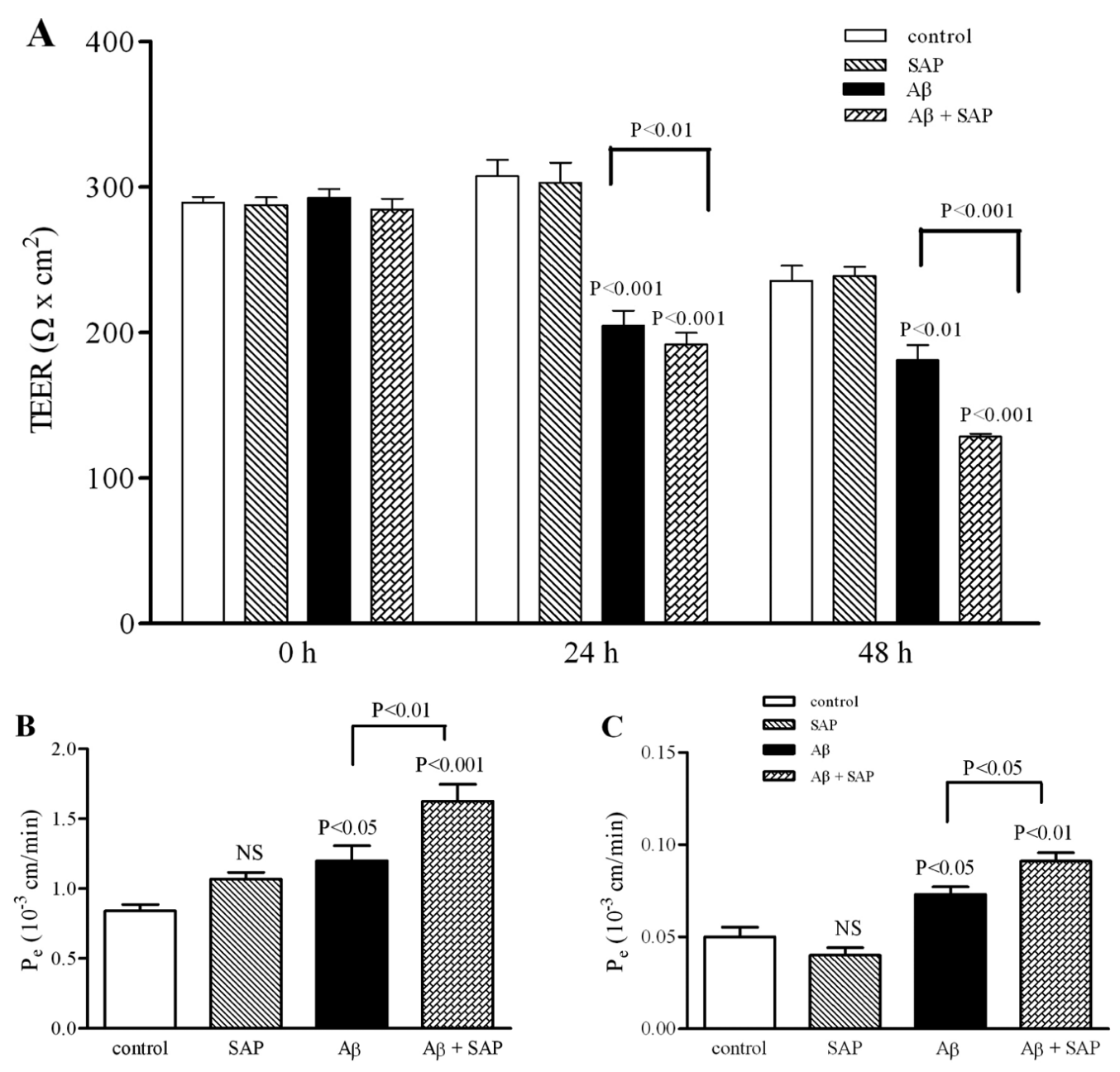

Fig. 6. Changes in transendothelial electrical resistance (TEER) (A), and in transendothelial permeability $\left(\mathrm{P}_{e}\right)$ for permeability markers sodium fluorescein (B) and Evans blue labelled albumin (C) in rat brain endothelial cell monolayers treated with $\mathrm{A} \beta_{1-42}$ peptide $(25 \mu \mathrm{M})$ and serum amyloid P component (SAP, $40 \mu \mathrm{g} / \mathrm{ml}$ ). All values presented are means \pm S.E.M., $n=8, p<0.05$.

reduction at the highest, $100 \mu \mathrm{g} / \mathrm{ml}$ dose (Fig. 7A). Lower concentrations of PPS $(0.1-10 \mu \mathrm{g} / \mathrm{ml})$ had no effect. Pentosan alone did not change MTT reduction in the cells not even at high concentrations. PPS at 100 $\mu \mathrm{g} / \mathrm{ml}$ dose could effectively block the LDH release after amyloid exposure (Fig. 7B).

The same dose of PPS effective in the toxicity assays had protective effect against the $\mathrm{A} \beta_{1-42}$ peptideinduced TEER decrease in brain endothelial cells at $24 \mathrm{~h}$ and $48 \mathrm{~h}$ timepoints (Fig. 8A). Pentosan alone had no significant effect on barrier integrity. The $\mathrm{A} \beta_{1-42}$ treatment-induced increases in the BBB permeability for markers (Figs 8B and 8C) were significantly decreased by PPS, however PPS alone did not change the permeability of monolayers.
Effect of $A \beta_{1-42}$ peptide on immunostaining for junctional proteins in rat brain endothelial cells

To further investigate the effect of $\mathrm{A} \beta_{1-42}$ on the morphology of interendothelial junctions of the brain endothelial cells immunostainings for junctional proteins were also performed. In control monolayers ZO1 , occludin and claudin-5 staining localized to the cell border and the tightly apposed, elongated endothelial cells were well delineated (Fig. 9). The pattern of the staining has been dramatically changed in $\mathrm{A} \beta_{1-42^{-}}$ treated $(25 \mu \mathrm{M}, 48 \mathrm{~h})$ cells. Treatment with $\mathrm{A} \beta$ peptide resulted in decreased immunostaining intensity, fragmentation or loss of the continuous cortical staining pattern, and appearance of intercellular gaps in rat brain endothelial cells (shown by arrows on Fig. 9). 

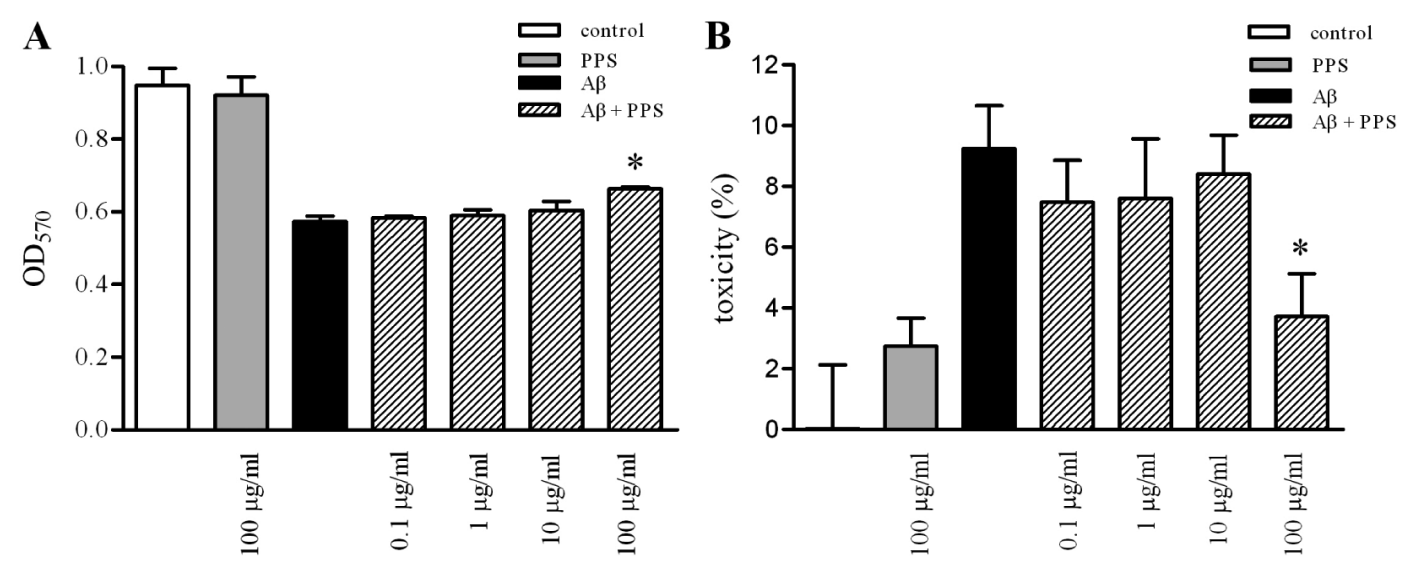

Fig. 7. The effect of PPS on rat brain endothelial cells induced toxicity of $\mathrm{A} \beta_{1-42}$ peptide in MTT reduction assay (A) and LDH release assay (B). All values presented are means \pm S.E.M., $n=8, p<0.05$.

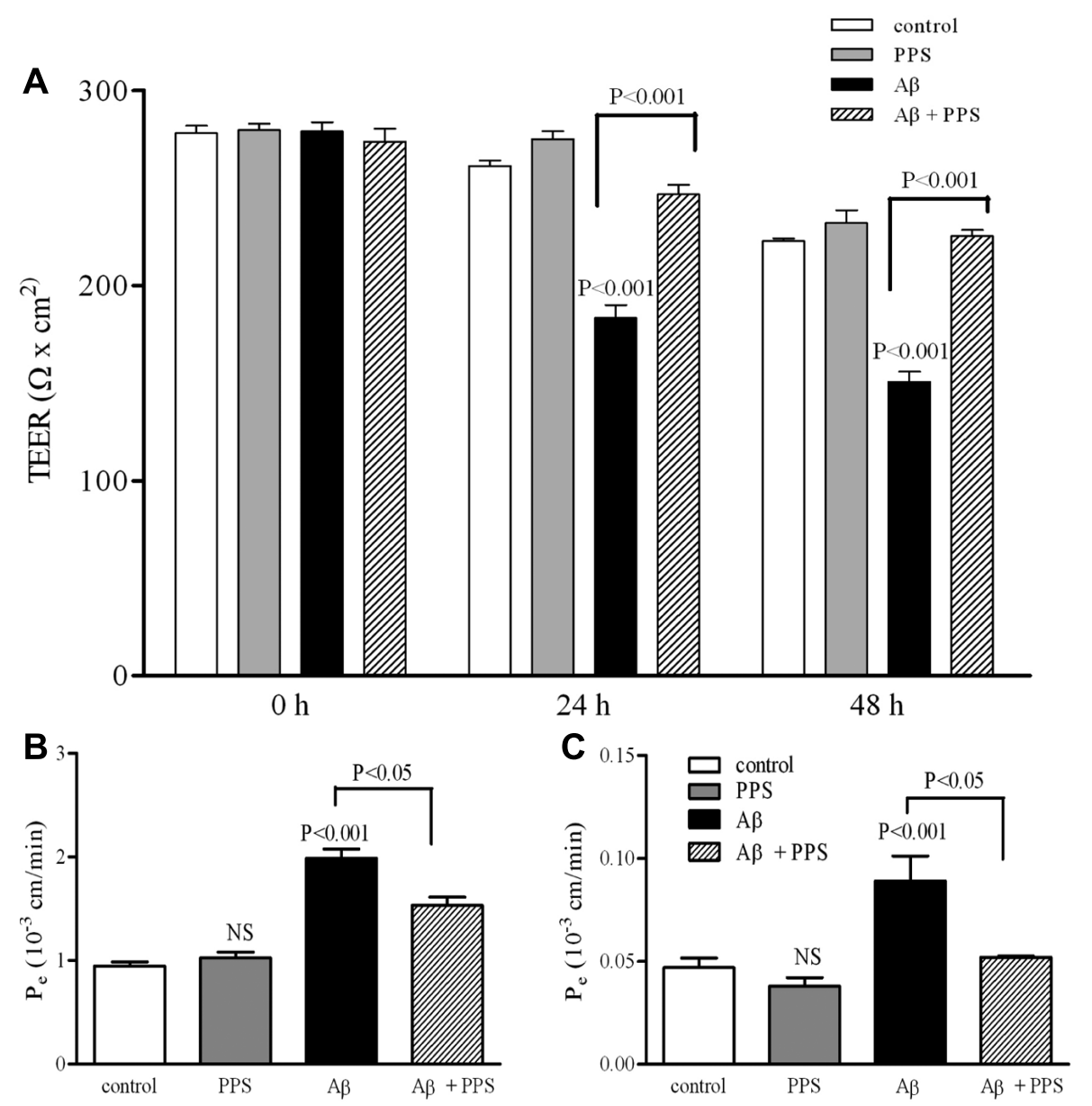

Fig. 8. Changes in transendothelial eletrical resistance (TEER) (A), and in transendothelial permeability $\left(\mathrm{P}_{e}\right)$ for permeability markers sodium fluorescein (B) and Evans blue labelled albumin (C) in rat brain endothelial cell monolayers treated with $\mathrm{A} \beta_{1-42}$ peptide $(25 \mu \mathrm{M})$ and pentosan polysulfate (PPS, $100 \mu \mathrm{g} / \mathrm{ml}$ ) for 24 or $48 \mathrm{~h}$. All values presented are means \pm S.E.M., $n=4, p<0.05$. 


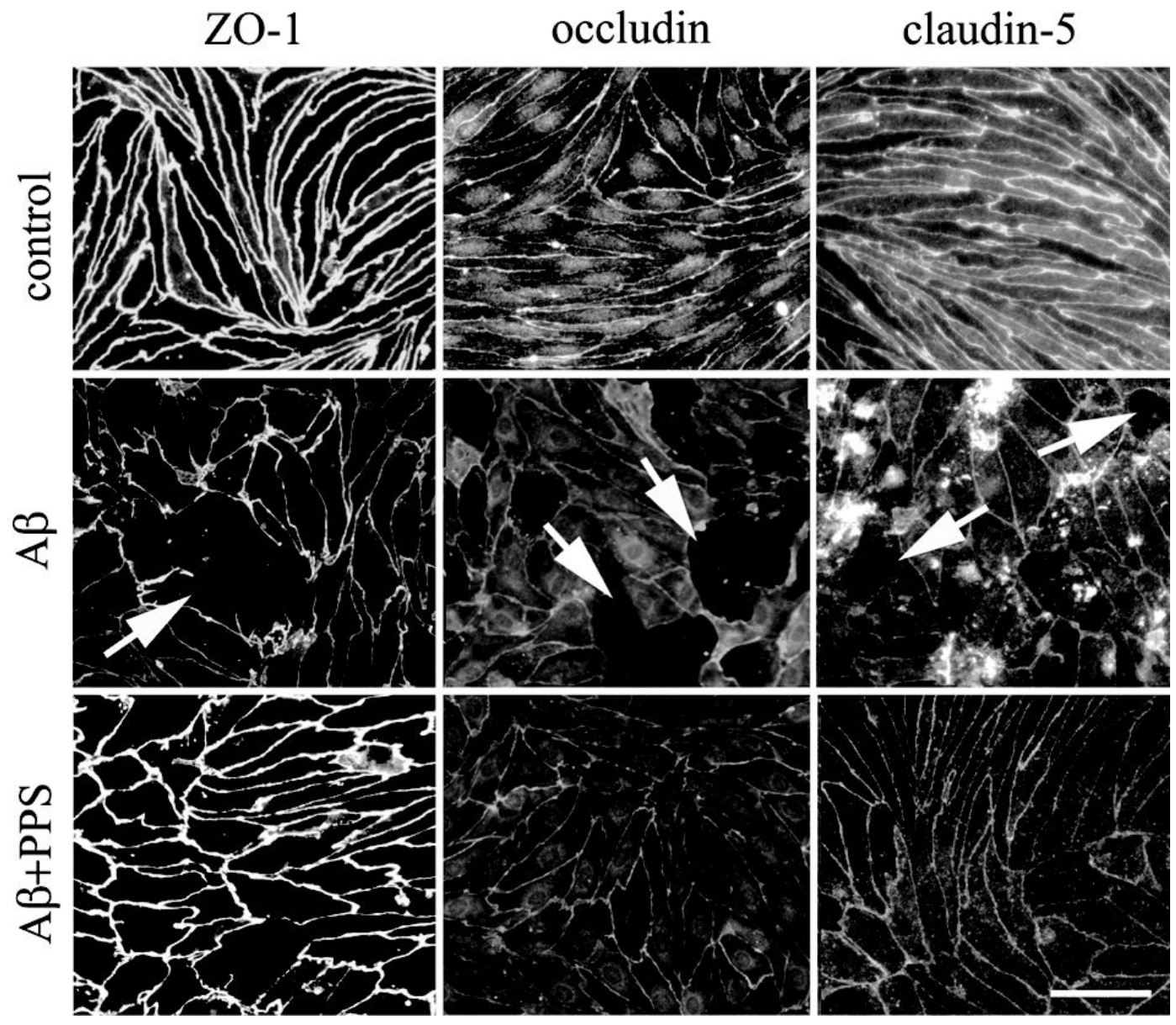

Fig. 9. Effect of $\mathrm{A} \beta_{1-42}$ peptide ( $\left.25 \mu \mathrm{M}\right)$ and pentosan polysulfate (PPS, $100 \mu \mathrm{g} / \mathrm{ml}$ ) for $48 \mathrm{~h}$ on immunostaining for junctional proteins ZO-1, occludin, and claudin-5 in rat brain endothelial cells. Arrows show holes formed between endothelial cells, fragmentation or loss of junctional immunostaining. Bar: $25 \mu \mathrm{m}$.

Co-administration of PPS inhibited these changes, the monolayer integrity was better preserved and the immunostaining pattern resembled to the control ones. The visualization of $\mathrm{A} \beta_{1-42}$ peptide aggregates attached to the cells as cloudy patches by the anti-claudin5 antibody (Fig. 9) is most probably due to non-specific binding of the antibody to the aggregates.

\section{Atomic force microscopy measurement}

To investigate the interaction between $\mathrm{A} \beta_{1-42}$ peptide and pentosan, the biomolecules were attached to linear-grated laser-sculpted surfaces and examined by tapping-mode AFM to reveal the topography (not shown) and adhesion (Fig. 10A). The AFM pictures of the samples demonstrate that $\mathrm{A} \beta_{1-42}$ peptide aggregates attached to the surface quite evenly, with a high density and had an average diameter less than
$33 \mathrm{~nm}\left(100.30 \pm 6.59\right.$ particles $/ \mu \mathrm{m}^{2}$ for aggregates with largest diameter below $33 \mathrm{~nm}$, and $17.44 \pm 1.02$ particles $/ \mu \mathrm{m}^{2}$ for aggregates with largest diameter between 33 and $66 \mathrm{~nm}$; Fig. 10B). PPS molecules gave a small number of very characteristical large, oval aggregates on the samples with a largest diameter of 200-320 nm and attached to the "hills" of the gratings (Fig. 10A). The majority of PPS particles was in the size range of 260-290 nm. There was no overlap between the size distribution of PPS as compared to $\mathrm{A} \beta$ particles from $\mathrm{A} \beta$ or $\mathrm{A} \beta+\mathrm{PPS}$ treatment groups. The AFM investigation has shown that the number of the $\mathrm{A} \beta_{1-42}$ aggregates in the presence of PPS was significantly reduced and the size of attached peptide aggregates became larger ( 0 particle $/ \mu \mathrm{m}^{2}$ for aggregates below 33 $\mathrm{nm} ; 1.42 \pm 0.44$ particles $/ \mu \mathrm{m}^{2}$ for $33-66 \mathrm{~nm}$ aggregates; Fig. 10B). The size of the highest number of attached particles was below $33 \mathrm{~nm}$ for $\mathrm{A} \beta_{1-42}$ treatment 
A
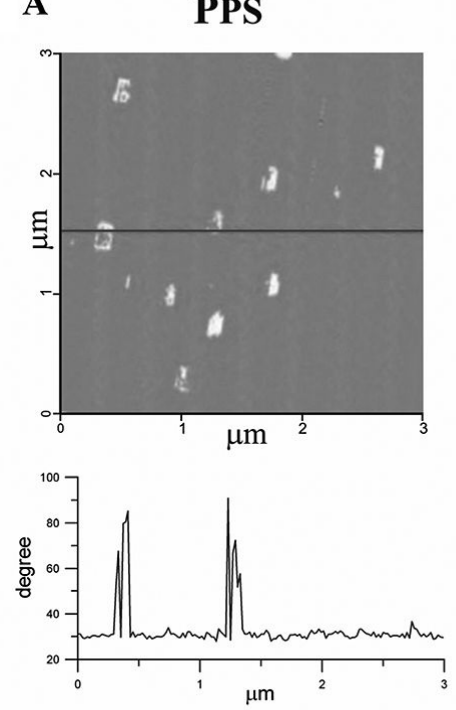

B

B
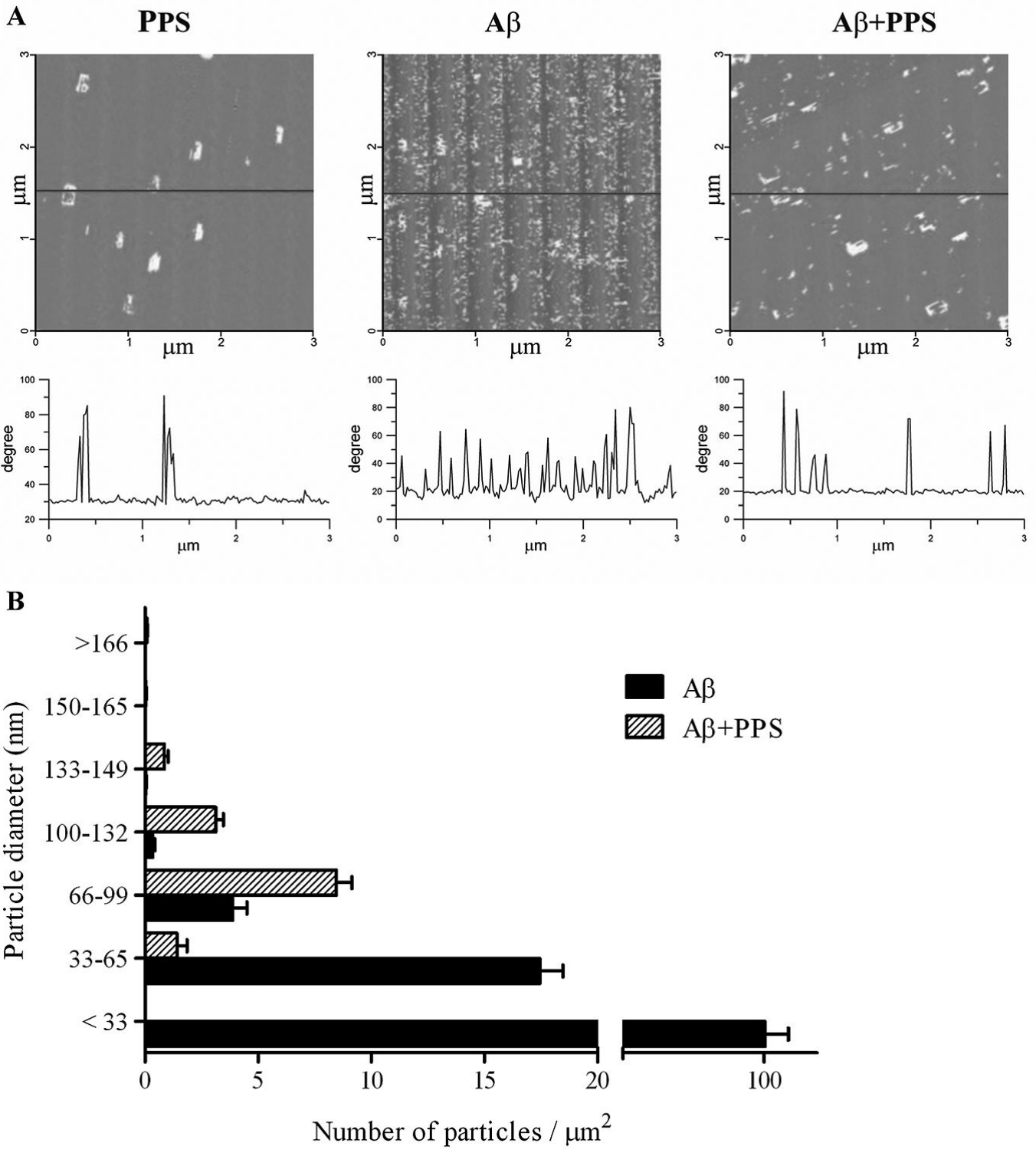

Fig. 10. Atomic force microscopy pictures about the phase of biomolecule aggregates attached to laser-grated polycarbonate surfaces (A). AFM pictures show attachment of pentosan (PPS), amyloid $\beta_{1-42}$ peptide $\left(\mathrm{A} \beta_{1-42}\right)$, and both $\mathrm{A} \beta_{1-42}$ peptide and PPS to the linearly grated surfaces. Concentration of the incubation solutions were $10 \mu \mathrm{g} / \mathrm{ml}$ for $\mathrm{A} \beta_{1-42}$ peptide and $100 \mu \mathrm{g} / \mathrm{ml}$ for PPS. Analysis of the size (largest diameter) and density of the $\mathrm{A} \beta_{1-42}$ peptide aggregates (B) on laser grated surfaces in the absence and presence of pentosan (100 $\left.\mu \mathrm{g} / \mathrm{ml}\right) \mathrm{measured}$ by atomic force microscopy (mean \pm S.E.M., two-way ANOVA followed by Bonferroni test, significant $p<0.001$ differences were found between the two groups).

and 66-99 $\mathrm{nm}$ for $\mathrm{A} \beta_{1-42}$ and PPS treatments $(8.46 \pm$ 0.69 particles $/ \mu \mathrm{m}^{2}$ ).

Grating coupled surface plasmon resonance investigation was performed on biomolecule-covered polymer-bimetal interfacial gratings in a separate experiment [32]. The forward shift of the secondary resonance minima detected on samples treated by $\mathrm{A} \beta_{1-42}$ and PPS was smaller than the shift measured after pure
$\mathrm{A} \beta_{1-42}$ attachment. Since the resonance minima shifts are proportional to changes in dielectric layer thickness, the smaller shift indicates that the PPS therapeutic molecules prevent the adherence of large amount of $\mathrm{A} \beta_{1-42}$ to the examined surfaces. The analyses of the results have shown that in presence of PPS the average thickness of the adhered biomolecule layer is reduced from $4.5 \mathrm{~nm}$ to $3.8 \mathrm{~nm}$. The difference between 
the layer thickness enhancements is significantly larger than the change caused when PPS was applied solely $(-0.2 \mathrm{~nm})$. Both AFM and plasmon resonance experiments prove that PPS can directly interact with $\mathrm{A} \beta_{1-42}$ resulting in decreased adherence.

\section{DISCUSSION}

\section{Changes in blood-brain barrier function and morphology in $A D$}

Recent clinical data indicate that vascular changes play an important role early in AD pathogenesis. Cerebral blood flow (CBF) and cerebral glucose uptake reductions were demonstrated in the early stages of $\mathrm{AD}$ and both low CBF and reduced brain glucose uptake may precede neurodegeneration and contribute to the progression of dementia prior to cerebral atrophy [7]. Positive links and overlap exist between cerebrovascular disorders and AD. Severe atherosclerosis increases threefold the risk of developing AD or vascular dementia [38].

Pathological $\mathrm{A} \beta$ fibrils are deposited both in brain parenchyma and around brain vessels in $\mathrm{AD}[2,4]$. The cerebrovascular amyloidosis or cerebral amyloid angiopathy is a hallmark of the disease, it is present in more than $80 \%$ of AD patients, and is causally involved in the development of neurodegeneration in $\mathrm{AD}[2$, 7]. Accumulation of $\mathrm{A} \beta$ in the wall of cerebral blood vessels and in the brain parenchyma in $A D$ is due to imbalances between its production and clearance from the brain [4]. Several transporters were identified to participate in the transport of $\mathrm{A} \beta$ across the $\mathrm{BBB}$, including receptor for advanced glycation end products (RAGE) [39,40], low-density lipoprotein receptor related protein 1 [41,42] and 2 [43], P-glycoprotein [44], and breast cancer resistance protein (BCRP) [5].

Morphological abnormalities in the cerebral microvasculature in AD include atrophy and irregularities of arterioles and capillaries, swelling and increased number of pinocytic vesicles in endothelial cells, increase in collagen IV, heparan sulfate proteoglycans and laminin deposition in the basement membrane, disruption of the basement membrane, reduced total microvascular density and occasional swelling of astrocytic end feets [7]. An extensive degeneration of brain microvascular endothelium was also demonstrated during the disease progression in $\mathrm{AD}$ [45].

The morphological changes are accompanied by functional alterations, microvascular segments directly surrounded by amyloid plaques or representing cerebral amyloid angiopathy show increased permeability to endogenous albumin [46]. The degree of AD can influence these changes: in mild dementia the integrity of the BBB can be well preserved, while it is disturbed in a graded manner according to the progression of dementia [47]. When $\mathrm{A} \beta_{1-42}$ is directly infused into the carotid artery, it increased permeability to albumin in rats [13]. Using the AD model Tg2576 mice a higher BBB permeability for albumin was measured in cerebral cortex, which preceded senile plaque formation [14]. Even if extensive BBB damage or substantial increases in $\mathrm{BBB}$ permeability in $\mathrm{AD}$ can not be found in some animal studies [48] or clinical evaluations [49], considering all available data focal and transient loss of integrity of the BBB in AD seems probable [50].

\section{Studies with A $\beta$ on culture-based BBB models}

BBB changes in AD were confirmed by experimental data showing the effects of $\mathrm{A} \beta$ on cultured endothelial cells. $\mathrm{A} \beta$ peptides inhibited the proliferation of brain endothelial cells [2]. In addition, $\mathrm{A} \beta$ peptides exerted toxic effects on both peripheral and cerebral microvessel endothelial cells. $\mathrm{A} \beta_{1-40}$ and $\mathrm{A} \beta_{25-35}$ peptide treatments resulted in apoptosis in cultured pulmonary endothelial cells, and elevated the monolayers' albumin permeability [15]. A similar toxicity was described in RBE4 rat brain endothelial cell line [16]. $\mathrm{A} \beta_{1-40}$ and $\mathrm{A} \beta_{1-42}$ peptides derived from rat and human amyloid, alone or complexed with aluminum, decreased cell viability in rat brain endothelial cells between passage 3-4 [17,51]. Aggregates of $\mathrm{A} \beta_{1-40}$, and its mutation $\mathrm{A} \beta_{1-40} \mathrm{E} 22 \mathrm{Q}$ (Dutch), as well as of $\mathrm{A} \beta_{1-42}$ and $\mathrm{A} \beta_{25-35}$ were toxic to cultured human cerebrovascular endothelial cells obtained from the brain of a victim of $\mathrm{AD}$ [52]. The toxic effect of the Dutch $\mathrm{A} \beta$ peptides on BBB is further supported by an in vivo study showing that these mutant peptides are not cleared from CSF [53]. The Akt [54], and protein kinase C [55] signalling pathways, the RAGE [56] and the activation of caspase-8 [57] can participate in the decrease of cell viability and apoptotic cascade induced by $\mathrm{A} \beta$ in endothelial cells.

In our study, $\mathrm{A} \beta_{1-42}$ peptide induced remarkable ultrastructural alterations in primary rat brain endothelial cells, which have not been described in the literature earlier. In agreement with amyloid-induced changes in brain microvessel morphology in pathological samples and animal studies [7,45] degeneration of the cells, namely, dark cytoplasm, pronounced vacuolization, de- 
creased number of caveolae and Golgi, and shrunken mitochondria could be observed after peptide treatment. Irregular interendothelial contacts and junctions with less kissing points were especially notable, indicating an increased paracellular pathway. Cytoplasmic vacuolization could be seen by both electron and phase contrast microscopy. These toxic effects were also confirmed by reduced MTT dye reduction, and increased LDH release indicating plasma membrane damage. In the $\mathrm{A} \beta$ dose-range used in our experiments (10-200 $\mu \mathrm{M})$ endothelial cell death did not exceed $20 \%$. Both $\mathrm{A} \beta_{1-40}$ and $\mathrm{A} \beta_{1-42}$ peptides exerted a similar toxic effect to primary rat brain endothelial cells.

$\mathrm{A} \beta$-induced permeability changes have been studied only for $\mathrm{A} \beta_{1-40}$ and only in not co-cultured brain endothelial cells so far and no data have been published on pertinent co-culture in vitro $\mathrm{BBB}$ model yet. $\mathrm{A} \beta_{1-40}$ at doses exceeding $5 \mu \mathrm{M}$ increased the paracellular permeability in bovine brain endothelial cells [19]. It also induced a marked elevation in the permeability for the paracellular tracer $70 \mathrm{kDa}$ FITC-dextran in an immortalized human brain endothelial cell line, hCMEC/D3 cells [58] and for the transcellular marker albumin in human brain microvascular endothelial monolayers between passages 4-8 [20].

We have studied the effect of $A \beta$ on several aspects of the barrier function in BBB model of rat primary brain endothelial cells, in which barrier properties were induced by glial cells. $\mathrm{A} \beta_{1-42}$ decreased the resistance and increased the permeability for markers fluorescein and albumin. The modulating effect of SAP on $\mathrm{A} \beta$ in a $\mathrm{BBB}$ model was also demonstrated for the first time. SAP, a serum protein belonging to the pentraxin protein family, participates in the regulation of chromatin-induced autoimmunity and the immune defense against bacterial infections due to its ability to bind chromatin and bacterial lipopolysaccharides [59]. SAP treatment alone did not change brain endothelial paracellular permeability or morphology. In a previous in vivo study, when mice were injected with human SAP no deleterious effect on paracellular permeability was noticed [60]. Based on these observations, SAP in physiological concentrations has no effect on brain endothelial TJs. SAP avidly binds amyloid fibrils and can be found in all types of amyloid depositions either in the periphery or in the CNS [61]. While SAP is absent from the brain tissue in physiological conditions, it is present in amyloid plaques and depositions around brain vessels in $\mathrm{AD}$ and contributes to the stabilization of A $\beta$ fibrils [62]. In our experiments, SAP significantly increased the damaging effect of $\mathrm{A} \beta$ on barrier integrity of brain endothelial cells.
Since the paracellular barrier at the BBB is regulated by TJ proteins $[5,8,63,64]$ immunostaining for TJ proteins was also investigated after $\mathrm{A} \beta$ treatment in brain endothelial cells. $\mathrm{A} \beta$ led to fragmentation and loss of junctional immunostaining for occludin, claudin-5 and ZO-1 in our model. These data are in agreement with previous observations, where $\mathrm{A} \beta_{1-42}$ altered occludin, claudin-5 and ZO-2 TJ protein distribution and expression [35], and $\mathrm{A} \beta_{1-40}$ resulted in relocalization of ZO-1 [20] in rat and human brain endothelial cells, respectively. Interestingly, a specific decrease of occludin but not of claudin-5 and ZO-1 was described in an immortalized human brain endothelial cell line [58].

Our data indicate that $\mathrm{A} \beta_{1-40}$ and $\mathrm{A} \beta_{1-42}$ peptides exerted a direct damaging effect on the morphology and barrier integrity of brain endothelial cells which could be aggravated by SAP. Using the same BBB model we have recently confirmed the effect of human truncated tau protein, another pathological factor in AD [65]. Truncated tau also impaired the barrier integrity, but this effect was indirect. Tau-induced BBB damage was mediated by pro-inflammatory cytokine tumor necrosis factor- $\alpha$ and chemokine monocyte chemotactic protein-1 released from activated microglial cells. These observations indicate that while both $\mathrm{A} \beta$ and truncated tau damage the $\mathrm{BBB}$, the underlying mechanisms may be different [65].

\section{Protection of BBB as a New Therapeutical Approach in $A D$}

$\mathrm{AD}$, the most common form of degenerative dementia, represents a huge unmet medical need. Although AD had already been described about 100 years ago, at present only few symptomatic treatment options exist for the more than 25 million patients worldwide despite continuous research efforts. Only two classes of medications have been approved by the US Food and Drug Administration for the treatment of AD: cholinesterase inhibitors for mild to moderate $\mathrm{AD}$, and the noncompetitive NMDA receptor antagonist memantine for the moderate to severe stages of AD [66].

$\mathrm{BBB}$ breakdown, due to disruption of the TJs, altered transport of molecules at the BBB, aberrant angiogenesis, vessel regression, brain hypoperfusion, and inflammatory responses initiate and contribute to a "vicious circle" of the disease process, resulting in progressive synaptic and neuronal dysfunction and loss in AD [5, 67]. This current understanding places the neurovascular unit at the epicenter of AD pathophysiology and recognizes brain endothelial cells as new therapeuti- 
cal targets in AD [5,6]. Since previous therapeutical attempts were focused on the prevention of neuronal death there are a great number of experimental data on the protection of neurons against the toxic effects of $\mathrm{A} \beta$ [68]. In contrast, only few studies examined protective molecules in brain endothelial cells. Partial protection against $\mathrm{A} \beta_{25-35}$ peptide-induced cell damage by carnosine, an endogenous antiglycating dipeptide with free radical scavenging activity, homocarnosine and $\beta$-alanine was described on a rat brain endothelial cell line [16]. Simvastatin effectively blocked the proinflammatory reactions induced by $\mathrm{A} \beta_{1-40}$ peptide in a human brain endothelial cell line [69]. Tauroursodeoxycholic acid, an antiapoptotic endogenous bile acid inhibited the apoptosis of human brain cerebral endothelial cells triggered by the vasculotropic $\mathrm{A} \beta_{1-40}$ E22Q mutant peptide [70]. While apolipoprotein-E4 increased, apolipoprotein-E2 decreased the cytotoxic effect of $\mathrm{A} \beta_{1-40}$ and $\mathrm{A} \beta_{1-42}$ pepides [71]. Recently, the JNK-AP1 signaling pathway [72], transcription factors mesenchyme homebox gene 2 (MEOX-2) [5, 72], and serum response factor and myocardin [73] have been identified as potential therapeutical targets in brain endothelial cells in AD.

PPS, a drug of plant origin used clinically for a long time, protected primary mouse cerebral endothelial cells against prion peptide toxicity $[3,22,23]$ and attenuated both the permeability barrier impairment and inhibition of P-glycoprotein in lipopolysaccharideexposed primary rat brain endothelial cells [24] in our previous experiments.

PPS is excessively sulphated, has a high negative charge density and a rod-like conformation; therefore it competes more effectively with endogenous glycosaminoglycans than most of the polyanions [74]. Since glycosaminoglycans are important regulators in many biologically diverse processes, PPS has a wide range of pharmacological effects $[74,75]$. It has long been used in clinical practice as an anticoagulant [75], and it is effective in the treatment of interstitial cystitis [76], and osteoarthritis [77]. Experimental and clinical data suggest that PPS may also have a therapeutic efficacy in prion disease [78]. Because PPS does not cross the BBB [79], endothelial cells of blood-nerve and blood-brain barriers may be among the cellular targets of PPS in the prevention of prion diseases in vivo $[22,23]$.

In our present and previous studies we demonstrated for the first time that PPS did not change BBB parameters TEER, permeability or fluid phase endocytosis or morphology in cultured brain endothelial cells [18,21,
23 ], but successfully attenuated the toxic effects of $\mathrm{A} \beta$. PPS also protected the barrier integrity of endothelial monolayers treated with $\mathrm{A} \beta$. The exact mode of action of PPS at the BBB has not been elucidated yet.

In other cell types PPS inhibits a wide range of enzymes and biological modulators, like protein kinase A, protein kinase $\mathrm{C}$, tyrosine protein kinase in smooth muscle cells [75], serine proteases, matrix metalloproteinases, lysosomal enzymes, coagulation factors, complement factors and cytokines in chondrocytes [74]. In peripheral endothelial cells PPS stimulates the release of tissue-type plasminogen activator, superoxide dismutase and lipase contributing to its efficacy in arthritis [74]. The inhibition of serine proteases, matrix metalloproteinases and cytokines or increased levels of superoxide dismutase could also contribute to the protection of the BBB; however other actions of PPS could also be important.

Our previous and present surface plasmon resonance and AFM data indicate for the first time that PPS can directly interact with $\mathrm{A} \beta$, and may have a physicochemical effect resulting in fewer adherences to the examined surfaces. This is in agreement with the only study that examined the effect of PPS on the binding of heparan sulfate glycosaminoglycans to A $\beta$ [25]. PPS was the most effective to displace heparan sulfate glycosaminoglycans bound to $\mathrm{A} \beta$. Since heparan sulfate glycosaminoglycans are involved in $\mathrm{A} \beta$ aggregation in vivo, sulfated polyanions, like PPS, can be useful against amyloid deposition in AD brain [25].

Pentosan may exert multiple effects; some of these could be cellular while others could be related to its direct interaction with $\mathrm{A} \beta$. The present results support this dual mode of action and the endothelial protective properties of PPS. Further experiments are needed to fully map the mode of action of pentosan on brain endothelial cells and on its direct interaction with $\mathrm{A} \beta$.

In conclusion, pentosan can represent a new type of molecule to protect brain endothelial cells in pathological conditions, including $\mathrm{A} \beta$ toxicity, and to contribute to the maintenance of brain homeostasis and prevention of neuronal loss.

\section{ACKNOWLEDGMENTS}

Supported by research grants RET 08/2004, OTKA T37834, M36252, GVOP-KMA-52, TÁMOP-4.2.208/1/2008-0002. L.F. wishes to thank the Hungarian Academy of Sciences for the support of the János Bolyai Research Grant.

Authors' disclosures available online (http://www.jalz.com/disclosures/view.php?id=546). 


\section{REFERENCES}

[1] European Commission Health and Consumers DirectorateGeneral, Communication from the Comission to the European Parliament and the Council on a European initiative on Alzheimer's disease and other dementias, COM (2009) $380 \mathrm{fi}-$ nal, http://ec.europa.eu/health/ph_information/dissemination /documents/com2009_380_en.pdf, Brussels, 22.7.2009, access: 07.04.2010.

[2] Grammas P, Yamada M, Zlokovic BV (2002) The cerebromicrovasculature: a key player in the pathogenesis of Alzheimer's disease. J Alzheimers Dis 4, 217-223.

[3] Deli MA (2005) The role of blood-brain barrier in neurodegenerative diseases. In Molecular Bases of Neurodegeneration, Di Liegro I, Savettieri G, eds., Research Signpost, Kerala, India, 2005, pp. 137-161.

[4] Zlokovic BV (2005) Neurovascular mechanisms of Alzheimer's neurodegeneration. Trends Neurosci 28, 202-208.

[5] Zlokovic BV (2008) The blood-brain barrier in health and chronic neurodegenerative disorders. Neuron 57, 178-201.

[6] Jaeger LB, Dohgu S, Hwang MC, Farr SA, Murphy MP, Fleegal-Demotta MA, Lynch JA, Robinson SM, Niehoff ML, Johnson SN, Kumar VB, Banks WA (2009) Testing the neurovascular hypothesis of Alzheimer's disease: LRP-1 antisense reduces blood-brain barrier clearance and increases brain levels of amyloid- $\beta$ protein and impairs cognition. $J$ Alzheimers Dis 17, 553-570.

[7] Bell RD, Zlokovic BV (2009) Neurovascular mechanisms and blood-brain barrier disorder in Alzheimer's disease. Acta Neuropathol 118, 103-113.

[8] Abbott NJ, Rönnbäck L, Hansson E (2006) Astrocyteendothelial interactions at the blood-brain barrier. Nat Rev Neurosci 7, 41-53.

[9] Zlokovic BV, Yamada S, Holtzman D, Ghiso J, Frangione B (2000) Clearance of amyloid $\beta$-peptide from brain: transport or metabolism? Nat Med 6, 718-719.

[10] Forman MS, Trojanowski JQ, Lee VM (2004) Neurodegenerative diseases: a decade of discoveries paves the way for therapeutic breakthroughs. Nat Med 10, 1055-1063.

[11] DeMager PP, Penke B, Walter R, Harkany T, Härtignny W (2002) Pathological peptide folding in Alzheimer's disease and other conformational disorders. Curr Med Chem 9, 17631780 .

[12] Hirschfield GM, Hawkins PN (2003) Amyloidosis: new strategies for treatment. Int J Biochem Cell Biol 35, 1608-1613.

[13] Jancsó G, Domoki F, Sántha P, Varga J, Fischer J, Orosz K, Penke B, Becskei A, Dux M, Tóth L (1998) $\beta$-Amyloid (1-42) peptide impairs blood-brain barrier function after intracarotid infusion in rats. Neurosci Lett 253, 139-141.

[14] Ujiie M, Dickstein DL, Carlow DA, Jefferies WA (2003) Blood-brain barrier permeability precedes senile plaque formation in an Alzheimer disease model. Microcirculation 10, 463-470

[15] Blanc EM, Toborek M, Mark RJ, Hennig B, Mattson MP (1997) Amyloid $\beta$-peptide induces cell monolayer albumin permeability, impairs glucose transport, and induces apoptosis in vascular endothelial cells. J Neurochem 68, 1870-1881.

[16] Preston JE, Hipkiss AR, Himsworth DT, Romero IA, Abbott NJ (1998) Toxic effects of $\beta$-amyloid(25-35) on immortalised rat brain endothelial cell: protection by carnosine, homocarnosine and $\beta$-alanine. Neurosci Lett 242, 105-108.

[17] Folin M, Baiguera S, Tommasini M, Guidolin D, Conconi MT, De Carlo E, Nussdorfer GG, Parnigotto PP (2005) Effects of $\beta$ - amyloid on rat neuromicrovascular endothelial cells cultured in vitro. Int J Mol Med 15, 929-935.

[18] Deli MA, Ábrahám CS, Kataoka Y, Niwa M (2005) Permeability studies on in vitro blood-brain barrier models: physiology, pathology, and pharmacology. Cell Mol Neurobiol 25, 59-127.

[19] Strazielle N, Ghersi-Egea JF, Ghiso J, Dehouck M-P, Frangione B, Patlak C, Fenstermacher J, Gorevic P (2000) In vitro evidence that $\beta$-amyloid peptide 1-40 diffuses across the blood-brain barrier and affects its permeability. J Neuropathol Exp Neurol 59, 29-38.

[20] Gonzalez-Velasquez FJ, Kotarek JA, Moss MA (2008) Soluble aggregates of the amyloid- $\beta$ protein selectively stimulate permeability in human brain microvascular endothelial monolayers. J Neurochem 107, 466-477.

[21] Deli MA, Ábrahám CS, Takahata H, Katamine S, Niwa M (2000) Pentosan polysulfate regulates scavenger receptormediated, but not fluid-phase, endocytosis in immortalized cerebral endothelial cells. Cell Mol Neurobiol 20, 731-745.

[22] Deli MA, Niwa M, Katamine S, Ábrahám CS (1999) Pentosan in transmissible spongiform encephalopathies. Lancet 353, 1272.

[23] Deli MA, Sakaguchi S, Nakaoke R, Ábrahám CS, Takahata H, Kopáček J, Shigematsu K, Katamine S, Niwa M (2000) PrP fragment 106-126 is toxic to cerebral endothelial cells expressing PrPC. Neuroreport 11, 3931-3936.

[24] Veszelka S, Pásztói M, Farkas AE, Krizbai I, Dung NTK, Niwa M, Ábrahám CS, Deli MA (2007) Pentosan polysulfate protects brain endothelial cells against bacterial lipopolysaccharide-induced damages. Neurochem Int 50, 219228.

[25] Leveugle B, Scanameo A, Ding W, Fillit H (1994) Binding of heparan sulfate glycosaminoglycan to $\beta$-amyloid peptide: inhibition by potentially therapeutic polysulfated compounds. Neuroreport 5, 1389-1392.

[26] Zarándi M, Soós K, Fülöp L, Bozsó Z, Datki Z, Tóth GK, Penke B (2007) Synthesis of A $\beta$ [1-42] and its derivatives with improved efficiency. J Peptide Sci 13, 94-99.

[27] Sipos E, Kurunczi A, Fehér A, Penke Z, Fülöp L, Kasza A, Horváth J, Horvát S, Veszelka S, Balogh G, Kürti L, Erõs I, Szabó-Révész P, Párducz A, Penke B, Deli MA (2010) Intranasal delivery of human $\beta$-amyloid peptide in rats: effective brain targeting. Cell Mol Neurobiol 30, 405-413.

[28] Hetényi A, Fülöp L, Martinek TA, Wéber E, Soós K, Penke B (2008) Ligand-induced flocculation of neurotoxic fibrillar A $\beta(1-42)$ by noncovalent crosslinking. ChemBioChem $\mathbf{9}$, 748-757.

[29] Bozso Z, Penke B, Simon D, Laczkó I, Juhász G, Szegedi V, Kasza A, Soós K, Hetényi A, Wéber E, Tóháti H, Csete M, Zarándi M, Fülöp L (2010) Controlled in situ preparation of $\mathrm{A} \beta(1-42)$ oligomers from the isopeptide "iso-A $\beta(1-42)$ ", physicochemical and biological characterization. Peptides 31, 248-256.

[30] Perrière N, Demeuse P, Garcia E, Regina A, Debray M, Andreux JP, Couvreur P, Scherrmann JM, Temsamani J, Couraud P-O, Deli MA, Roux F (2005) Puromycin-based purification of rat brain capillary endothelial cell cultures. Effect on the expression of blood-brain barrier-specific properties. $\mathrm{J} \mathrm{Neu-}$ rochem $\mathbf{9 3}, 279-289$.

[31] Kis B, Deli MA, Kobayashi H, Ábrahám CS, Yanagita T, Kaiya H, Isse T, Nishi R, Gotoh S, Kangawa K, Wada A, Greenwood J, Niwa M, Yamashita H, Ueta Y (2001) Adrenomedullin regulates blood-brain barrier functions in vitro. Neuroreport 12, 4139-4142. 
[32] Csete M, Sipos Á, Kõházi-Kis A, Szalai A, Szekeres G, Matesz A, Csákó T, Osvay K, Bor Z, Penke B, Deli MA, Veszelka S, Schmatulla A, Marti O (2007) Comparative study of submicrometer polymeric dot-arrays, linear and crossed gratings generated by UV laser based two-beam interference as surfaces for AFM and SPR based bio-sensing. Appl Surf Sci 254, 1194-1205.

[33] Klein WL (2002) A $\beta$ toxicity in Alzheimer's disease: globular oligomers (ADDLs) as new vaccine and drug targets. Neurochem Int 41, 345-352.

[34] Hepler RW, Grimm KM, Nahas DD, Breese R, Dodson EC, Acton P, Keller PM, Yeager M, Wang H, Shughrue P, Kinney G, Joyce JG (2006) Solution state characterization of amyloid $\beta$-derived diffusible ligands. Biochemistry 45, 15157-15167.

[35] Marco S, Skaper SD (2006) Amyloid $\beta$-peptide 1-42 alters tight junction protein distribution and expression in brain microvessel endothelial cells. Neurosci Lett 401, 219-224.

[36] Vukic V, Callaghan D, Walker D, Lue LF, Liu QY, Couraud PO, Romero IA, Weksler B, Stanimirovic DB, Zhang W (2009) Expression of inflammatory genes induced by beta-amyloid peptides in human brain endothelial cells and in Alzheimer's brain is mediated by the JNK-AP1 signaling pathway. Neurobiol Dis 34, 95-106.

[37] Gumbleton M, Audus KL (2001) Progress and limitations in the use of in vitro cell cultures to serve as a permeability screen for the blood-brain barrier. J Pharm Sci 90, 1681-1698.

[38] van Oijen M, de Jong FJ, Witteman JC, Hofman A, Koudstaal PJ, Breteler MM (2007) Atherosclerosis and risk for dementia. Ann Neurol 61, 403-410.

[39] Deane R, Du Yan S, Submamaryan RK, LaRue B, Jovanovic S, Hogg E, Welch D, Manness L, Lin C, Yu J, Zhu H, Ghiso J, Frangione B, Stern A, Schmidt AM, Armstrong DL, Arnold B, Liliensiek B, Nawroth P, Hofman F, Kindy M, Stern D, Zlokovic B (2003) RAGE mediates amyloid- $\beta$ peptide transport across the blood-brain barrier and accumulation in brain. Nat Med 9, 907-913.

[40] Giri R, Shen Y, Stins M, Du Yan S, Schmidt AM, Stern D, Kim KS, Zlokovic B, Kalra VK (2000) $\beta$-Amyloid-induced migration of monocytes across human brain endothelial cells involves RAGE and PECAM-1. Am J Physiol Cell Physiol 279, C1772-C1781.

[41] Shibata M, Yamada S, Kumar SR, Calero M, Bading J, Frangione $\mathrm{B}$, Holtzman DM, Miller CA, Strickland DK, Ghiso J, Zlokovic BV (2000) Clearance of Alzheimer's amyloid$\beta_{1-40}$ peptide from brain by LDL receptor-related protein-1 at the blood-brain barrier. J Clin Invest 106, 1489-1499.

[42] Deane R, Wu Z, Sagare A, Davis J, Du Yan S, Hamm K, Xu F, Parisi M, LaRue B, Hu HW, Spijkers P, Guo H, Song X, Lenting PJ, Van Nostrand WE, Zlokovic BV (2004) LRP/amyloid $\beta$-peptide interaction mediates differential brain efflux of $\mathrm{A} \beta$ isoforms. Neuron 43, 333-344.

[43] Calero M, Tokuda T, Rostagno A, Kumar A, Zlokovic B, Frangione B, Ghiso J (1999) Functional and structural properties of lipid-associated apolipoprotein J (clusterin). Biochem J 344, 375-383.

[44] Cirrito JR, Deane R, Fagan AM, Spinner ML, Parsadanian M, Finn MB, Jiang H, Prior JL, Sagare A, Bales KR, Paul SM, Zlokovic BV, Piwnica-Worms D, Holtzman DM (2005) P-glycoprotein deficiency at the blood-brain barrier increases amyloid- $\beta$ deposition in an Alzheimer disease mouse model. J Clin Invest 115, 3285-3290.

[45] Kalaria RN, Hedera P (1995) Differential degeneration of the cerebral microvasculature in Alzheimer's disease. Neuroreport 6, 477-480.
[46] Wisniewski HM, Vorbrodt AW, Wegiel J (1997) Amyloid angiopathy and blood-brain barrier changes in Alzheimer's disease. Ann NY Acad Sci 826, 161-172.

[47] Wada H (1998) Blood-brain barrier permeability of the demented elderly as studied by cerebrospinal fluid-serum albumin ratio. Internal Med 37, 509-513.

[48] Poduslo JF, Curran GL, Wengenack TM, Malester B, Duff K (2001) Permeability of proteins at the blood-brain barrier in the normal adult mouse and double transgenic mouse model of Alzheimer's disease. Neurobiol Dis 8, 555-567.

[49] Bronge L (2002) Magnetic resonance imaging in dementia. A study of brain white matter changes. Acta Radiol Suppl 428, $1-32$.

[50] Starr JM, Farrall AJ, Armitage P, McGurn B, Wardlaw J (2009) Blood-brain barrier permeability in Alzheimer's disease: a case-control MRI study. Psychiatr Res Neuroim 171, 239-241.

[51] Drago D, Folin M, Baiguera S, Tognon G, Ricchelli F, Zatta $\mathrm{P}$ (2007) Comparative effects of A $\beta(1-42)-\mathrm{Al}$ complex from rat and human amyloid on rat endothelial cell cultures. $J$ Alzheimers Dis 11, 33-44.

[52] Eisenhauer PB, Johnson RJ, Wells JM, Davies TA, Fine RE (2000) Toxicity of various amyloid $\beta$ peptide species in cultured human blood-brain barrier endothelial cells: increased toxicity of dutch-type mutant. J Neurosci Res 60, 804-810.

[53] Monro OR, Mackic JB, Yamada S, Segal MB, Ghiso J, Maurer C, Calero M, Frangione B, Zlokovic BV (2002) Substitution at codon 22 reduces clearance of Alzheimer's amyloid- $\beta$ peptide from the cerebrospinal fluid and prevents its transport from the central nervous system into blood. Neurobiol Aging 23, 405-412.

[54] Yin KJ, Lee JM, Chen H, Xu J, Hsu CY (2005) A $325-35$ alters Akt activity, resulting in Bad translocation and mitochondrial dysfunction in cerebrovascular endothelial cells. J Cereb Blood Flow Metab 25, 1445-1455.

[55] Pákáski M, Baláspiri L, Checler F, Kása P (2002) Human amyloid- $\beta$ causes changes in the levels of endothelial protein kinase $\mathrm{C}$ and its alpha isoform in vitro. Neurochem Int 41, 409-414.

[56] Baiguera S, Fioravanzo L, Grandi C, Di Liddo R, Parnigotto PP, Folin M (2009) Involvement of the receptor for advanced glycation-end products (RAGE) in $\beta$-amyloid-induced toxic effects in rat cerebromicrovascular endothelial cells cultured in vitro. Int J Mol Med 24, 9-15.

[57] Folin M, Baiguera S, Fioravanzo L, Conconi MT, Grandi C, Nussdorfer GG, Parnigotto PP (2006) Caspase-8 activation and oxidative stress are involved in the cytotoxic effect of $\beta$ amyloid on rat brain microvascular endothelial cells. Int $\mathrm{J} \mathrm{Mol}$ Med 17, 431-435.

[58] Tai LM, Holloway KA, Male DK, Loughlin AJ, Romero IA (2010) Amyloid- $\beta$-induced occludin down-regulation and increased permeability in human brain endothelial cells is mediated by MAPK activation. J Cell Mol Med 14, 1101-1112.

[59] de Haas CJ (1999) New insights into the role of serum amyloid P component, a novel lipopolysaccharide-binding protein. FEMS Immunol Med Microbiol 26, 197-202.

[60] Veszelka S, Urbányi Z, Pázmány T, Németh L, Obál I, Dung NTK, Ábrahám CS, Szabó G, Deli MA (2003) Human serum amyloid $\mathrm{P}$ component attenuates the bacterial lipopolysaccharide-induced increase in blood-brain barrier permeability in mice. Neurosci Lett 352, 57-60.

[61] Pepys MB (2001) Pathogenesis, diagnosis and treatment of systemic amyloidosis. Philos Trans Royal Soc B: Biol Sci 356, 203-210. 
[62] McGeer EG, Yasojima K, Schwab C, McGeer PL (2001) The pentraxins: possible role in Alzheimer's disease and other innate inflammatory diseases. Neurobiol Aging 22, 843-848.

[63] Virgintino D, Errede M, Robertson D, Capobianco C, Girolamo F, Vimercati A, Bertossi M, Roncali L (2004) Immunolocalization of tight junction proteins in the adult and developing human brain. Histochem Cell Biol 122, 51-59.

[64] Krause G, Winkler L, Mueller SL, Haseloff RF, Piontek J, Blasig IE (2008) Structure and function of claudins. Biochim Biophys Acta 1778, 631-645.

[65] Kovac A, Zilkova M, Deli MA, Zilka N, Novak M (2009) Human truncated tau is using different mechanism from $\beta$ amyloid to damage blood-brain barrier. J Alzheimers Dis $\mathbf{1 8}$, 897-906.

[66] Bassil N, Grossberg GT (2009) Novel regimens and delivery systems in the pharmacological treatment of Alzheimer's disease. CNS Drugs 23, 293-307.

[67] Banks WA, Robinson SM, Verma S, Morley JE (2003) Efflux of human and mouse amyloid $\beta$ proteins $1-40$ and $1-42$ from brain: impairment in a mouse model of Alzheimer's disease. Neuroscience 121, 487-492.

[68] Farr SA, Poon HF, Dogrukol-Ak D, Drake J, Banks WA, Eyerman E, Butterfield DA, Morley JE (2003) The antioxidants alpha-lipoic acid and N-acetylcysteine reverse memory impairment and brain oxidative stress in aged SAMP8 mice. $J$ Neurochem 84, 1173-1183.

[69] András IE, Rha G, Huang W, Eum S, Couraud P-O, Romero IA, Hennig B, Toborek M (2008) Simvastatin protects against amyloid $\beta$ and HIV-1 Tat-induced promoter activities of inflammatory genes in brain endothelial cells. Mol Pharmacol 73, 1424-1433.

[70] Viana RJ, Nunes AF, Castro RE, Ramalho RM, Meyerson J, Fossati S, Ghiso J, Rostagno A, Rodrigues CM (2009) Tauroursodeoxycholic acid prevents E22Q Alzheimer's A $\beta$ toxicity in human cerebral endothelial cells. Cell Mol Life Sci 66, 1094-1104.

[71] Folin M, Baiguera S, Guidolin D, Di Liddo R, Gran- di C, De Carlo E, Nussdorfer GG, Parnigotto PP (2006) Apolipoprotein-E modulates the cytotoxic effect of $\beta$-amyloid on rat brain endothelium in an isoform-dependent specific manner. Int J Mol Med 17, 821-826.

[72] Wu Z, Guo H, Chow N, Sallstrom J, Bell RD, Deane R, Brooks AI, Kanagala S, Rubio A, Sagare A, Liu D, Li F, Armstrong D, Gasiewicz T, Zidovetzki R, Song X, Hofman F, Zlokovic BV (2005) Role of the $\mathrm{MEOX}_{2}$ homeobox gene in neurovascular dysfunction in Alzheimer disease. Nat Med 11, 959-965.

[73] Bell RD, Deane R, Chow N, Long X, Sagare A, Singh I, Streb JW, Guo H, Rubio A, Van Nostrand W, Miano JM, Zlokovic BV (2009) SRF and myocardin regulate LRPmediated amyloid- $\beta$ clearance in brain vascular cells. Nat Cell Biol 11, 143-153.

[74] Ghosh P (1999) The pathobiology of osteoarthritis and the rationale for the use of pentosan polysulfate for its treatment. Semin Arthritis Rheum 28, 211-267.

[75] Maffrand JP, Herbert JM, Bernat A, Defreyn G, Delebasse D, Savi P, Pinot JJ, Sampol J (1991) Experimental and clinical pharmacology of pentosan polysulfate. Semin Thromb Hemost 17, 186-198.

[76] Hwang P, Auclair B, Beechinor D, Diment M, Einarson TR (1997) Efficacy of pentosan polysulfate in the treatment of interstitial cystitis: a meta-analysis. Urology 50, 39-43.

[77] Kumagai K, Shirabe S, Miyata N, Murata M, Yamauchi A, Kataoka Y, Niwa M (2010) Sodium pentosan polysulfate resulted in cartilage improvement in knee osteoarthritis - An open clinical trial. BMC Clin Pharmacol 10, 7.

[78] Dealler S, Rainov NG (2003) Pentosan polysulfate as a prophylactic and therapeutic agent against prion disease. IDrugs 6, 470-478.

[79] Leveugle B, Ding W, Laurence F, Dehouck M-P, Scanameo A, Cecchelli R, Fillit H (1998) Heparin oligosaccharides that pass the blood-brain barrier inhibit $\beta$-amyloid precursor protein secretion and heparin binding to $\beta$-amyloid peptide. $J$ Neurochem 70, 736-744. 
PUBLICATION II. 


\title{
Patented In Vitro Blood-Brain Barrier Models in CNS Drug Discovery
}

\author{
Andrea Tóth ${ }^{1}$, Szilvia Veszelka ${ }^{1}$, Shinsuke Nakagawa ${ }^{2,3}$, Masami Niwa ${ }^{2,3}$ and Mária A. Deli ${ }^{1,2^{*}}$
}

\author{
${ }^{1}$ Laboratory of Molecular Neurobiology, Institute of Biophysics, Biological Research Centre of the Hungarian Academy \\ of Sciences, Szeged, Hungary; ${ }^{2}$ PharmaCo-Cell Co. Ltd., Nagasaki, Japan; ${ }^{3}$ Department of Pharmacology 1, Nagasaki \\ University Graduate School of Biomedical Sciences, Nagasaki, Japan
}

Received: April 12, 2011; Accepted: April 21, 2011; Revised: May 5, 2011

\begin{abstract}
The blood-brain barrier (BBB) is a regulatory interface between the circulation and the central nervous system (CNS). Therapy of neurological diseases is limited due to restricted penetration of pharmacons across the BBB. Models for screening the brain penetration of drug candidates are needed early in drug discovery. Culture-based models are useful tools for both basic research on BBB, and testing the permeability of new therapeutical molecules. This review focuses on patented in vitro BBB models and their potential application in CNS drug discovery. Cell culture models using primary and immortalized brain endothelial cells of non-human and human origin, in co-culture or mono-culture setting, in static or dynamic conditions are discussed, as well as methods to induce BBB properties in such in vitro models. The aim of these models is to reproduce as many aspects as possible of the in vivo BBB. All models should show some elements of general endothelial and specific BBB properties, like physiologically realistic cell architecture, restrictive paracellular pathway, and functional expression of transport mechanisms. Though no "ideal in vitro BBB model" has been constructed yet, the currently available models provide valuable information on BBB permeability and are useful tools in CNS drug discovery.
\end{abstract}

Keywords: Blood-brain barrier, brain endothelial cell, co-culture, in vitro blood-brain barrier model, model for CNS drug testing, prediction model for CNS permeability.

\section{INTRODUCTION}

Endothelial cells lining the microvessels of the central nervous system (CNS) differ fundamentally from peripheral vascular endothelium both in their morphological and functional features including the regulation of the exchange of molecules and cells between the blood and the neural parenchyma. The blood-brain barrier (BBB) is constituted by brain capillaries, which possess specialized structural and functional characteristics. In humans, the estimated total length of cerebral capillaries is about $650 \mathrm{~km}$ and the total surface area is about $20 \mathrm{~m}^{2}[1,2]$.

Cerebral endothelial cells form the anatomical basis of the BBB. There is a dynamic interaction between brain endothelial and other neighboring cells, such as astroglia, pericytes, perivascular microglia, and neurons as depicted on Fig. (1). The cross-talk between these cells induce a unique BBB phenotype in endothelial cells including (i) a morphological barrier based on interendothelial tight junctions (TJ) that markedly limit paracellular permeability, (ii) a unique pattern of receptors, transporters and drug efflux pumps, and (iii) enzymatic and metabolic barriers [3]. The three major functions of the $\mathrm{BBB}$ are the creation and maintenance of ionic homeostasis for neuronal functions, supply of the CNS with nutrients, and protection from toxic insults [4].

*Address correspondence to this author at the Laboratory of Molecular Neurobiology, Institute of Biophysics, Biological Research Centre of the Hungarian Academy of Sciences, Temesvári krt. 62, H-6726 Szeged, Hungary; Tel: +36 62 599602; Fax: +36 62 433133; E-mail: deli@brc.hu
By separating the brain from systemic circulation the $\mathrm{BBB}$ is the major entry gate for therapeutic compounds to the CNS. The low level of paracellular flux and transendothelial vesicular trafficking results in a transport barrier for drugs which are hydrophilic and have a molecular mass bigger than 400 Da. Efflux pumps at the luminal membrane of brain endothelial cells limit the brain penetration of lipophilic xenobiotics and drugs [5]. These properties of the $\mathrm{BBB}$ and other factors contributing to the rate and extent of drug disposition within the brain prevent $98 \%$ of potential neuropharmaceuticals, especially new biopharmacons, nucleic acids, peptide or protein drugs, to reach therapeutical levels in the CNS [1, 6]. Despite efforts to increase drug delivery to brain through strategies to overcome the junctional or efflux barriers, to exploit BBB transport mechanisms or to circumvent the BBB [7], still the majority of newly developed neuropharmaceuticals fail due to poor CNS pharmacokinetics [2]. Therefore, the early screening of potential drug candidate molecules for brain penetration is a very important task in drug discovery and development.

BBB models have been widely used in pharmaceutical industry for testing the permeability of cerebral capillaries and investigating brain penetration. Cell culture-based models proved to be one of the most versatile tools in basic $\mathrm{BBB}$ research and also in testing CNS drug penetration [8]. In drug development, several sequential and parallel steps for screening BBB permeability are suggested [9]. Computational approaches to predict drug penetrability can be used to screen big compound libraries with the advantages of being quick and high throughput. Non-cell based in vitro models of permeability can further refine and specify penetration 


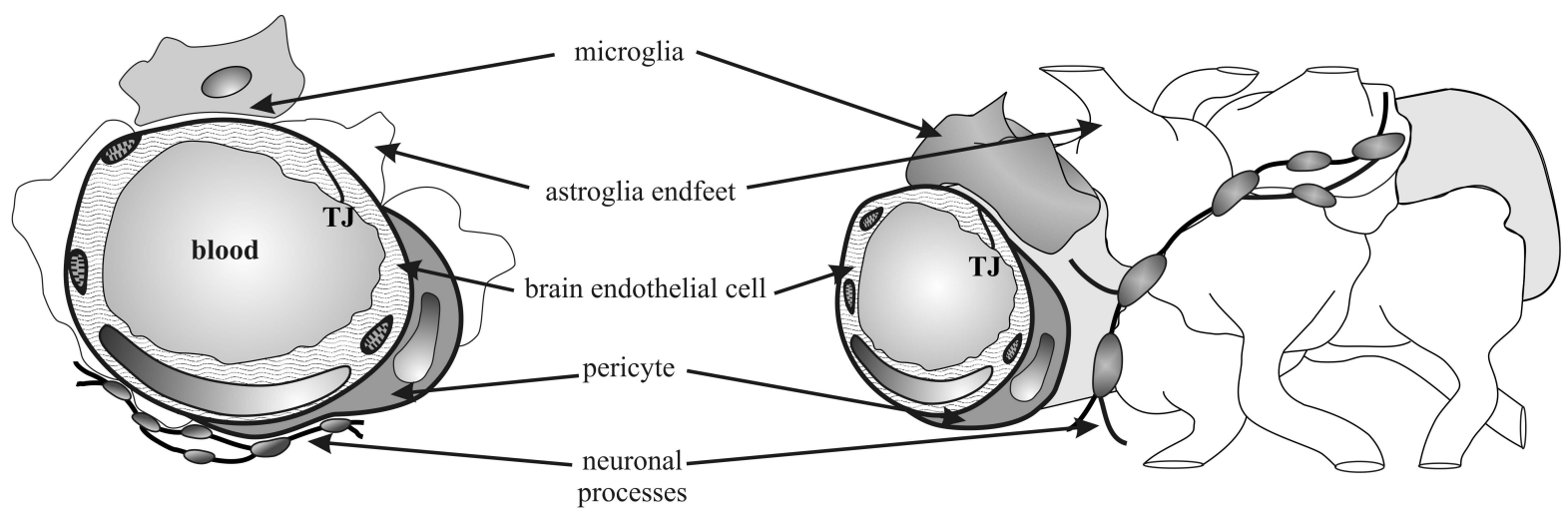

Fig. (1). Drawing on the structure of the neurovascular unit. Brain endothelial cells and the tight junctions (TJ) between them constitute the anatomical basis of the blood-brain barrier.

properties. Epithelial cell line models offer better estimation of efflux transport of drug candidates, while brain endothelial cell culture models mimic best BBB properties and complexity $[2,9]$. Our main aim is to present a short overview on in vitro $\mathrm{BBB}$ models and to review patented $\mathrm{BBB}$ models that can be used as screening tools in CNS drug discovery.

\section{OVERVIEW OF IN VITRO BLOOD-BRAIN BARRIER MODELS}

Viable cerebral microvessels isolated 40 years ago by Ferenc Joó and his co-workers can be considered as the first in vitro model of the BBB [10]. Studies on brain microvessels opened a new era in BBB research and provided important data on cerebral endothelial receptors, transporters and signaling mechanisms $[11,12]$. Cerebral microvessels were also used to reveal the transcriptome and proteome of the BBB [13,14]. Despite of their versatility, isolated microvessels are not suitable for transcellular transport studies and cannot be recommended for drug screening [15].

Just five years after the first isolation of cerebral microvessels, Panula and his colleagues observed endothelial cells growing out of brain capillaries in culture conditions [16]. Following this observation, several culture methods have been developed resulting in an increasing number of different BBB models, for review see $[17,18]$. The use of puromycin to selectively enrich brain endothelial cells and kill contaminating cell types in primary brain microvessel cultures was an important step to develop better BBB models $[19,20]$.

Primary brain microvessel endothelial cells have been isolated from many species, including dog, cat, and gerbil, but well-characterized BBB models suitable for permeability experiments are prepared from bovine, human, mouse, porcine and rat endothelial cells as reviewed in $[8,17,18$, 21]. The advantages of the bovine [22] and porcine [23] BBB models are the high yield of brain endothelial cells, tight paracellular barrier and good cost-effectiveness [18]. Human BBB models would be the best to screen drugs developed for human therapy. However, access to human brain tissue is difficult, the yield of cells from surgical samples is low, and available human models show weaker barrier properties than bovine or porcine models [18, 21]. It is also questionable whether brain tissue samples from autopsy or surgery could be considered suitable for physiological BBB models. Advantages of rat and mouse culture BBB models include the easy preparation of syngenic co-cultures, good comparison with data obtained by in vivo experiments, and the availability of transgenic and gene-targeted animals, and a wide range of antibodies [17, 18]. In case of rodent, especially of mouse, BBB models the cell yield is low, therefore they are mainly used in basic research $[17,18]$.

Early studies applied monocultures of primary cerebral endothelial cells [16,24-27], but it turned out, that long-term cultivation and passages lead to the loss of barrier properties. The interaction between the cells of the neurovascular unit, brain endothelial cells, astroglia, pericytes and neurons Fig. (1) is crucial for the formation and maintenance of a functional $\mathrm{BBB}[4,28]$. The introduction of cell culture insert with porous membranes enabled the use of brain endothelial cells in co-culture with other cell types and thus the construction of the next generation of in vitro $\mathrm{BBB}$ models [12].

Astrocytes were the first to be recognized as regulators of brain endothelial characteristics and functions, for review see [4, 29]. Astrocytic endfeet covering the surface of brain capillaries allow both cross-talk between the two cell types and transport between blood and the neural tissue as it is shown on Fig. (1) [29]. It has been demonstrated that glial cells induce the development of TJs and barrier properties in cerebral endothelial cells, and both purified type- 1 astrocytes and primary mixed glial cultures are efficient in the induction of BBB properties [21, 30, 31]. These results further supported the use of the co-culture of brain endothelial cells and astroglia, which became the most widespread type of in vitro $\mathrm{BBB}$ model. In some models cells from different spe-cies are used, like the co-culture of bovine brain endothelial cells with rat glial cells [22]. Syngenic models were also developed using microvascular endothelial cells and astroglia from rat [19, 32], mouse [33], or human [34] brain.

A well-characterized bovine BBB model has been established [22] and it was successfully used in the last 20 years as a permeability screen for CNS drugs [2]. The model, coculture of cloned and passaged bovine brain capillary endothelial cells with rat glia, shows good barrier properties 
and has been used for several permeability studies [22, 35, 36]. Good correlations were obtained when the model was compared to other BBB models or in vivo data $[37,38]$. A new version of the model uses 24-well format and a special inducing medium [39]. The largest number of data for compound permeability was published on this bovine BBB model [2, 18]. This model was not patented, and is used for pharmacological and toxicological evaluation of compounds by Cellial Technologies (Lens, France).

While the role of glial cells in the development of BBB properties has been extensively studied, for review see [21, $29,31]$, few data are available on the effect of neurons on the induction of $\mathrm{BBB}$ characteristics. Co-culture of a brain endothelial cell line with primary neurons induced $\mathrm{BBB}$ differentiation [40] and a similar effect was seen in the case of a brain slice culture [41]. Co-culture of endothelial cells in the presence of both neuronal and glial cells induced BBB characteristics in a brain endothelial cell line in a static model [42, 43] and in endothelial cells under dynamic conditions [44, 45].

Pericytes are the nearest neighbours of endothelial cells, and the two cell types share a common basal membrane in cerebral capillaries [46]. They participate in the development, maintenance, and regulation of the $\mathrm{BBB}$ and have fundamental role in stabilizing brain capillary structure in vivo [28, 47, 48]. Pericytes are also able to tighten the paracellular barrier in cultured brain endothelial cells and to increase their BBB properties similarly to astrocytes [49, 50].

Since primary cultures are expensive, time-consuming and need expertise, immortalized brain endothelial cell lines have been generated in growing number to overcome these difficulties and to establish easy, reproducible, and sufficiently tight in vitro BBB models. Currently bovine, human, mouse, porcine and rat cell lines are available [18]. There are efforts to establish an ideal immortalized BBB model which could be applicable to high-throughput screening systems to estimate drug permeability across the BBB. Several brain endothelial cell lines were developed from human tissue, but only few of them were tested in permeability studies. Human brain endothelial cell lines are widely applied in basic research, mostly in infectological studies with human pathogens $[8,21]$. The paracellular barrier properties of monolayers from these human cell lines are rather weak, even compared to cell lines from other species [18, 21].

The pharmaceutical industry needs simple, reliable, in vitro $\mathrm{BBB}$ models for predicting the brain penetrability of CNS drugs. A model to serve as a permeability screen should display (i) a physiologically realistic cell architecture, (ii) a restrictive paracellular pathway, (iii) functional expression of transporter mechanisms and (iv) ease of culture to facilitate drug screening [51]. The aim of any model is to reproduce as many aspects as possible of the in vivo BBB.

All models should show some elements of general endothelial and specific BBB properties [18]. The adjacent cells should possess endothelial morphology, like growing in monolayer and having tight interendothelial junctions between overlapping plasmamembranes. Expression and typical pericellular localization of integral membrane TJ proteins, such as occludin, junctional adherent molecules (JAM), endothelial cell-specific adhesion molecule (ESAM), and claudin-3, -5 contribute to the maintenance of the restrictive paracellular pathway of the BBB. Absence of fenestration and low number of pinocytotic vesicles are also important elements of the physiological barrier [52].

The tightness of the paracellular barrier is a fundamental property of BBB, which prevents hydrophilic molecules and even ions and water to enter freely the CNS [28]. One of the most direct methods to determine the tightness of a model is the measurement of transendothelial electrical resistance (TEER) [21]. The TEER of brain parenchymal microvessels in vivo exceeds $1000 \Omega$ [53]. Commercially available VoltOhm resistance meters (World Precision Instruments, Millipore) and custom devices with "chopstick", chamber type or needle electrodes can be used as TEER measurement systems, which give different background resistance values and enable repeated measurements or continuous monitoring [21]. Special culture conditions, like in the case of the dynamic BBB model, need custom TEER measurement systems [54], but it is difficult to compare results obtained by different devices [21]. BBB models should reach a tightness of at least $150-200 \Omega \times \mathrm{cm}^{2}$ to study the permeability or transport of molecules [8, 18, 21, 55]. Another way to assess the integrity of the paracellular barrier is the measurement of passive flux of small hydrophilic tracers across monolayers. The endothelial or apparent permeability coefficients $\left(\mathrm{P}_{\mathrm{e}}\right.$ or $\left.\mathrm{P}_{\mathrm{app}}\right)$ are important parameters of the quality of BBB models $[18,21]$. The in vivo $\mathrm{P}_{\mathrm{app}}$ of sucrose, a marker of passive permeability, is $3 \times 10^{-7} \mathrm{~cm} / \mathrm{s}$ [37]. The barrier properties of different $\mathrm{BBB}$ models can be compared by TEER and $\mathrm{P}_{\mathrm{e}}$ values, which in case of the best in vitro models can approach the values measured in vivo [18, 21].

The polarized expression of transporters, receptors and enzymes at either the luminal or abluminal cell surface is a crucial aspect of models used for drug screening. Saturable, bi-directional transport systems exist for nutrients, vitamins and minerals at the BBB $[28,52,56]$. About 40 members of the solute carrier (SLC) transporter family were identified in brain microvessels [13]. Efflux pumps protect the brain from xenobiotics, but they are also responsible for restricting the penetration of many therapeutical molecules to brain. The primary efflux pumps at the BBB belong to the ATP-binding cassette $(A B C)$ transporter family [5]. The presence of the most important carriers supplying the CNS with glucose, ketons or amino acids, like glucose transporter 1 (GLUT1), monocarboxylic acid transporter 1 (MCT1), large neutral amino acid transporter (LAT1), and the primary efflux pumps, e.g. P-glycoprotein (ABCB1), breast cancer resistance protein (ABCG2) and multidrug resistance proteins (ABCC family) should be verified in BBB models [56]. In addition, elements of the metabolic barrier, such as alkaline phosphatase, $\gamma$-glutamyl transpeptidase, monoamine oxidases or cytochrome P450 enzymes should be also expressed on BBB models.

Furthermore, an ideal in vitro model should not only show BBB characteristics, it also needs to be simple to use, reproducible, cost-effective and applicable for medium or high throughput screening. Unfortunately, none of the available model fulfills all the above mentioned criteria, but 
models expressing the most critical features of the BBB can provide valuable information on $\mathrm{BBB}$ permeability and be useful tools in CNS drug discovery.

\section{PATENTED IN VITRO BLOOD-BRAIN BARRIER MODELS}

Eight in vitro BBB models patented between 1990 and 2010 and their important features are summarized in Table 1 [57-64]. The characteristics, advantage, disadvantage and application of these models will be discussed.

\section{PRIMARY CULTURE BASED BBB MODELS}

\subsection{Brain Endothelial Cells in Co-culture with Astrocytes}

The BBB model patented by Rubin et al. [57] is based on the culture of an essentially confluent monolayer of brain microvascular endothelial cells from any vertebrate species on porous solid support in the presence of endothelial- or astrocyte-derived conditioned medium, or the co-culture of these monolayers on porous solid support, which enables the communication with the astrocytes at the lower compartment Fig. (2) $[57,65,66]$. The major novelty of the patent is that endothelial cells are grown in contact with agents elevating cyclic AMP (cAMP) concentration in these cells leading to increased barrier function. This aspect of the model will be discussed in section 3.1.

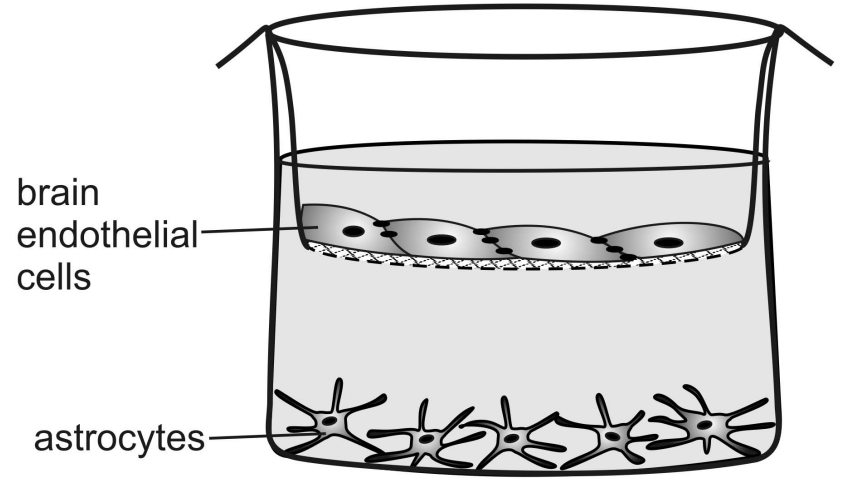

Fig. (2). BBB model based on co-culture of brain endothelial and astroglial cells or cell lines using inserts with porous membrane.

\subsection{Brain Endothelial Cells in Triple Culture with Astrocytes and Pericytes}

In the triple culture model described in the patent by Niwa et al. [58] endothelial cells are grown in the presence of both astrocytes and pericytes Fig. (3), so a synergetic effect on the induction of BBB properties can be observed. The model closely mimics the anatomical position of the cells at the $\mathrm{BBB}$ in vivo. Primary cultured rat brain microvascular endothelial cells are seeded onto the upper surface of the filter while pericytes grow on the opposite surface of the filter sharing a common membrane as in vivo. Primary astrocytes are placed at the bottom of the well Fig. (3). The permeable membrane of the inserts enables a bidirectional communication between the cells by exchanging soluble factors in both directions leading to the induction of good

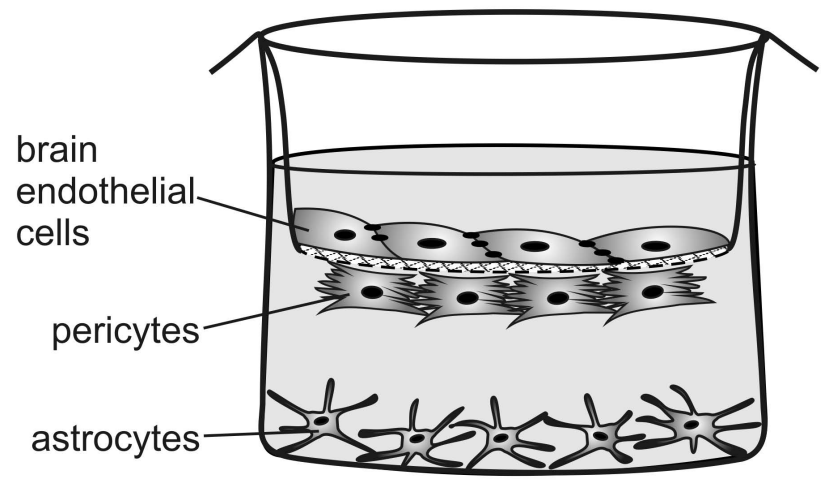

Fig. (3). BBB model based on co-culture of brain endothelial, brain pericyte and astroglial cells using inserts with porous membrane. The triple co-culture model mimics the in vivo anatomical structure of the BBB.

BBB properties. In the presence of both pericytes and astrocytes rat brain endothelial cells expressed enhanced levels of TJ proteins occludin, claudin-5 and ZO-1 [50]. The barrier function of the monolayers was elevated as measured by higher TEER and lower $\mathrm{P}_{\mathrm{e}}$ for marker molecules $[49,50]$. Brain endothelial cells in this new model expressed glucose transporter-1, efflux transporters P-glycoprotein and multidrug resistance protein-1, and showed a polarized transport of rhodamine 123, a ligand for P-glycoprotein. Drug permeability assays were performed using a set of 19 compounds with known in vivo BBB permeability and good correlation $\left(\mathrm{R}^{2}=0.89\right)$ was found between in vitro $\mathrm{P}_{\mathrm{e}}$ values obtained from measurements on the $\mathrm{BBB}$ model and in vivo $\mathrm{BBB}$ permeability data [50].

This BBB model is intended to provide a screening system for centrally acting drugs transported across the BBB, drugs acting on brain endothelial cells, and peripheral acting drugs to exclude brain penetration and potential side effects. Furthermore, the model is suitable to study BBB pathology in neurological diseases by testing pathogenetic factors/ conditions, and cellular changes and drug transport in pathological conditions.

The advantages of the model are that it is made from primary cultures, has good barrier properties, and mimicks the anatomical situation in vivo. The model is used for primary research in different laboratories, for example the effect of oxygen-glucose deprivation was tested on ectonucleotidase activity in the cells of the BBB [67]. However, development of such a complex model in a laboratory can be time-consuming and needs expertise. To solve these problems a patented frozen ready-to-use kit version of the model [68] was prepared by PharmaCo-Cell Co. Ltd. (Nagasaki, Japan) which is commercially available. The three types of cells are seeded in the appropriate compartments and surfaces of the porous inserts and the culture plate Fig. (3), and are frozen in situ using a cryoprotecting medium. After storage and delivery of the frozen model, cells are thawed and after four days in culture the model is ready for experiments [68]. The BBB kit has been successfully used in drug discovery to measure the permeability of different alkaloids in vitro [69]. 
Recently, a monkey triple co-culture BBB model was developed by the same group, in which brain microvascular endothelial cells from Macaca irus are cultured together with rat pericytes and astrocytes [70]. The model shows morphological and functional characteristics similar to the patented rat $\mathrm{BBB}$ model, and there is a good correlation between permeability data obtained on the two BBB models.

\subsection{Brain Endothelial Cells in Co-culture with Neural Progenitor Cells}

During the embryogenesis angiogenic vessels invade the immature neural environment and begin establishing $\mathrm{BBB}$ characteristics well in advance of the onset of gliogenesis $[71,72]$. The BBB development begins prenatally and is followed by a gradual maturation to full $\mathrm{BBB}$ function in which the influence of both neuronal precursors and glial cells takes part. In direct contact culture condition, endothelial cells regulate neuronal precursor cell differentiation, proliferation, and quiescence showing mutual influence between them [73, 74]. Differentiating embryonic neural progenitor cells were shown to be able to induce BBB properties $[75,76]$.

Based on this knowledge a BBB model using co-culture of primary brain microvascular endothelial cells or embryonic stem cell-derived endothelial cells with neural progenitor cells (NPC) Fig. (4) was disclosed [59]. After a few days the cultured NPC differentiate into mixtures of astrocytes, neurons, and oligodendrocytes and a multicellular BBB model is created, where barrier properties are enhanced in endothelial cells [75]. The inventors claim that the model more accurately predicts in vivo behavior than current models, it is reproducible and reliable and less labor intensive. Because embryonic NPCs are easily isolated and expand rapidly, a large relatively homogeneous cell stock can be obtained. NPCs survive cryopreservation, making possible multiple uses of the same NPC stock over a long period of time. The relative percentages of neurons and astrocytes differentiated from NPCs can be controlled to create designer mixtures of brain cells that can be cocultured with the brain endothelial cells [59].

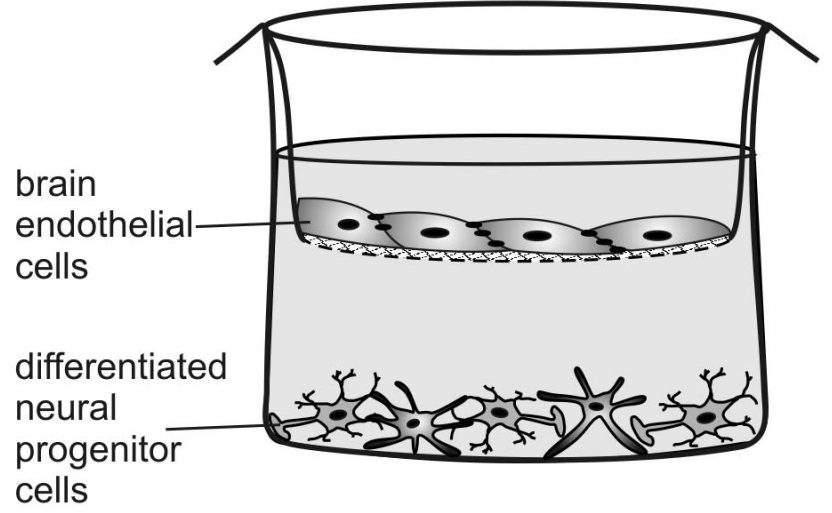

Fig. (4). BBB model based on co-culture of brain endothelial cells grown on inserts with porous membrane and neural progenitor cells that can differentiate into a mixture of astroglia, neurons and oligodendroglia.
The model is described to be suitable for testing potential drug candidates in a multicellular environment with the contribution of perivascular non-endothelial cells in the local microenvironment. However, since the recent publication of the patent no further application of the model for CNS drug testing is known.

\section{CELL LINE BASED BBB MODELS}

Immortalized cell lines could serve as simple and nonexpensive tools for CNS drug delivery and discovery research.

\subsection{Bovine Cell Line}

The only patented bovine cell line, TBMEC P11, was made by transfecting the cells with a vector containing the entire coding region of virus middle-T antigen gene [60]. According to the inventor this cell line shows substantial impermeability to small substances imparted by their ability to form confluent monolayers. It is claimed that TBMEC P11 cell line was tested for 39 low molecular weight hydrophilic and lipophilic pharmaceuticals and other chemicals and according to the permeability data this cell line is appropriate for drug permeability tests.

The general disadvantage of immortalized endothelial cells, the low paracellular permeability, can be seen in the case of this cell line, too. The permeability for sucrose, a paracellular marker is ten times higher than for primary cell based BBB models Table 1. There are no scientific publications on the model and no commercial or other application of the model for CNS drug testing is known.

\subsection{Rat Cell Line}

Several immortalized rat cerebral endothelial cell lines were prepared but only few of them were tested in permeability assays. One of the cell lines applicable for drug screening is the conditionally immortalized BBB model prepared by cocultivating cerebral capillary endothelial cell line TR-BBB and astrocyte cell line originating from a transgenic rat transfected by large $T$ antigen gene from the temperature-sensitive mutant SV 40 tsA58 [61]. The cells acquire immortalized characteristics if they are cultured at $33^{\circ} \mathrm{C}$ because the temperature-sensitive SV40 large Tantigen gene product is activated only at this temperature. However shifting the culture temperature to $37^{\circ} \mathrm{C}$ the SV40 large T-antigen is inactivated and the cell growth is repressed or arrested. Therefore, these cells are conditionally immortal which is one of the biggest advantages of the model. As large T-antigen interacts with many kinds of protein, including $\mathrm{Rb}$ protein and $\mathrm{p} 53$, these interactions would affect cell functions by drug effect screening studies without the inactivation facilities [77, 78]. The conditionally immortalized endothelial cells express several BBB transporters and give a good correlation with in vivo permeability data for six selected compounds although they do not form rigid TJs $[79,80]$. The expression of TJ proteins, such as claudin-5, occludin and junctional adhesion molecule $[79,80]$, might be down-regulated in this cell line due to the transfection.

In summary, the conditionally immortalized BBB model is suitable to investigate regulation of $\mathrm{BBB}$ functions, 
Table 1. Patented In Vitro BBB Models and Their Parameters.

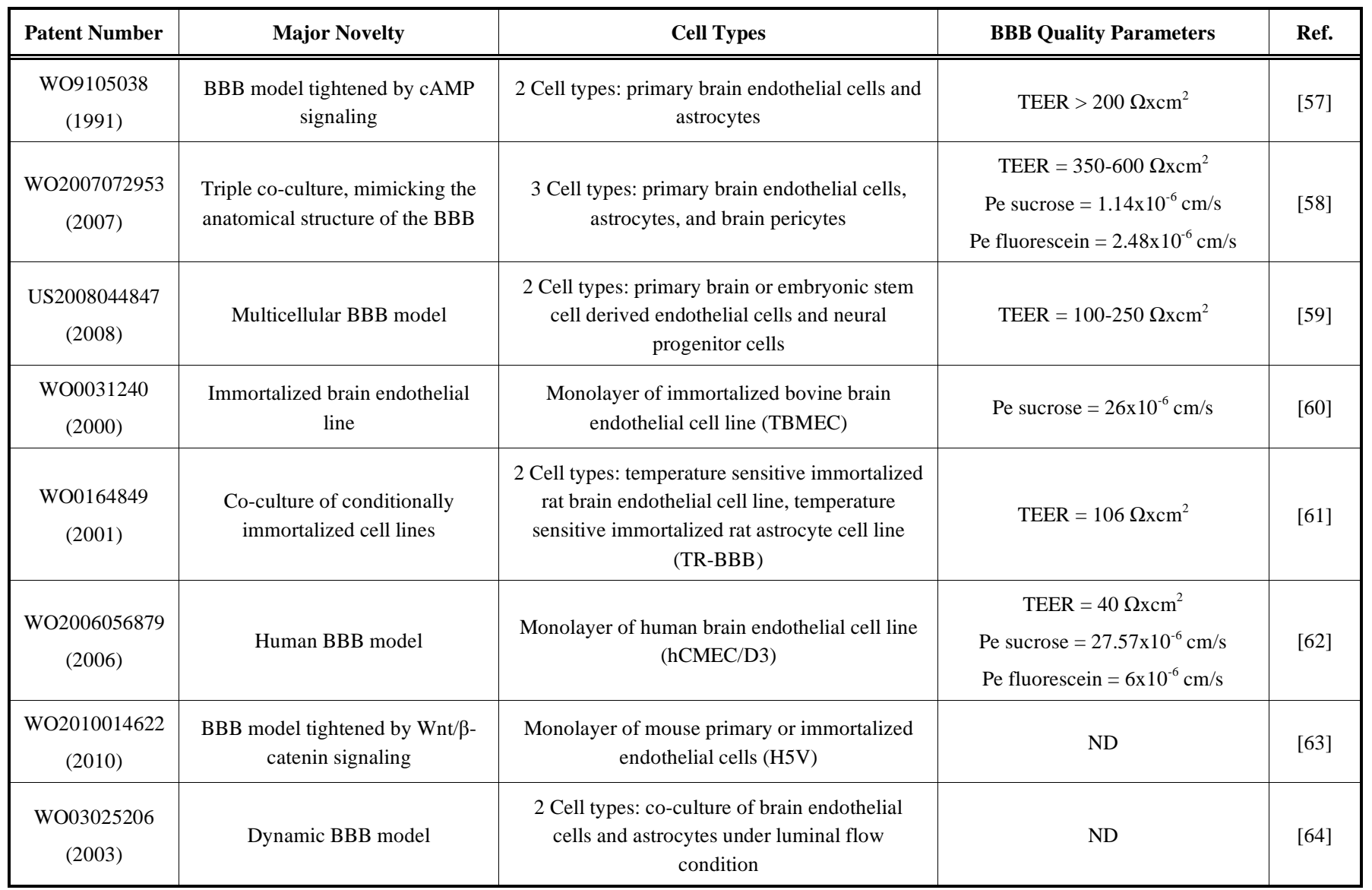

Abbreviations: ND, no data; TEER, transendothelial electrical resistance; $\mathrm{P}_{\mathrm{e}}$, endothelial permeability coefficient

especially transporter functions and can help to understand drug distribution under pathophysiologic conditions, such as brain edema and inflammation [81]. The TR-BBB cell line is mainly used in primary research, and nineteen scientific studies have been published since 2001, but application of the model for CNS drug testing or screening is not known.

\subsection{Human Cell Line}

The first stable, well characterized human brain endothelial cell line, hCMEC/D3 was patented in 2006 [62]. It shows several endothelial and $\mathrm{BBB}$ characteristics, including chemokine receptors, TJ proteins and drug efflux mechanisms [82]. It is claimed that the cell line retains many of the morphological and functional characteristics of brain endothelial cells, and expresses the major BBB efflux pumps [83-85] and several carriers from the SLC transporter family [86]. hCMEC/D3 cell layers in mono-culture show moderate paracellular barrier properties, see Table 1 [82]. When hCMEC/D3 cells were maintained in a dynamic system, the paracellular barrier properties were significantly improved and a high TEER value exceeding $1000 \Omega \times \mathrm{cm}^{2}$ was achieved [54]. It should be noted, that these TEER values were measured by a newly developed device (Flocel Inc., Cleveland, USA), which allows for real-time measurements in the cell culture cartridges of the dynamic model [54]. The permeability of the cell line was tested for 5 drugs and markers in static condition [82,83] and for two antiepileptic drugs in dynamic condition [54].

The two main advantages of hCMEC/D3 cell line are that it is a human cell line and has become the most widely used brain endothelial cell line in BBB research since 2005. The published data demonstrate that hCMEC/D3 cell line constitutes a valuable in vitro $\mathrm{BBB}$ model, which mimics the restricted permeability of brain endothelium for a wide variety of compounds, except for small hydrophilic molecules $(<300 \mathrm{Da})$ and ions. Permeability of centrally acting drugs, liposomes and solid lipid nanoparticles was also tested on the model [87-90]. Commercial application of the cell line for drug testing is not known.

\section{FACTORS AND CULTURE CONDITIONS INCREASING BBB PROPERTIES OF IN VITRO MODELS}

The unique BBB phenotype of brain endothelial cells is the result of continuous influence from the surrounding nervous tissue, although the details of this induction and the exact signalling mechanisms are still unclear [21, 28]. Besides co-culture with different cell types, several other culture conditions and factors, like sera, and serum components, hormones and growth factors, lipids, lipid mediators and lipoproteins have been tested to induce complex BBB 
phenotype and tighten paracellular barrier in BBB models [21]. Three of these treatment modalities were patented.

\subsection{Cyclic AMP Pathway}

Although previous studies were performed with second messenger systems to regulate $\mathrm{BBB}$ transport using in vivo and isolated brain capillary models, for review see Joó [12], Rubin et al. [57, 65] were the first to describe the effect of intracellular cAMP elevation on the barrier function of cultured brain endothelial cells. Increased cAMP in bovine brain endothelial cells either in co-culture with astrocytes or treated with astrocyte-conditioned medium resulted in a barrier tightening measured by 7 -fold higher TEER. In the patent, agents which can increase intraendothelial cAMP, namely cAMP analogs, compounds that stimulate endogenous adenylate cyclase activity, or compounds that inhibit the activity of cAMP phosphodiesterase (PDE) thereby inhibiting cAMP degradation were examined on cultures of endothelial cells [57]. The cAMP analog 8-(4-chlorophenylthio) cAMP (CPT-cAMP), forskolin, a cell-permeable adenylate cyclase activator, the PDE inhibitor 4-(3-butoxy-4methoxybenzyl)-2-imidazolidinone (RO-20-1724), and isoproterenol, a selective $\beta$-adrenergic agonist that stimulates adenylate cyclase activity and activates mitogen-activated protein (MAP) kinases all raised brain endothelial TEER [57, $65,66]$. The effect of forskolin on brain endothelial cells was also confirmed by other studies [91, 92]. Calcitonin generelated peptide and parathyroid hormone [65] and adrenomedullin $[32,93]$ also clearly demonstrated a cAMPlike effect. The permeability decreasing effect of cAMP analogs was more pronounced in the presence of PDE inhibitors theophylline, methylisobutylxanthine, rolipram, or RO-20-1724 [57]. Elevated intracellular cAMP levels resulted in barrier tightening and decreased paracellular flux in all BBB models tested, for review see [21].

The inventors claimed that the mode of action of cAMP analogs is the activation of protein kinases and protein phosphorylation Fig. (5A), and that the effects of cAMP are reversed by phosphoprotein phosphatases [57]. This finding is also supported by the quick effect of cAMP on brain endothelial permeability [94]. The integral membrane TJ proteins [95] were discovered after the issue of the patent, therefore they could not have been investigated at that time. Since then a protein kinase A independent cAMP-induced pathway has been identified to increase claudin- 5 expression, the most important occluding TJ protein at the BBB $[93,96]$. The freeze fracture electron microscopy results of Wolburg et al. [97] confirmed that an increased TJ strand formation between brain endothelial cells contribute to the effect of cAMP on paracellular permeability.

Importantly, the other regulatory cyclic nucleotide, cyclic GMP (cGMP) has an opposite effect than cAMP [57]. It has been discovered that increasing cGMP concentrations in brain endothelial cells lead to a decrease in resistance, and thus to an increase in TJ permeability [65, 98].

The application of cAMP elevation to induce barrier properties in BBB models became a widely used method in primary research $[17,19,20]$. However, such a model presents a problem in the screening of drugs that may influence intracellular cyclic nucleotides.

\subsection{Wnt/ק-catenin Signaling Pathway}

One of the major pathways regulating brain development is the wingless (Wnt) pathway, acting via $\beta$-catenin stabilization [99]. This favors translocation of $\beta$-catenin to the nucleus, binding to transcription factors of the lymphoid enhancer factor/T-cell factor (Lef/TCF) family and modulating gene transcription [100]. Dejana, Liebner and coworkers have found that endothelial $\mathrm{Wnt} / \beta$-catenin signaling regulates induction and maintenance of $\mathrm{BBB}$ characteristics during brain angiogenesis and postnatal vascular maturation $[63,101]$. This signaling pathway can upregulate BBBrelated genes, like TJ protein claudin-3 and barrier-related transporters, in endothelial cells Fig. (5B), whereas permeability-related genes, such as plasmalemma vesicle-associated protein (Plvap1), are down regulated [102]. Loss of $\beta$-catenin or inhibition of its signaling abrogates this effect causing down-regulation of claudin-3, an increase in Plvap1 and BBB breakdown [101].

Based on this knowledge, Dejana and Liebner have patented the method to tighten TJ between cultured brain endothelial cells via the Wnt/ $\beta$-catenin signaling [63]. Stabilization of $\beta$-catenin in primary or in $\mathrm{H} 5 \mathrm{~V}$ immortalized mouse brain endothelial cells increases claudin- 3 expression, TJ formation and a gene signature characteristic to BBB. Agents that stabilize $\beta$-catenin or inhibit its degradation activate $\mathrm{Wnt} / \beta$-catenin signaling. Such an agent can be a Wnt protein (Wntl, Wnt3, Wnt3a, and Wnt7a), or an agonist specific for Wnt/ $\beta$-catenin signaling, or an inhibitor of glycogen synthase kinase 3 (GSK3), such as lithium [63].

The Wnt/ $\beta$-catenin signaling pathway is a novel method to increase barrier functions in BBB models and shows a great potential [103]. However, further experiments and results are needed to reveal its applicability for models to test CNS drugs. A potential disadvantage of the method could be that it might not be suitable to screen neuropharmacon candidates interfering with the $\mathrm{Wnt} / \beta$-catenin signaling pathway.

\subsection{Fluid-induced Shear Stress}

In contrast to the static environment in standard culture conditions, blood vessels are exposed to fluid-induced shear and circumferential stresses in vivo. While all the abovementioned in vitro $\mathrm{BBB}$ models are static, a new dynamic BBB model has been developed by the group of Janigro [64, 104-107]. This model has a 3-dimensional tube structure with a continuous flow of culture medium mimicking the physiological shear stress in blood vessels Fig. (6). The dynamic BBB model was prepared by using different types of mono- and co-cultures, e.g. rat brain endothelial cells and rat astrocytes [45, 106, 107], human brain endothelial cells [108], and hCMEC/D3 immortalized human brain endothelial cell line [54] and the barrier and permeability properties were characterized. In the dynamic BBB model flow upregulated the barrier functions in all endothelial cell types [17].

A device to prepare such a dynamic BBB model was patented in 2003 [64]. The goal of the model is to better reproduce the physiological conditions found in vivo and to reintroduce important $\mathrm{BBB}$ properties in brain endothelial 

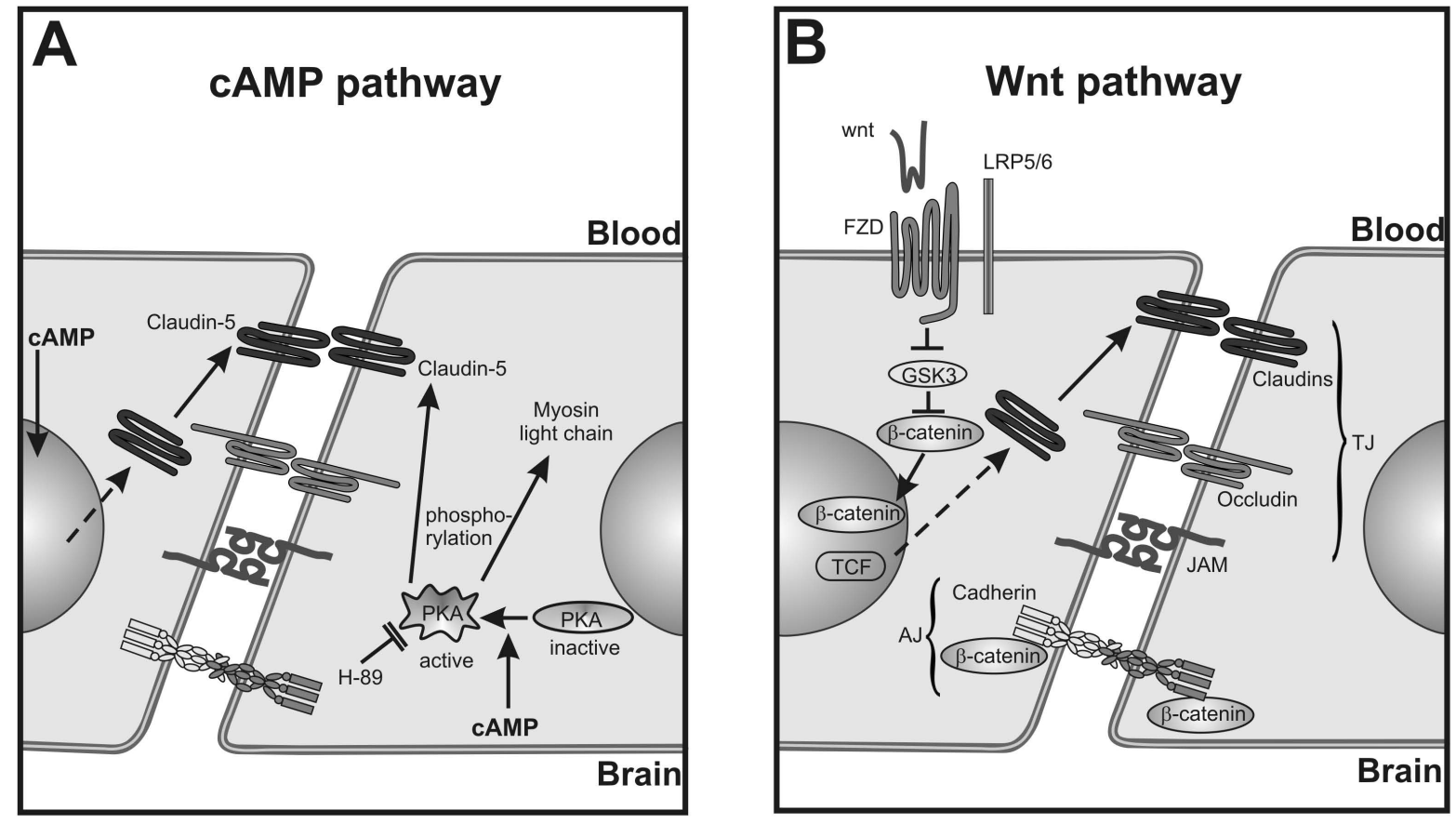

Fig. (5). Signaling pathways that lead to the tightening of the intercellular tight junctions (TJ) of brain endothelial cells. (A) Signaling pathways of cyclic AMP (cAMP) increase the tightness of brain endothelial cell monolayers via the activated expression of the claudin-5 gene in a protein kinase A (PKA)-independent manner and the cAMP-induced phosphorylation of claudin-5 and myosin light chain through a PKA-dependent way. (B) The activation of the Wnt pathway leads to the stabilization of $\beta$-catenin via the inhibition of glycogen synthase kinase 3 (GSK3). Translocation of $\beta$-catenin to the nucleus results in the activation of T-cell factor (TCF) dependent gene transcription of claudins, which in turn enhance the barrier function. Abbreviations: AJ, adherens junction; FZD, Wnt ligand receptor Frizzled; H-89, inhibitor of PKA; JAM, junctional adhesion molecule; LRP5/6, Wnt ligand receptor LDL receptor related protein 5/6. Figure modified from Refs. [95] and [102].

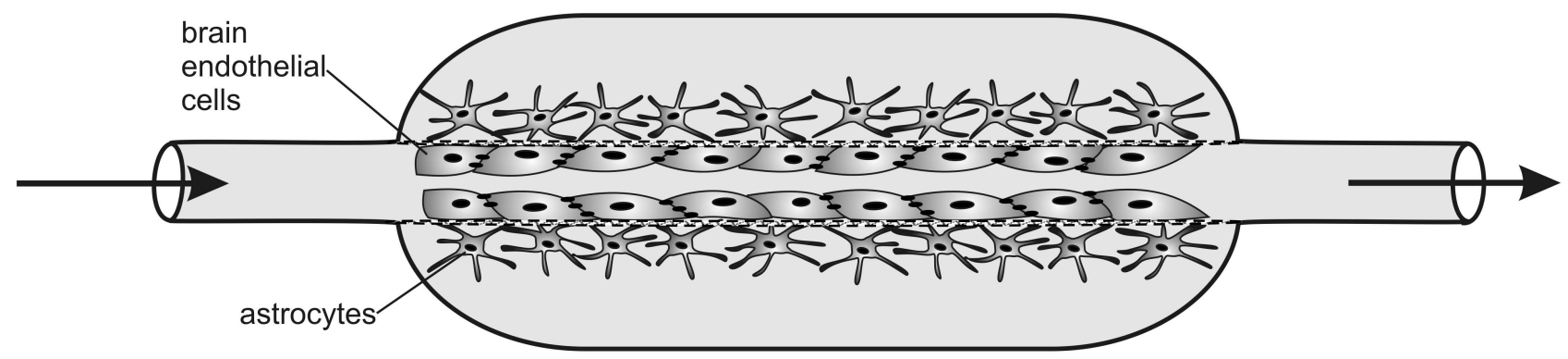

Fig. (6). A dynamic BBB model based on co-culture of brain endothelial and astroglial cells or cell lines using a device with porous membrane and flow condition to induce physiological BBB properties by shear stress.

cells. The aim of the invention was to address the limitations of a commercially available cell culture device not designated for BBB application and add functionality, modularity, and expandability of the experimental configuration. The dynamic model is monitored by a TEER measurement system (Flocel Inc., Cleveland, USA). Four electrodes are positioned in the culture cartridges, one pair in the luminal and one pair in the abluminal compartments that connect to a computerized monitoring system [54].

The major advantage of the arrangement is that it is more similar to in vivo conditions than static models. Due to the complexity of dynamic model, however, static models remain much more widespread both in primary and in applied research. The model is used by Flocel Inc., a company that does business in the field of cerebrovascular and $\mathrm{BBB}$ research.

\section{CURRENT \& FUTURE DEVELOPMENTS}

The increasing prevalence of CNS disorders and the introduction of new centrally active pharmacons and biomolecules need the prediction of brain penetration and $\mathrm{BBB}$ permeability. There is a demand for efficient and inexpensive in vitro $\mathrm{BBB}$ models to screen novel drug candidates that can be adapted as high throughput systems. The present BBB models will be further refined to achieve this goal.

Due to the requirement that a reliable model should present anatomically and physiologically realistic cell 
architecture, non-brain endothelial models will be replaced by systems using brain endothelial cells in co-culture with other elements of the neurovascular unit.

The introduction of new miniaturized microfluidic biochips in endothelial research will certainly enter the field of BBB models, too. Other important advances in cell culture based research are the optical and impedance-based real-time label-free measurements of cell changes, which could be combined with the present in vitro $\mathrm{BBB}$ systems in the future. Such future models may provide real-time tracking of TEER, optical monitoring of cell morphology with parallel measurement of permeability.

CNS penetration is multifaceted and is determined by three major parameters of drug delivery to brain, the permeability clearance to brain, the concentration ratio of unbound drug in brain to blood and the intra-brain distribution [6]. To estimate the rate and extent of drug disposition within the CNS an integrated approach is needed, where additional factors, such as plasma and brain tissue binding, brain interstitial fluid dynamics and plasma profile are also taken into account $[6,8]$. Therefore, a combination of different in vivo and in vitro methods, including the presented in vitro $\mathrm{BBB}$ models is suggested for estimating brain drug delivery.

Since species differences exist in the transport proteins of the BBB [109] and in pharmacokinetic parameters [110], monkey and human models are valuable and important for further development. Despite research efforts a simple, costeffective, validated human BBB cell culture model is not yet available for drug screening. The use of human pluripotent stem cells may provide breakthrough in this field. Our present knowledge on the permeability of the human BBB for different drugs is very limited and is mostly based on studies using positron emission tomography (PET) and single photon emission computed tomography. There are only a few papers with correlations between permeability data obtained on human in vitro BBB models and by PET imaging [111]. Novel techniques like near infrared optical tomography will lead to the accumulation of data on human $\mathrm{BBB}$ and will permit better and more relevant correlations between clinical data and in vitro models. It is expected, that in vitro models with parameters more closely matching the in vivo $\mathrm{BBB}$ will be developed in the near future that can provide more accurate and valuable data for CNS drug discovery than the present ones.

\section{ACKNOWLEDGEMENTS}

Andrea Tóth is grateful for the student grant and training course of the Hungarian Intellectual Property Office. The work in Dr. Niwa's laboratory was supported by a Grant-inAid for Scientific Research (C) (21591848) from the Ministry of Education, Culture, Sports, Science and Technology, Japan.

\section{CONFLICT OF INTEREST}

Dr. Masami Niwa is the applicant manager, and Drs. Shinsuke Nakagawa and Mária A. Deli are the inventors of patent WO2007072953 on the in vitro BBB model discussed in this review. Dr. Niwa (Director) and Dr. Nakagawa
(President) are shareholders of PharmaCo-Cell Co. Ltd. (Nagasaki, Japan), a company that does business in the field of $\mathrm{BBB}$ research. Dr. Deli is a scientific consultant to PharmaCo-Cell Co. Ltd.

\section{REFERENCES}

[1] Pardridge WM. Drug and gene targeting to brain with molecular Trojan horses. Nat Rev Drug Discov 2002; 1(2): 131-9.

[2] Cecchelli R, Berezowski V, Lundquist S, Culot M, Renftel M, Dehouck M-P, et al. Modelling of the blood-brain barrier in drug discovery and development. Nat Rev Drug Discov 2007; 6(8): 65061 .

[3] Abbott NJ. Dynamics of CNS barriers: Evolution, differentiation and modulation. Cell Mol Neurobiol 2005; 25(1): 5-23.

[4] Abbott NJ, Rönnbäck L, Hansson E. Astrocyte-endothelial interactions at the blood-brain barrier. Nature Rev Neurosci 2006; 7(1): 41-53.

[5] Terasaki T, Ohtsuki S. Brain-to-blood transporters for endogenous substrates and xenobiotics at the blood-brain barrier: an overview of biology and methodology. NeuroRx 2005; 2(1): 63-72.

[6] Hammarlund-Udenaes M, Fridén M, Syvänen S, Gupta A. On the rate and extent of drug delivery to the brain. Pharm Res 2008 25(8): 1737-50.

[7] Czeisler BM, Janigro D. Reading and writing the blood-brain barrier: Relevance to therapeutics. Recent Pat CNS Drug Discov 2006; 1(2): 157-73.

[8] Reichel A, Begley DJ, Abbott NJ. An overview of in vitro techniques for blood-brain barrier studies. In: Nag S, Ed. The Blood-Brain Barrier: Biology and Research Protocols, Vol. 89, Methods Molecular Medicine. Totowa: Humana Press 2003: 30724.

[9] Vastag M, Keserü GM. Current in vitro and in silico models of blood-brain barrier penetration: a practical view. Curr Opin Drug Discov Devel 2009; 12(1): 115-24.

[10] Joó F, Karnushina I. A procedure for the isolation of capillaries from rat brain. Cytobios 1973; 8(29): 41-8.

[11] Joó F. The blood-brain barrier in vitro: ten years of research on microvessels isolated from the brain. Neurochem Int 1985; 7(1): 125 .

[12] Joó F. The cerebral microvessels in culture, an update. J Neurochem 1992; 58(1): 1-17.

[13] Enerson BE, Drewes LR. The rat blood-brain barrier transcriptome. J Cereb Blood Flow Metab 2006; 26(7): 959-73.

[14] Ohtsuki S, Sato S, Yamaguchi H, Kamoi M, Asashima T, Terasaki T. Exogenous expression of claudin-5 induces barrier properties in cultured rat brain capillary endothelial cells. J Cell Physiol 2007; 210(1): 81-6.

[15] Bickel U. How to measure drug transport across the blood-brain barrier. NeuroRx 2005; 2(1): 15-26.

[16] Panula P, Joó F, Rechardt L. Evidence for the presence of viable endothelial cells in cultures derived from dissociated rat brain. Experientia 1978; 34(1): 95-7.

[17] Deli MA. Blood-Brain Barrier Models. In: Lajtha A, Ed. Handbook of Neurochemistry and Molecular Neurobiology, Neural Membranes and Transport, Vol. 11, New York: Springer 2007; 2956.

[18] Veszelka S, Kittel Á, Deli MA. Tools of Modelling Blood-Brain Barrier Penetrability (Chapter 11). In: Tihanyi K, Vastag M, Eds. Solubility, Delivery, and ADME Problems of Drugs and Drug Candidates, Bentham Science Publishers eBooks, 2011; in press.

[19] Perrière N, Demeuse P, Garcia E, Regina A, Debray M, Andreux $\mathrm{JP}$, et al. Puromycin-based purification of rat brain capillary endothelial cell cultures. Effect on the expression of blood-brain barrier-specific properties. J Neurochem 2005; 93(2): 279-89.

[20] Perrière N, Yousif S, Cazaubon S, Chaverot N, Bourasset F, Cisternino $\mathrm{S}$, et al. A functional in vitro model of rat blood-brain barrier for molecular analysis of efflux transporters. Brain Res 2007; 1150: 1-13.

[21] Deli MA, Ábrahám CS, Kataoka Y, Niwa M. Permeability studies on in vitro blood-brain barrier models: physiology, pathology and pharmacology. Cell Mol Neurobiol 2005; 25(1): 59-127. 
[22] Dehouck M-P, Méresse S, Delorme P, Fruchart JC, Cecchelli R. An easier, reproducible, and mass-production method to study the blood-brain barrier in vitro. J Neurochem 1990; 54(5): 1798-801.

[23] Hoheisel D, Nitz T, Franke H, Wegener J, Hakvoort A, Tilling T, et al. Hydrocortisone reinforces the blood-brain properties in a serum free cell culture system. Biochem Biophys Res Commun 1998; 247(2): 312-5.

[24] Bowman PD, Betz AL, Wolinsky JS, Penny JB, Shivers RR, Goldstein GW. Primary cultures of capillary endothelium from rat brain. In Vitro 1981; 17(4): 353-62.

[25] Bowman PD, Ennis SR, Rarey KE, Betz AL, Goldstein GW. Brain microvessel endothelial cells in tissue culture: A model for study of blood-brain barrier permeability. Ann Neurol 1983; 14(4): 396402.

[26] Rutten MJ, Hoover RL, Karnovsky MJ. Electrical resistance and macromolecular permeability of brain endothelial monolayer cultures. Brain Res 1987; 425(2): 301-10.

[27] Abbott NJ, Hughes CCW, Revest PA, Greenwood J. Development and characterization of a rat brain capillary endothelial culture: Towards an in vitro blood-brain barrier. J Cell Sci 1992; 103(1): 23-37.

[28] Zlokovic BV. The blood-brain barrier in health and chronic neurodegenerative disorders. Neuron 2008; 57(2): 178-201.

[29] Abbott NJ. Astrocyte-endothelial interactions and blood-brain barrier permeability. J Anat 2002; 200(5): 629-38.

[30] Tao-Cheng JH, Nagy Z, Brightman MW. Tight junctions of brain endothelium in vitro are enhanced by astroglia. J Neurosci 1987; 7(10): 3293-9.

[31] Haseloff RF, Blasig IE, Bauer H-C, Bauer H. In search of the astrocytic factor(s) modulating blood-brain barrier functions in brain capillary endothelial cells in vitro. Cell Mol Neurobiol 2005; 25(1): 25-39.

[32] Kis B, Deli MA, Kobayashi H, Ábrahám CS, Yanagita T, Kaiya H, et al. Adrenomedullin regulates blood-brain barrier functions in vitro. Neuroreport 2001; 12(18): 4139-42.

[33] Coisne C, Dehouck L, Faveeuw C, Delplace Y, Miller F, Landry C, et al. Mouse syngenic in vitro blood-brain barrier model: a new tool to examine inflammatory events in cerebral endothelium. Lab Invest 2005; 85(6): 734-46.

[34] Kása P, Pákáski M, Joó F, Lajtha A. Endothelial cells from human fetal brain microvessels may be cholinoceptive, but do not synthesize acetylcholine. J Neurochem 1991; 56(6): 2143-6.

[35] Dehouck M-P, Méresse S, Dehouck B, Fruchart JC, Cecchelli R. In vitro reconstituted blood-brain barrier. J Control Release 1992; 21(1-3): 81-92.

[36] Cecchelli R, Dehouck B, Descamps L, Fenart L, Buée-Scherrer V, Duhem $\mathrm{C}$, et al. In vitro model for evaluating drug transport across the blood-brain barrier. Adv Drug Deliv Rev 1999; 36(2-3): 16578

[37] Garberg P, Ball M, Borg N, Cecchelli R, Fenart L, Hurst RD, et al. In vitro models of the blood-brain barrier. Toxicol In Vitro 2005; 19(3): 299-334.

[38] Lundquist S, Renftel M, Brillault J, Fénart L, Cecchelli R, Dehouck M-P. Prediction of drug transport through the blood-brain barrier in vivo: a comparison between two in vitro cell models. Pharm Res 2002; 19(7): 976-81

[39] Culot M, Lundquist S, Vanuxeem D, Nion S, Landry C, Delplace $\mathrm{Y}$, et al. An in vitro blood-brain barrier model for high throughput (HTS) toxicological screening. Toxicol In Vitro 2008; 22(3): 799811.

[40] Cestelli A, Catania C, D'Agostino S, Di Liegro I, Licata L, Schiera $\mathrm{G}$, et al. Functional feature of a novel model of blood brain barrier: studies on permeation of test compounds. J Control Release 2001; 76(1-2): 139-47.

[41] Duport S, Robert F, Muller D, Grau G, Parisi L, Stoppini L. An in vitro blood-brain barrier model: Cocultures between endothelial cells and organotypic brain slice cultures. Proc Natl Acad Sci USA 1998; 95(4): 1840-5.

[42] Schiera G, Bono E, Raffa MP, Gallo A, Pitarresi GL, Di Liegro I, et al. Synergistic effects of neurons and astrocytes on the differentiation of brain capillary endothelial cells in culture. $\mathrm{J}$ Cell Mol Med 2003; 7(2): 165-70.

[43] Schiera G, Sala S, Gallo A, Raffa MP, Pitarresi GL, Savettieri G, et al. Permeability properties of a three-cell type in vitro model of blood-brain barrier. J Cell Mol Med 2005; 9(2): 373-9.
[44] Stanness KA, Guatteo E, Janigro D. A dynamic model of the blood-brain barrier "in vitro". Neurotoxicology 1996; 17(2): 48196.

[45] Stanness KA, Westrum LE, Fornaciari E, Mascagni P, Nelson JA, Stenglein SG, et al. Morphological and functional characterization of an in vitro blood-brain barrier model. Brain Res 1997; 771(2): 329-42.

[46] Kamouchi M, Ago T, Kitazono T. Brain pericytes: emerging concepts and functional roles in brain homeostasis. Cell Mol Neurobiol 2011; 31(2): 175-93.

[47] Armulik A, Genové G, Mäe M, Nisancioglu MH, Wallgard E, Niaudet $\mathrm{C}$, et al. Pericytes regulate the blood-brain barrier. Nature 2010; 468(7323): 557-61

[48] Daneman R, Zhou L, Kebede AA, Barres BA. Pericytes are required for blood-brain integrity during embryogenesis. Nature 2010; 468(7323): 562-6.

[49] Nakagawa S, Deli MA, Nakao S, Honda M, Hayashi K, Nakaoke $\mathrm{R}$, et al. Pericytes from brain microvessels strengthen the barrier integrity in primary cultures of rat brain endothelial cells. Cell Mol Neurobiol 2007; 27(6): 687-94.

[50] Nakagawa S, Deli MA, Kawaguchi H, Shimizudani T, Shimono T, Kittel Á, et al. A new blood-brain barrier model using brain endothelial cells, pericytes and astrocytes. Neurochem Int 2009; 54(3-4): 253-63.

[51] Gumbleton M, Audus KL. Progress and limitations in the use of in vitro cell cultures to serve as a permeability screen for the bloodbrain barrier. J Pharm Sci 2001; 90(1): 1681-98.

[52] Abbott NJ, Patabendige AA, Dolman DE, Yusof SR, Begley DJ. Structure and function of the blood-brain barrier. Neurobiol Dis 2010; 37(1): 13-25.

[53] Butt AM, Jones HC, Abbott NJ. Electrical resistance across the blood-brain barrier in anaesthetized rats: a developmental study. J Physiol 1990; 429(1): 47-62.

[54] Cucullo L, Couraud PO, Weksler B, Romero IA, Hossain M, Rapp $\mathrm{E}$, et al. Immortalized human brain endothelial cells and flowbased vascular modeling: A marriage of convenience for rational neurovascular studies. J Cereb Blood Flow Metab 2008; 28(2): 312-28.

[55] Gaillard PJ, de Boer AG. Relationship between permeability status of the blood-brain barrier and in vitro permeability coefficient of a drug. Eur J Pharm Sci 2000; 12(2): 95-102.

[56] Deli MA. Drug Transport and the Blood-Brain Barrier (Chapter 10). In: Tihanyi K, Vastag M, Eds. Solubility, Delivery, and ADME Problems of Drugs and Drug Candidates, Bentham Science Publishers eBooks, 2011; in press.

[57] Rubin, L.L., Porter, S., Horner, H.C., Yednock, T.A. Blood-brain barrier model. WO91005038 (1991)

[58] Niwa, M., Nakagawa, S., Deli, M.A. Blood-brain barrier in vitro model, pathologic blood-brain barrier in vitro model, drug screening method using the same, pathologic blood-brain barrier function analysis method and pathogenesis analysis method WO2007072953 (2007)

[59] Shusta, E.V., Weidenfeller, C., Svendsen, C.N. Blood-brain barrier model. US20080044847 (2008)

[60] Yazdanian, M., Bormann, B.J. Immortalized brain endothelial cells. WO00031240 (2000).

[61] Terasaki, T., Nakashima, E., Iizasa, H., Hosoya, K., Hattori, K. Blood-brain barrier reconstruction model prepared by cocultivation. WO01064849 (2001)

[62] Couraud, P.-O., Romero, I., Weksler, B. Human blood brain barrier model. WO2006056879 (2006).

[63] Dejana, E., Liebner, S. In vitro model for modulating the blood brain barrier and methods of screening. WO2010014622 (2010).

[64] Janigro, D., McAllister, M.S. Cell and tissue culture modeling device and apparatus and method of using same. WO2003025206 (2003).

[65] Rubin LL, Hall DE, Porter S, Barbu K, Cannon C, Horner HC, et al. A cell culture model of the blood-brain barrier. J Cell Biol $1991 ; 115(6)$ : 1725-35.

[66] Rubin LL, Staddon JM. The cell biology of the blood-brain barrier. Annu Rev Neurosci 1999; 22: 11-28.

[67] Ceruti S, Colombo L, Magni G, Viganò F, Boccazzi M, Deli MA et al. Oxygen-glucose deprivation increases ectonucleotidase activity in the cells composing the blood-brain barrier. Neurochem Int 2011; in press. 
[68] Nakagawa, S., Shimono, T. Method for freeze-preserving cell and method for culturing cell. JP 2008212062 (2008).

[69] Imamura S, Tabuchi M, Kushida H, Nishi A, Kanno H, Yamaguchi $\mathrm{T}$, et al. The blood-brain barrier permeability of geissoschizine methyl ether in uncaria hook, a galenical constituent of the traditional Japanese medicine Yokukansan. Cell Mol Neurobiol 2011; in press (DOI 10.1007/s10571-011-9676-3).

[70] Nakagawa S, Deli MA, Thuy DHD, Sagara M, So G, Yamada N, et al. An in vitro monkey BBB model. $13^{\text {th }}$ International Symposium Signal Transduction in the Blood-Brain Barrier. Zurich, Switzerland, September 2-4, 2010.

[71] LeVine SM, Goldman JE. Embryonic divergence of oligodendrocyte and astrocyte lineages in developing rat cerebrum. J Neurosci 1988; 8(11): 3991-4006.

[72] Virgintino D, Errede M, Robertson D, Girolamo F, Masciandaro A, Bertossi M. VEGF expression is developmentally regulated during human brain angiogenesis. Histochem Cell Biol 2003; 119(3): 22732.

[73] Shen Q, Goderie SK, Jin L, Karanth N, Sun Y, Abramova N, et al. Endothelial cells stimulate self-renewal and expand neurogenesis of neural stem cells. Science 2004; 304(5675): 1338-40.

[74] Mathieu C, Fouchet P, Gauthier LR, Lassalle B, Boussin FD, Mouthon MA. Coculture with endothelial cells reduces the population of cycling LeX neural precursors but increases that of quiescent cells with a side population phenotype. Exp Cell Res 2006; 312(6): 707-18.

[75] Weidenfeller C, Svendsen CN, Shusta EV. Differentiating embryonic neural progenitor cells induce blood-brain barrier properties. J Neurochem 2007; 101(2): 555-65.

[76] Lim JC, Wolpaw AJ, Caldwell MA, Hladky SB, Barrand MA. Neural precursor cell influences on blood-brain barrier characteristics in rat brain endothelial cells. Brain Res 2007; 1159: 67-76.

[77] Yanai N, Obinata M. Apoptosis is induced at nonpermissive temperature by a transient increase in p53 in cell lines immortalized with temperature-sensitive SV40 large T-antigen gene. Exp Cell Res 1994; 211(2): 296-300.

[78] Taher A, Yanai N, Obinata M. Properties of incompletely immortalized cell lines generated from a line established from temperature-sensitive SV40 T-antigen gene transgenic mice. Exp Cell Res 1995; 219(2): 332-8.

[79] Hosoya KI, Takashima T, Tetsuka K, Nagura T, Ohtsuki S, Takanaga $\mathrm{H}$, et al. mRNA expression and transport characterization of conditionally immortalized rat brain capillary endothelial cell lines; a new in vitro BBB model for drug targeting. J Drug Target 2000; 8(6): 357-70.

[80] Hosoya K, Tetsuka K, Nagase K, Tomi M, Saeki S, Ohtsuki S, et al. Conditionally immortalized brain capillary endothelial cell lines established from a transgenic mouse harboring temperaturesensitive simian virus 40 large T-antigen gene. AAPS PharmSci 2000; 2(3): E27.

[81] Terasaki T, Ohtsuki S, Hori S, Takanaga H, Nakashima E, Hosoya $\mathrm{K}$. New approaches to in vitro models of blood-brain barrier drug transport. Drug Discov Today 2003; 8(20): 944-54.

[82] Weksler BB, Subileau EA, Perrière N, Charneau P, Holloway K, Levegue $\mathrm{M}$, et al. Blood-brain barrier-specific properties of a human adult brain endothelial cell line. FASEB J 2005; 19(13): 1872-4.

[83] Poller B, Gutmann H, Krähenbühl S, Weksler B, Romero I, Couraud PO, et al. The human brain endothelial cell line hCMEC/D3 as a human blood-brain barrier model for drug transport studies. J Neurochem 2008; 107(5): 1358-68.

[84] Dauchy S, Dutheil F, Weaver RJ, Chassoux F, Daumas-Duport C, Couraud PO, et al. ABC transporters, cytochromes $\mathrm{P} 450$ and their main transcription factors: Expression at the human blood-brain barrier. J Neurochem 2008; 107(6): 1518-28.

[85] Tai LM, Reddy PS, Lopez-Ramirez MA, Davies HA, Male DK, Loughlin AJ, et al. Polarized P-glycoprotein expression by the immortalised human brain endothelial cell line, hCMEC/D3, restricts apical-to-basolateral permeability to rhodamine 123 . Brain Res 2009; 1292: 14-24.

[86] Carl SM, Lindley DJ, Couraud PO, Weksler BB, Romero I, Mowery SA, et al. ABC and SLC transporter expression and pot substrate characterization across the human CMEC/D3 blood-brain barrier cell line. Mol Pharm 2010; 7(4): 1057-68.
[87] Chattopadhyay N, Zastre J, Wong HL, Wu XY, Bendayan R. Solid lipid nanoparticles enhance the delivery of the HIV protease inhibitor, atazanavir, by a human brain endothelial cell line. Pharm Res 2008; 25(10): 2262-71.

[88] van Rooy I, Cakir-Tascioglu S, Couraud PO, Romero IA, Weksler $\mathrm{B}$, Storm G, et al. Identification of peptide ligands for targeting to the blood-brain barrier. Pharm Res 2010; 27(4): 673-82.

[89] Markoutsa E, Pampalakis G, Niarakis A, Romero IA, Weksler B, Couraud PO, et al. Uptake and permeability studies of BBBtargeting immunoliposomes using the hCMEC/D3 cell line. Eur J Pharm Biopharm 2011; 77(2): 265-74.

[90] Nieto L, Mascaraque A, Miller F, Glacial F, Ríos Martínez C, Kaiser M, et al. Synthesis and antiprotozoal activity of N-alkoxy analogues of the trypanocidal lead compound 4,4' bis(imidazolinylamino)diphenylamine with improved human blood-brain barrier permeability. J Med Chem 2011; 54(2): 485-94.

[91] Brückener KE, el Bayâ A, Galla H-J, Schmidt MA. Permeabilization in a cerebral endothelial barrier model by pertussis toxin involves the PKC effector pathway and is abolished by elevated levels of cAMP. J Cell Sci 2003; 116(Pt 9): 1837-46.

[92] Zenker D, Begley D, Bratzke H, Rübsamen-Waigmann H, von Briesen H. Human blood-derived macrophages enhance barrier function of cultured brain capillary endothelial cells. J Physiol 2003; 551(Pt 3): 1023-32.

[93] Honda M, Nakagawa S, Hayashi K, Kitagawa N, Tsutsumi K, Nagata I, et al. Adrenomedullin improves the blood-brain barrier function through the expression of claudin-5. Cell Mol Neurobiol 2006; 26(2): 109-18.

[94] Deli MA, Dehouck MP, Ábrahám CS, Cecchelli R, Joó F. Penetration of small molecular weight substances through cultured bovine brain capillary endothelial cell monolayers: The early effects of cyclic adenosine 3',5'-monophosphate. Exp Physiol 1995; 80(4): 675-8

[95] Krizbai IA, Deli MA. Signalling pathways regulating the tight junction permeability in the blood-brain barrier. Cell Mol Biol (Noisy-le-grand) 2003; 49(1): 23-31.

[96] Ishizaki T, Chiba H, Kojima T, Fujibe M, Soma T, Miyajima H, et al. Cyclic AMP induces phosphorylation of claudin-5 immunoprecipitates and expression of claudin-5 gene in blood-brain-barrier endothelial cells via protein kinase A-dependent and -independent pathways. Exp Cell Res 2003; 290(2): 275-88

[97] Wolburg H, Neuhaus J, Kniesel U, Krauss B, Schmid EM, Oçalan $\mathrm{M}$, et al. Modulation of tight junction structure in blood-brain barrier endothelial cells. Effects of tissue culture, second messengers and cocultured astrocytes. J Cell Sci 1994; 107(Pt 5): 1347-57.

[98] Fischer S, Clauss M, Wiesnet M, Renz D, Schaper W, Karliczek GF. Hypoxia induces permeability in brain microvessel endothelial cells via VEGF and NO. Am J Physiol 1999; 276(4 Pt 1): C812-20.

[99] Clevers H. Wnt/beta-catenin signaling in development and disease. Cell 2006; 127(3): 469-80.

[100] Moon SO, Kim W, Kim DH, Sung MJ, Lee S, Kang KP, et al. Angiopoietin-1 reduces iopromide-induced endothelial cell apoptosis through activation of phosphatidylinositol 3'-kinase/p70 S6 kinase. Int J Tissue React 2005; 27(3): 115-24.

[101] Liebner S, Corada M, Bangsow T, Babbage J, Taddei A, Czupalla $\mathrm{CJ}$, et al. Wnt/ $\beta$-catenin signaling controls development of the blood-brain barrier. J Cell Biol 2008; 183(3): 409-17.

[102] Liebner S, Plate KH. Differentiation of the brain vasculature: the answer came blowing by the Wnt. J Angiogenes Res 2010; 2:1.

[103] Polakis P. Formation of the blood-brain barrier: Wnt signaling seals the deal. J Cell Biol 2008; 183(3): 371-3.

[104] Stanness KA, Neumaier JF, Sexton TJ, Grant GA, Emmi A, Maris DO, et al. A new model of the blood-brain barrier: co-culture of neuronal, endothelial and glial cells under dynamic conditions. Neuroreport 1999; 10(18): 3725-31.

[105] Parkinson FE, Friesen J, Krizanac-Bengez L, Janigro D. Use of a three-dimensional in vitro model of the rat blood-brain barrier to assay nucleoside efflux from brain. Brain Res 2003; 980(2): 23341.

[106] Krizanac-Bengez L, Kapural M, Parkinson F, Cucullo L, Hossain M, Mayberg MR, et al. Effects of transient loss of shear stress on blood-brain barrier endothelium: role of nitric oxide and IL-6. Brain Res 2003; 977(2): 239-46

[107] Krizanac-Bengez L, Mayberg MR, Cunningham E, Hossain M, Ponnanpalam S, Parkinson FE, et al. Loss of shear stress induces 
leukocyte-mediated cytokine release and blood-brain barrier failure in dynamic in vitro blood-brain barrier model. J Cell Physiol 2006; 206(1): 68-77.

[108] Cucullo L, Hossain M, Rapp E, Manders T, Marchi N, Janigro D. Development of a humanized in vitro blood-brain barrier model to screen for brain penetration of antiepileptic drugs. Epilepsia 2007; 48(3): 505-16

[109] Syvänen S, Lindhe O, Palner M, Kornum BR, Rahman O, Långström $\mathrm{B}$, et al. Species differences in blood-brain barrier transport of three positron emission tomography radioligands with emphasis on P-glycoprotein transport. Drug Metab Dispos 2009; 37(3): 635-43.

[110] Ward KW, Coon DJ, Magiera D, Bhadresa S, Nisbett E, Lawrence MS. Exploration of the African green monkey as a preclinical pharmacokinetic model: intravenous pharmacokinetic parameters. Drug Metab Dispos 2008; 36(4): 715-20.

[111] Mabondzo A, Bottlaender M, Guyot AC, Tsaouin K, Deverre JR, Balimane PV. Validation of in vitro cell-based human blood-brain barrier model using clinical positron emission tomography radioligands to predict in vivo human brain penetration. Mol Pharm 2010; 7(5): 1805-15. 


\section{PUBLICATION III.}




\title{
Docosahexaenoic Acid Reduces Amyloid- $\beta$ Induced Toxicity in Cells of the Neurovascular Unit
}

\author{
Szilvia Veszelka ${ }^{\mathrm{a}}$, Andrea E. Tóth ${ }^{\mathrm{a}}$, Fruzsina R. Walter ${ }^{\mathrm{a}}$, Zsolt Datki ${ }^{\mathrm{b}}$, Emese Mózes ${ }^{\mathrm{b}}$, Lívia Fülöp ${ }^{\mathrm{b}}$, \\ Zsolt Bozsó $^{b}$, Éva Hellinger ${ }^{\mathrm{c}}$, Monika Vastag ${ }^{\mathrm{c}}$, Barbara Orsolits ${ }^{\mathrm{d}}$, Zsuzsanna Környei ${ }^{\mathrm{d}}$, \\ Botond Penke ${ }^{\mathrm{b}}$ and Mária A. Deli ${ }^{\mathrm{a}, *}$ \\ ${ }^{\mathrm{a}}$ Institute of Biophysics, Biological Research Centre of the Hungarian Academy of Sciences, Szeged, Hungary \\ ${ }^{\mathrm{b}}$ Department of Medical Chemistry, University of Szeged, Szeged, Hungary \\ ${ }^{\mathrm{c}}$ Division of Pharmacology and Drug Safety Research, Gedeon Richter Plc., Budapest, Hungary \\ ${ }^{\mathrm{d}}$ Institute of Experimental Medicine of the Hungarian Academy of Sciences, Budapest, Hungary
}

Handling Associate Editor: William Banks

Accepted 3 April 2013

\begin{abstract}
Alzheimer's disease (AD) is characterized by the accumulation of amyloid- $\beta$ peptides (A $\beta$ ) as perivascular deposits and senile plaques in the brain. The intake of the polyunsaturated fatty acid docosahexaenoic acid (DHA) has been associated with decreased amyloid deposition and reduced risk in $\mathrm{AD}$ in several epidemiological trials; however the exact underlying molecular mechanism remains to be elucidated. The aim of the study was to test whether DHA can exert a direct protective effect on the elements of the neurovascular unit, such as neurons, glial cells, brain endothelial cells, and pericytes, treated with $\mathrm{A} \beta_{42}(15 \mu \mathrm{M})$. A dose-dependent high cellular toxicity was found in viability assays in all cell types and on acute hippocampal slices after treatment with $\mathrm{A} \beta_{42}$ small oligomers prepared in situ from an isopeptide precursor. The cell morphology also changed dramatically in all cell types. In brain endothelial cells, damaged barrier function and increased para- and transcellular permeability were observed after peptide treatment. The production of reactive oxygen species was elevated in pericytes and endothelial and glial cells. DHA $(30 \mu \mathrm{M})$ significantly decreased the $A \beta_{42}$-induced toxic effects in all cell types measured by viability assays, and protected the barrier integrity and functions of brain endothelial cells. DHA also decreased the elevated rhodamine 123 accumulation in brain endothelial cells pre-treated with $\mathrm{A} \beta_{42}$ indicating an effect on efflux pump activity. These results indicate for the first time that DHA can protect not only neurons but also the other elements of the neurovascular unit from the toxic effects of $A \beta_{42}$ and this effect may be beneficial in $A D$.
\end{abstract}

Keywords: Alzheimer's disease, amyloid- $\beta$, blood-brain barrier, brain endothelial cells, docosahexaenoic acid, glia, neuron, neurovascular unit, pericyte, P-glycoprotein

${ }^{*}$ Correspondence to: Mária A. Deli, M.D., Ph.D., D.Sc., Institute of Biophysics, Biological Research Centre of the Hungarian Academy of Sciences, Temesvári krt. 62., H-6726 Szeged, Hungary. Tel.: +36 62 599602; Fax: +36 62 433133; E-mail: deli.maria@ brc.mta.hu.

\section{INTRODUCTION}

Neurons and their associated glial cells interacting with endothelial cells and pericytes of brain microvessels are organized into well-structured neurovascular units. The proper function of this unit is responsible not only for the neuronal activity dependent oxygen and nutrient supply of the brain, but also for 
neuro-hemodynamic coupling, neuro-angiogenic coupling, and neuro-trophic coupling [1]. Neurovascular mechanisms play a crucial role in cognitive decline and neurodegeneration in Alzheimer's disease (AD) [2-6]. Cerebral amyloid angiopathy and senile plaques are two of the pathological hallmarks in brains of patients with $\mathrm{AD}$. The major component of amyloid deposition is the amyloid- $\beta$ peptide $(A \beta)$, cleaved from amyloid$\beta$ protein precursor by secretases. The dysfunction of the cerebral circulation induces decreased clearance of $\mathrm{A} \beta$ across the blood-brain barrier (BBB) formed by brain microvascular endothelial cells and pericytes. In addition to production of the peptide, transport of $A \beta$ across the $\mathrm{BBB}$ is essential in controlling $\mathrm{A} \beta$ levels in the brain [7, 8]. The dysfunction of the cerebrovascular system leads to disturbed homeostasis, neuronal dysfunction, and secondary neuronal loss $[2,4,6]$. Protection of the neurovascular unit from injury is among the proposed new strategies for the therapy of $\mathrm{AD}$ [1].

Epidemiological observations suggest that high unsaturated fatty acid intake has been associated with decreased risk of dementia [9-12]. In particular longchain polyunsaturated $\omega-3$ fatty acids ( $n-3$ PUFAs) found in marine fish have become of major interest. Docosahexaenoic acid (DHA), the end product of $n-3$ PUFA synthesis, is essential for brain maturation and as an important membrane component it plays a primary role in neurotransmission. DHA is responsible for the neuroprotective action on developing cholinergic neurons against glutamate cytotoxicity [13]. A reduced level of DHA was found in AD patients [14] and in AD postmortem brains [15] compared with age-matched healthy controls. DHA reduces $A \beta_{42}$ peptide production in animal models of $\mathrm{AD}[16,17]$ and chronic DHA treatment improves cognition in 3xTG-AD mice [18]. However clinical studies found no effect or only minor effects of DHA on the improvement of cognitive functions in the very early stage of the disease [19-22].

Based on these data, DHA can be potentially important in the prevention of $\mathrm{AD}$, however there are no data on its effect on the cells of the neurovascular unit, except neurons [23-25], and its mechanism of action against $A \beta_{42}$ peptide toxicity. Therefore the aim of the present study was to test the effect of DHA not only on neurons, but also on other important elements of neurovascular unit, such as glial cells, brain endothelial cells, and pericytes. In addition, BBB functions and reactive oxygen species (ROS) production were also tested on a relevant in vitro BBB model made from primary rat brain endothelial cells, glial cells, and pericytes [26, 27].

\section{MATERIALS AND METHODS}

All reagents were purchased from Sigma-Aldrich, Hungary, unless otherwise indicated.

\section{Synthesis of 'iso- $A \beta_{42}$ ' and characterization of oligomers}

The synthesis of 'iso- $A \beta_{42}$ ' was discussed in details by Bozso et al. [28]. Briefly the peptide was synthesized using Boc-chemistry on a Boc-Ala-PAM resin. Acylation of the $\alpha$-amino groups was done by activating threefold excess of $\mathrm{N}^{\alpha}$ - Boc protected amino acids (or 2-Cl-Z-Ser(OtBu)-OH for position 26) with DCC/1-hydroxybenzotriazole in DCM/DMF (dichloromethane-dimethyl formamide, 1:1) and the peptide resin was reacted with this mixture for $2 \mathrm{~h}$. If incomplete acylation was detected by the qualitative ninhydrin test, the coupling was repeated with DCC/1-hydroxy-7-azabenzotriazole activation. Boc and $\mathrm{tBu}$ groups were removed by treating the resin with $50 \%$ triflouroacetic acid/DCM mixture twice $(5+25 \mathrm{~min})$. Neutralization was performed with $5 \%$ N,N-diisopropylethylamine/DCM $(2 \times 1 \mathrm{~min})$. Esterification of the hydroxyl group of $\mathrm{Ser}^{26}$ with Boc-Gly-OH was performed by treating the peptide-resin with Fmoc-Gly/DCC/Nmethylimidazole (10-fold excess) in DCM/DMF ( $3: 1)$ for $2 \times 4 \mathrm{~h}$. The peptide was cleaved from the resin with a mixture containing hydrogen fluoride $(10 \mathrm{~mL})$, anisol $(0.2 \mathrm{~mL})$, dimethyl sulfide $(0.8 \mathrm{~mL})$, and dithiothreitol $(0.1 \mathrm{~g})$ at $0^{\circ} \mathrm{C}$ for $45 \mathrm{~min}$. The crude product was precipitated and washed with diethyl-ether, dissolved in $50 \%$ acetic acid/water, lyophilized, and purified by HPLC. At physiological conditions $\left(37^{\circ} \mathrm{C}\right.$ and $\left.\mathrm{pH} 7.4\right)$, iso- $\mathrm{A} \beta_{42}$ in situ forms oligomeric $\mathrm{A} \beta_{42}$ via an $\mathrm{O}-\mathrm{N}$ acyl-transfer reaction. The aggregates were visualized by transmission electron microscopy. Iso- $\mathrm{A} \beta_{42}$ forms round shaped oligomers, which can be characterized with a bimodal size-distribution: the small aggregates have an average diameter of $5.3 \pm 1.0 \mathrm{~nm}$, while the large spherical aggregates have $7.9 \pm 3.3 \mathrm{~nm}$. The oligomers applied in $15 \mu \mathrm{M}$ concentration aggregate slowly in vitro after $24 \mathrm{~h}$ of incubation. Protofibrillar assemblies having a length of 30-100 nm with an average diameter of $8.4 \pm 2.1 \mathrm{~nm}$ are present together with spherical oligomers.

\section{Cell culture}

Primary neuronal cultures were prepared from Wistar rat forebrains at embryonic day 16 by mechanical 
dissociation using fire-polished Pasteur pipettes as described previously [29]. The cell suspension was filtered through a nylon mesh with a pore diameter of $45 \mu \mathrm{m}$ to obtain single cells. The cells were seeded onto poly-L-lysine coated 96-well plates or glass coverslips with a density of $2.5 \times 10^{5} \mathrm{cell} / \mathrm{cm}^{2}$ in Eagle's Minimum Essential Medium (MEM) supplemented with $4 \mathrm{mM}$ glutamine, $40 \mu \mathrm{g} / \mathrm{ml}$ gentamycin, and $5 \%$ fetal calf serum (FCS; PAA, Austria). The medium was changed to defined medium (MEM-F12 supplemented with insulin, transferrin, and sodium selenite) $24 \mathrm{~h}$ after plating. The cultures were maintained in humidified air atmosphere containing 5\% $\mathrm{CO}_{2}$, at $37^{\circ} \mathrm{C}$. The obtained primary cultures has been extensively studied and characterized and the number of neurons was above $80-90 \%$ of total cell number [29].

Primary cultures of cerebral endothelial cells were prepared from 2-week-old rats as described earlier in detail [30-32]. Forebrains were collected in ice-cold sterile phosphate buffered saline (PBS); meninges were removed, gray matter was minced by scalpels to $1 \mathrm{~mm}^{3}$ pieces and digested with $1 \mathrm{mg} / \mathrm{ml}$ collagenase CLS2 (Worthington, USA) in Dulbecco's modified Eagle medium (DMEM) for $1.5 \mathrm{~h}$ at $37^{\circ} \mathrm{C}$. Microvessels were separated by centrifugation in $20 \%$ bovine serum albumin (BSA)-DMEM $(1000 \times \mathrm{g}, 20 \mathrm{~min})$ from myelin containing elements, and further digested with $1 \mathrm{mg} / \mathrm{ml}$ collagenase-dispase (Roche) in DMEM for $1 \mathrm{~h}$. Microvascular endothelial cell clusters were separated on a $33 \%$ continuous Percoll gradient $(1000 \times \mathrm{g}, 10 \mathrm{~min})$, collected, and washed twice in DMEM before plating on collagen type IV and fibronectin coated dishes (Falcon, Becton Dickinson). Cultures were maintained in DMEM/F12 supplemented with $50 \mu \mathrm{g} / \mathrm{ml}$ gentamicin, $15 \%$ plasma-derived bovine serum (First Link, UK), $1 \mathrm{ng} / \mathrm{ml}$ basic fibroblast growth factor (Roche), insulin $(5 \mu \mathrm{g} / \mathrm{ml})$, transferrin $(5 \mu \mathrm{g} / \mathrm{ml})$, sodium selenite $(5 \mathrm{ng} / \mathrm{ml})$ (insulin-transferrin-sodium selenite media supplement), and $100 \mu \mathrm{g} / \mathrm{ml}$ heparin. In the first 3 days, culture medium contained puromycin ( $4 \mu \mathrm{g} / \mathrm{ml})$ to selectively remove P-glycoprotein negative contaminating cells [33]. The endothelial cell cultures were immunopositive for von Willebrand factor and negative for the astroglia cell marker glial fibrillary acidic protein (GFAP) and $\alpha$-smooth muscle actin ( $\alpha$-SMA) in accordance with earlier published results [33, 34]. When the cultures reached $80 \%$ confluency (fourth day in vitro), the purified endothelial cells were passaged to multiwell plates or Transwell filter inserts by a brief treat- ment with trypsin $(0.05 \% \mathrm{wt} / \mathrm{vol})$-EDTA $(0.02 \%$ $\mathrm{wt} / \mathrm{vol}$ ) solution, and used for experiments. To induce BBB characteristics, brain endothelial cells were treated with glia/pericyte-conditioned medium or cocultured with rat cerebral glial cells and rat pericytes [26].

Primary cultures of glial cells were prepared from newborn Wistar rats [31, 32]. Meninges were removed, and cortical pieces were mechanically dissociated in DMEM containing $50 \mu \mathrm{g} / \mathrm{ml}$ gentamicin and $10 \%$ FBS and plated in poly-L-lysin coated 12-well dishes and kept for minimum 3 weeks before use. In confluent glia cultures, $90 \%$ of cells were immunopositive for GFAP, while the remaining $10 \%$ were immunopositive for CD11b, a marker of microglia. For co-culture, brain endothelial cells in cell culture inserts were placed into multiwells containing astroglia at the bottom of the wells with endothelial culture medium in both compartments.

Pure cultures of rat cerebral pericytes were obtained by a prolonged, 2-week culture of isolated rat brain microvessel fragments that contain pericytes beside endothelial cells. The same preparations yield primary brain endothelial cells except puromycin-treatment. Pericyte survival and proliferation were favored by selective culture conditions, using uncoated dishes, and DMEM supplemented with $10 \%$ FBS and antibiotics. Culture medium was changed every 3 days. As described in our previous papers [34, 35], cultured brain microvascular pericytes show typical morphology of large, flat multipolar cells with several branches in accordance with literature data [36] and look similar to the pericyte cultures described by Vandenhaute et al. [37]. Pericyte cultures are regularly checked and positive for $\alpha$-SMA (97\% positivity) and NG2 (94\% positivity) and completely negative for GFAP and vWF immunostaining as shown by Nakagawa et al. [34]. Therefore we can exclude the glial and endothelial contamination of the pericyte cultures. Since the cultures are made from brain microvessel fractions where pericytes are more numerous than smooth muscle cells, we assume that the number of smooth muscle cells in our preparations is minimal.

To construct the three cell-type BBB model, Transwell cell culture inserts were placed into multiwell plates containing astroglia at the bottom of the wells, pericytes were seeded on the bottom side of the inserts, and finally endothelial cells were passaged to the upper side of the inserts coated with fibronectin and collagen type IV with endothelial culture medium in both compartments [26]. 
Preparation and treatment of acute hippocampal slices

A slightly modified version of the method reported by Datki et al. [38, 39] was used in our slice viability experiments. After anesthesia with chloral hydrate $(0.4 \mathrm{~g} / \mathrm{kg}), 10 \pm 1$ week-old male Wistar rats were decapitated and the whole heads (without scalpleather) were put in ice cold distillated water for $1 \mathrm{~min}$. The brains were quickly removed and immersed in $\mathrm{H}-\mathrm{ACSF} / 1$ (preparation solution substituted with HEPES) with very low $\mathrm{Ca}^{2+}$ and with elevated $\mathrm{Mg}^{2+}$ concentration at $4^{\circ} \mathrm{C}$. The composition of this preparation solution (in $\mathrm{mM}$ ) was the following: $\mathrm{NaCl} 122$, $\mathrm{KCl} 3, \mathrm{CaCl}_{2}$ 0.3, $\mathrm{MgCl}_{2}$ 3.7, $\mathrm{NaHCO}_{3}$ 25, HEPES 5 , D-glucose 10, $\mathrm{pH}=7.4$. Brain slices (thickness was $400 \mu \mathrm{m}$ ) were prepared from the hippocampus with a McIlwain tissue chopper at $4^{\circ} \mathrm{C}$. After the preparation of the slices in ice-cold H-ACSF/1 solution, we took photos of them (to measure the slice area). The slices (with an area of approximately $9 \mathrm{~mm}^{2}$ ) were quickly transferred into the ExViS mini-chamber (maximum 5 slices in $1 \mathrm{ml}$ ) for conditioning $(30 \mathrm{~min})$ in the carboxygenated $\left(95 / 5 \%: \mathrm{O}_{2} / \mathrm{CO}_{2}\right)$ preparation solution at room temperature $\left(24^{\circ} \mathrm{C}\right)$.

After resting $(30 \mathrm{~min})$ in the carboxygenated $\mathrm{H}$ $\mathrm{ACSF} / 1$ solution at room temperature, the transduction of the brain slices from the mini-chamber into the plastic Petri dish was executed with cut-off pipettes (type $200 \mu \mathrm{l}$ ) and was left to rest in glucose- and carboxygenated-free (glucose-oxygen deprivation) $\mathrm{H}$ ACSF/2 (4 ml/Petri dish) for $1 \mathrm{~h}$. The composition of this $\mathrm{H}-\mathrm{ACSF} / 2$ (in $\mathrm{mM}$ ) was the following: $\mathrm{NaCl}$ $132, \mathrm{KCl} 3, \mathrm{CaCl}_{2} 2, \mathrm{MgCl}_{2} 2, \mathrm{NaHCO}_{3} 25$, HEPES $5, \mathrm{pH}=7.4$. The Petri dish was continuously being stirred at $370 \mathrm{rpm}$ (modified BIOSAN TS-100 thermo shaker). After resting being treated in glucose- and oxygen-free $\mathrm{H}-\mathrm{ACSF} / 2$, the content (supernatant) of the Petri dish was changed to the H-ACSF/3 solution ( $3 \mathrm{ml} /$ Petri dish). The composition of this preparation solution (in $\mathrm{mM}$ ) was the following: $\mathrm{NaCl} 120$, $\mathrm{KCl} 3, \mathrm{CaCl}_{2} 2, \mathrm{MgCl}_{2} 2, \mathrm{NaHCO}_{3}$ 25, HEPES 5, D-glucose $12, \mathrm{pH}=7.4$ (with normal calcium, magnesium, and glucose levels). The slices were quickly transferred into the ExViS mini-chambers (maximum 5 slices in $1 \mathrm{ml}$ ) for treating with actual $A \beta_{42}$ peptide $(50 \mu \mathrm{l}$ stock solution was added into $950 \mu \mathrm{l}$ $\mathrm{H}-\mathrm{ACSF} / 3$ per chamber; $20 \mu \mathrm{M} \mathrm{A} \beta_{42}$ in final concentration). Before each slice viability assay, the stock solution of $A \beta_{42}$ peptide $(0.4 \mathrm{mM})$ was freshly prepared (and stored for maximum $10 \mathrm{~min}$ ) in distilled water $(\mathrm{pH}=5)$. The foaming was inhibited by a floating plastic ball (diameter: $5 \mathrm{~mm}$ ) in mini tube chambers.

$A \beta_{42}$ treatment and cell toxicity assays in cell culture

Living cells convert the yellow dye 3-(4,5dimethyltiazol-2-yl)-2,5-diphenyltetrazolium bromide (MTT, Sigma M5655) to purple, insoluble formazan crystals. For MTT reduction assay the neurons, rat brain endothelial cells, glial cells, or pericytes were cultured in 96-well plates. The $75 \mu \mathrm{M}$ stock solution of $A \beta_{42}$ was freshly prepared in phosphate buffer and the further dilutions were in cell culture medium. DHA was diluted in culture medium from a $300 \mathrm{mM}$ stock solution prepared in ethanol. Control conditions were similar to other treatment conditions except they did not contain peptide or DHA. The medium for the controls was also diluted with the vehicle (PBS) in the appropriate proportion. All stock solutions were prepared freshly and separately, and added to the cells consecutively. After treatments of $A \beta_{42}$ $(24 \mathrm{~h} ; 0.1-30 \mu \mathrm{M})$ or DHA $(24 \mathrm{~h} ; 1-300 \mu \mathrm{M}$ in culture medium) endothelial cells were incubated with $0.5 \mathrm{mg} / \mathrm{ml}$ MTT solution for $3 \mathrm{~h}$ in $\mathrm{CO}_{2}$ incubator. The amount of formazan crystals was dissolved in dimethyl-sulfoxide (DMSO) and determined by measuring absorbance at $595 \mathrm{~nm}$ with microplate reader (Fluostar Optima, BMG Labtechnologies, Germany).

\section{Cell viability assay on acute hippocampal slices}

After treating the slices with $20 \mu \mathrm{M} \mathrm{A} \beta_{42}$ (or with 30 or $50 \mu \mathrm{M}$ DHA) for $4 \mathrm{~h}$, we changed the supernatant to $\mathrm{H}-\mathrm{ASCF} / 3$ and we added $0.1 \mathrm{ml}$ MTT (stock solution $5 \mathrm{mg} / \mathrm{ml} \mathrm{MTT}$ dye in H-ACSF) to the wells in which they were left to rest for $15 \mathrm{~min}$ without carboxygenation (the $\mathrm{H}-\mathrm{ACSF} / 3$ solution was saturated with carboxygen before using). To block the reduction of the MTT to formazan crystals, we changed the supernatant on the slices from $\mathrm{H}-\mathrm{ACSF} / 3$ to pure DMSO and left the slices rest for $30 \mathrm{~min}$ in a 96-well plate (Costar 3595; $100 \mu \mathrm{l} \mathrm{DMSO/slice/well).} \mathrm{After} \mathrm{dissolving} \mathrm{the}$ formazan, we transferred $70 \mu 1$ DMSO from each slice (well) into another 96-well plate (Costar 3695). The optical density (OD) of the dissolved formazan was measured at 550 and $620 \mathrm{~nm}$. To synchronize the data, we used the following formula: $\left[\left(\mathrm{OD}_{550}-\mathrm{OD}_{620}\right) /\right.$ area of slice $\left.\left(\mathrm{mm}^{2}\right)\right]=100 \%$ in control $\left(\mathrm{A} \beta_{42}\right.$ untreated slices). 


\section{Evaluation of the barrier integrity}

Transendothelial electrical resistance (TEER), representing the permeability of tight junctions for sodium ions, was measured by an EVOM resistance meter (World Precision Instruments Inc., USA) using STX-2 electrodes, and it was expressed relative to the surface area of endothelial monolayer $\left(\Omega \times \mathrm{cm}^{2}\right)$. TEER values of cell-free inserts $\left(90-100 \Omega \times \mathrm{cm}^{2}\right)$ were subtracted from the measured data. The TEER of rat primary brain endothelial monolayers in co-culture varied between 650 and $780 \Omega \times \mathrm{cm}^{2}$, with an average of $723 \pm 41$ $\Omega \times \mathrm{cm}^{2}$ (mean \pm S.D., $n=12$ ).

The flux of sodium fluorescein and Evans bluelabeled albumin across endothelial monolayers was determined as previously described $[31,32]$. Cell culture inserts, following treatment of $\mathrm{A} \beta_{42}(24 \mathrm{~h}, 15 \mu \mathrm{M})$ and/or DHA ( $24 \mathrm{~h}, 30 \mu \mathrm{M})$ and measurement of TEER, were transferred to 12 -well plates containing $1.5 \mathrm{ml}$ Ringer-Hepes solution (118 mM NaCl, $4.8 \mathrm{mM} \mathrm{KCl}$, $2.5 \mathrm{mM} \mathrm{CaCl}_{2}, 1.2 \mathrm{mM} \mathrm{MgSO}_{4}, 5.5 \mathrm{mM}$ D-glucose, $20 \mathrm{mM}$ Hepes, $\mathrm{pH}$ 7.4) in the basolateral compartments. In apical chambers, culture medium was replaced by $500 \mu 1$ Ringer-Hepes containing $10 \mu \mathrm{g} / \mathrm{ml}$ sodium fluorescein (mw: $376 \mathrm{Da}$ ) and $165 \mu \mathrm{g} / \mathrm{ml}$ Evans blue bound to $0.1 \%$ BSA (mw: $67 \mathrm{kDa}$ ). The inserts were transferred at 20,40 , and $60 \mathrm{~min}$ to a new well containing Ringer-Hepes solution. The concentrations of the marker molecules in samples from the upper and lower compartments were determined. Evans blue (excitation: $584 \mathrm{~nm}$, emission: $680 \mathrm{~nm}$ ) and fluorescein (excitation: $485 \mathrm{~nm}$, emission: $520 \mathrm{~nm}$ ) concentrations were measured by a Fluostar Optima (BMG Labtechnologies, Germany) plate reader.

Transport was expressed as $\mu l$ of donor (luminal) compartment volume from which the tracer is completely cleared. Transendothelial permeability coefficient $\left(\mathrm{P}_{\mathrm{e}}\right)$ was calculated as previously described $[32,40]$. Cleared volume was calculated from the concentration $(\mathrm{C})$ of the tracer in the abluminal and luminal compartments and the volume $(\mathrm{V})$ of the abluminal compartment $(0.5 \mathrm{ml})$ by the following equation:

$$
\text { Cleared volume }(\mu \mathrm{l})=\frac{C_{\text {abluminal }} \times V_{\text {abluminal }}}{C_{\text {luminal }}}
$$

The average cleared volume was plotted versus time, and permeability $\times$ surface area product value for endothelial monolayer $\left(\mathrm{PS}_{\mathrm{e}}\right)$ was calculated by the following formula:

$$
\frac{1}{P S_{\text {endothelial }}}=\frac{1}{P S_{\text {total }}}-\frac{1}{P S_{\text {insert }}}
$$

$\mathrm{PS}_{\mathrm{e}}$ divided by the surface area $\left(1 \mathrm{~cm}^{2}\right.$ for Transwell12) generated the endothelial permeability coefficient $\left(\mathrm{P}_{\mathrm{e}}\right.$; in $\left.10^{-3} \mathrm{~cm} / \mathrm{min}\right)$.

\section{Functional assay for P-glycoprotein}

Efflux pump activity was determined by the measurement of cellular accumulation of rhodamine 123 [41]. While rhodamine 123 is also a substrate of breast cancer resistance protein (BCRP or ABCG2), it is widely used as a P-glycoprotein (ABCB1) ligand $[26,32,37,41,42]$. In brief, endothelial monolayers pretreated with $A \beta_{42}(15 \mu \mathrm{M})$ and/or DHA $(30 \mu \mathrm{M})$ for $24 \mathrm{~h}$ in 24-well plates were washed, and incubated with Ringer-Hepes buffer containing $10 \mu \mathrm{M}$ rhodamine 123 for $1 \mathrm{~h}$ at $37^{\circ} \mathrm{C}$. The solution was quickly removed; endothelial cells were washed three times with ice-cold PBS, and solubilized in $0.2 \mathrm{M}$ $\mathrm{NaOH}$. Rhodamine 123 content was determined by Fluostar Optima (BMG Labtechnologies, Germany) plate reader with excitation at $485 \mathrm{~nm}$, emission at $520 \mathrm{~nm}$. Verapamil ( $2 \mathrm{mM}, 30 \mathrm{~min}$ preincubation) was used as a reference P-glycoprotein inhibitor.

\section{Western blot}

After amyloid and DHA treatment brain endothelial cells were washed in ice-cold PBS and scraped into $8 \mathrm{M}$ urea/PBS containing $0.1 \%$ Triton-X, $1 \mu \mathrm{g} / \mathrm{ml}$ leupeptin, $10 \mathrm{ng} / \mathrm{ml}$ aprotinin, $100 \mu \mathrm{M}$ phenylmethylsulphonyl fluoride (PMSF), $100 \mu \mathrm{M}$ dithiothreitol, $200 \mu \mathrm{M}$ sodium orthovanadate, and $1 \mathrm{mM}$ sodium fluoride. Cells were lysed with three cycles of snapfreezing and thawing. The extracts were centrifuged at $12,000 \mathrm{~g}$ for $20 \mathrm{~min}$ and protein concentration in the supernatant was determined using the method described by Lowry et al. [43]. For Western blotting, $25 \mu \mathrm{g}$ protein samples were loaded on $7.5 \%$ Tris-glycine gel (PAGEr ${ }^{\circledR}$ Gold Precast Gel, Lonza, Rockland, ME, USA) and blotted onto polyvinylidene difluoride membrane (BioRad Laboratories, Hercules, CA, USA). Blots were probed overnight at $4^{\circ} \mathrm{C}$ with primary rabbit polyclonal anti-P-glycoprotein antibody (H-241, 1:200, Santa Cruz Biotechnology, Inc., Santa Cruz, CA, USA), or for loading control with primary rabbit anti-actin polyclonal antibody (1:200, Sigma-Aldrich, St. Louis, MO, USA) for $1 \mathrm{~h}$ at room temperature. Then, secondary antibody (goat anti-rabbit HRP-conjugated IgG antibody $1: 3000$, Bio-Rad) were added for $1 \mathrm{~h}$ at room temperature. Chemoluminescence method (SuperSignal West Pico Chemiluminescent Substrate, 
Thermo scientific Rockford, IL, USA) was applied for detection of P-glycoprotein. For loading control, 3,3'-diaminobenzidine (Sigma-Aldrich) was used.

\section{Detection of reactive oxygen species}

To measure ROS, we used a fluorometric detection probe from Molecular Probes [32]. Chloromethyldichloro-dihydro-fluorescein diacetate (DCFDA) indicator penetrates the cells by diffusion and becomes deacetylated by intracellular esterases. Oxidation of CM- $\mathrm{H}_{2}$ DCFDA by ROS yields a fluorescent molecule. Confluent rat primary pericyte, glial, and brain endothelial cell layers cultured in 96-well plates were pretreated with $\mathrm{A} \beta_{42}(15 \mu \mathrm{M})$ and/or DHA $(30 \mu \mathrm{M})$ for $24 \mathrm{~h}$, then washed, and incubated with Ringer-Hepes buffer containing $1 \mathrm{mM}$ $\mathrm{CM}-\mathrm{H}_{2}$ DCFDA for $1 \mathrm{~h}$ at $37^{\circ} \mathrm{C}$. Hydrogen peroxide pretreatment $(100 \mu \mathrm{M}, 15 \mathrm{~min})$ served as a positive control in the ROS assay. The plates were measured by Fluostar Optima fluorescent plate reader (BMG Labtechnologies, Germany) with excitation at $485 \mathrm{~nm}$, emission at $520 \mathrm{~nm}$.

\section{Statistical analysis}

All data presented are means \pm S.E.M. The values were compared using the analysis of variance followed by Dunnett, Bonferroni or Newman-Keuls posthoc tests using GraphPad Prism 5.0 software (GraphPad Software Inc., San Diego, CA, USA). Changes were considered statistically significant at $p<0.05$ or $p<0.001$. All experiments were repeated at least three times, the number of parallel wells or inserts for each treatment and time point varied between 3 and 16 .

\section{RESULTS}

The effect of $A \beta_{42}$ on the viability of the cells of the neurovascular unit

The direct effect of oligomeric $A \beta_{42}$ peptide on the viability of neurons, glial cells, brain endothelial cells, and pericytes was examined by MTT cytotoxicity assay. The yellow MTT dye was efficiently converted to purple formazan crystals by non-treated cells, but in the $A \beta_{42}$ treated groups a dose-dependent decrease in viability could be observed in all four cell types. The different cell types had different sensitivity for the peptide treatment (Fig. 1). The most sensitive cells were the neurons and the brain endothelial cells (Fig. 1A, C). Oligomeric $A \beta_{42}$ peptide-treatment in concentrations of $0.1 \mu \mathrm{M}$ or higher for $24 \mathrm{~h}$ significantly decreased the viability of both cells. In contrast, only $5 \mu \mathrm{M}$ or higher doses exerted significant effects in glial cells and pericytes (Fig. 1B, D).

The effect of DHA on the viability of the elements of the neurovascular unit

Before testing the potential protective effect of DHA against oligomeric $A \beta_{42}$ toxicity, its direct effect on cell viability was elucidated. Cells were incubated with DHA in the $1-300 \mu \mathrm{M}$ concentration range for $24 \mathrm{~h}$, than MTT assays were performed as shown in Fig. 2. In neurons (Fig. 2A), glial cells (Fig. 2B), and brain endothelial cells (Fig. 2C), the highest dose of DHA $(300 \mu \mathrm{M})$ significantly decreased the MTT conversion. In pericytes, $10 \mu \mathrm{M}$ DHA and higher doses significantly decreased the cellular viability and only the $1 \mu \mathrm{M}$ concentration of DHA was found to be safe and non-toxic (Fig. 2D). In the most sensitive cell type, brain pericytes, these results were also supported by elevated lactate dehydrogenase release by $10 \mu \mathrm{M}$ and higher concentrations of DHA (data not shown) indicating membrane perturbance.

\section{The effect of DHA on $A \beta_{42}$-induced damages: toxicity tests}

Based on the results of the toxicity assay (Fig. 1), the $15 \mu \mathrm{M}$ concentration of oligomeric $\mathrm{A} \beta_{42}$ was selected to be optimal to reproducibly induce damages to the cell cultures. The $30 \mu \mathrm{M}$ dose of DHA was chosen to be tested as a protective agent against $A \beta_{42}$ toxicity in neurons and endothelial and glial cells. In the case of pericytes, the previously determined non-toxic $1 \mu \mathrm{M}$ dose of DHA was selected (Fig. 3). DHA significantly decreased the $A \beta_{42}$-induced toxic effects in all cells of the neurovascular unit, neurons, glial cells, endothelial cells, and pericytes measured by MTT viability assays (Fig. 3). The DHA (30 $\mu \mathrm{M})$ administration was most effective in brain endothelial cells (Fig. 3C). The protective effect of DHA was confirmed not only in cell cultures but also in experiments using acute hippocampal slices (Fig. 4). A $\beta_{42}$ treatment induced significant decrease in the viability of the hippocampal cells that was dose-dependently inhibited by DHA.

\section{The effect of DHA on $A \beta_{42}$-induced damages: morphological changes}

In the primary culture of neurons, the cells have small and rounded cell bodies connected with long 

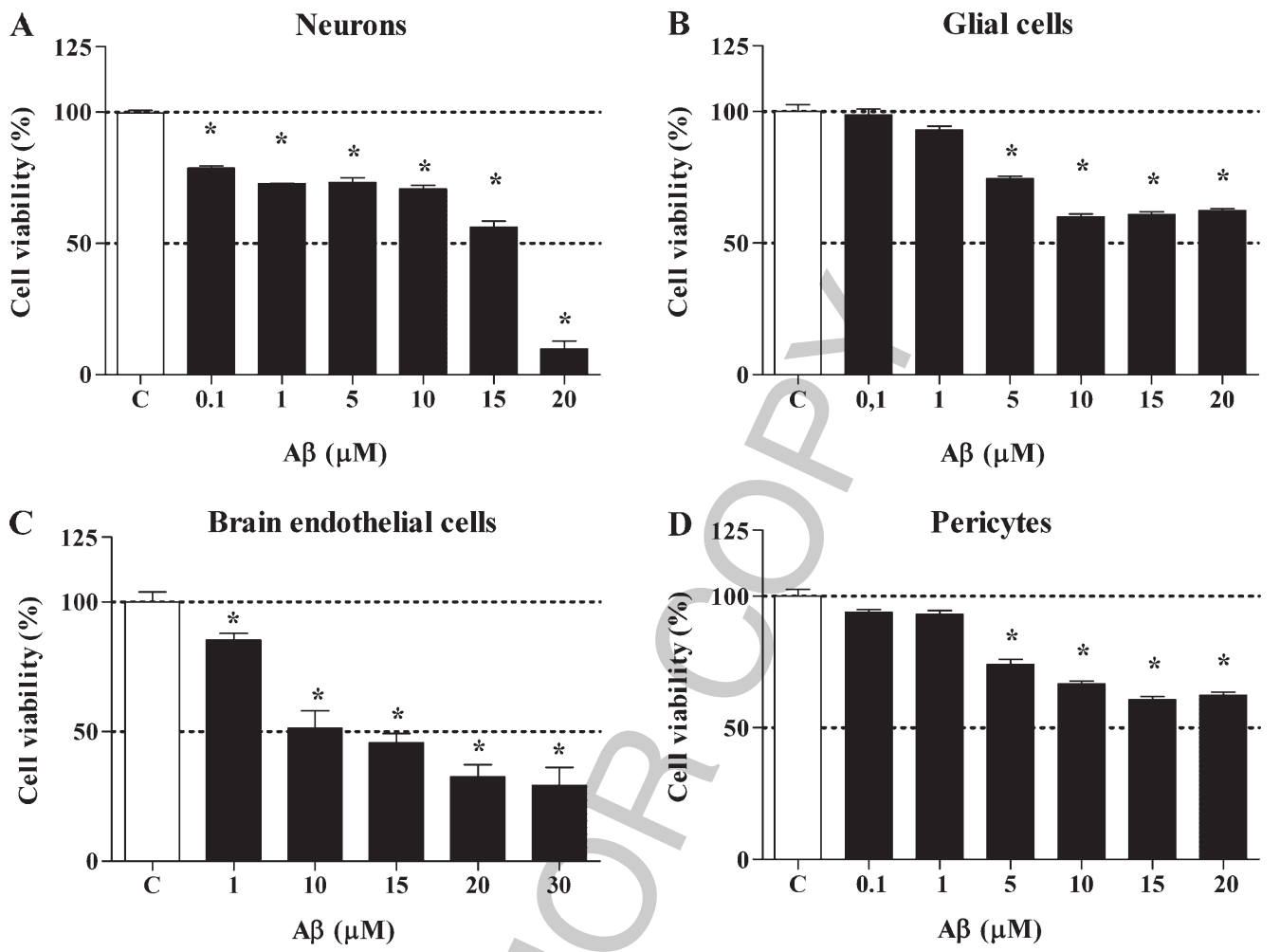

Fig. 1. Dose-dependent toxic effect of oligomeric amyloid- $\beta$ 1-42 (A $\left.\beta_{42}\right)$ in neuronal (A), glial (B), brain endothelial (C), and pericyte (D) primary cell cultures measured by MTT assay. Values presented are means \pm S.E.M., $n=8$. Statistically significant differences $(p<0.05)$ between the controls and $\mathrm{A} \beta$ treated groups $(*)$ are indicated.

neurites (Fig. 5 control). Oligomeric $A \beta_{42}$ peptide treatment $(15 \mu \mathrm{M}$ for $24 \mathrm{~h})$ induced cell death in neuronal cultures; apoptotic cells and loss of cellular processes were observed. The co-administration of DHA $(30 \mu \mathrm{M})$ with $A \beta_{42}$ attenuated the level of the damage in neurons; the network of the neurites was preserved (Fig. 5). In our culture conditions, glial cells showed a mature, differentiated phenotype with astroglia showing multiple, long and thin processes. After $A \beta_{42}$ treatment, glial cells underwent cellular hypertrophy, and fewer and thicker cell processes and increased number of apoptotic cells were observed. In the presence of DHA, more glial cell processes and less damaged cells could be seen. Brain endothelial cells formed confluent monolayers (Fig. 5) and the cellular morphology was typical for primary cultures as described earlier [32]. Treatment with $A \beta_{42}$ resulted in big intercellular gaps in the monolayers and floating apoptotic cells in the culture medium. At higher magnification, cytoplasmic vacuolization could be observed, as in our previous study earlier [44]. DHA inhibited these changes; the monolayer integrity was better preserved and resembled to the control ones. Brain microvascular pericytes in cell culture may form multiple cell layers. These cells are multipolar, large and flat with irregular projections. Even by phase contrast microscopy, the cytoskeletal fibers are visible (Fig. 5). After peptide treatment, the cytoplasmic fibers in pericytes were diminished and some rounded cells full with vacuoles could be observed. DHA $(1 \mu \mathrm{M})$ was able to ameliorate the phenotypic changes in pericytes (Fig. 5).

\section{Effect of DHA on $A \beta_{42}$-induced changes in barrier integrity of brain endothelial cells}

Treatment of endothelial cell monolayers with oligomeric $A \beta_{42}(15 \mu \mathrm{M})$ reduced the TEER by $70 \%$ of the control after $24 \mathrm{~h}$ (data not shown). In $A \beta_{42}$ treated monolayers, the flux of the paracellular marker of fluorescein was 4.6 fold higher as compared to the control group (Fig. 6A). The $\mathrm{P}_{\mathrm{e}}$ values for transcellular permeability marker albumin were lower with one order of magnitude than the values for fluorescein, in agreement with literature data [40] and our previous results $[31,32,40]$. The permeability for albumin was elevated by 5.9 fold in monolayers treated 
A

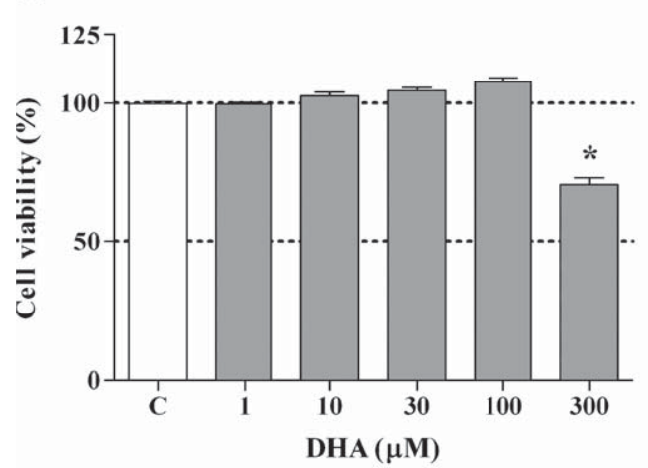

C

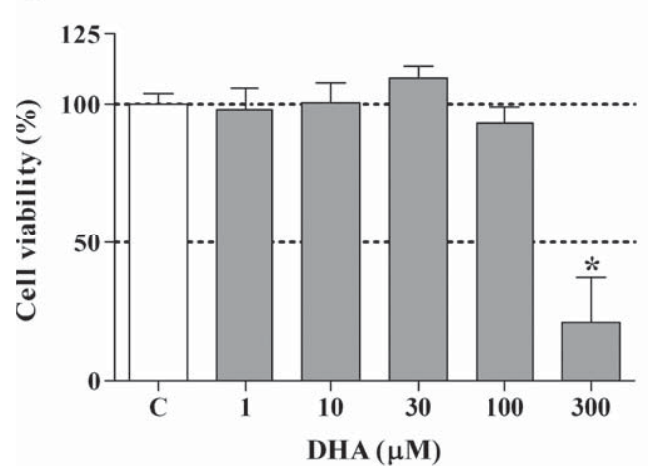

B

Glial cells

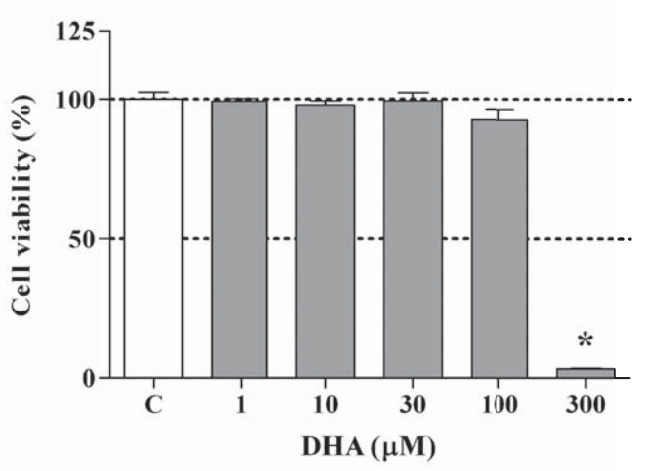

D

Pericytes

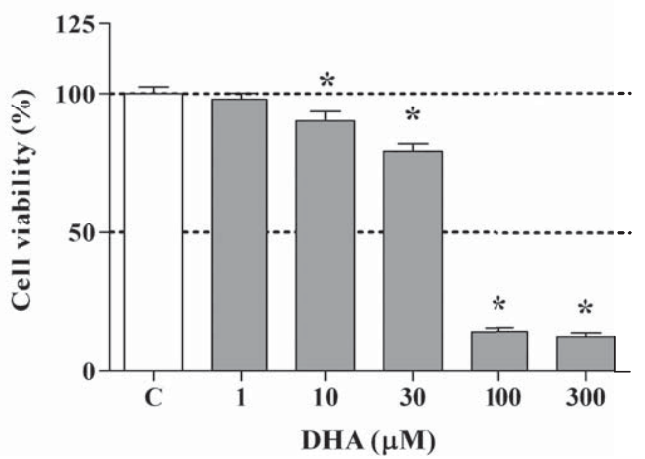

Fig. 2. Dose-dependent effect of docosahexaenoic acid (DHA) in neuronal (A), glial (B), brain endothelial (C), and pericyte (D) primary cell cultures measured by MTT assay. Values presented are means \pm S.E.M., $n=8$. Statistically significant differences $(p<0.05)$ between the controls and DHA treated groups $(*)$ are indicated.

with $A \beta_{42}$ (Fig. 6B). Co-administration of DHA could significantly decrease the flux of permeability markers through endothelial monolayers (Fig. 6B). DHA alone had no effect on permeability of brain endothelial monolayers.

Effect of DHA on $A \beta_{42}$-induced changes in efflux pump activity and P-glycoprotein expression of brain endothelial cells

Brain endothelial cells expressed a functional Pglycoprotein efflux pump (Fig. 7B) similar to our previous studies $[32,34]$ and as demonstrated by the robust effect of verapamil, an inhibitor of $\mathrm{P}$ glycoprotein used as a reference blocker in this rhodamine 123 uptake assay (Fig. 7A). Administration of oligomeric $\mathrm{A} \beta_{42}(15 \mu \mathrm{M}$ for $24 \mathrm{~h}$ ) as a pre-treatment significantly decreased efflux pump activity of brain endothelial cells in the absence of the peptide as indicated by the high level of rhodamine 123 accumulation (Fig. 7A). The administration of DHA decreased the rhodamine 123 accumulation in brain endothelial cells pre-treated with $A \beta_{42}$ for $24 \mathrm{~h}$ (Fig. 7A). There was no significant difference in the protein level of $\mathrm{P}$ glycoprotein in the treated groups as compared to the control group (Fig. 7B).

\section{Effect of DHA on $A \beta_{42}$-induced reactive oxygen species production in brain endothelial cells}

The ROS production in cultured pericytes, glial, and brain endothelial cells measured by DCFDA assay was significantly enhanced by oligomeric $A \beta_{42}$ treatment $(15 \mu \mathrm{M}, 24 \mathrm{~h})$ compared to that in control cells (1.71 fold in glial cells, 1.4 fold in endothelial cells, 1.67 fold in pericytes compared to control group) (Fig. 8). DHA in 30 and $1 \mu \mathrm{M}$ concentrations, which had no effect alone, effectively inhibited the $A \beta$-induced change in ROS production in brain endothelial and glial cells, and pericytes, respectively. Hydrogen peroxide treatment $(100 \mu \mathrm{M}, 15 \mathrm{~min})$, a positive control in the ROS assay, elevated by 3.4 fold the amount of ROS measured in brain endothelial cells and 2.5 fold in glial cells and pericytes. 
A

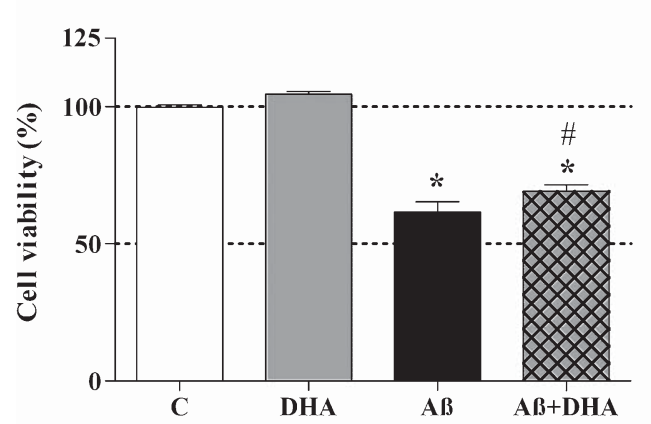

C

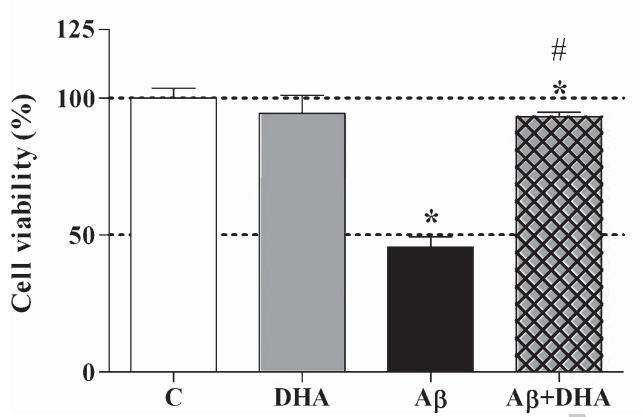

B

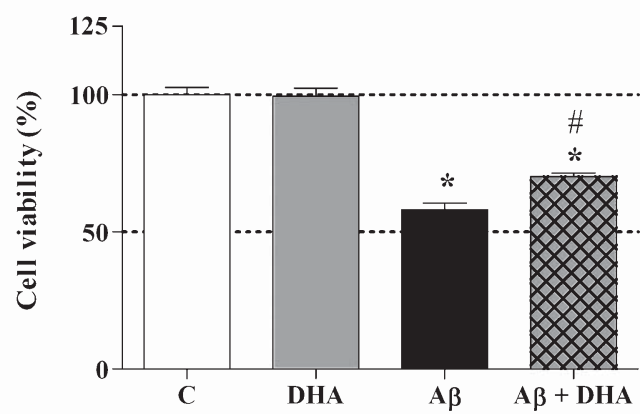

D

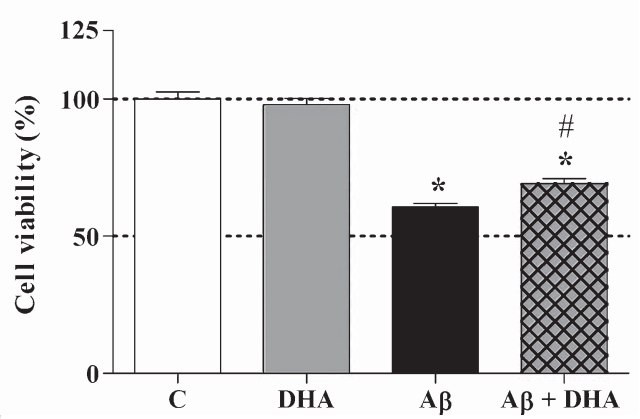

Fig. 3. The effect of docosahexaenoic acid (DHA, $1 \mu \mathrm{M}$ on pericytes and $30 \mu \mathrm{M}$ on the other three cell types) on oligomeric amyloid- $\beta$ 1-42 $\left(\mathrm{A} \beta_{42}, 15 \mu \mathrm{M}\right)$ induced toxicity in neurons (A), glial cells (B), brain endothelial (C), and pericyte primary cell cultures (D). Values presented are means \pm S.E.M., $n=8$. Statistically significant differences $(p<0.05)$ between the control and treated groups $(*), A \beta_{42}$ and $\mathrm{A} \beta_{42}+\mathrm{DHA}$ treated groups (\#) are indicated.

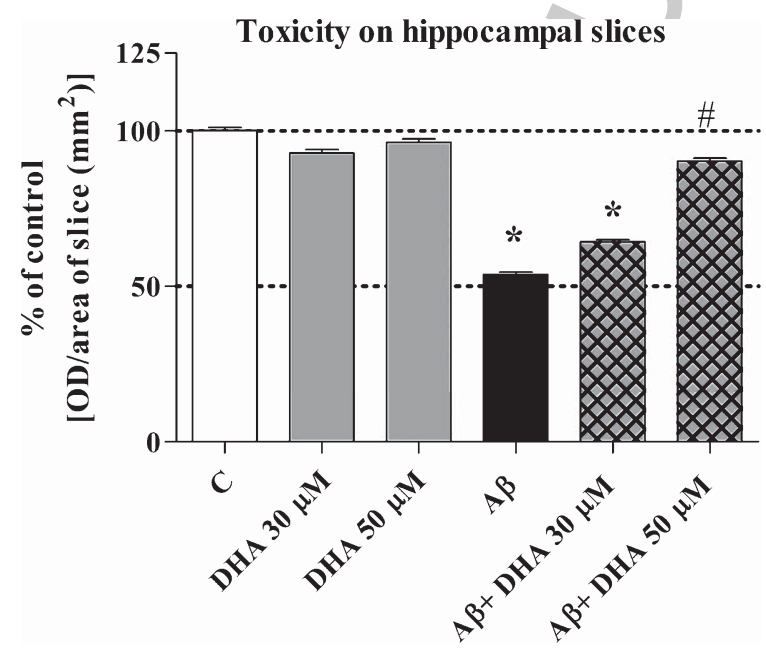

Fig. 4. The effect of docosahexaenoic acid (DHA) on oligomeric amyloid- $\beta$ 1-42 $\left(\mathrm{A} \beta_{42}, 20 \mu \mathrm{M}\right)$ induced toxicity on acute hippocampal slices measured by MTT assay. Values presented are means \pm S.E.M., $n=16$. Statistically significant differences $(p<0.05)$ between the controls and treated groups $(*), \mathrm{A} \beta_{42}$ and $\mathrm{A} \beta_{42}+$ DHA treated groups (\#) are indicated.

\section{DISCUSSION}

The toxicity of $A \beta_{42}$ on the cells of the neurovascular unit

The direct toxic effect of different $A \beta_{42}$ peptides on cultured neurons and glial cells have been extensively investigated and established [39, 45, 46]. The present results confirm the toxicity of oligomeric $A \beta_{42}$ not only on cultured neurons but also on acute hippocampal slices. Brain endothelial cells are much less studied, despite their importance in the transport and clearance of $A \beta_{42}$ peptides and the pathological cerebrovascular changes in $\mathrm{AD}[2,4,7]$. Studies on cultured brain endothelial cells demonstrate that $A \beta_{42}$ peptides are directly toxic to these cells $[47,44]$, disturb the barrier integrity, and increase the permeability of brain endothelial cell monolayers as presented in our previous study [44]. Cultured brain pericytes have been examined so far only by the group of Verbeek et al. $[48,49]$ and were found to be also sensitive to $A \beta_{42}$ toxicity. Our results are in agreement with these data. 
C

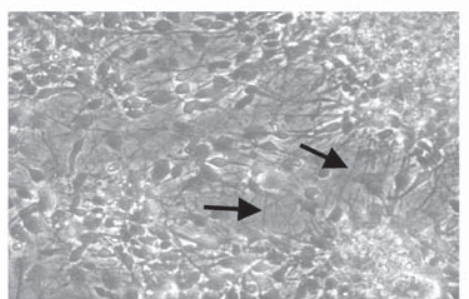

Neurons

Glial cell
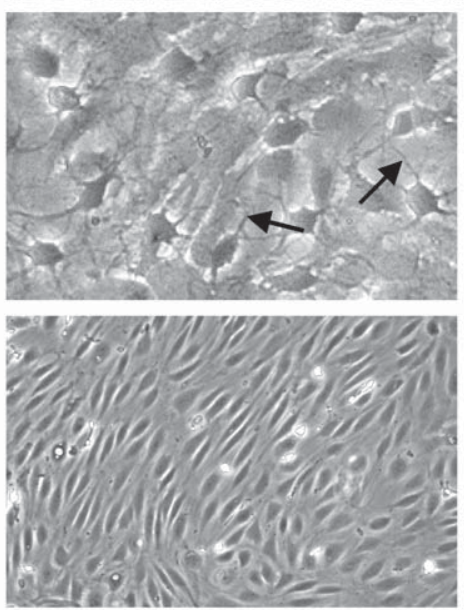

Brain endothelial cell

\section{Pericytes}

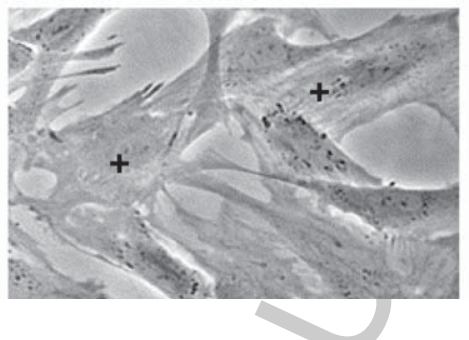

AB
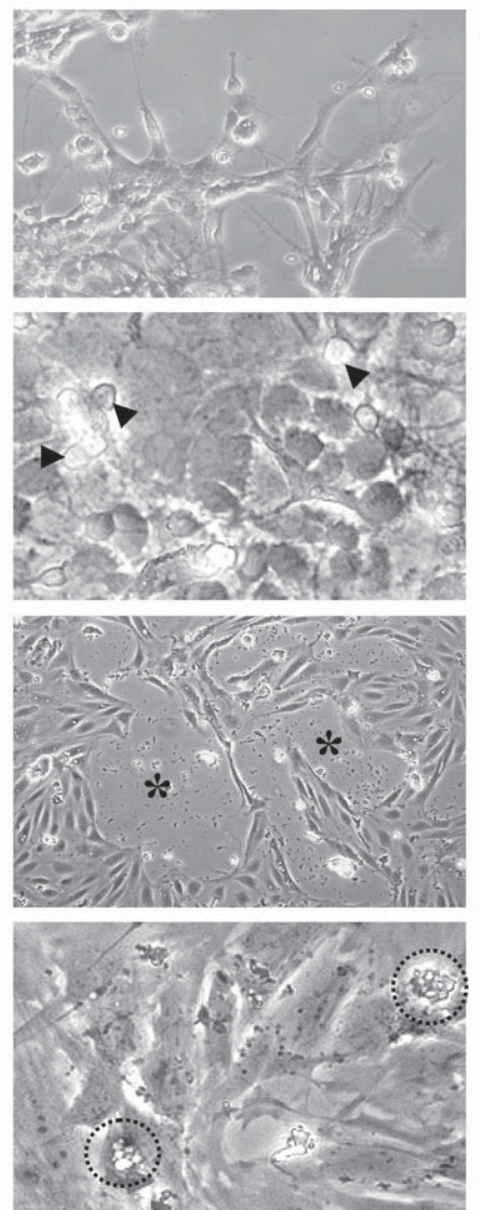

AB + DHA
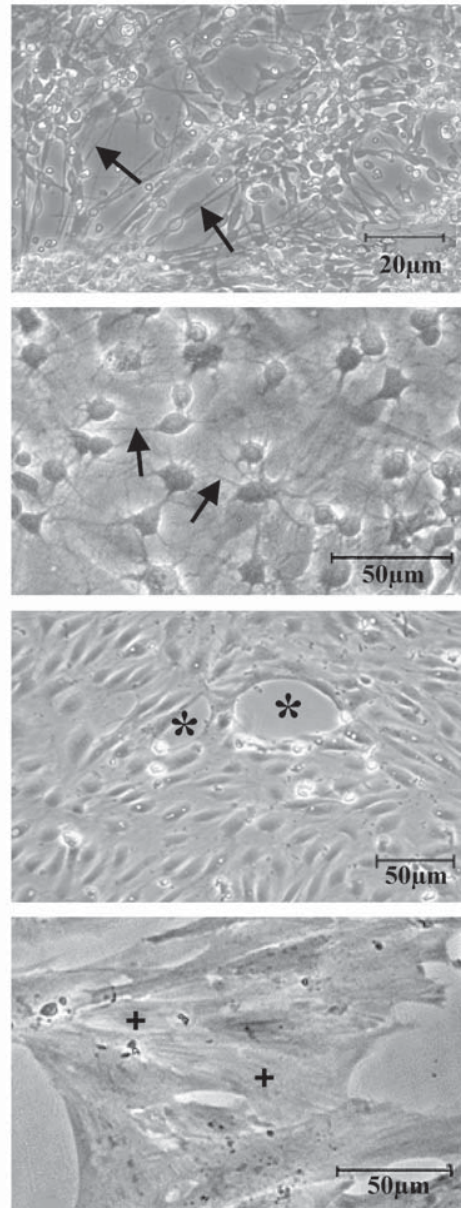

Fig. 5. The effect of docosahexaenoic acid (DHA, $1 \mu \mathrm{M}$ on pericytes and $30 \mu \mathrm{M}$ on the other three cell types) on oligomeric amyloid- $\beta$ 1-42 $\left(\mathrm{A} \beta_{42}, 15 \mu \mathrm{M}\right)$ induced toxicity on the morphology of neuronal, glial, brain endothelial, and pericyte primary cell cultures examined by phase contrast microscopy. Arrows show processes of neurons or glial cells, arrow heads point to apoptotic cells, asterisks show holes of in endothelial monolayers, cross signs show cytoplasmic fibers inside pericytes. The pericyte encircled by dotted line has cytoplasmic vacuolization.
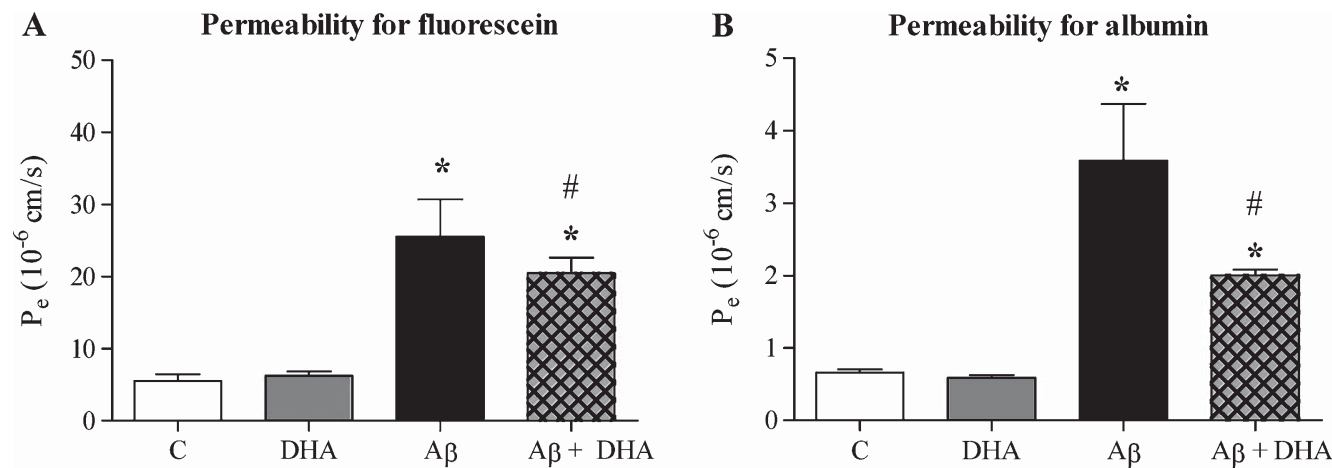

Fig. 6. Effect of docosahexaenoic acid (DHA, $30 \mu \mathrm{M})$ on oligomeric amyloid- $\beta$ 1-42 (A $\left.\beta_{42}, 15 \mu \mathrm{M}\right)$ induced changes in the permeability of primary brain endothelial cells for fluorescein (A) and Evans blue labeled albumin (B) Values presented are means \pm S.E.M., $n=6$. Statistically significant differences $(p<0.05)$ between the controls and treated groups $(*), A \beta_{42}$ and $A \beta_{42}+$ DHA treated groups (\#) are indicated. 


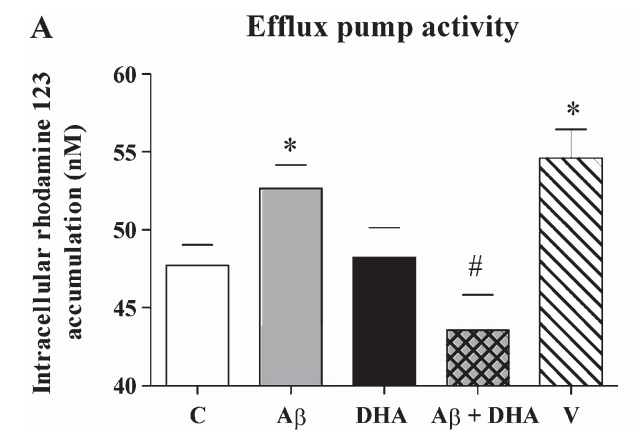

B Expression of P-glycoprotein

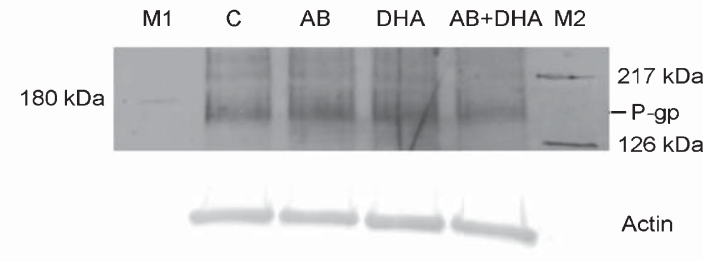

Fig. 7. Effect of docosahexaenoic acid (DHA, $30 \mu \mathrm{M})$ on oligomeric amyloid- $\beta 1-42\left(\mathrm{~A} \beta_{42}, 15 \mu \mathrm{M}\right)$ induced changes in efflux pump activity of primary brain endothelial cells measured by rhodamine 123 accumulation (A). Changes of expression level of P-glycoprotein measured by Western blot analyses (B). Values presented are means \pm S.E.M., $n=5$. Statistically significant differences $(p<0.05)$ between the control and treated groups (*), $\mathrm{A} \beta_{42}$ and $\mathrm{A} \beta_{42}+\mathrm{DHA}$ treated groups (\#) are indicated.

It is important to note that the cellular toxicity of oligomeric $A \beta_{42}$ on the four types of cells was tested using the same assay conditions, therefore a comparison on their sensitivity can be made for the first time. The highest and similar level of toxicity was observed in the case of neurons and brain endothelial cells, while both glial cells and pericytes were more resistant to the damaging effect of oligomeric $A \beta_{42}$. This novel observation on cultured cells is in agreement with $A D$ pathology, where the two hallmarks of the disease are the cerebrovascular damages and neuronal loss [50]. A possible explanation for the higher sensitivity of neurons and brain endothelial cells to oligomeric $A \beta_{42}$ as compared to glia and perictyes could be the higher expression level of receptors and transporters related to $A \beta_{42}$ efflux, uptake, or transport, but further comparative analysis is needed to prove this hypothesis.

\section{Protection of the cells of the neurovascular unit against $A \beta_{42}$ by $D H A$}

BBB dysfunction initiates and contributes to the disease process in $\mathrm{AD}$ [4]; therefore in addition to neurons, brain endothelial cells and other elements of the neurovascular unit are increasingly recognized as therapeutic targets in $\mathrm{AD}[1,3]$. There is little data on the protection of BBB and brain endothelial cells against the toxic effects of $A \beta_{42}$. Partial protection was described against $A \beta_{25-35}$ peptide induced cell damage by carnosine, an endogenous antiglycating dipeptide, homocarnosine and $\beta$-alanine on a rat brain endothelial cell line [51] and by simvastatin on a human brain endothelial cell line [47]. In a recent study on a human brain endothelial cell line, $A \beta_{42}$ cytotoxicity was reversed by administration of exogenous antioxidants, NADPH oxidase-2 inhibitors, and by blocking receptor for advanced glycation end products (RAGE) [52]. In our previous study, pentosan, a clinically used sulfated polysaccharide, protected rat brain endothelial cells against $A \beta_{42}$ toxicity [44].

The prospect of reducing the risk of AD by preventative strategies such as diet or lifestyle modification is highly favorable. Several epidemiological studies [9-12] and growing experimental data have shown that dietary DHA may improve neuronal development [53], restore and enhance cognitive functions [18, 54-56], and increase neuronal resistance to amyloid-induced oxidative stress [57-59]. Importantly, DHA readily crosses the BBB by diffusion $[60,61]$ and can easily reach glial cells and neurons.

Except for the highest tested dose, DHA was not toxic for neurons or glial and brain endothelial cells. Interestingly, pericytes showed an increased sensitivity to DHA treatment. The DHA content is high in retina, brain tissue, isolated brain microvessels, and cultured brain endothelial cells [62]. The high percentage of PUFAs in retinal microvessels was hypothesized to contribute to oxidation products and be involved in the pathogenic process of diabetic retinopathy [63]. Enrichment of cultured cells with DHA increases lipid peroxidation [64]. Differences in antioxidant enzyme activities, especially the higher level of superoxide dismutase and glutathione peroxidase were observed in retina endothelial cells as compared to retina pericytes, explaining their different behavior during the pathogenesis of diabetic retinopathy, early cell death of pericytes, and late endothelial cell proliferation [65]. No data on the ROS producing and antioxidant enzyme capacities of brain endothelial cells as compared to pericytes is available, but the high ROS-tolerance of brain endothelial cells was described recently [66]. We speculate that the lower level of ROS-scavenging capacity 
A Glial cells

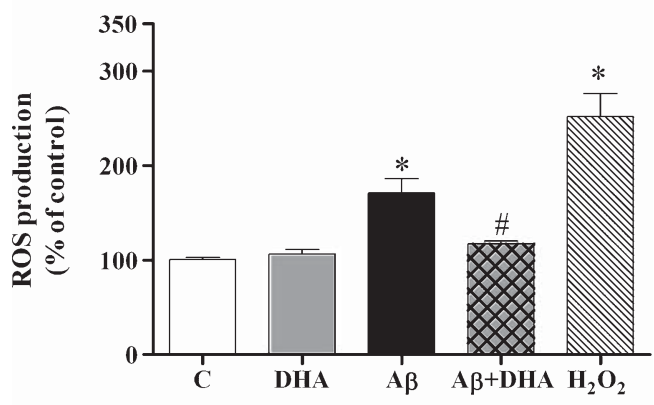

B

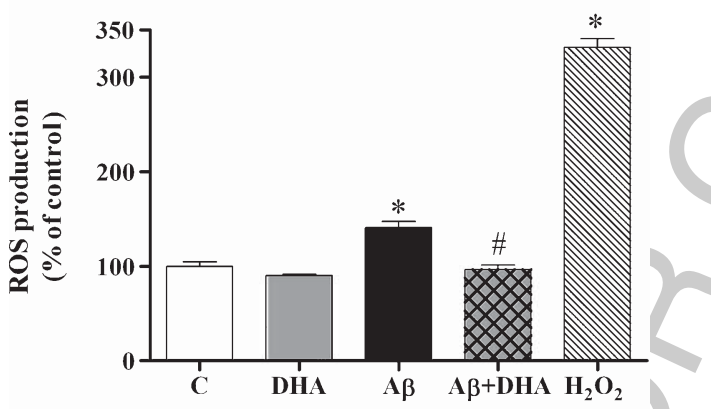

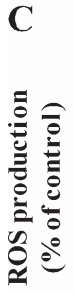

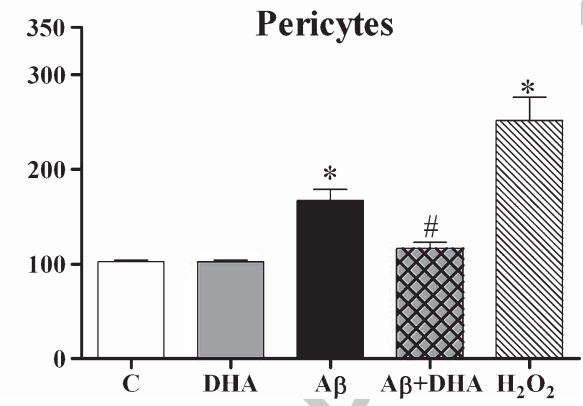

Fig. 8. Effect of docosahexaenoic acid (DHA, $30 \mu \mathrm{M}$ ) on oligomeric amyloid- $\beta$ 1-42 $\left(\mathrm{A} \beta_{42}, 15 \mu \mathrm{M}\right)$ induced changes in reactive oxygen species production in glial (A), brain endothelial cells (B), and pericyte $(\mathrm{C})$ primary cell cultures measured by chloromethyldichloro-dihydro-fluorescein diacetate (DCFDA). Values presented are means \pm S.E.M., $n=8$. Statistically significant differences $(p<0.05)$ between the control and treated groups $(*), \mathrm{A} \beta_{42}$ and $\mathrm{A} \beta_{42}$ + DHA treated groups (\#) are indicated.

of cultured brain pericytes, as compared to other neurovascular cells, might explain the observed sensitivity to DHA.

The beneficial effect of DHA was investigated in several model of $\mathrm{AD}$ but they were focused on neurons [17]. In neuroblastoma cells, DHA reduced amyloidogenic $\mathrm{A} \beta \mathrm{PP}$ processing and $\mathrm{A} \beta_{42}$ production [23]. In the present study DHA was not only protective against oligomeric $A \beta_{42}$ toxicity in primary neurons but also on acute hippocampal slices, a more com- plex, ex vivo model. Our main results indicate for the first time that DHA can protect not only neurons but also the other elements of the neurovascular unit (brain endothelial cells, glial cells, and pericytes) from the toxic effects of $A \beta_{42}$. DHA was effective in neuronal, endothelial, glial, and pericyte cell cultures in toxicity tests and improved the morphological changes in all four cell types after oligomeric $\mathrm{A} \beta_{42}$ treatment, indicating a more extensive and diverse protective effect than previously supposed. The permeability of cerebral endothelial monolayers was increased by $\mathrm{A} \beta_{42}$ similarly to our previous study [44], which was attenuated by DHA.

The mechanism of the DHA action is not fully understood. While there are no data on how DHA may affect RAGE, it was demonstrated recently in cultured brain endothelial cells that $A \beta$ accumulation is lipid raftand caveolae-dependent and involves RAGE and the caveolae-associated Ras signaling [67]. Disruption of lipid rafts by pretreatment with $\beta$-methyl-cyclodextrin protected against $A \beta$ accumulation in this model. DHA is a well-known inducer of membrane fluidity [68] and by reducing cholesterol [23], it has a raft destabilizing effect and decreases the docking of $A \beta$ [25], which may influence RAGE activity and contribute to the protective effect of DHA.

P-glycoprotein and BCRP are important efflux pumps at the BBB limiting the flux of drugs and xenobiotics to brain [69] and participating in $A \beta_{42}$ transport [70-72]. Beside changes in barrier function, $A \beta_{42}$ pretreatment inhibited the efflux activity of brain endothelial cells, in agreement with data from the literature $[73,74]$. However, no change in P-glycoprotein expression level was observed. There could be several explanations for this observation: in addition to protein levels, several other factors influence the activity efflux pumps, like plasma membrane lipid composition, intracellular signaling pathways, and also intracellular ATP levels; and other pumps may also participate in rhodamine efflux.

The relevance of these results is emphasized by a recent clinical observation providing the first direct evidence that the P-glycoprotein transporter at the BBB is compromised in sporadic AD [75]. Since decreased P-glycoprotein function may be involved in the pathogenesis of $\mathrm{AD}[72,75]$, our novel finding that DHA can prevent the decrease in $\mathrm{P}$-glycoprotein activity induced by $A \beta_{42}$ treatment strengthens the therapeutic potential of DHA.

In $\mathrm{AD}$, the accumulation of $A \beta_{42}$ increases the production of ROS resulting in increased lipid peroxidation in the brain [76]. Oxidative damage and 
formation of oxidized lipids and proteins have been observed in the brains of patients with AD during postmortem analysis [77]. Lipid peroxide levels are significantly lower in DHA-administered rats indicating that dietary DHA contributes to the antioxidant defense, decreases oxidative stress, and protects against memory loss [12]. The levels of ROS in the cerebral cortex and hippocampus increase significantly after the infusion of $A \beta_{42}$ into the cerebral ventricle of rats, but then decrease significantly after the dietary administration of DHA [58]. In the present study, ROS production was elevated by oligomeric $\mathrm{A} \beta_{42}$ in primary brain endothelial cells, in agreement with data obtained on a brain endothelial cell line [52]. Similarly to cytotoxicity and BBB dysfunction, this effect could be also inhibited by DHA. These observations suggest that DHA increases the antioxidant defense in the brain including the BBB and its mode of action may be related to direct scavenging of ROS or to the induction of antioxidant enzymes. Additional mechanisms cannot be excluded. Since the activation of the $W n t / \beta$-catenin pathway increases BBB functions [78] and the effect of $A \beta_{42}$ on P-glycoprotein is mediated via $W n t / \beta$-catenin signaling [73], it is tempting to speculate that DHA may also act through this pathway.

In conclusion, DHA may be a potent agent to prevent $A \beta_{42}$ induced damages on the elements of the neurovascular unit acting via multiple ways. Based on these new observations, DHA might exert a protective effect not only on neurons but also on the BBB and its functions, and this effect may be beneficial in AD.

\section{ACKNOWLEDGMENTS}

The research leading to these results has received funding from the European Community's 7th Framework Programme (FP/2007-2013) under grant agreement no. 211696 and TÁMOP-4.2.2.A-11/1/KONV2012-0052 grant financed by the European Union and the European Regional Development Fund.

Authors' disclosures available online (http://www.jalz.com/disclosures/view.php?id=1737).

\section{REFERENCES}

[1] Neuwelt EA, Bauer B, Fahlke C, Fricker G, Iadecola C, Janigro D, Leybaert L, Molnár Z, O’Donnell ME, Povlishock JT, Saunders NR, Sharp F, Stanimirovic D, Watts RJ, Drewes LR (2011) Engaging neuroscience to advance translational research in brain barrier biology. Nat Rev Neurosci 12, 169182.
[2] Zlokovic BV (2005) Neurovascular mechanisms of Alzheimer's neurodegeneration. Trends Neurosci 28, 202208.

[3] Deli MA (2005) The role of blood-brain barrier in neurodegenerative diseases. In Molecular Bases of Neurodegeneration, Di Liegro I, Savettieri G, eds. Research Signpost, Kerala, India, pp. 137-161.

[4] Zlokovic BV (2008) The blood-brain barrier in health and chronic neurodegenerative disorders. Neuron 57, 178-201.

[5] Jaeger LB, Dohgu S, Hwang MC, Farr SA, Murphy MP, Fleegal-Demotta MA, Lynch JA, Robinson SM, Niehoff ML, Johnson SN, Kumar VB, Banks WA (2009) Testing the neurovascular hypothesis of Alzheimer's disease: LRP-1 antisense reduces blood-brain barrier clearance and increases brain levels of amyloid- $\beta$ protein and impairs cognition. J Alzheimers Dis 17, 553-570.

[6] Abbott NJ, Patabendige AA, Dolman DE, Yusof SR, Begley DJ (2010) Structure and function of the blood-brain barrier. Neurobiol Dis 37, 13-25.

[7] Zlokovic BV, Yamada S, Holtzman D, Ghiso J, Frangione B (2000) Clearance of amyloid $\beta$-peptide from brain: Transport or metabolism. Nat Med 6, 718-719.

[8] Banks WA, Niehoff ML, Drago D, Zatta P (2006) Aluminum complexing enhances amyloid beta protein penetration of blood-brain barrier. Brain Res 1116, 215-221.

[9] Kalmijn S, Launer LJ, Ott A, Witteman JC, Hofman A, Breteler MM (1997) Dietary fat intake and the risk of incident dementia in the Rotterdam Study. Ann Neurol 42, 776-782.

[10] Morris MC, Evans DA, Bienias JL, Tangney CC, Bennett DA, Wilson RS, Aggarwal N, Schneider J (2003) Consumption of fish and n-3 fatty acids and risk of incident Alzheimer disease. Arch Neurol 60, 940-946.

[11] Lopez LB, Kritz-Silverstein D, Barrett Connor E (2011) High dietary and plasma levels of the omega-3 fatty acid docosahexaenoic acid are associated with decreased dementia risk: the Rancho Bernardo study. J Nutr Health Aging 15, 25-31.

[12] Morley JE, Banks WA (2010) Lipids and cognition. J Alzheimers Dis 20, 737-747.

[13] Hőgyes E, Nyakas C, Kiliaan A, Farkas T, Penke B, Luiten PG (2003) Neuroprotective effect of developmental docosahexaenoic acid supplement against excitotoxic brain damage in infant rats. Neuroscience 119, 999-1012.

[14] Tully AM, Roche HM, Doyle R, Fallon C, Bruce I, Lawlor B, Coakley D, Gibney MJ (2003) Low serum cholesteryl esterdocosahexaenoic acid levels in Alzheimer's disease: A casecontrol study. Br J Nutr 89, 483-489.

[15] Söderberg M, Edlund C, Kristensson K, Dallner G (1991) Fatty acid composition of brain phospholipids in aging and in Alzheimer's disease. Lipids 26, 421-425.

[16] Lim GP, Calon F, Morihara T, Yang F, Teter B, Ubeda O, Salem NJr, Frautschy SA, Cole GM (2005) A diet enriched with the omega-3 fatty acid docosahexaenoic acid reduces amyloid burden in an aged Alzheimer mouse model. J Neurosci 25, 3032-3040.

[17] Oksman M, Iivonen H, Hőgyes E, Amtul Z, Penke B, Leenders I, Broersen L, Lütjohann D, Hartmann T, Tanila H (2006) Impact of different saturated fatty acid, polyunsaturated fatty acid and cholesterol containing diets on beta-amyloid accumulation in APP/PS1 transgenic mice. Neurobiol Dis 23, 563-572.

[18] Arsenault D, Julien C, Tremblay C, Calon F (2011) DHA improves cognition and prevents dysfunction of entorhinal cortex neurons in 3 x TG-AD mice. PLOS ONE 6, e17397.

[19] Freund-Levi Y, Eriksdotter-Jönhagen M, Cederholm T, Basun H, Faxén-Irving G, Garlind A, Vedin I, Vessby B, Wahlund 
LO, Palmblad J (2006) Omega-3 fatty acid treatment in 174 patients with mild to moderate Alzheimer disease: OmegAD study: A randomized double-blind trial. Arch Neurol 63, 14021408 .

[20] Kotani S, Sakaguchi E, Warashina S, Matsukawa N, Ishikura Y, Kiso Y, Sakakibara M, Yoshimoto T, Guo J, Yamashima T (2006) Dietary supplementation of arachidonic and docosahexaenoic acids improves cognitive dysfunction. Neurosci Res 56, 159-164.

[21] Chiu CC, Su KP, Cheng TC, Liu HC, Chang CJ, Dewey ME, Stewart R, Huang SY (2008) The effects of omega-3 fatty acids monotherapy in Alzheimer's disease and mild cognitive impairment: A preliminary randomized double-blind placebo-controlled study. Prog Neuropsychopharmacol Biol Psychiatry 32, 1538-1544.

[22] Quinn JF, Raman R, Thomas RG, Yurko-Mauro K, Nelson EB, Van Dyck C, Galvin JE, Emond J, Jack CRJr, Weiner M, Shinto L, Aisen PS (2010) Docosahexaenoic acid supplementation and cognitive decline in Alzheimer disease: A randomized trial. JAMA 304, 1903-1911.

[23] Grimm MO, Kuchenbecker J, Grösgen S, Burg VK, Hundsdörfer B, Rothhaar TL, Friess P, de Wilde MC, Broersen LM, Penke B, Péter M, Vígh L, Grimm HS, Hartmann T (2011) Docosahexaenoic acid reduces amyloid $\beta$ production via multiple pleiotropic mechanisms. J Biol Chem 286, 14028-14039.

[24] Zhao Y, Calon F, Julien C, Winkler JW, Petasis NA, Lukiw WJ, Bazan NG (2011) Docosahexaenoic acid-derived neuroprotectin D1 induces neuronal survival via secretase- and PPAR $\gamma$-mediated mechanisms in Alzheimer's disease models. PLOS ONE 6, e15816.

[25] Hashimoto M, Katakura M, Hossain S, Rahman A, Shimada T, Shido O (2011) Docosahexaenoic acid withstands the A $\beta(25-$ $35)$-induced neurotoxicity in SH-SY5Y cells. J Nutr Biochem 22, 22-29.

[26] Nakagawa S, Deli MA, Kawaguchi H, Shimizudani T, Shimono T, Kittel Á, Tanaka M, Niwa M (2009) A new blood-brain barrier model using brain endothelial cells, pericytes and astrocytes. Neurochem Int 54, 253-263.

[27] Tóth A, Veszelka S, Nakagawa S, Niwa M, Deli MA (2011) Patented in vitro blood-brain barrier models in CNS drug discovery. Recent Pat CNS Drug Discov 6, 107-118.

[28] Bozso Z, Penke B, Simon D, Laczkó I, Juhász G, Szegedi V, Kasza A, Soós K, Hetényi A, Wéber E, Tóháti H, Csete M, Zarándi M, Fülöp L (2010) Controlled in situ preparation of $A \beta(1-42)$ oligomers from the isopeptide "iso- $A \beta(1-42)$ ", physicochemical and biological characterization. Peptides 31, 248-256.

[29] Környei Z, Tóth B, Tretter L, Madarász E (1998) Effects of retinoic acid on rat forebrain cells derived from embryonic and perinatal rats. Neurochem Int 33, 541-549.

[30] Deli MA, Joó F, Krizbai I, Lengyel I, Nunzi GM, Wolff J$\mathrm{R}$ (1993) Calcium/calmodulin stimulated protein kinase II is present in primary cultures of cerebral endothelial cells. $J$ Neurochem 60, 1960-1963.

[31] Kis B, Deli MA, Kobayashi H, Ábrahám CS, Yanagita T, Kaiya H, Isse T, Nishi R, Gotoh S, Kangawa K, Wada A, Greenwood J, Niwa M, Yamashita H, Ueta Y (2001) Adrenomedullin regulates blood-brain barrier functions in vitro. Neuroreport 12, 4139-4142.

[32] Veszelka S, Pásztói M, Farkas AE, Krizbai I, Dung NTK, Niwa M, Ábrahám CS, Deli MA (2007) Pentosan polysulfate protects brain endothelial cells against bacterial lipopolysaccharide-induced damages. Neurochem Int 50, 219-228.
[33] Perrière N, Demeuse P, Garcia E, Regina A, Debray M, Andreux JP, Couvreur P, Scherrmann JM, Temsamani J, Couraud P-O, Deli MA, Roux F (2005) Puromycin-based purification of rat brain capillary endothelial cell cultures. Effect on the expression of blood-brain barrier-specific properties. J Neurochem 93, 279-289.

[34] Nakagawa S, Deli MA, Nakao S, Honda M, Hayashi K, Nakaoke R, Kataoka Y, Niwa M (2007) Pericytes from brain microvessels strengthen the barrier integrity in primary cultures of rat brain endothelial cells. Cell Mol Neurobiol 27, 687-694.

[35] Ceruti S, Colombo L, Magni G, Viganò F, Boccazzi M, Deli MA, Sperlágh B, Abbracchio MP, Kittel Á (2011) Oxygenglucose deprivation increases the enzymatic activity and the microvesicle-mediated release of ectonucleotidases in the cells composing the blood-brain barrier. Neurochem Int $\mathbf{5 9}$, 259-271.

[36] Dore-Duffy P, Katychev A, Wang X, Van Buren E (2006) CNS microvascular pericytes exhibit multipotential stem cell activity. J Cereb Blood Flow Metab 26, 613-624.

[37] Vandenhaute E, Dehouck L, Boucau MC, Sevin E, Uzbekov R, Tardivel M, Gosselet F, Fenart L, Cecchelli R, Dehouck MP (2011) Modelling the neurovascular unit and the blood-brain barrier with the unique function of pericytes. Curr Neurovasc Res 8, 258-269.

[38] Datki Z, Hunya A, Penke B (2007) A novel and simple fluorescence method for the measurement of presynaptic vesicular zinc release in acute hippocampal slices with a fluorescence plate reader. Brain Res Bull 74, 183-187.

[39] Datki Z, Juhász A, Gálfi M, Soós K, Papp R, Zádori D, Penke B (2003) Method for measuring neurotoxicity of aggregating polypeptides with the MTT assay on differentiated neuroblastoma cells. Brain Res Bull 62, 223-229.

[40] Deli MA, Ábrahám CS, Kataoka Y, Niwa M (2005) Permeability studies on in vitro blood-brain barrier models: physiology, pathology, and pharmacology. Cell Mol Neurobiol 25, 59-127.

[41] Fontaine M, Elmquist WF, Miller DW (1996) Use of rhodamine 123 to examine the functional activity of P-glycoprotein in primary cultured brain microvessels endothelial cell monolayers. Life Sci 59, 1521-1531.

[42] Perrière N, Yousif S, Cazaubon S, Chaverot N, Bourasset F, Cisternino S, Declèves X, Hori S, Terasaki T, Deli M, Scherrmann JM, Temsamani J, Roux F, Couraud PO (2007) A functional in vitro model of rat blood-brain barrier for molecular analysis of efflux transporters. Brain Res 1150, 1-13.

[43] Lowry OH, Rosebrough NJ, Farr AL, Randall RJ (1951) Protein measurement with the Folin phenol reagent. J Biol Chem 193, 265-275.

[44] Deli MA, Veszelka S, Csiszár B, Tóth A, Kittel Á, Csete M, Sipos Á, Szalai A, Fülöp L, Penke B, Ábrahám CS, Niwa M (2010) Protection of the blood-brain barrier by pentosan against amyloid- $\beta$-induced toxicity. J Alzheimers Dis 22, 777 794.

[45] Abramov AY, Canevari L, Duchen MR (2004) Calcium signals induced by amyloid beta peptide and their consequences in neurons and astrocytes in culture. Biochim Biophys Acta 1742, 81-87.

[46] Verdier Y, Zarándi M, Penke B (2004) Amyloid beta-peptide interactions with neuronal and glial cell plasma membrane: Binding sites and implications for Alzheimer's disease. J Pept Sci 10, 229-248.

[47] András IE, Rha G, Huang W, Eum S, Couraud P-O, Romero IA, Hennig B, Toborek M (2008) Simvastatin protects against amyloid $\beta$ and HIV-1 Tat-induced promoter activities of 
inflammatory genes in brain endothelial cells. Mol Pharmacol 73, 1424-1433.

[48] Verbeek MM, de Waal RM, Schipper JJ, Van Nostrand WE (1997) Rapid degeneration of cultured human brain pericytes by amyloid beta protein. $J$ Neurochem $\mathbf{6 8}, 1135-1141$.

[49] Wilhelmus MM, Otte-Holler I, van Triel JJ, Veerhuis R, MaatSchieman ML, Bu G, de Waal RM, Verbeek MM (2007) Lipoprotein receptor-related protein- 1 mediates amyloid- $\beta$ mediated cell death of cerebrovascular cells. Am J Pathol 171, 1989-1999.

[50] Jeynes B, Provias J (2008) Evidence for altered LRP/RAGE expression in Alzheimer lesion pathogenesis. Curr Alzheimer Res 5, 432-437.

[51] Preston JE, Hipkiss AR, Himsworth DT, Romero IA, Abbott NJ (1998) Toxic effects of $\beta$-amyloid(25-35) on immortalized rat brain endothelial cell: Protection by carnosine, homocarnosine and $\beta$-alanine. Neurosci Lett 242, 105-108.

[52] Carrano A, Hoozemans JJ, van der Vies SM, Rozemuller AJ, van Horssen J, de Vries HE (2011) Amyloid Beta induces oxidative stress-mediated blood-brain barrier changes in capillary amyloid angiopathy. Antioxid Redox Signal 15, $1167-1178$

[53] Tixier-Vidal A, Picart R, Loudes C, Bauman AF (1986) Effects of polyunsaturated fatty acids and hormones on synaptogenesis in serum-free medium cultures of mouse fetal hypothalamic cells. Neuroscience 17, 115-132.

[54] Greiner RS, Moriguchi T, Hutton A, Slotnick BM, Salem N Jr. (1999) Rats with low levels of brain docosahexaenoic acid show impaired performance in olfactory-based and spatial learning tasks. Lipids 34, S239-S243.

[55] Gamoh S, Hashimoto M, Sugioka K, Hossain MS, Hata N, Misawa Y (1999) Chronic administration of docosahexaenoic acid improves reference memory-related learning ability in young rats. Neuroscience 93, 237-241.

[56] Karr JE, Alexander JE, Winningham RG (2011) Omega-3 polyunsaturated fatty acids and cognition throughout the lifespan. Nutr Neurosci 14, 216-225.

[57] Lauritzen I, Blondeau N, Heurteaux C, Widmann C, Romey G, Lazdunski M (2000) Polyunsaturated fatty acids are potent neuroprotectors. EMBO J 19, 1784-1793.

[58] Hashimoto M, Tanabe Y, Fujii Y, Kikuta T, Shibata H, Shido O (2005) Chronic administration of docosahexaenoic acid ameliorates the impairment of spatial cognition learning ability in amyloid $\beta$-infused rats. J Nutr 135, 549-555.

[59] Calon F, Lim GP, Yang F, Morihara T, Teter B, Ubeda O (2004) Docosahexaenoic acid protects from dendritic pathology in an Alzheimer's disease mouse model. Neuron 43, 633-645.

[60] Lagarde M, Bernoud N, Brossard N, Lemaitre-Delaunay D, Thiès F, Croset M, Lecerf J (2001) Lysophosphatidylcholine as a preferred carrier form of docosahexaenoic acid to the brain. J Mol Neurosci 16, 201-204.

[61] Ouellet M, Emond V, Chen CT, Julien C, Bourasset F, Oddo S, LaFerla F, Bazinet RP, Calon F (2009) Diffusion of docosahexaenoic and eicosapentaenoic acids through the blood-brain barrier: An in situ cerebral perfusion study. Neurochem Int $\mathbf{5 5}$, 476-482.

[62] Bénistant C, Dehouck MP, Fruchart JC, Cecchelli R, Lagarde M (1995) Fatty acid composition of brain capillary endothelial cells: Effect of the coculture with astrocytes. J Lipid Res 36, 2311-2319.

[63] Lecomte M, Paget C, Ruggiero D, Wiernsperger N, Lagarde M (1996) Docosahexaenoic acid is a major n-3 polyunsaturated fatty acid in bovine retinal microvessels. $J$ Neurochem 66, 2160-2167.
[64] Roig-Pérez S, Cortadellas N, Moretó M, Ferrer R (2010) Intracellular mechanisms involved in docosahexaenoic acidinduced increases in tight junction permeability in Caco- 2 cell monolayers. J Nutr 140, 1557-1563.

[65] Paget C, Lecomte M, Ruggiero D, Wiernsperger N, Lagarde M (1998) Modification of enzymatic antioxidants in retinal microvascular cells by glucose or advanced glycation end products. Free Radic Biol Med 25, 121-129.

[66] Quimby S, Fern R (2011) Novel morphological features of developing white matter pericytes and rapid scavenging of reactive oxygen species in the neighbouring endothelia. JAnat 219, 65-77.

[67] András IE, Eum SY, Toborek M (2012) Lipid rafts and functional caveolae regulate HIV-induced amyloid beta accumulation in brain endothelial cells. Biochem Biophys Res Commun 421, 177-183.

[68] Yang X, Sheng W, Sun GY, Lee JC (2011) Effects of fatty acid unsaturation numbers on membrane fluidity and $\alpha$-secretasedependent amyloid precursor protein processing. Neurochem Int 58, 321-329.

[69] Pardridge WM (2002) Drug and gene targeting to brain with molecular Trojan horses. Nat Rev Drug Disc 1, 131-139.

[70] Tai LM, Loughlin AJ, Male DK, Romero IA (2009) Pglycoprotein and breast cancer resistance protein restrict apical-to-basolateral permeability of human brain endothelium to amyloid-beta. J Cereb Blood Flow Metab 29, 1079-1083.

[71] Candela P, Gosselet F, Saint-Pol J, Sevin E, Boucau MC, Boulanger E, Cecchelli R, Fenart L (2010) Apicalto-basolateral transport of amyloid- $\beta$ peptides through blood-brain barrier cells is mediated by the receptor for advanced glycation end-products and is restricted by $\mathrm{P}$ glycoprotein. J Alzheimers Dis 22, 849-859.

[72] Vogelgesang S, Jedlitschky G, Brenn A, Walker LC (2011) The role of the ATP-binding cassette transporter $\mathrm{P}$-glycoprotein in the transport of $\beta$-amyloid across the loodbrain barrier. Curr Pharm Des 17, 2778-2786.

[73] Kania KD, Wijesuriya HC, Hladky SB, Barrand MA (2011) Beta amyloid effects on expression of multidrug efflux transporters in brain endothelial cells. Brain Res 1418, 1-11.

[74] Kuhnke D, Jedlitschky G, Grube M, Krohn M, Jucker M, Mosyagin I, Cascorbi I, Walker LC, Kroemer HK, Warzok RW, Vogelgesang S (2007) MDR1-P-Glycoprotein (ABCB1) Mediates Transport of Alzheimer's amyloid-beta peptidesimplications for the mechanisms of Abeta clearance at the blood-brain barrier. Brain Pathol 17, 347-353.

[75] van Assema DM, Lubberink M, Bauer M, van der Flier WM, Schuit RC, Windhorst AD, Comans EF, Hoetjes NJ, Tolboom N, Langer O, Müller M, Scheltens P, Lammertsma AA, van Berckel BN (2012) Blood-brain barrier P-glycoprotein function in Alzheimer's disease. Brain 135, 181-189.

[76] Floyd RA, Hensley K (2002) Oxidative stress in brain aging. Implications for therapeutics of neurodegenerative diseases. Neurobiol Aging 23, 795-807.

[77] Choi J, Levey AI, Weintraub ST, Rees HD, Gearing M, Chin LS, Li L (2004) Oxidative modifications and down-regulation of ubiquitin carboxyl-terminal hydrolase L1 associated with idiopathic Parkinson's and Alzheimer's diseases. J Biol Chem 279, 13256-13264.

[78] Liebner S, Corada M, Bangsow T, Babbage J, Taddei A, Czupalla CJ, Reis M, Felici A, Wolburg H, Fruttiger M, Taketo $\mathrm{MM}$, von Melchner H, Plate KH, Gerhardt H, Dejana E (2008) Wnt/beta-catenin signaling controls development of the blood-brain barrier. J Cell Biol 183, 409-417. 


\section{PUBLICATION IV.}




\section{Edaravone Protects against Methylglyoxal-Induced Barrier Damage in Human Brain Endothelial Cells}

Andrea E. Tóth ${ }^{1}$, Fruzsina R. Walter ${ }^{1}$, Alexandra Bocsik ${ }^{1}$, Petra Sántha ${ }^{1}$, Szilvia Veszelka ${ }^{1}$, Lajos Nagy ${ }^{2}$, László G. Puskás ${ }^{2}$, Pierre-Olivier Couraud ${ }^{3,4,5}$, Fuyuko Takata ${ }^{6}$, Shinya Dohgu ${ }^{6}$, Yasufumi Kataoka ${ }^{6}$, Mária A. Deli ${ }^{1 *}$

1 Institute of Biophysics, Biological Research Centre of the Hungarian Academy of Sciences, Szeged, Hungary

2 Avidin Ltd., Szeged, Hungary

3 Inserm, U1016, Institut Cochin, Paris, France

4 CNRS, UMR8104, Paris, France

5 Université Paris Descartes, Sorbonne Paris Cité, Paris, France

6 Department of Pharmaceutical Care and Health Sciences, Fukuoka University, Fukuoka, Japan

Correspondence to: Mária A. Deli, Telephone: +36 62 599602; Fax: +36 62 433133; E-mail: deli.maria@brc.mta.hu

\section{Abstract}

Background: Elevated level of reactive carbonyl species, such as methylglyoxal, triggers carbonyl stress and activates a series of inflammatory responses leading to accelerated vascular damage. Edaravone is the active substance of a Japanese medicine, which aids neurological recovery following acute brain ischemia and subsequent cerebral infarction. Our aim was to test whether edaravone can exert a protective effect on the barrier properties of human brain endothelial cells (hCMEC/D3 cell line) treated with methylglyoxal.

Methodology: Cell viability was monitored in real-time by impedance-based cell electronic sensing. The barrier function of the monolayer was characterized by measurement of resistance and flux of permeability markers, and visualized by immunohistochemistry for claudin-5 and $\beta$-catenin. Cell morphology was also examined by holographic phase imaging.

Principle Findings: Methylglyoxal exerted a time- and dose-dependent toxicity on cultured human brain endothelial cells: a concentration of $600 \mu \mathrm{M}$ resulted in about $50 \%$ toxicity, significantly reduced the integrity and increased the permeability of the barrier. The cell morphology also changed dramatically: the area of cells decreased, their optical height significantly increased. Edaravone $(3 \mathrm{mM})$ provided a complete protection against the toxic effect of methylglyoxal. Co-administration of edaravone restored cell viability, barrier integrity and functions of brain endothelial cells. Similar protection was obtained by the well-known antiglycating molecule, aminoguanidine, our reference compound.

Conclusion: These results indicate for the first time that edaravone is protective in carbonyl stress induced barrier damage. Our data may contribute to the development of compounds to treat brain endothelial dysfunction in carbonyl stress related diseases.

Keywords: carbonyl stress, methylglyoxal, edaravone, aminoguanidine, human brain endothelial cells, hCMEC/D3, impedance, holographic phase contrast microscopy, permeability, reactive oxygen species, immunhistochemistry, $\beta$-catenin, claudin- 5 , resistance

\section{Introduction}

Increased serum levels of reactive carbonyl species, such as methylglyoxal, are present in several pathologies and cause complications in severe conditions and diseases, like diabetes mellitus [1,2], cardiovascular diseases [3,4], atherosclerosis [5], hypertension [6], metabolic syndrome [7], obesity [8], psoriasis [9], aging [10,11] Alzheimer's disease [12] [13], dementias [14], and other neurobiological diseases [15]. Methylglyoxal is a highly reactive $\alpha$-oxoaldehyde with strong oxidant and glycation properties [16]. Its immediate elimination by detoxification systems is crucial [17]. Accumulated methylglyoxal reacts with proteins, DNA and other biomolecules [18] causing inhibition of enzyme activity [19], transcriptional activation [20], apoptosis [21]. The end products of the reactions between methylgyoxal and free amino groups of molecules are insoluble protease-resistant polymers (advanced glycation end products AGE) [22]. Methylglyoxal triggers carbonyl [18] and oxidative stress [23,24] and activates a series of inflammatory responses leading to accelerated vascular endothelial damage [25-27].

Based on data obtained on peripheral endothelial cells, the effect of methylglyoxal on brain microvascular endothelium, which forms the blood-brain barrier was also investigated $[25,28]$. A concentrationdependent cell toxicity and barrier dysfunction was recently described on a brain endothelial cell line [28]. This study reported methylglyoxal-induced glycation of the tight junction protein occludin in culture, as well as in 
brain microvessels of diabetic rats, and a disturbed architectural organization of zonula occludens-1 protein. Similar to other cellular systems, methylglyoxal-treatment promoted carbonyl and oxidative stress in brain endothelial cells [28]. Methylglyoxal induced mitochondrial apoptotic signaling: decreased mitochondrial membrane potential, activated caspases and perturbed the cellular glutathione redox status [25]. These findings indicate that methylglyoxal-induced carbonyl and oxidative stress may play an important role in neurovascular pathology, and brain endothelium can be an early and significant target site of methylglyoxal.

The prevention of methylglyoxal-induced injury is in the focus of current research [29]. Aminoguanidine was the first drug extensively studied, and attenuated the development of a range of diabetic vascular complications both in vitro and in vivo. However, due to toxic side effects at high doses, it failed in clinical trials. This compound is considered as a prototype for antiglycation agents and used as a reference molecule in experiments [30]. Recently, a new promising agent, edaravone is investigated for its beneficial effects on brain endothelial cells. Edaravone is a neuroprotective free radical scavenger. It is the active substance of a Japanese medicine, which helps neurological recovery following acute brain and subsequent cerebral infarct [31,32]. To further reveal the mechanism of protection, brain microvessels [33] and the blood-brain barrier [34] were investigated as potential pharmaceutical targets of edaravone in animal models of stroke. The effect of edaravone alone has been described on barrier function: it promoted tight junction formation via activation of sphingosin-1-phospate signaling pathway [35] and down-regulation of interleukin-1 $\beta$ induced monocyte chemoattractant protein-1 secretion [36] in human microvascular endothelial cells. In a recent study, methylglyoxal-induced decrease in cell viability and methylglyoxal enhanced cell injury by oxygen-glucose deprivation were alleviated by pretreatment with edaravone in brain endothelial cells [37]. However, it remained unanswered whether edaravone can also protect against methylglyoxal-induced barrier dysfunction of brain endothelial monolayers.

The tight intercellular barrier maintaining low permeability is the fundamental characteristic of brain endothelial cells [38]. Therefore, this study aimed to clarify the effect of edaravone against methylglyoxalinduced barrier and morphological damage. In the experiments the widely used human hCMEC/D3 brain endothelial cell line [39], and new investigation methods, such as impedance monitoring in multiwell plates and holographic phase contrast imaging were used in addition to viability assays, permeability tests and immunohistochemistry for junctional proteins.

\section{Materials and Methods}

\section{Ethics statement}

All procedures involving experimental animals adhered to the law (No. 105) and notification (No. 6) of the Japanese Government, and were approved by the Laboratory Animal Care and Use Committee of Fukuoka University. The details of the isolation of primary brain endothelial cells from rats is described in Text S1.

\section{Materials}

All reagents were purchased from Sigma-Aldrich Ltd., Hungary, unless otherwise indicated.

\section{Cell Culture}

Human hCMEC/D3 brain endothelial cell line $[39,40]$ at passage number $\leq 35$ was used in the experiments. Cells were plated on rat tail collagen-coated culture dishes (Orange Scientific, Braine-l'Alleud, Belgium) or Transwell clear inserts (polyethylene membrane, $0.4 \mu \mathrm{m}$ pore size, $1.2 \mathrm{~cm}^{2}$ surface area, Corning Life Sciences, Tewksbury, MA, USA) depending on the experiment and cultured at $37{ }^{\circ} \mathrm{C}, 5 \% \mathrm{CO}_{2}$ in $\mathrm{EBM}-2$ medium (Lonza, Basel, Switzerland) containing $5 \%$ fetal bovine serum, hydrocortisone $(1.4 \mu \mathrm{M}), 10 \mathrm{mM}$ HEPES, gentamycin $(50 \mu \mathrm{g} / \mathrm{mL})$, acid ascorbic $(5 \mu \mathrm{g} / \mathrm{mL}), 1 \%$ chemically defined lipid concentrate, basic fibroblast growth factor $(1 \mathrm{ng} / \mathrm{mL}$ ) (Roche, Basel, Switzerland). Cells were seeded in culture dishes at a density of $2.5 \times 10^{4}$ cells $/ \mathrm{cm}^{2}$ and the medium was changed every 3 days. At the first change of medium, the medium was supplemented with $10 \mathrm{mM}$ lithium chloride [41]. When cells reached approximately $80-90 \%$ of confluence in the dish, they were subcultured with $0.05 \%$ trypsin-EDTA solution. For the cytotoxicity assays cells were cultured in 96-well culture plates (Orange Scientific, Braine-l'Alleud, Belgium). For real-time cell electronic sensing 96-well plates with gold electrodes (E-plate 96, ACEA Biosciences, San Diego, USA) were used. For permeability studies cells were cultured on Transwell inserts.

\section{Treatments}

Human brain endothelial cells were treated with methylglyoxal in the $100-1000 \mu \mathrm{M}$ concentration range in EBM-2 medium containing $10 \%$ fetal bovine serum, HEPES $(10 \mathrm{mM})$ and gentamycin $(50 \mu \mathrm{g} / \mathrm{mL})$. Edaravone was used in the 600-3000 $\mu \mathrm{M}$ concentration range. Aminoguanidine, a well-known antiglycation agent, was tested at $600-2000 \mu \mathrm{M}$ concentration and applied as a positive control [42]. Triton X-100 detergent was used at $10 \mathrm{mg} / \mathrm{ml}$ concentration in viability assays as a reference compound to cause cell death. 


\section{Real-Time Monitoring of Impedance}

Impedance-based cell electronic sensing is a label-free technique for dynamic monitoring of living cells. The RTCA-SP instrument (ACEA Biosciences, Inc., USA) utilizes an automatical and continuous impedance measurement to non-invasively quantify adherent cell proliferation and viability in real-time. This method has been succesfully used to measure number, adherence, growth and health of cells in control and treatment conditions [43-46]. E-plates were coated with rat tail collagen at room temperature and dried for 40 min under UV and air-flow. Culture medium $(50 \mu \mathrm{L})$ was added to each well for background readings, then $50 \mu \mathrm{L}$ of cell suspension was dispensed at the density of $1.6 \times 10^{4}$ cells/well. The cells were kept in incubator at $37^{\circ} \mathrm{C}$ for 5 days until reaching confluence. Impedance was monitored every 2 minutes. The cell index at each time point was defined as $(\mathrm{Rn}-\mathrm{Rb}) / 15$, where $\mathrm{Rn}$ is the cell-electrode impedance of the well when it contains cells and $\mathrm{Rb}$ is the background impedance of the well with the medium alone.

\section{MTT Dye Reduction Cell Viability Assay}

Living cells convert the yellow dye 3-(4,5-dimethyltiazol-2-yl)-2,5-diphenyltetrazolium bromide (MTT) to purple, insoluble formazan crystals. Decrease in dye conversation reflects cellular damage. Human endothelial hCEMC/D3 cells grown to confluency in 96-well culture plates were treated with methylglyoxal with or without protective agents for 8 hours. Then the treatment medium was removed from the wells and the cells were incubated with MTT solution $(0.5 \mathrm{mg} / \mathrm{mL})$ in Dulbecco's modified Eagle's medium for 3 hours in $\mathrm{CO}_{2}$ incubator. The amount of formazan crystals was dissolved in dimethyl-sulfoxide and determined by measuring absorbance at $570 \mathrm{~nm}$ wavelength with a microplate reader (Fluostar Optima, BMG Labtechnologies, Germany). Cells receiving treatment medium without methylglyoxal or protective agents, the control group, was considered as $100 \%$ viable.

\section{Detection of Reactive Oxygen Species}

To measure reactive oxygen species (ROS) we used a fluorometric detection probe, chloromethyldichloro-dihydro-fluorescein diacetate (DCFDA) (Molecular Probes, Life Technologies Corp., Carlsbad, USA). This indicator penetrates the cells by diffusion and becomes deacetylated by intracellular esterases. Oxidation of DCFDA by reactive oxygen species yields a fluorescent molecule. Confluent brain endothelial cell layers cultured in 96-well plates were pretreated with methylglyoxal $(600 \mu \mathrm{M})$ and/or protective agents for 0-8 hours, then washed, and incubated with Ringer-Hepes buffer containing $2 \mu \mathrm{M}$ DCFDA and $1.5 \mu \mathrm{M}$ pluronic acid (Life Technologies, Molecular Probes, USA) for 1 hour at $37^{\circ} \mathrm{C}$. Hydrogen peroxide pretreatment (100 $\left.\mu \mathrm{M}, 30 \mathrm{~min}\right)$ served as a positive control in the ROS assay. The plates were measured by Fluostar Optima fluorescent plate reader (BMG Labtechnologies, Germany) at $485 \mathrm{~nm}$ excitation and $520 \mathrm{~nm}$ emission wavelengths. The fluorescent values were presented as percent of the control group (cells receiving treatment medium without methylglyoxal or protective agents) after 1 hour incubation with DCFDA indicator.

\section{Measurement of Barrier Functions: Transendothelial Electrical Resistance}

Transendothelial electrical resistance (TEER) reflects the permeability of intercellular tight junctions for ions. TEER was measured by an EVOM resistance meter using STX-2 electrodes (World Precision Instruments Inc., Sarasota, FL, USA) and expressed relative to the surface area $\left(\Omega \times \mathrm{cm}^{2}\right)$. TEER values of cellfree inserts were subtracted from the measured data. The TEER of untreated human hCMEC/D3 brain endothelial cell monolayers was $43.3 \pm 6.1 \Omega \times \mathrm{cm}^{2}$ (mean $\left.\pm \mathrm{SD} ; \mathrm{n}=60\right)$ in agreement with literature data [40]. Resistance measurements were carried out before and after treatments to check the barrier integrity. The TEER values are presented as percent of non treated control groups.

\section{Measurement of Barrier Functions: Permeability Experiments}

To measure the flux of permeability marker molecules fluorescein isothiocyanate labeled dextran (FITC-dextran, mw: $4.4 \mathrm{kDa}$ ) and Evans blue-labeled albumin (mw: $67 \mathrm{kDa}$ ) across endothelial cell layers hCMEC/D3 cells were seeded onto Transwell inserts and grown for 5 days. Inserts with confluent layers were transferred to 12-well plates containing $1.5 \mathrm{~mL}$ Ringer-Hepes solution $(118 \mathrm{mM} \mathrm{NaCl}, 4.8 \mathrm{mM} \mathrm{KCl}, 2.5 \mathrm{mM}$ $\mathrm{CaCl}_{2}, 1.2 \mathrm{mM} \mathrm{MgSO}_{4}, 5.5 \mathrm{mM}$ D-glucose, $20 \mathrm{mM}$ Hepes, $\mathrm{pH}$ 7.4), which was the abluminal (lower) compartment in the permeability experiments. In the upper chambers (luminal compartment) culture medium was replaced by $500 \mu \mathrm{L}$ of Ringer-Hepes buffer containing $100 \mu \mathrm{g} / \mathrm{mL}$ FITC-dextran solution and $165 \mu \mathrm{g} / \mathrm{mL}$ Evans blue bound to $0.1 \% \mathrm{BSA}$. The plates were kept in a $37{ }^{\circ} \mathrm{C}$ incubator with $5 \% \mathrm{CO}_{2}$ on a horizontal shaker $(100 \mathrm{rpm})$ for $1 \mathrm{~h}$. After incubation the concentrations of the marker molecules in samples from the luminal (upper) and abluminal (lower) compartments were determined by a fluorescent microplate reader (Fluostar Optima; emission wavelength: $485 \mathrm{~nm}$, excitation wavelength: $520 \mathrm{~nm}$ ). Flux across cell-free inserts was also measured.

The apparent permeability coefficient $\left(\mathrm{P}_{\text {app }}\right)$ was calculated from the concentration difference of the tracer in the abluminal compartments $\left(\Delta[\mathrm{C}]_{\mathrm{A}}\right)$ after 1 hour and luminal compartments at 0 hour $\left([\mathrm{C}]_{\mathrm{L}}\right)$, the 
volume of the abluminal compartment $\left(\mathrm{V}_{\mathrm{A}} ; 1.5 \mathrm{~mL}\right)$ and the surface area available for permeability $\left(\mathrm{A} ; 1.1 \mathrm{~cm}^{2}\right)$ by the following equation [47]. The $\mathrm{P}_{\text {app }}$ values were presented as percent of non treated control groups.

$$
P_{\text {app }}(\mathrm{cm} / \mathrm{s})=\frac{\Delta[C]_{A} \times V_{A}}{A \times[C]_{L} \times \Delta t}
$$

\section{Immunohistochemistry}

Cell-cell connections and morphology of hCMEC/D3 cells were confirmed by immunostaining for junctional proteins $\beta$-catenin and claudin-5. Cells cultured on rat tail collagen coated Transwell inserts were washed in phosphate buffered saline (PBS) and fixed with acetone-methanol (1:1) for $\beta$-catenin and with ethanol-acetic acid (95:5) for claudin-5 at $-20{ }^{\circ} \mathrm{C}$ for 10 minutes. After rehydrating with PBS containing $1 \%$ fetal bovine serum and washing with PBS cells were blocked with $3 \%$ BSA in PBS at room temperature for 30 minutes. Samples were incubated overnight at $4{ }^{\circ} \mathrm{C}$ with anti- $\beta$-catenin or anti-claudin-5 primary antibodies (Invitrogen, Life Technologies Corp., Carlsbad, USA; 1:200). Incubation with Cy3-labeled or Alexa Fluoro 488labeled anti-rabbit IgG secondary antibodies and bis-benzimide (Hoechst dye 33342) to stain cell nuclei lasted for 1 hour. Between and after incubations cells were washed three times with PBS. Inserts were mounted in Gel Mount (Biomeda, USA) and staining was examined by Olympus Fluoview FV1000 and Leica SP5 confocal laser scanning microscopes (Leica Microsystems GmbH, Wetzlar, Germany).

\section{Holographic Phase Contrast Microscopy}

Digital holographic images were taken with a Holo-Monitor M3 instrument (Phase Holographic Imaging AB, Lund, Sweden). Endothelial cells were cultured on collagen coated culture dishes with borosilicate glass bottom (MatTek, Ashland, MA, USA). All treatments lasted for 4 hours. Holographic images of the same culture area were captured before and during treatments. Cell morphological changes were analysed by the Holostudio 2.4 software provided with the microscope (Phase Holographic Imaging AB, Lund, Sweden). Each point in the box plot reflects the data obtained on a single cell $[48,49]$.

\section{Statistical Analysis}

All data presented are means \pm SD or SEM as indicated in the text. The values were compared using the analysis of variance followed by Dunnett or Bonferroni posthoc tests using GraphPad Prism 5.0 software (GraphPad Software Inc., San Diego, CA, USA). Changes were considered statistically significant at $p<0.05$. All experiments were repeated at least three times, the number of parallel wells or inserts for each treatment and time point varied between 3 and 16 .

\section{Results}

\section{Methylglyoxal-induced Time- and Dose-dependent Cellular Toxicity Measured by Real-Time Impedance Monitoring}

The direct effect of methylglyoxal on cellular changes and cell viability was investigated by real-time impedance monitoring with an RTCA-SP instrument. Methylglyoxal showed dose and time-dependent toxicity in hCMEC/D3 endothelial cells (Figure 1A). The highest concentrations of methylglyoxal $(300-1000 \mu \mathrm{M})$ caused a very quick and significant decrease of cell index values compared to control. However, this initial impedance drop was compensated with time depending on the amount of methylglyoxal. In case of cells treated with 100-400 $\mu \mathrm{M}$ methylglyoxal no effect on cell index was measured from 3 to 24 hour. A significant toxicity of methylglyoxal was seen in concentrations of $500 \mu \mathrm{M}$ and above. Irreversible cell damage was observed at 800 and $1000 \mu \mathrm{M}$ (Figure 1A).

To validate our data, $600 \mu \mathrm{M}$ methylglyoxal concentration was tested using the colorimetric end-point MTT assay at 8-hour time point. The cell viability values after methylglyoxal treatment measured by the MTT test decreased to $56.7 \pm 4.6 \%$ (mean $\pm \mathrm{SD}, \mathrm{n}=50$ ) in good agreement with the decrease of cell index at the same concentration of methylglyoxal at the same time point $(58.2 \pm 5.8 \%$, mean $\pm \mathrm{SD}, \mathrm{n}=10)$. The $600 \mu \mathrm{M}$ concentration of methylglyoxal causing approximately $50 \%$ toxicity was selected for further tests.

To support the relevance of our data on endothelial cell line, the effect of methylglyoxal was also tested on cultures of primary rat brain endothelial cells (for preparation of cultures see Text S1). The toxicity of methylglyoxal was investigated by the WST-8 colorimetric assay of cell metabolism and LDH release reflecting cell membrane damage. No effect on viability was measured in primary cells treated with 100-300 $\mu \mathrm{M}$ methylglyoxal compared to control. Toxic effect was seen at $500 \mu \mathrm{M}$ : the cell viability values decreased to 68.0 $\pm 15.5 \%$ of the control (mean \pm SEM, $n=8$ ) by WST- 8 assay and $76.7 \pm 5.9 \%$ (mean \pm SEM, $n=12$ ) by LDH assay (Figure S2). 


\section{Co-administration of Edaravone Protects against Methylglyoxal-Induced Toxicity Measured by Real-} Time Impedance Monitoring

To investigate the protective effects of edaravone on methylglyoxal-induced cell injury, brain endothelial cells were co-treated with different concentrations of edaravone and with a fixed concentration of methylglyoxal $(600 \mu \mathrm{M})$. Cell index decreased by half in the methylglyoxal group (Figure 1B). Edaravone protected cells at 1000-3000 $\mu \mathrm{M}$ concentrations and reversed or attenuated the drop in cell index caused by methylglyoxal in a dose and time-dependent way. In case of cells co-treated with $60-600 \mu \mathrm{M}$ edaravone no effect on cell index was measured compared to the methylglyoxal group. Edaravone at $1 \mathrm{mM}$ showed a short term (0.5-2 hour) but statistically significant effect. The 1.5 and $2 \mathrm{mM}$ concentrations of edaravone could protect the endothelial cells till 6 and 8 hours post-treatment, respectively. Long lasting protection of hCMEC/D3 cells could be observed at 2.5 and $3 \mathrm{mM}$ concentrations of edaravone.

Our reference compound, aminoguanidine at $2 \mathrm{mM}$ concentration showed a complete protection against methylglyoxal-induced cellular toxicity (Figure 1B). This result is in agreement with its effect determined by MTT test. Aminoguanidine at $2 \mathrm{mM}$ concentration was found to be the most effective against methylglyoxalinduced cell damage in the colorimetric assay: cell viability was $93.2 \pm 0.6 \%$ of control at 8 hour time point. To determine the effect of protective agents alone, cells were incubated with different concentrations of edaravone $(600-3000 \mu \mathrm{M})$ and aminoguanidine $(600-2000 \mu \mathrm{M})$. There was no statistically significant decrease in cell viability measured by MTT assay and impedance monitoring in cells treated with edaravone or aminoguanidine alone. (Figure S1). Edaravone at $3 \mathrm{mM}$ concentration increased both the impedance of the endothelial layers and the metabolic activity measured by MTT assay $(121.8 \pm 5.9 \%$, mean $\pm \mathrm{SD}, \mathrm{n}=4, p<0.05)$.

Based on these results, the $3 \mathrm{mM}$ concentration of edaravone showing the best protection of brain endothelial cells was selected for other investigation.

\section{Methylglyoxal-induced Time-Dependent ROS Production}

As methylglyoxal generates not just carbonyl [18] but also oxidative stress [23,24], ROS production in cells treated with $600 \mu \mathrm{M}$ methylglyoxal was investigated at different time points (Figure 2A). The fluorescence intensity in cultured human brain endothelial cells measured by DCFDA assay at 1 hour time point was considered as $100 \%(1285.6 \pm 105.2$, fluorescence intensity in arbitrary units). ROS production was significantly enhanced $(126.1 \pm 12.0 \%, p<0.001)$ after one hour treatment by methylglyoxal as compared to control group, and remained elevated $(114.7 \pm 14.9 \%$ and $114.4 \pm 9.7 \%)$ at 2 and 4 hours time points, respectively. ROS production in endothelial cells treated for 8 hours by methylglyoxal $(109.7 \pm 5.7 \%)$ did not differ significantly from non-treated group. Hydrogen peroxide treatment (100 $\mu \mathrm{M}, 15 \mathrm{~min})$, a positive control in the ROS assay, elevated the amount of ROS measured in brain endothelial cells by 2 fold (199.4 $\pm 7.1 \%$; Figure $2 \mathrm{~A})$. Based on these data and results from real-time monitoring, the 4 hours time point of $600 \mu \mathrm{M}$ methylglyoxal treatment causing significantly elevated ROS production was chosen for further experiments.

\section{Co-administration of Edaravone Protects against Methylglyoxal-induced ROS Production}

Edaravone $(3 \mathrm{mM})$ completely inhibited the methylglyoxal-induced increase in ROS production (120.9 $\pm 7.3 \%$,) bringing back to the level of control $(97.2 \pm 1.7 \%, p<0.001$ as compared to the methylglyoxal treated group) at the 4 hours time point. Co-administration of aminoguanidine $(2 \mathrm{mM})$ also decreased ROS production stimulated by methylglyoxal $(89.1 \pm 2.1 \%)$. In contrast to edaravone, which had no effect alone $(102.5 \pm 1.7 \%)$, treatment with aminoguanidine alone decreased the amount of ROS in endothelial cells below the level of the control group ( $87.4 \pm 1.3 \%$; Figure 2B).

\section{Methylglyoxal-Induced Decrease of Resistance}

The direct effect of different concentrations of methylglyoxal on the ionic permeability of brain endothelial monolayers was determined by TEER measurement. The resistance of hCMEC/D3 control group was $37.5 \pm 5.5 \Omega \times \mathrm{cm}^{2}$ (mean $\pm \mathrm{SD} ; \mathrm{n}=14$ ). Methylglyoxal at 100 and $300 \mu \mathrm{M}$ concentrations (4 hours) did not cause significant changes. Treatment of endothelial cell monolayers with methylglyoxal at $600 \mu \mathrm{M}$ and $1 \mathrm{mM}$ concentrations significantly impaired the barrier integrity and decreased TEER to $90.6 \pm 2.5 \%$ and $89.9 \pm 2.7 \%$ ( $p<0.01$ for both treatment groups) compared to control (Figure 3A). Treatment of primary brain endothelial cells with methylglyoxal at 300 and $500 \mu \mathrm{M}$ concentrations also damaged the integrity of the barrier (Figure S3A). Methylglyoxal at 300 and $500 \mu \mathrm{M}$ concentrations decreased the resistance $(80.2 \pm 4.9 \%$ and $56.8 \pm 4.6$ $\%$, respectively) as compared to the control $(96.1 \pm 11.4 \% ; \mathrm{n}=14)$.

\section{Co-administration of Edaravone Protects against Methylglyoxal-Induced Resistance Decrease}

Co-administration of the protective agents with methylglyoxal preserved the barrier tightness and elevated resistance values to the level of control (edaravone: $97.9 \pm 0.8 \%$; aminoguanidine: $99.2 \pm 2.1 \%$ ). There was no significant difference between the resistance value of control and the groups treated with edaravone $(3 \mathrm{mM})$ or aminoguanidine $(2 \mathrm{mM})$ alone (Figure $3 \mathrm{~B})$. 


\section{Methylglyoxal-Induced Dose-dependent Permeability Increase}

Following the real-time impedance monitoring experiments, the direct effect of different methylglyoxal concentrations on the permeability of brain endothelial monolayers was measured using dextran (Figure 4A) and albumin (Figure 4B) as marker molecules. Cells were incubated with methylglyoxal (100-1000 $\mu \mathrm{M}, 4$ hours), then permeability measurements were performed. Methylglyoxal at 100 and $300 \mu \mathrm{M}$ concentrations did not cause barrier disruption. Treatment of hCMEC/D3 endothelial cell monolayers with methylglyoxal at $600 \mu \mathrm{M}$ and $1 \mathrm{mM}$ concentrations significantly impaired the barrier integrity and increased the permeability for both markers. The flux of the paracellular marker $4.4 \mathrm{kDa}$ FITC-dextran was elevated by 1.5 fold $(158.9 \pm 5.8 \%)$ in monolayers treated with $600 \mu \mathrm{M}$ methylglyoxal and was doubled $(196.4 \pm 7.2 \%)$ by $1 \mathrm{mM}$ methylglyoxal treatment as compared to the control group (Figure 3A). The permeability coefficient values for transcellular permeability marker albumin $(67 \mathrm{kDa})$ were one sixth of the values for FITC-dextran $(4.4 \mathrm{kDa}), 0.6 \pm 0.03 \times 10^{6}$ $\mathrm{cm} / \mathrm{s}$ and $3.6 \pm 0.8 \times 10^{6} \mathrm{~cm} / \mathrm{s}$, respectively, in agreement with literature data [39]. The permeability for albumin was doubled (221.8 $\pm 8.7 \%$ ) after incubation with $600 \mu \mathrm{M}$ methylglyoxal and tripled $(307.2 \pm 8.1 \%)$ in the case of $1 \mathrm{mM}$ methylglyoxal treatment (Figure 4B). Treatment of primary brain endothelial cells with $500 \mu \mathrm{M}$ methylglyoxal also increased the permeability of monolayers for fluorescein $(209.69 \pm 17.7 \%)$ and albumin $(168.9 \pm 38.6 \%)$, but $100-300 \mu \mathrm{M}$ concentrations had no effect (Figure S3B and S3C).

These results, that low concentrations of methylglyoxal $(100-300 \mu \mathrm{M})$ do not increase permeability, while higher concentrations significantly reduce barrier integrity are in agreement with our results from impedance measurements. In further permeability assays to test the effect of protective agents, human brain endothelial cells were treated with $600 \mu \mathrm{M}$ concentration of methylglyoxal.

\section{Co-administration of Edaravone Protects against Methylglyoxal-Induced Permeability Increase}

Co-administration of edaravone at $3 \mathrm{mM}$ concentration, selected previously by impedance measurement, could completely protect brain endothelial monolayers from the damaging effects of methylglyoxal (Figure 4C and 4D). Co-administration of edaravone shielded the cells from the damaging effect of methylglyoxal and kept the permeability for FITC-dextran at the control level (MG+E: $103.8 \pm 4.9 \%$ vs. MG: $165.6 \pm 6.0 \%$ ). The same effect was seen by the co-administration of aminoguanidine at $2 \mathrm{mM}$ concentration, endothelial permeability stayed at the level of control group $(100.6 \pm 1.7 \%)$ (Figure 4C). The increased permeability for albumin of brain endothelial cell layers treated with methylglyoxal $(261.3 \pm 12.2 \%)$ was completely prevented by the co-administration of $3 \mathrm{mM}$ edaravone $(112.1 \pm 2.8 \%)$ or $2 \mathrm{mM}$ aminoguanidine $(113.0 \pm 6.5 \%)$ (Figure 4D).

Aminoguanidine $(2 \mathrm{mM})$ alone had no effect on the permeability of brain endothelial monolayers. Edaravone $(3 \mathrm{mM})$ was able to tighten the barrier for both FITC-dextran $(81.9 \pm 2.0 \%$; Figure $4 \mathrm{C})$ and albumin $(56.5 \pm 3.5 \%$; Figure $4 \mathrm{D})$ as compared to the permeability of the control group.

\section{Co-administration of Edaravone Protects against Methylglyoxal-Induced Changes in Immunostaining}

The effect of methylglyoxal on cell-cell adhesion was investigated by immunostaining for $\beta$-catenin, a cytoplasmic adherens junction protein, and claudin-5, a transmembrane tight junction protein (Figure 5). In control monolayers $\beta$-catenin staining was localized to the cell border and the tightly apposed, elongated endothelial cells were well delineated (Figure 5A). Claudin-5 localization at the interendothelial junctions was less stringent than for $\beta$-catenin but clearly visible in part of the cell borders (Figure 5E) and resembled the immunostaining shown in the paper describing this cell line [39]. The pattern of the staining was dramatically changed in methylglyoxal $(600 \mu \mathrm{M}, 4$ hours) treated cells. Treatment with methylglyoxal resulted in decreased immunostaining intensity, fragmentation or loss of the continuous cortical staining pattern, the appearance of intercellular gaps (Figure 5B and 5F) and apoptotic cells (Figure 5F). Co-administration of protective agents, edaravone (Figure 5C and 5G) and aminoguanidine (Figure 5D and 5H) attenuated these changes, the monolayer integrity was better preserved and the immunostaining pattern resembled to the control ones.

\section{Co-administration of Edaravone Protects against Methylglyoxal-Induced Morphological Changes Examined by Holographic Phase Contrast Microscopy}

Holographic phase contrast microscopic analysis was performed to visualize the morphological changes caused by methylglyoxal and the protective effect of edaravone (Figure 6). This novel technology enabled us to follow living cells in a label-free and non-invasive way. Morphological parameters of treated cells, such as surface area, optical thickness and cell volume could be measured. Holographic images were taken every 30 minutes before and during the 4-hour treatment of hCMEC/D3 cells. Endothelial cells show a flat, elongated shape and grow next to each other. Treatment with methylglyoxal caused drastic changes in cell morphology: as indicated by the colour-scale, growth of cell height was especially prominent (Figure 6). In contrast, in endothelial cells co-treated with edaravone $(3 \mathrm{mM})$ and methylglyoxal $(600 \mu \mathrm{M})$ there was no change in cell morphology during the treatment period (Figure 6). Two short videos on the cell morphology in both treatment groups at all timepoints are shown as supplementary data (Video S1 and S2). The analysis of morphological data is shown on Figure 7. During treatment with methylglyoxal the area of the cells significantly decreased $(63.1 \pm$ 
$33.7 \%)$ and their optical thickness increased by 1.8 fold $(176.2 \pm 36.1 \%)$ compared to the values at the beginning of treatment. These data indicate that endothelial cells treated with methylglyoxal contracted and rounded up, which is also visible on Figures 6 and Video S1. The volume of the cells was unchanged. Meanwhile, no changes were observed in cells co-treated with edaravone and methylglyoxal (Figure 7) or in the control group which was treated with medium only. This is the first report on methylglyoxal-induced morphology changes in brain endothelial cells using holographic phase contrast imaging.

\section{Discussion}

\section{Carbonyl stress and brain endothelial damage}

Higher incidence of stroke, dementia and Alzheimer's disease is observed in diabetes mellitus [50,51]. Carbonyl stress induced by high level of methylglyoxal is responsible for the diabetes related vascular complications [52]. A direct toxic effect of methylglyoxal on brain microvessels was proposed in a recent study [28]. In the present study we further supported the fact that methylglyoxal alone could induce damage to brain endothelial cells. Methylglyoxal exerted a time- and dose-dependent toxicity on cultured human brain endothelial cells; it significantly reduced the integrity of the barrier measured by both functional and morphological experiments. This is the first study to provide kinetic data on the toxicity of methylglyoxal by impedance-based cell electronic sensing, a noninvasive label-free technique. The two different cell viability assays we used were in complete agreement on the direct cellular damaging effect of methylglyoxal, impedance data reflecting changes in cell adhesion, cell shape and number were confirmed by MTT tests measuring the metabolic activity of cells. Our data lend support to and expand previous findings on the effect of methylglyoxal on human brain endothelial cells $[25,28,37,53]$. We selected the human hCMEC/D3 cell line as a simplified model of the blood-brain barrier. This cell line is widely used in different experiments, including pharmacological and drug studies [40]. To support the relevance of our data on hCMEC/D3 endothelial cell line, the effect of methylglyoxal was also tested on primary cultures of rat brain endothelial cells. The observed effects were in agreement with our observations on the human cell line, indicating a similar sensitivity of primary endothelial cells and hCMEC/D3 endothelial cell line for the toxic effects of methylglyoxal. We found no data on primary brain endothelial cells related to methylglyoxal in the literature, therefore the present observation is the first study to include primary brain endothelial cells in this setting. The relevance of our findings on endothelial cells is limited by the use of high concentrations of methylglyoxal to induce barrier damage, a common concern in cell culture studies. However, in four recent and independent studies both the time needed to measure methylglyoxal-induced injury in cultured endothelial cells and the concentrations used were in similar range as in our study $[25,28,37,53]$.

Damage by methylglyoxal is mediated not only via carbonyl stress, but also by oxidative stress. [23,24]. Reactive oxygen species are generated as by-products of protein glycation [54]. Furthermore, methylglyoxal increases glycation of selected mitochondrial proteins resulting in increased formation of superoxide [55]. Elevated level of ROS weakens the barrier integrity [56], however the contribution of methylglyoxal-triggered ROS production in the increased endothelial permeability is controversial [28]. In the present study we confirmed that methylglyoxal treatment promotes oxidative stress in brain endothelial cells, similarly to previous studies on endothelial cells [28,53] and other cellular systems [57]. The kinetics of ROS production also helped to determine the optimal time point for protection assays and other experiments: a time point, where ROS formation was still elevated, was purposefully selected.

In good agreement with the data from toxicity measurements methylglyoxal increased the permeability of human and rat brain endothelial monolayers. The effect was dose-dependent, with only high concentrations of methylglyoxal causing significant damage in barrier integrity. These data are in accordance with findings of a previous study showing that methylglyoxal induced permeability increase in brain endothelial cells [28]. In that study decreased transendothelial electrical resistance and increased dextran flux were coupled with glycation of occludin and disturbed localization of zonula occludens-1 tight junction proteins [28]. In the present study we found the redistribution of two other junctional proteins important for the regulation of brain endothelial permeability, namely the tight junction protein claudin- 5 and adherens junctional protein $\beta$-catenin in methylglyoxal-treated brain endothelial cells. Claudin-5 is the most abundant integral membrane protein of the brain endothelial tight junctions and a major regulator of the blood-brain barrier permeability [59]. $\beta$-catenin binds the cytoplasmic tail of vascular endothelial cadherin (VE-cadherin) to the actin cytoskeleton [58]. Besides its role as a cytoskeletal linker, $\beta$-catenin is an important signaling and transcriptional factor at the blood-brain barrier regulating its tightness [59]. Delocalization/redistribution of $\beta$-catenin in brain endothelial cells is linked to permeability increase in many pathologies $[60,61,62]$. We demonstrated for the first time, that treatment with methylglyoxal resulted in fragmentation and loss of the continuous cortical pattern of $\beta$-catenin in brain endothelial cells, confirming the importance of $\beta$-catenin in barrier integrity.

For the maintenance of the integrity of the blood-brain permeability barrier the attachment of endothelial cells to the basement membrane is crucial [63]. Damage to the basal lamina weakens microvascular 
wall structures and results in increase of brain vessel permeability in vivo [64]. Our data confirmed these observations and visualized for the first time the kinetics of morphological changes caused by methylglyoxal using a novel technique, holographic phase contrast microscopy. This technology follows the morphology of living cells in a label-free and non-invasive way and detects only the effects of the tested compound $[48,49]$. In our study methylglyoxal changed drastically the shape of brain endothelial cells by time: the area of cells decreased, their optical height significantly increased indicating cell-cell and cell-basal lamina detachment. Similar observation was made in case of peripheral endothelial cells, where modification of basement membrane by methylglyoxal caused cell detachment, anoikis and inhibition of angiogensis [65].

\section{Protective effect of edaravone on methylglyoxal-injured brain endothelial cells}

Edaravone was reported to protect brain microvessels and the blood-brain barrier after ischemic stroke [33,34]. In a recent study, edaravone reduced cell injury in oxygen-glucose deprivation in vitro model. Edaravone pretreatment attenuated methylglyoxal-induced decrease in cell viability of brain endothelial cells [37]. In our study co-treatment with edaravone provided a complete protection against the toxic effect of methylglyoxal. We could see a dose- and time-dependent effect based on kinetic data from impedance measurements. Our data are in agreement with viability studies on the effect of edaravone pretreatment against methylglyoxal-induced toxicity [37]. Edaravone treatment alone increased the metabolic activity and impedance of the endothelial layers. A beneficial effect of edaravone on human endothelial cells was also found previously by resistance measurement and proteomic assay [35,36]. The edaravone concentrations used were in the millimolar range similarly to another independent work on cultured human brain endothelial cells. For longlasting protection suprapharmacological concentration of edaravone [66] was needed in our culture study. However, the applied methylglyoxal levels were also comparably high, as in other in vitro methylglyoxal studies $[25,28,37,53]$. Although we use higher concentrations in cultured cells, importantly, the ratio of the methylglyoxal to edaravone used in our study is the same as the ratio of the pathological plasma methylglyoxal concentrations [67] to clinical concentrations of edaravone [66].

Originally, edaravone has been described as a drug to treat ischemic stroke by protecting against oxidative stress [31]. Its antioxidant effect was observed in our experiment, too. In a recent independent study edaravone suppressed methyglyoxal-induced ROS production in human brain endothelial cells by two possible mechanisms [37]. Pre-treatment with edaravone decreased methylglyoxal-induced AGE accumulation and activation of its receptor RAGE [37], and the subsequent production of ROS [68,69]. Furthermore, edaravone inhibited protein-glycation by methylglyoxal in a cell free system [37], therefore, it decreased ROS generated as by-products during protein glycation [54]. All these results together indicate that the antioxidant mechanisms induced by edaravone contribute to its protective effect against methylglyoxal-induced oxidative stress.

Prior work described, that edaravone protects from methylglyoxal-induced injury by inhibiting AGEs/RAGE/oxidative stress in human brain microvascular endothelial cells [37]. However, it remained unanswered whether edaravone can also protect against methylglyoxal-induced barrier dysfunction in brain endothelial monolayers. Therefore, this study focused on the protective effect of edaravone against methylglyoxal-induced barrier damage. We found that co-treatment with edaravone restored barrier properties of endothelial cells and protected against methylglyoxal-induced decrease of resistance and increase in permeability for paracellular and transcellular markers. Moreover, we also demonstrated that edaravone treatment alone tightened the brain endothelial barrier. Our data expand and further support previous observations on barrier enhancing effect of edaravone [35,36].

Increased endothelial permeability was coupled with disturbed localization of junctional proteins claudin-5 and $\beta$-catenin after incubation with methylglyoxal, while co-treatment with edaravone restored distribution of both proteins along the cell borders. Similar observation was made in a previous study, where edaravone treatment enhanced $\beta$-catenin at cell-cell contact area and the cortical arrangement for its linked protein, actin on half confluent endothelial monolayer [35]. Our holographic phase contrast microscopic data are in accordance with these observations: edaravone completely prevented methylglyoxal-induced changes in cell morphology, no sign of detachment and cellular morphological change was observed, indicating there was no cytoskeletal rearrangement.

Our results have answered the question that edaravone can protect against methylglyoxal-induced barrier dysfunction in brain endothelial cells. However, the underlying signal transduction pathways during cotreatment were not examined and further work is needed to elucidate the precise mechanism.

\section{Conclusion}

This is the first study to investigate the protection of cerebral endothelial cells by edaravone in cotreatment with methylglyoxal. Our results provide compelling evidence for barrier protective effect of edaravone in cultured endothelium of brain microvasculature. Data from this study could have therapeutical implication for disorders and diseases that are associated with carbonyl stress. 


\section{Materials and Methods for supplementary figures S2 and S3}

All procedures involving experimental animals adhered to the law (No. 105) and notification (No. 6) of the Japanese Government, and were approved by the Laboratory Animal Care and Use Committee of Fukuoka University.

\section{Materials}

All reagents were purchased from Sigma-Aldrich Ltd., unless otherwise indicated.

\section{Isolation of primary rat brain endothelial cells}

Primary cultures of rat brain capillary endothelial cells (PRBECs) were prepared from 3 week-old Wistar rats CREA Japan, Inc. (Tokyo, Japan). The rats had free access to food and water and were maintained on a 12-h dark/light cycle in a room with controlled temperature $\left(24-1^{\circ} \mathrm{C}\right)$ and humidity $(55-5 \%)$. After decapitation the meninges were carefully removed from the forebrains, and the gray matter was minced in DMEM cooled at $2^{\circ} \mathrm{C}$, and digested with collagenase type $2\left(1 \mathrm{mg} / \mathrm{mL}\right.$, Worthington, Lakewood, NJ, USA) for $1.5 \mathrm{~h}$ at $37^{\circ} \mathrm{C}$. The pellet was separated by centrifugation in $20 \%$ bovine serum albumin (BSA)-DMEM (10006g, $20 \mathrm{~min}$ ). The microvessels obtained in the pellet were further digested with collagenase/dispase $(1 \mathrm{mg} / \mathrm{mL}$, Roche, Mannheim, Germany) for $1 \mathrm{~h}$ at $37^{\circ} \mathrm{C}$. Microvessel clusters containing pericytes and endothelial cells were separated on a $33 \%$ continuous Percoll (GE Healthcare, Buckinghamshire, UK) gradient, collected and washed twice with DMEM before plating on collagen type IV-fibronectin (both $0.1 \mathrm{mg} / \mathrm{mL}$ ) coated dishes. Rat brain endothelial cell cultures were maintained in DMEM/F12 medium supplemented with $10 \%$ plasma derived sera, basic fibroblast growth factor $(1.5 \mathrm{ng} / \mathrm{mL}$, Roche), heparin $(100 \mu \mathrm{g} / \mathrm{mL})$, insulin $(5 \mu \mathrm{g} / \mathrm{mL})$, transferrin $(5 \mathrm{mg} / \mathrm{mL})$, sodium selenite $(5 \mathrm{ng} / \mathrm{mL}$; insulin-transferrin-sodium selenite media supplement) and gentamicin $(50 \mu \mathrm{g} / \mathrm{mL})]$ containing puromycin $(4 \mu \mathrm{g} / \mathrm{mL})$ at $37^{\circ} \mathrm{C}$ in a humidified atmosphere of $5 \% \mathrm{CO} / 95 \%$ air, for two days. To remove the puromycin, cells were washed three times with fresh medium and cultured for three days. On the fifth day, cell culture typically reached $80-90 \%$ confluency.

\section{Treatments}

Brain endothelial cells were treated with methylglyoxal in the $100-500 \mu \mathrm{M}$ concentration range. Confluent primary rat brain endothelial cells were treated in DMEM/F12 medium supplemented with basic fibroblast growth factor $(1.5 \mathrm{ng} / \mathrm{mL}$, Roche), heparin $(100 \mu \mathrm{g} / \mathrm{mL})$, insulin $(5 \mu \mathrm{g} / \mathrm{mL})$, transferrin $(5 \mathrm{mg} / \mathrm{mL})$, sodium selenite $(5 \mathrm{ng} / \mathrm{mL}$; insulin-transferrin-sodium selenite media supplement) and gentamicin $(50 \mu \mathrm{g} / \mathrm{mL})$.

\section{Cell Viability Assays}

For endpoint viability assays brain endothelial cells were grown to confluency in 96-well culture plates and treated with methylglyoxal, with or without protective agents for 8 hours. In WST-8 assay (Cell Counting Kit, Dojindo, Kumamoto, Japan) similarly to MTT assay, living cells produce formazan by mitochondrial dehydrogenase. The absorbance of the highly water-soluble formazan dye (WST-8) was measured in each sample at wavelengths of $450 \mathrm{~nm}$ (test wavelength) and $700 \mathrm{~nm}$ (reference wavelength). Cells receiving treatment medium without methylglyoxal or protective agents, the control group, was considered as $100 \%$ viable.

Lactate dehydrogenase (LDH) release is the indicator of cell membrane damage. was determined from culture supernatants by a commercially available kit (Cytotoxicity detection kit LDH, Roche, Basel, Switzerland). After the treatment $50 \mu \mathrm{l}$ samples from culture supernatants were removed and incubated with equal amounts of reaction mixture for 15 minutes. The enzyme reaction was stopped by $0.1 \mathrm{M} \mathrm{HCl}$. Absorbance was measured at a wavelength of $492 \mathrm{~nm}$ with a microplate reader (Opsys MR, DYNEX Technologies, Chantilly, VA,USA). Cell death was calculated as percentage of the total LDH release from cells treated by $1 \%(\mathrm{w} / \mathrm{v})$ Triton X-100 detergent.

\section{Measurement of Barrier Functions: Transendothelial Electrical Resistance}

Transendothelial electrical resistance (TEER) reflects the permeability of intercellular tight junctions for ions. TEER was measured an Epithelial-volt-ohm meter and Endohm-6 chamber electrodes (World Precision Instruments, Sarasota, FL, USA) and expressed relative to the surface area $\left(\Omega \times \mathrm{cm}^{2}\right)$. TEER values of cell-free inserts were subtracted from the measured data. Resistance measurements were carried out before and after treatments to check the barrier integrity. The TEER values are presented as percent of non treated control groups.

\section{Measurement of Barrier Functions: Permeability Experiments}

Cell culture inserts were transferred to 24-well plates containing $0.6 \mathrm{ml}$ permeability assay buffer $(141 \mathrm{mM}$ $\mathrm{NaCl}, 2.8 \mathrm{mM} \mathrm{CaCl}_{2}, 1 \mathrm{mM} \mathrm{MgSO}_{4}, 4 \mathrm{mM} \mathrm{KCl}, 1 \mathrm{mM} \mathrm{NaH}_{2} \mathrm{PO}_{4}, 10 \mathrm{mM}$ glucose and $10 \mathrm{mM}$ Hepes, $\mathrm{pH} 7.4$ ) 
in the lower or abluminal compartments. In the inserts (luminal compartment), culture medium was replaced by $0.1 \mathrm{ml}$ buffer containing $100 \mu \mathrm{g} / \mathrm{ml} \mathrm{Na}$-Fluorescein (MW: $376 \mathrm{Da}$ ) and 4\% bovine serum albumin mixed with $0.67 \mathrm{mg} / \mathrm{mL}$ Evan's blue dye (EBA; MW: 67,000 Da). Samples (400 $\mu \mathrm{L})$ were removed from each side at 15, 30, 45, 60, 120 and $180 \mathrm{~min}$. To ensure mixing of the layers, we stirred the assay buffer in the receiver chamber, into which test compounds permeate, with a pipette before removing the buffer and immediately replacing with fresh permeability assay buffer. The concentrations of Na-Fluorescein were determined with a CytoFluor Series 4000 fluorescence multiwall plate reader (PerSeptive Biosystems) using a fluorescein filter pair $(\operatorname{Ex}(\lambda) 485 \pm 10$ $\mathrm{nm} ; \operatorname{Em}(\lambda) 530 \pm 10 \mathrm{~nm})$. The EBA concentration in the abluminal chamber was measured by determining the absorbance of samples at $630 \mathrm{~nm}$ with a microplate reader (Opsys MR, DYNEX Technologies, Chantilly, VA,USA).

Transendothelial permeability coefficient $\left(\mathrm{P}_{\mathrm{e}}\right)$ was calculated from the transport of donor (luminal) compartment volume from which the tracer is completely cleared. Cleared volume was calculated from the concentration $(\mathrm{C})$ of the tracer in the abluminal and luminal compartments and the volume $(\mathrm{V})$ of the abluminal compartment $(0.5$ $\mathrm{ml}$ ) by the following equation:

$$
\text { Cleared volume }(\mu \mathrm{l})=\frac{C_{\text {abluminal }} \times V_{\text {abluminal }}}{C_{\text {luminal }}}
$$

The average cleared volume was plotted $v s$. time, and permeability $\times$ surface area product value for endothelial monolayer $\left(\mathrm{PS}_{\mathrm{e}}\right)$ was calculated by the following formula:

$$
\frac{1}{P S_{\text {endothelial }}}=\frac{1}{P S_{\text {total }}}-\frac{1}{P S_{\text {insert }}}
$$

$\mathrm{PS}_{\mathrm{e}}$ divided by the surface area $\left(1 \mathrm{~cm}^{2}\right.$ for Transwell-12) generated the endothelial permability coefficient $\left(\mathrm{P}_{\mathrm{e}}\right.$; in $10^{-3} \mathrm{~cm} / \mathrm{min}$ ). The values were presented as percent of non treated control groups.

\section{Statistical Analysis}

Data are presented as means \pm SEM. The values were compared using the analysis of variance followed by Dunnett or Bonferroni posthoc tests using GraphPad Prism 5.0 software (GraphPad Software Inc., San Diego, CA, USA). Changes were considered statistically significant at $p<0.05$. All experiments were repeated at least three times, the number of parallel wells or inserts for each treatment and time point varied between 3 and 6 . 


\section{References}

1. Lapolla A, Flamini R, Dalla Vedova A, Senesi A, Reitano R, et al. (2003) Glyoxal and methylglyoxal levels in diabetic patients: quantitative determination by a new GC/MS method. Clin Chem Lab Med 41: 11661173.

2. Vander Jagt DL, Hunsaker LA (2003) Methylglyoxal metabolism and diabetic complications: roles of aldose reductase, glyoxalase-I, betaine aldehyde dehydrogenase and 2-oxoaldehyde dehydrogenase. Chem Biol Interact 143-144: 341-351.

3. Rabbani N, Godfrey L, Xue M, Shaheen F, Geoffrion M, et al. (2011) Glycation of LDL by methylglyoxal increases arterial atherogenicity: a possible contributor to increased risk of cardiovascular disease in diabetes. Diabetes 60: 1973-1980.

4. Uchida K (2000) Role of reactive aldehyde in cardiovascular diseases. Free Radic Biol Med 28: 1685-1696.

5. Moheimani F, Morgan PE, van Reyk DM, Davies MJ (2010) Deleterious effects of reactive aldehydes and glycated proteins on macrophage proteasomal function: possible links between diabetes and atherosclerosis. Biochim Biophys Acta 1802: 561-571.

6. Chang T, Wu L (2006) Methylglyoxal, oxidative stress, and hypertension. Can J Physiol Pharmacol 84: 12291238.

7. Liu J, Wang R, Desai K, Wu L (2011) Upregulation of aldolase B and overproduction of methylglyoxal in vascular tissues from rats with metabolic syndrome. Cardiovasc Res 92: 494-503.

8. Matafome P, Sena C, Seica R (2013) Methylglyoxal, obesity, and diabetes. Endocrine 43: 472-484.

9. Kaur S, Zilmer K, Leping V, Zilmer M (2013) Serum methylglyoxal level and its association with oxidative stress and disease severity in patients with psoriasis. Arch Dermatol Res 305: 489-494.

10. Srikanth V, Westcott B, Forbes J, Phan TG, Beare R, et al. (2013) Methylglyoxal, cognitive function and cerebral atrophy in older people. J Gerontol A Biol Sci Med Sci 68: 68-73.

11. Beeri MS, Moshier E, Schmeidler J, Godbold J, Uribarri J, et al. (2011) Serum concentration of an inflammatory glycotoxin, methylglyoxal, is associated with increased cognitive decline in elderly individuals. Mech Ageing Dev 132: 583-587.

12. Kuhla B, Luth HJ, Haferburg D, Boeck K, Arendt T, et al. (2005) Methylglyoxal, glyoxal, and their detoxification in Alzheimer's disease. Ann N Y Acad Sci 1043: 211-216.

13. Munch G, Kuhla B, Luth HJ, Arendt T, Robinson SR (2003) Anti-AGEing defences against Alzheimer's disease. Biochem Soc Trans 31: 1397-1399.

14. Dukic-Stefanovic S, Schinzel R, Riederer P, Munch G (2001) AGES in brain ageing: AGE-inhibitors as neuroprotective and anti-dementia drugs? Biogerontology 2: 19-34.

15. Munch G, Westcott B, Menini T, Gugliucci A (2012) Advanced glycation endproducts and their pathogenic roles in neurological disorders. Amino Acids 42: 1221-1236.

16. Turk Z (2010) Glycotoxines, carbonyl stress and relevance to diabetes and its complications. Physiol Res 59: 147-156.

17. Nemet I, Varga-Defterdarovic L, Turk Z (2006) Methylglyoxal in food and living organisms. Mol Nutr Food Res 50: 1105-1117.

18. Stitt AW, Jenkins AJ, Cooper ME (2002) Advanced glycation end products and diabetic complications. Expert Opin Investig Drugs 11: 1205-1223.

19. Murata-Kamiya N, Kamiya H (2001) Methylglyoxal, an endogenous aldehyde, crosslinks DNA polymerase and the substrate DNA. Nucleic Acids Res 29: 3433-3438.

20. Yao D, Taguchi T, Matsumura T, Pestell R, Edelstein D, et al. (2006) Methylglyoxal modification of mSin3A links glycolysis to angiopoietin-2 transcription. Cell 124: 275-286.

21. Thornalley PJ, Edwards LG, Kang Y, Wyatt C, Davies N, et al. (1996) Antitumour activity of S-pbromobenzylglutathione cyclopentyl diester in vitro and in vivo. Inhibition of glyoxalase I and induction of apoptosis. Biochem Pharmacol 51: 1365-1372.

22. Lo TW, Westwood ME, McLellan AC, Selwood T, Thornalley PJ (1994) Binding and modification of proteins by methylglyoxal under physiological conditions. A kinetic and mechanistic study with $\mathrm{N}$ alphaacetylarginine, $\mathrm{N}$ alpha-acetylcysteine, and $\mathrm{N}$ alpha-acetyllysine, and bovine serum albumin. J Biol Chem 269: 32299-32305.

23. Yim HS, Kang SO, Hah YC, Chock PB, Yim MB (1995) Free radicals generated during the glycation reaction of amino acids by methylglyoxal. A model study of protein-cross-linked free radicals. J Biol Chem 270: 28228-28233.

24. Kalapos MP (2008) The tandem of free radicals and methylglyoxal. Chem Biol Interact 171: 251-271.

25. Okouchi M, Okayama N, Aw TY (2009) Preservation of cellular glutathione status and mitochondrial membrane potential by $\mathrm{N}$-acetylcysteine and insulin sensitizers prevent carbonyl stress-induced human brain endothelial cell apoptosis. Curr Neurovasc Res 6: 267-278.

26. Yamawaki H, Saito K, Okada M, Hara Y (2008) Methylglyoxal mediates vascular inflammation via JNK and p38 in human endothelial cells. Am J Physiol Cell Physiol 295: C1510-1517. 
27. Sena CM, Matafome P, Crisostomo J, Rodrigues L, Fernandes R, et al. (2012) Methylglyoxal promotes oxidative stress and endothelial dysfunction. Pharmacol Res 65: 497-506.

28. Li W, Maloney RE, Circu ML, Alexander JS, Aw TY (2013) Acute carbonyl stress induces occludin glycation and brain microvascular endothelial barrier dysfunction: role for glutathione-dependent metabolism of methylglyoxal. Free Radic Biol Med 54: 51-61.

29. Desai K, Wu L (2007) Methylglyoxal and advanced glycation endproducts: new therapeutic horizons? Recent Pat Cardiovasc Drug Discov 2: 89-99.

30. Thornalley PJ (2003) Use of aminoguanidine (Pimagedine) to prevent the formation of advanced glycation endproducts. Arch Biochem Biophys 419: 31-40.

31. Watanabe T, Yuki S, Egawa M, Nishi H (1994) Protective effects of MCI-186 on cerebral ischemia: possible involvement of free radical scavenging and antioxidant actions. J Pharmacol Exp Ther 268: 1597-1604.

32. Kono S, Deguchi K, Morimoto N, Kurata T, Yamashita T, et al. (2013) Intravenous thrombolysis with neuroprotective therapy by edaravone for ischemic stroke patients older than 80 years of age. J Stroke Cerebrovasc Dis 22: 1175-1183.

33. Yamashita T, Kamiya T, Deguchi K, Inaba T, Zhang H, et al. (2009) Dissociation and protection of the neurovascular unit after thrombolysis and reperfusion in ischemic rat brain. J Cereb Blood Flow Metab 29: 715-725.

34. Lukic-Panin V, Deguchi K, Yamashita T, Shang J, Zhang X, et al. (2010) Free radical scavenger edaravone administration protects against tissue plasminogen activator induced oxidative stress and blood brain barrier damage. Curr Neurovasc Res 7: 319-329.

35. Omori K, Shikata Y, Sarai K, Watanabe N, Wada J, et al. (2007) Edaravone mimics sphingosine-1phosphate-induced endothelial barrier enhancement in human microvascular endothelial cells. Am J Physiol Cell Physiol 293: C1523-1531.

36. Onodera H, Arito M, Sato T, Ito H, Hashimoto T, et al. (2013) Novel effects of edaravone on human brain microvascular endothelial cells revealed by a proteomic approach. Brain Res 1534: 87-94.

37. Li W, Xu H, Hu Y, He P, Ni Z, et al. (2013) Edaravone Protected Human Brain Microvascular Endothelial Cells from Methylglyoxal-Induced Injury by Inhibiting AGEs/RAGE/Oxidative Stress. PLoS One 8: e76025.

38. Deli MA, Ábrahám CS, Kataoka Y, Niwa M (2005) Permeability studies on in vitro blood-brain barrier models: physiology, pathology, and pharmacology. Cell Mol Neurobiol 25: 59-127.

39. Weksler BB, Subileau EA, Perriere N, Charneau P, Holloway K, et al. (2005) Blood-brain barrier-specific properties of a human adult brain endothelial cell line. FASEB J 19: 1872-1874.

40. Weksler B, Romero IA, Couraud PO (2013) The hCMEC/D3 cell line as a model of the human blood brain barrier. Fluids Barriers CNS 10: 16.

41. Paolinelli R, Corada M, Ferrarini L, Devraj K, Artus C, et al. (2013) Wnt activation of immortalized brain endothelial cells as a tool for generating a standardized model of the blood brain barrier in vitro. PLoS One 8(8):e70233.

42. Edelstein D, Brownlee M (1992) Mechanistic studies of advanced glycosylation end product inhibition by aminoguanidine. Diabetes 41: 26-29.

43. Ózsvári B, Puskás LG, Nagy LI, Kanizsai I, Gyuris M, et al. (2010) A cell-microelectronic sensing technique for the screening of cytoprotective compounds. Int J Mol Med 25: 525-530.

44. Kiss L, Walter FR, Bocsik A, Veszelka S, Ózsvári B, et al. (2013) Kinetic analysis of the toxicity of pharmaceutical excipients Cremophor EL and RH40 on endothelial and epithelial cells. J Pharm Sci 102: 1173-1181.

45. Kürti L, Gáspár R, Márki A, Kápolna E, Bocsik A, et al. (2013) In vitro and in vivo characterization of meloxicam nanoparticles designed for nasal administration. Eur J Pharm Sci 50: 86-92.

46. Kürti L, Veszelka S, Bocsik A, Ózsvári B, Puskás LG, et al. (2013) Retinoic acid and hydrocortisone strengthen the barrier function of human RPMI 2650 cells, a model for nasal epithelial permeability. Cytotechnology 65: 395-406.

47. Youdim KA, Avdeef A, Abbott NJ (2003) In vitro trans-monolayer permeability calculations: often forgotten assumptions. Drug Discov Today 8: 997-1003.

48. Alm K, El-Schich Z, Miniotis FM, Wingren AG, Janicke B, et al. (2013) Cells and Holograms - Holograms and Digital Holographic Microscopy as a Tool to Study the Morphology of Living Cells. In: Mihaylova, editor. Holography - Basic Principles and Contemporary Applications: ISSB: 978-953-5151117-7, InTech. DOI:10.5772-54405 [http://www.intechopen.com/books/holography-basic-principles-and-contemporaryapplications/cells-and-holograms-holograms-and-digital-holographic-microscopy-as-a-tool-to-study-themorphology-o]

49. Madácsi R, Kanizsai I, Fehér LZ, Gyuris M, Ózsvári B, et al. (2013) Aromatic sulfonamides containing a condensed piperidine moiety as potential oxidative stress-inducing anticancer agents. Med Chem 9: 911919. 
50. Whitmer RA (2007) Type 2 diabetes and risk of cognitive impairment and dementia. Curr Neurol Neurosci Rep 7: 373-380.

51. Bruno A, Liebeskind D, Hao Q, Raychev R, Investigators US (2010) Diabetes mellitus, acute hyperglycemia, and ischemic stroke. Curr Treat Options Neurol 12: $492-503$.

52. Mukohda M, Okada M, Hara Y, Yamawaki H (2012) Exploring mechanisms of diabetes-related macrovascular complications: role of methylglyoxal, a metabolite of glucose on regulation of vascular contractility. J Pharmacol Sci 118: 303-310.

53. Li W, Liu J, He P, Ni Z, Hu Y, et al. (2013) Hydroxysafflor yellow A protects methylglyoxal-induced injury in the cultured human brain microvascular endothelial cells. Neurosci Lett 549: 146-150.

54. Lee C, Yim MB, Chock PB, Yim HS, Kang S (1998) Oxidation-reduction properties of methylglyoxalmodified protein in relation to free radical generation. J Biol Chem 273: 25272-25278.

55. Rabbani N, Thornalley PJ (2008) Dicarbonyls linked to damage in the powerhouse: glycation of mitochondrial proteins and oxidative stress. Biochem Soc Trans 36: 1045-1050.

56. Pun PB, Lu J, Moochhala S (2009) Involvement of ROS in BBB dysfunction. Free Radic Res 43: 348-364.

57. Desai KM, Wu L (2008) Free radical generation by methylglyoxal in tissues. Drug Metabol Drug Interact 23: 151-173.

58. Aberle H, Schwartz H, Kemler R (1996) Cadherin-catenin complex: protein interactions and their implications for cadherin function. J Cell Biochem 61: 514-523.

59. Liebner S, Plate KH (2010) Differentiation of the brain vasculature: the answer came blowing by the Wnt. J Angiogenesis Res 2: 1.

60. Beard RS Jr, Reynolds JJ, Bearden SE (2011) Hyperhomocysteinemia increases permeability of the bloodbrain barrier by NMDA receptor-dependent regulation of adherens and tight junctions. Blood 118: 20072014.

61 Cardoso FL, Kittel A, Veszelka S, Palmela I, Tóth A, et al. (2012) Exposure to lipopolysaccharide and/or unconjugated bilirubin impair the integrity and function of brain microvascular endothelial cells. PLoS One 7(5):e35919.

62 Roe K, Kumar M, Lum S, Orillo B, Nerurkar VR, et al. (2012) West Nile virus-induced disruption of the blood-brain barrier in mice is characterized by the degradation of the junctional complex proteins and increase in multiple matrix metalloproteinases. J Gen Virol 93: 1193-1203.

63. Del Zoppo GJ, Milner R, Mabuchi T, Hung S, Wang X, et al. (2006) Vascular matrix adhesion and the blood-brain barrier. Biochem Soc Trans 34: 1261-1266.

64. Wang CX, Shuaib A (2007) Critical role of microvasculature basal lamina in ischemic brain injury. Prog Neurobiol 83: 140-148.

65. Dobler D, Ahmed N, Song L, Eboigbodin KE, Thornalley PJ (2006) Increased dicarbonyl metabolism in endothelial cells in hyperglycemia induces anoikis and impairs angiogenesis by RGD and GFOGER motif modification. Diabetes 55: 1961-1969.

66. Kaste M, Murayama S, Ford GA, Dippel DW, Walters MR, et al. (2013) Safety, tolerability and pharmacokinetics of MCI-186 in patients with acute ischemic stroke: new formulation and dosing regimen. Cerebrovasc Dis 36: 196-204.

67. Kalapos MP (2013) Where does plasma methylglyoxal originate from? Diabetes Res Clin Pract 99: 260-271.

68. Mangalmurti NS, Chatterjee S, Cheng G, Andersen E, Mohammed A, et al. (2010) Advanced glycation end products on stored red blood cells increase endothelial reactive oxygen species generation through interaction with receptor for advanced glycation end products. Transfusion 50: 2353-2361.

69. Rouhiainen A, Kuja-Panula J, Tumova S, Rauvala H (2013) RAGE-mediated cell signaling. Methods Mol Biol 963: 239-263. 


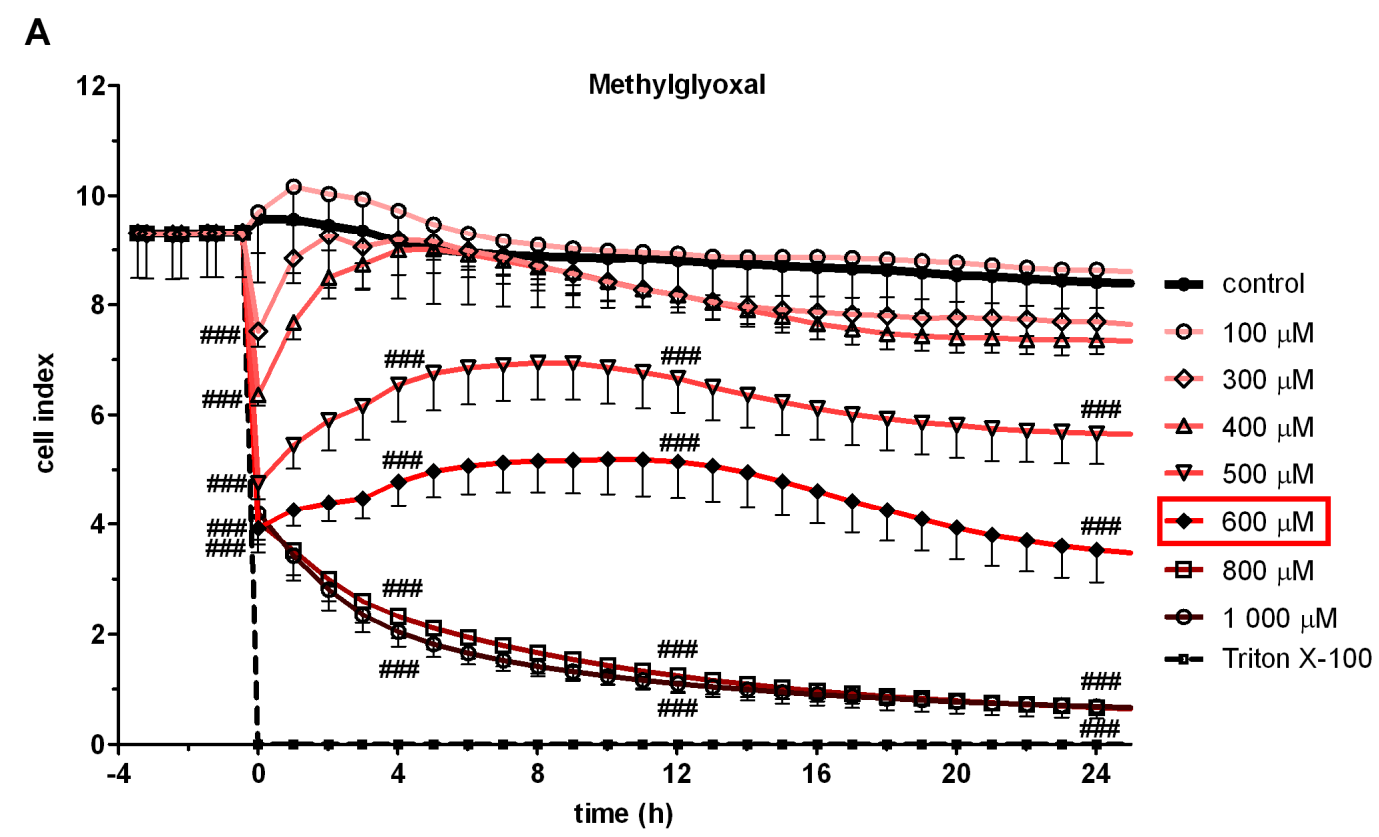

B

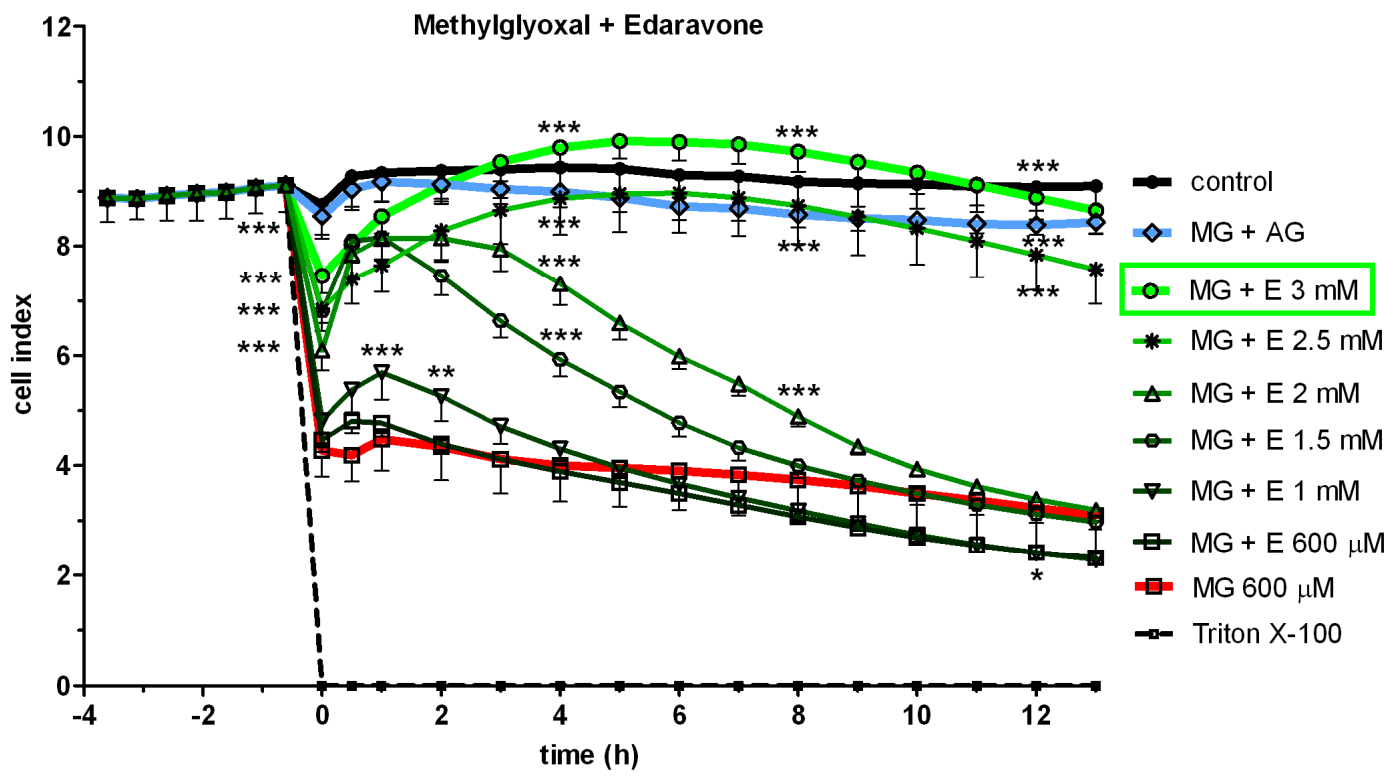

Figure 1. Effect of methylglyoxal and edaravone on cell viability

Effect of methylglyoxal $(100-1000 \mu \mathrm{M})$ on human hCMEC/D3 endothelial cells measured by real-time cell electronic sensing method (A). Effect of co-treament with $600 \mu \mathrm{M}$ methylglyoxal and different concentrations of edaravone (MG + E; 600-3000 $\mu \mathrm{M}$ ) or aminoguanidine (MG + AG; $2 \mathrm{mM})(\mathrm{B})$. Cell index is expressed as an arbitrary unit and calculated from impedance measurements between cells and sensors. Data are presented as means $\pm \mathrm{SD}, \mathrm{n}=10$. Triton X-100 was used at $10 \mathrm{mg} / \mathrm{mL}$ concentration. Statistical analysis: two-way ANOVA followed by Bonferroni test. Statistically significant differences $(p<0.05)$ from the control group $(\#)$ and from the methylglyoxal-treated group $(*)$ are indicated. 
A

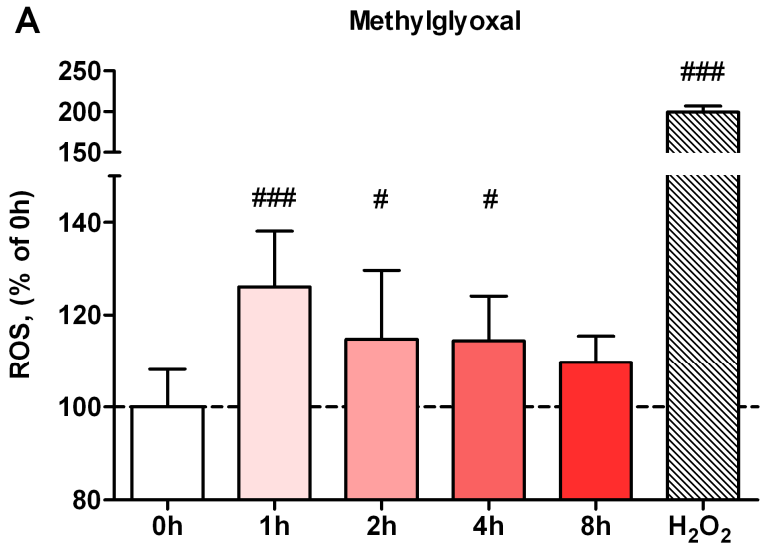

B
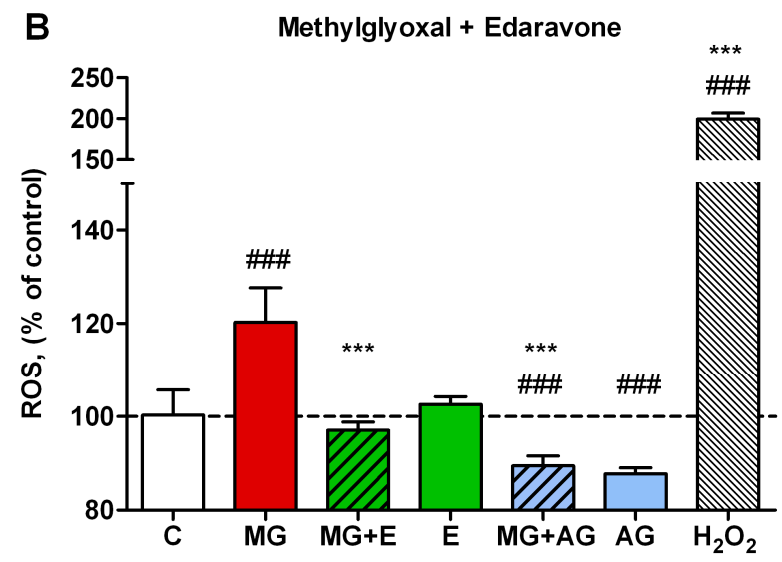

Figure 2. Effect of methylglyoxal and edaravone on reactive oxygen species production

Time-dependent effect of methylglyoxal (MG; $600 \mu \mathrm{M})$ on ROS production of human brain endothelial cells (hCMEC/D3) (A). Effect of co-treament with $600 \mu \mathrm{M}$ methylglyoxal and $3 \mathrm{mM}$ edaravone (MG + E) or $2 \mathrm{mM}$ aminoguanidine $(\mathrm{MG}+\mathrm{AG})$ after 4 hours $(\mathrm{B})$. Fluorescent intensity of ROS expressed as a percentage of control (C). Values presented are means $\pm \mathrm{SD}, \mathrm{n}=9$. Statistical analysis: ANOVA followed by Dunnett test. Statistically significant differences $(p<0.05)$ from the control group $(\#)$ and from the methylglyoxal-treated group $(*)$ are indicated.

A

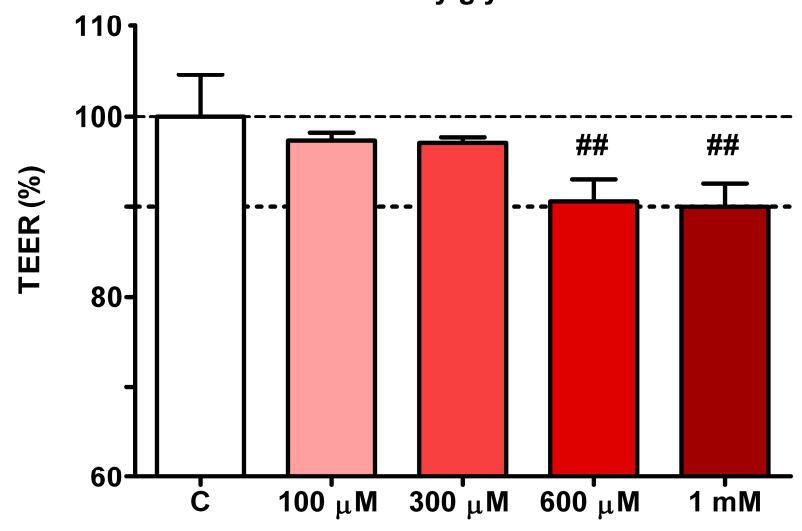

B

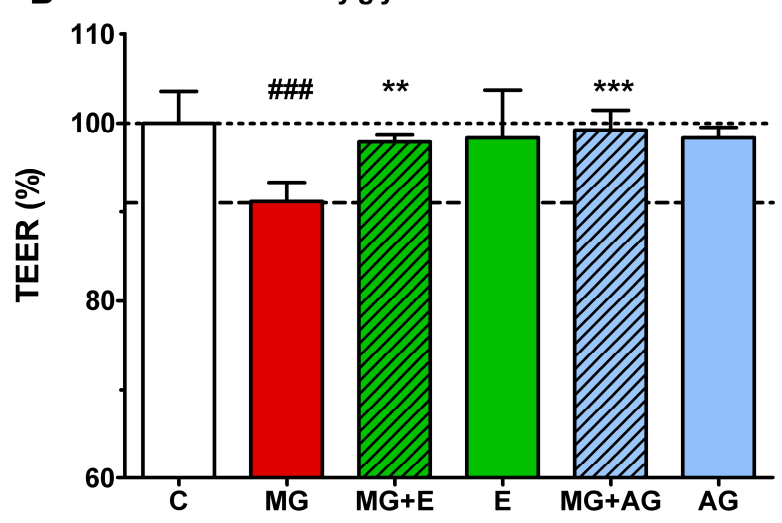

Figure 3. Effect of methylglyoxal and edaravone on the resistance of human brain endothelial monolayers

The effect of methylglyoxal on the resistance of human brain endothelial cells (hCMEC/D3) after 4-hours treatment (A). Protective effect of $3 \mathrm{mM}$ edaravone (MG + E;) and $2 \mathrm{mM}$ aminoguanidine $(\mathrm{MG}+\mathrm{AG})$ on methylglyoxal (MG, $600 \mu \mathrm{M}$ ) induced changes in the resistance of cell layers (4 hours co-treatment), and effect of $3 \mathrm{mM}$ edaravone (E) and $2 \mathrm{mM}$ aminoguanidine (AG) alone (B). TEER values are expressed as percentage of control (C). Values presented are means $\pm \mathrm{SD}, \mathrm{n}=4$. Statistical analysis: ANOVA followed by Dunnett test. Statistically significant differences $(p<0.05)$ from the control group $(\#)$ and from the methylglyoxal treated group $(*)$ are indicated. 

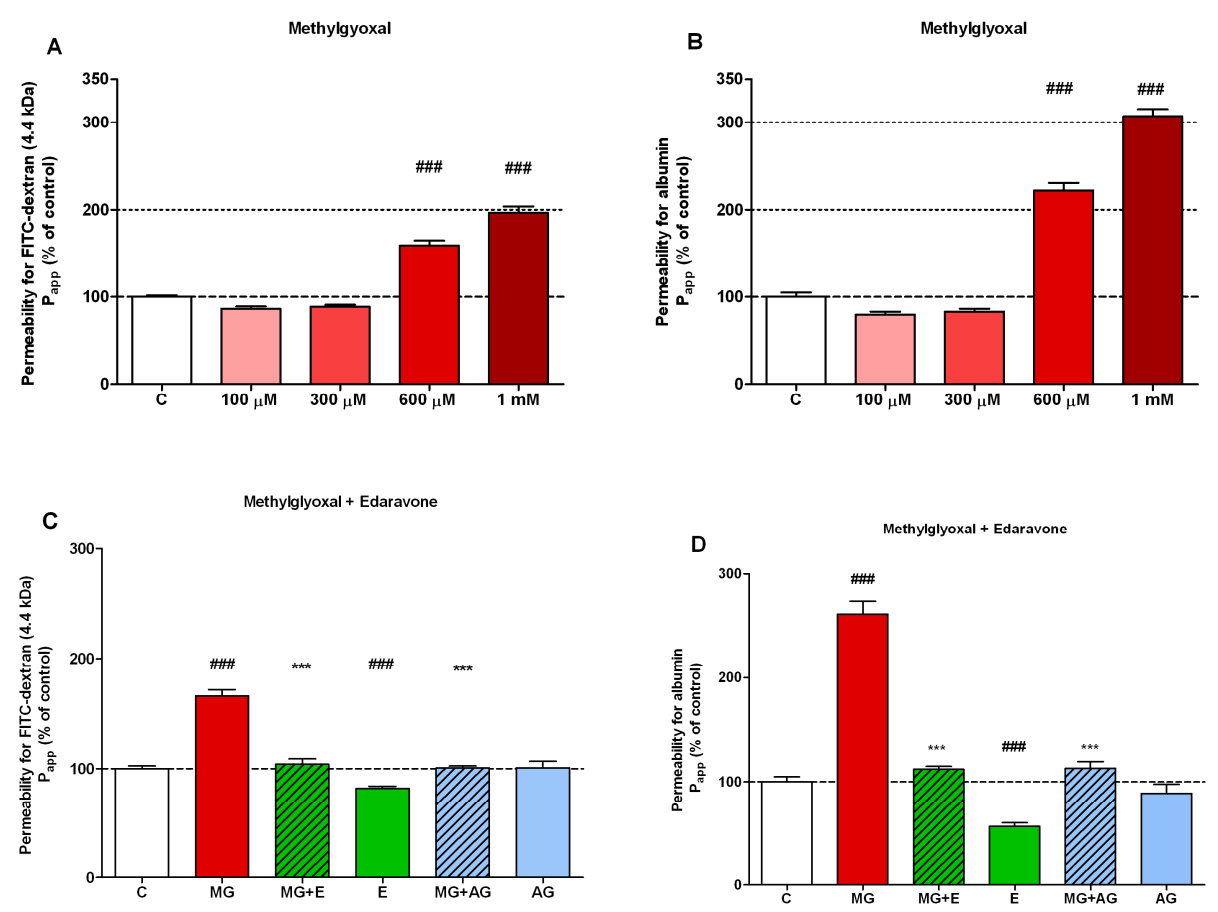

Figure 4. Effect of methylglyoxal and edaravone on the permeability of human brain endothelial monolayers

Dose-dependent effect of methylglyoxal-induced changes in the permeability of human brain endothelial cells (hCMEC/D3) for FITC-dextran (4.4 kDa) (A) and Evans blue labelled albumin (65 kDa) after 4 hours treatment (B). Protective effect of $3 \mathrm{mM}$ edaravone (MG + E;) and $2 \mathrm{mM}$ aminoguanidine (MG + AG) on methylglyoxalinduced $(\mathrm{MG}, 600 \mu \mathrm{M})$ changes in the permeability for FITC-dextran $(4.4 \mathrm{kDa})(\mathrm{C})$ and Evans blue labelled albumin (D), when co-treated for 4 hours. Effect of $3 \mathrm{mM}$ edaravone (E) and $2 \mathrm{mM}$ aminoguanidine (AG) alone (C, D). Papp, apparent permeability coefficient expressed as a percentage of control (C). Values presented are means $\pm \mathrm{SD}, \mathrm{n}=4$. Statistical analysis: ANOVA followed by Dunnett test. Statistically significant differences ( $p$ $<0.05)$ from the control group (\#) and from the methylglyoxal treated group $(*)$ are indicated.
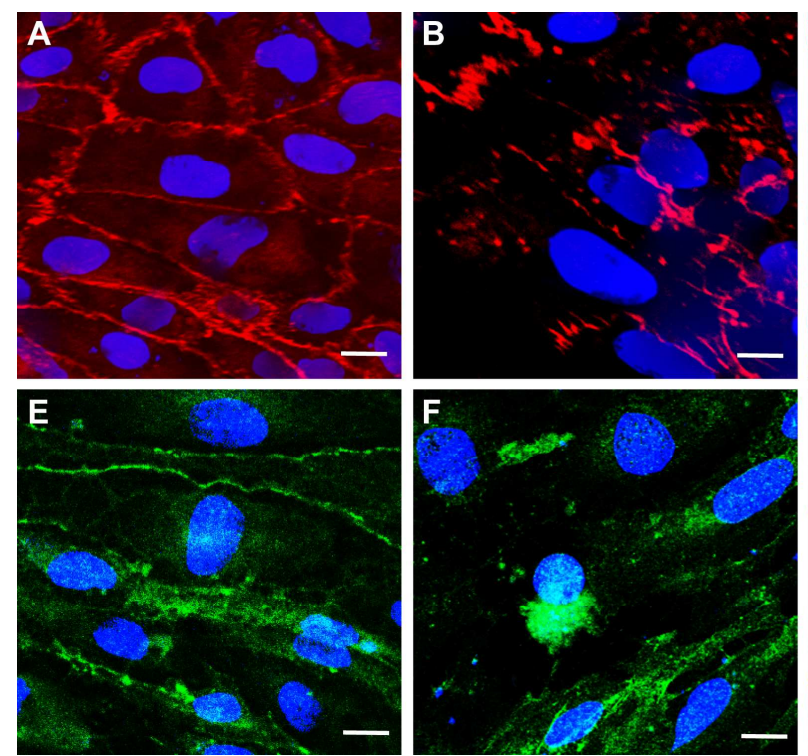
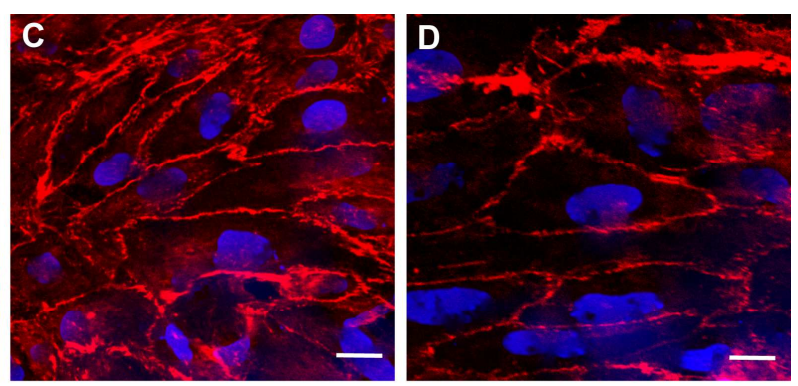
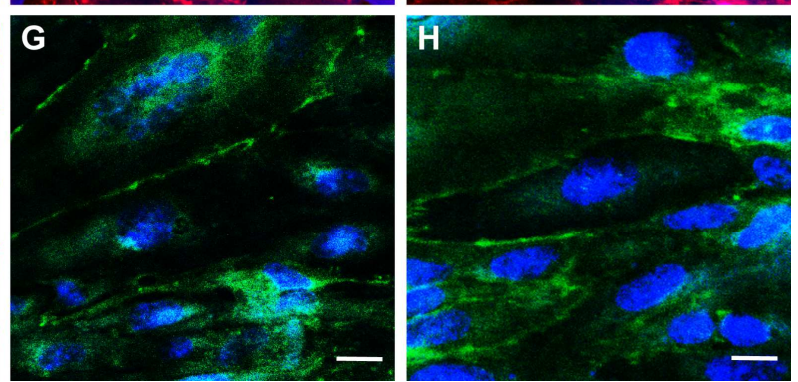

Figure 5. Effect of methylglyoxal and edaravone on junctional morphology

Immunostaining for adherens junction protein $\beta$-catenin (A-D) and integral tight junction membrane protein claudin-5 (E-H) in human hCMEC/D3 brain endothelial cells. Control (A and E), 4 hour treatment with methylglyoxal $(600 \mu \mathrm{M}$; B and F), co-treatment with edaravone (3 mM; C and G) or aminoguanidine (2 mM; D and $\mathrm{H}$ ). Blue color: bis-benzimide staining of cell nuclei; red color: immunostaining for $\beta$-catenin; green color: immunostaining for claudin-5. Bar $=20 \mu \mathrm{m}$. 
$\mathrm{Oh}$
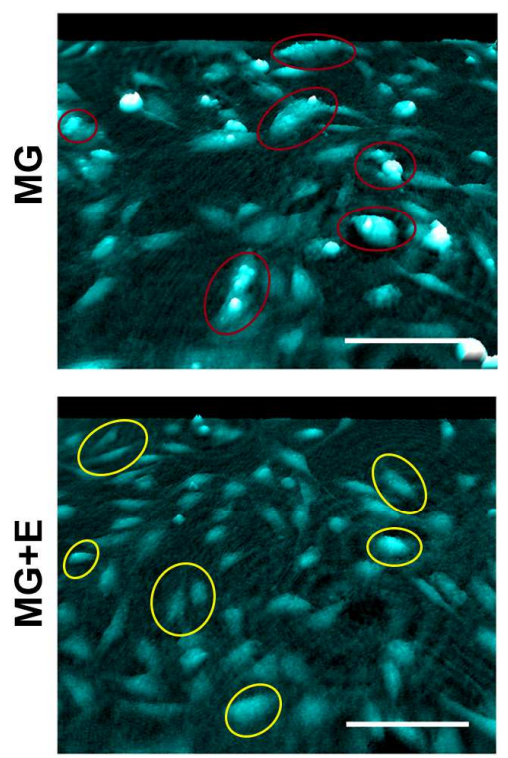

$1 \mathrm{~h}$
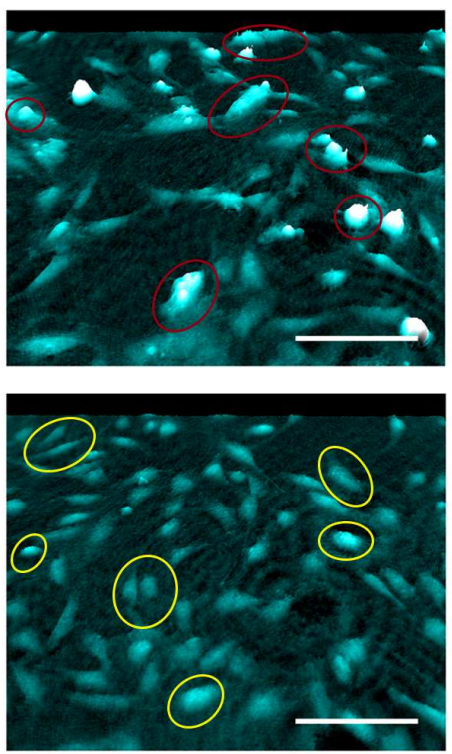

$4 \mathrm{~h}$
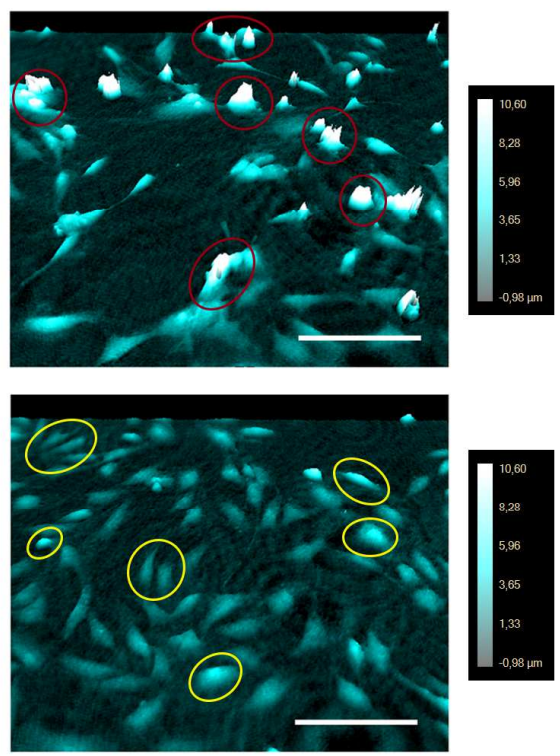

Figure 6. Effect of methylglyoxal and edaravone on cellular morphology

Holographic phase contrast images of morphological alterations induced in hCMEC/D3 human brain endothelial cells by treatment with methylglyoxal $(\mathrm{MG} ; 600 \mu \mathrm{M})$ and co-treatment with $3 \mathrm{mM}$ edaravone $(\mathrm{MG}+\mathrm{E})$ for 4 hours. Color scale bar correspond to the height of single cells. Data were analysed by means of HoloStudio 2.4 software. Red circles indicate cells with drastical changes in cell morphology. Yellow circles indicate cells without any morphological changes. Bar $=100 \mu \mathrm{m}$
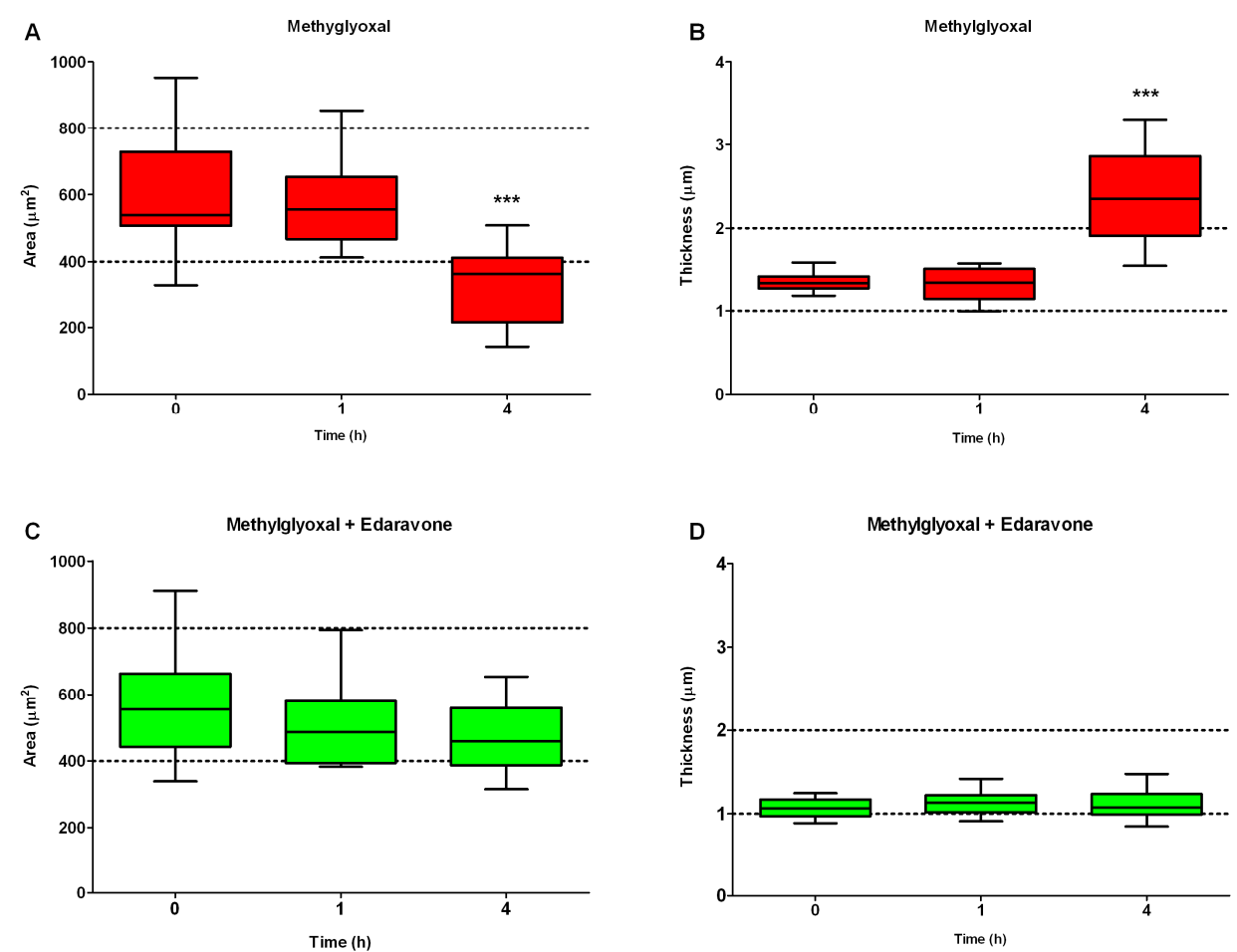

Figure 7. Effect of methylglyoxal and edaravone on area and thickness of adjacent cells

Morphological alterations induced in human brain endothelial cells (hCMEC/D3) by treatment with methylglyoxal at $600 \mu \mathrm{M}$ (A and B) and co-treatment with edaravone at $3 \mathrm{mM}(\mathrm{C}$ and $\mathrm{D})$ for 4 hours. Surface area $(\mathrm{A}$ and $\mathrm{C})$ and average optical thickness $(\mathrm{B}$ and $\mathrm{D})$ were calculated before and during treatments. Box represents 25 and 75 percentiles. Horizontal line represent the median. Whiskers show minimum and maximum values. Statistical analysis: ANOVA followed by Dunnett test, $\mathrm{n}=12$. Statistically significant differences $(p<$ 0.05 ) from 0 time point $(*)$ are indicated. 


\section{Supporting Information Legends}
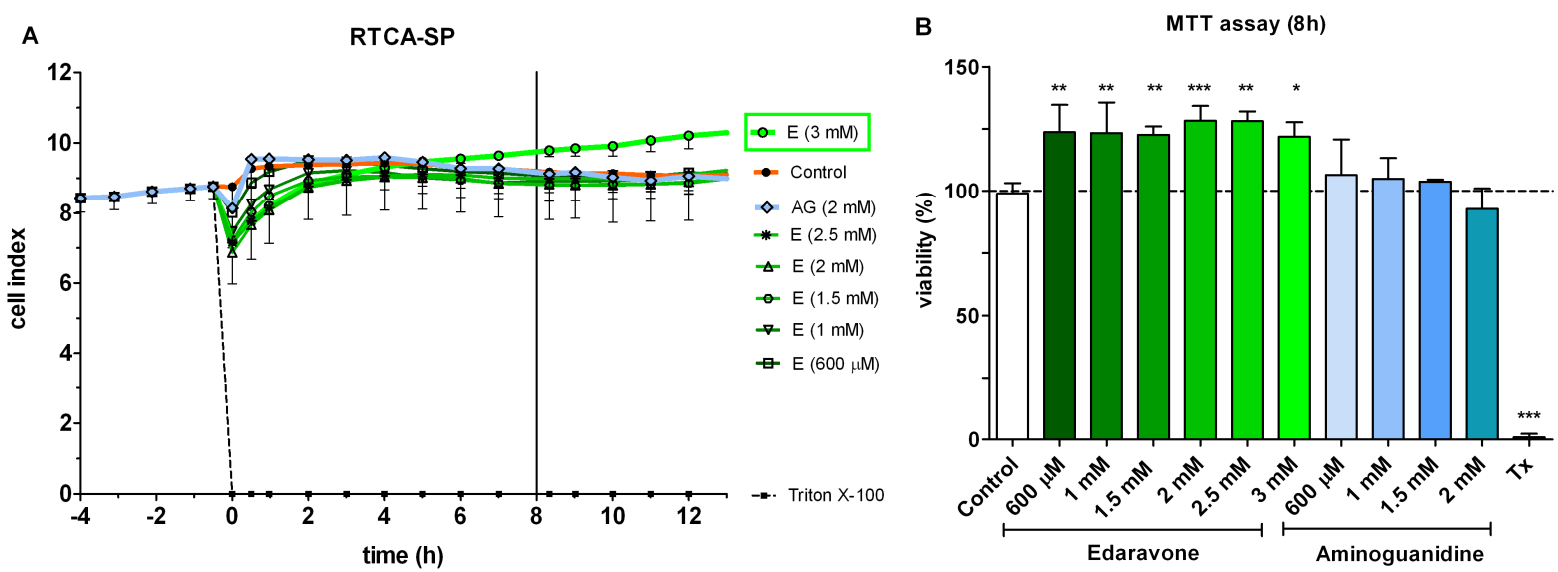

Figure S1. Effect of edaravone and aminoguanidine on cell viability

Effect of edaravone (E; $600 \mu \mathrm{M}-3 \mathrm{mM}$ ) and aminoguanidine (AG; $600 \mu \mathrm{M}-2 \mathrm{mM}$ ) on human hCMEC/D3 endothelial cells measured by real-time cell electronic sensing (RTCA-SP) method (A) and by MTT metabolic assay at 8 hours timepoint (B). MTT assay and cell index data are expressed as percentage of control. Data are presented as means $\pm \mathrm{SD}, \mathrm{n}=6$. Triton $\mathrm{X}-100$ was used at $10 \mathrm{mg} / \mathrm{mL}$ concentration. Statistical analysis: ANOVA followed by Dunnett or by Bonferroni test. Statistically significant differences $(p<0.001)$ from the control group (\#) are indicated.

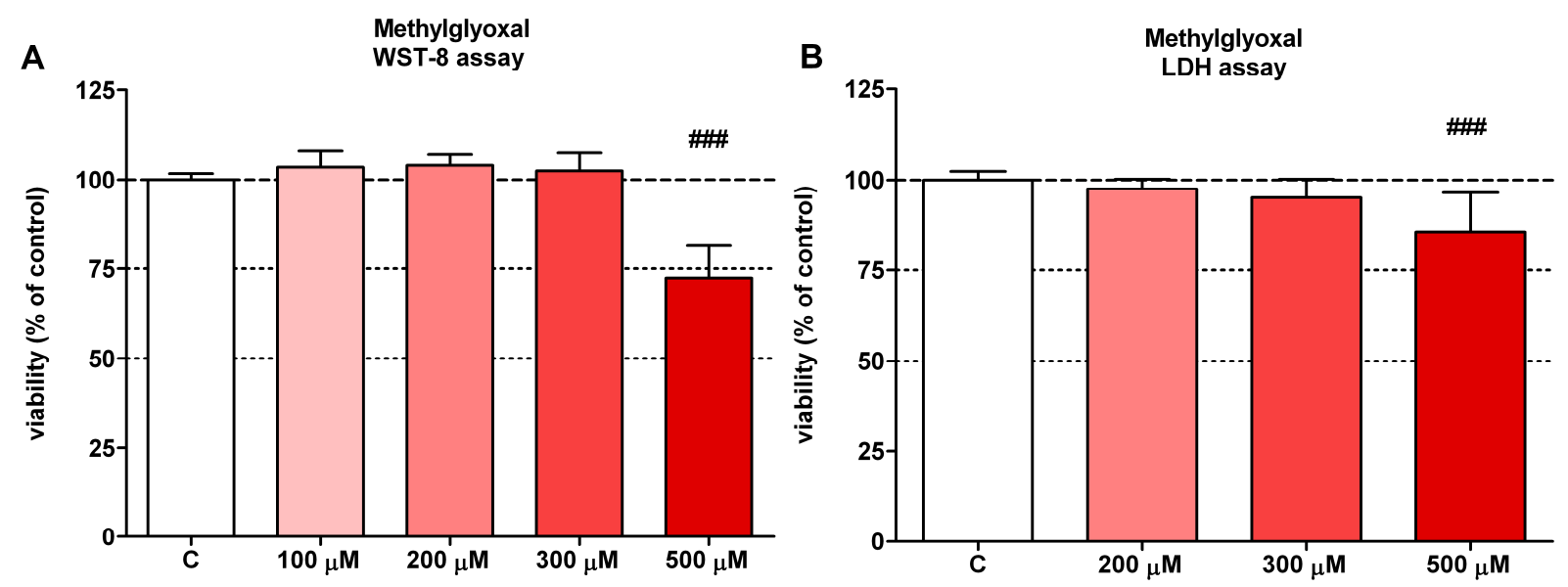

Figure S2. Effect of methylglyoxal on the viability of primary brain endothelial cells

Effect of methylglyoxal $(100-1000 \mu \mathrm{M})$ on primary rat brain endothelial cells measured by WST-8 (A) and lactate dehydrogenase (LDH) release assay (B). Values are expressed as percentage of control. Data are presented as means \pm SEM, $\mathrm{n}=20$. Statistical analysis: one-way ANOVA followed by Dunett test. Statistically significant differences $(p<0.05)$ from the control (C) group (\#) are indicated. 
A

Methylgyoxal

$$
\text { TEER }
$$

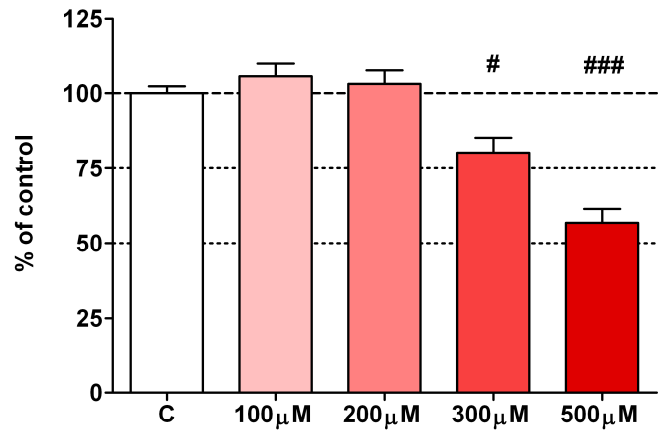

\section{B}

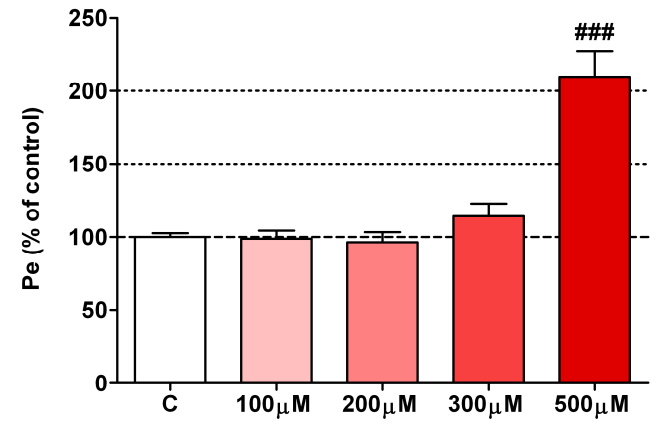

C

Methylglyoxal

Permeability for Evans blue-albumin

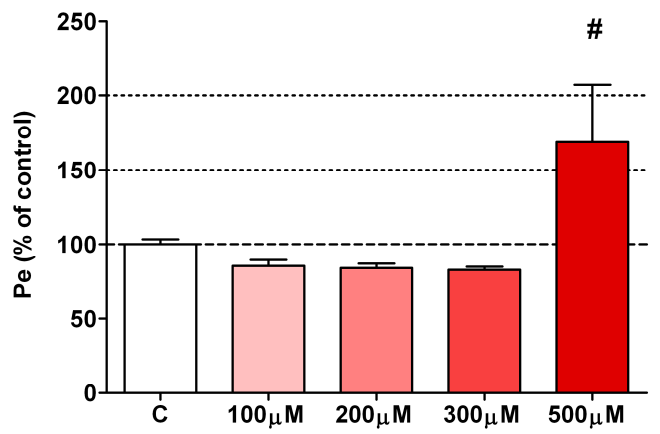

Figure S3. Effect of methylglyoxal on the barrier properties of primary brain endothelial monolayers Dose-dependent effect of methylglyoxal-induced changes in the resistance (A) and the permeability of primary rat brain endothelial cells for sodium-fluorescein (B) and Evans blue labeled albumin (B). Transendothelial electrical resistance (TEER) and endothelial permeability coefficient (Pe) are expressed as a percentage of control (C). Data presented are means \pm SEM, $\mathrm{n}=16-24$. Statistical analysis: ANOVA followed by Dunnett test. Statistically significant differences $(p<0.05)$ from the control group $(\#)$ and from the methylglyoxal treated group $(*)$ are indicated.

Video S1 and S2. Effect of methylglyoxal on cellular morphology

Videos were made from holographic phase contrast images on morphological alterations induced in hCMEC/D3 human brain endothelial cells by treatment with $600 \mu \mathrm{M}$ methylglyoxal (Video S1) and co-treatment with $3 \mathrm{mM}$ edaravone (Video S2). Pictures were taken every 30 min until 4 hours. Color scale bar correspond to the height of single cells. Data were analysed by means of HoloStudio 2.4 software. 